\title{
ISSN 1913-9004
}
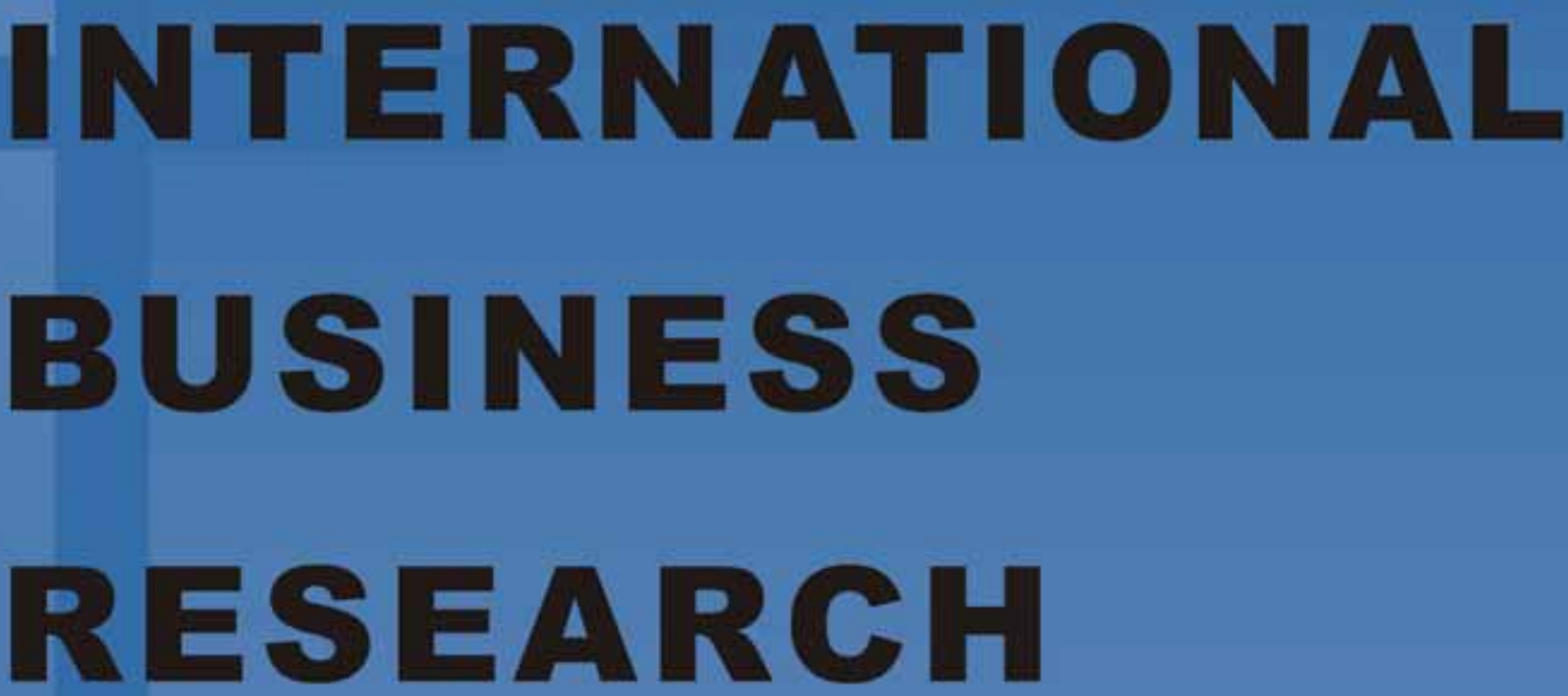

Vol. 1, No. 4

October 2008

CCSE

Canadian Center of Science and Education 


\section{Contents}

The Importance of the State's Entrepreneurial Role, Business Support Services, and Technological

Assistances to the Development of Vietnamese SMEs

Thanh Hai Nguyen, Quamrul Alam, Daniel Prajog \& Ai Ngoc Duong

Conducting Postgraduate Level Research: Selecting A Methodology- A Students' Perspective

Vlasios Sarantinos

Strategies for Developing 'Red Tourism': A Unique Tourism Activity in China

Bin Wang, Chunyou Wu \& Haiyao Peng

Marxist or Feminist Approaches to Sports Management Are There Traits in A Modern Days Society

Ian Arnott

Innovations in Trade Financing Process of Commercial Bank

Yijun Yuan, Xiaowei Dong \& Xiaoqing Lv

Audit Delay of Listed Companies: A Case of Malaysia

Ayoib Che-Ahmad \& Shamharir Abidin

Data Enriched Voice Service Analysis and Forecast

Qiaohong Zhou \& Guohua Zhou

Bayesian Approach for ARMA Process and Its Application

Chongjun Fan \& Sha Yao

A Strategic Competitive Advantage Perspective on Management Development

Law Kian Aun

E-collaboration: A Universal Key to Solve Fierce Competition in Tourism Industry?

Caiwei Ma

The Relationship between Ownership and Performance: A Review of Theory and Evidence

Yabei Hu \& Shigemi Izumida

Linkage between Money and Prices: A Causality Analysis for Malaysia

Mohd Fahmi Ghazali, Hanudin Amin, Mohd Zulkifli Muhammad \& Siti Hajar Samsu

Study on the Employee Training for China State-owned Enterprises Based on Harmony Concept

Shengming Hou

The Design of Knitting Dress and the Development Orientation of Knitting Enterprises

Tianpeng Liu

Partnering Project Success Criteria in Malaysia

Hj. Kamaruzaman Jusoff, Hamimah Adnan \& Nurul Fatanah Nazli

The Market Orientation and 4P Strategies of Ailing River Drifting Scenic Spot

Jin Zhang

The Crisis Management of Enterprise's Collective Brain Drain

Chunli Yuan \& Chunying Zhang

An Extended Model of Theory of Planned Behaviour in Predicting Exercise Intention

Yap Sheau Fen \& Noor Asyikin Sabaruddin 


\section{Contents}

Studies on Spillover of Scientific and Technological Knowledge in High-tech Industry Clusters

---Taking Jinan High-tech Development Zone for Example

Zhenpeng Kong \& Qigang Yuan

Study on the Cultivation of Special Industry with New Competitive Predominance for Xinjiang Economy

Xuefeng Wang

Student Satisfaction and Service Quality: Any Differences in Demographic Factors?

Azleen Ilias, Hishamuddin Fitri Abu Hasan, Rahida Abd Rahman \& Mohd Rushdan bin Yasoa'

Do Institutional Differences Affect Leverage Choice?

Xiaoyan Niu

Design and Evaluation to Internal Control of Shaanxi Textile Enterprises

Junxun Li \& Xiaoyan Wei

The Department Store in Hong Kong: Local Institutional Changes and the Concession Business Model

Matthew M. Chew 


\title{
The Importance of the State's Entrepreneurial Role, Business Support Services, and Technological Assistances to the Development of Vietnamese SMEs
}

\author{
Thanh Hai Nguyen \\ Department of Management, Monash University, Australia \\ E-mail: Thanh.Nguyen@Buseco.Monash.edu.au \\ Quamrul Alam \\ Department of Management, Monash University, Australia \\ E-mail: Quamrul.Alam@Buseco.Monash.edu.au \\ Daniel Prajogo \\ Department of Management, Monash University, Australia \\ E-mail: Daniel.Prajogo@buseco.monash.edu.au \\ Ai Ngoc Duong \\ Institute of Financial Science and Insurance, University Claude Bernard Lyon 1, France \\ E-mail: aingoc.duong@axa.fr
}

\begin{abstract}
This paper reports the findings of a study that examines the evolving relationships between the state's entrepreneurial role and market factors such as business support services, business training and professional development, technological and information support services and SMEs' development in Vietnam. This study uses an institutional approach to study how the entrepreneurial state influences the creation of market factors in Vietnam. The findings suggest that the state has taken some committed initiatives in attracting external support, building infrastructure both tangible and intangible, and enabling structural flexibility for the growth of SMEs. The state's entrepreneurial role is of special importance since it can coordinate with existing market factors to provide policy support, external resources, and institutional infrastructure for the growth of SMEs in Vietnam. However, inconsistency in policy, slow pace of market reform in selected business areas, and inadequate resource allocation practices have hindered the development of SMEs.
\end{abstract}

Keywords: Transitional economy, SMEs, State and Market

\section{Introduction}

The Central and Eastern European (CEE) experience suggests that the reduction of government ownership and control in business, business support infrastructure, and financial support, the legal and institutional framework, and cluster and network relationships play a fundamental role for business development (Katz, 1995; Assaf, 1998; Konopielko and Bell, 1997; McIntyre, 2002). In a similar pattern, the public sector has been playing a key role in strengthening the development of a dynamic private enterprise sector and efficient market in the context of an Asian socialist market economy model. State and market have been working together to create sustainable conditions for private sector business development and especially for the development of SMEs.

This paper examines the role of the state institutions in creating market conditions for SME growth. The adequacy of the policy regime and the effectiveness of the support infrastructure have been discussed to identify the problems of the market development process under the socialist market economy model of Vietnam.

\section{Factors impacting on SMEs in Vietnam}

\subsection{State Policies for SME Growth}

Support policies for SMEs vary from country to country and from developed countries to less developed countries due to differences in business contexts, culture and the level of industrialization. The CEE experience suggests that business support infrastructure, financial support, legal and institutional framework, and cluster and network relationships play a vital role for business development. According to Batra and Mahmood (2003), SMEs in developing countries in East 
Asia receive support from local governments in the form of micro finance, interventions to increase private sector training, technology development, and market information. China, Malaysia, Indonesia and Thailand benefited from these policy reforms, network relationships, cluster linkage to markets, and the new support infrastructure (Brimble, Oldfield and Monsakul, 2002; Harvie, 2001; Tambunan 2005; and Harvie, 2002. In Vietnam, policy support is a critical factor for SME growth.

\subsection{Business Support Services}

In CEE countries, privatisation was introduced to restructure large state-owned enterprises (SOEs) into SMEs (Gibb and Lyapunov, 1996). McIntyre (2002) recommends a contrary solution whereby disassembling large firms may not sustain SME growth. In Asia, due to the absence of an adequate support regime, this idea has proven reasonable, since SMEs in China still need large firms for support. From the experiences of CEE countries, Dallago, and McIntyre (2003) state that SMEs are not themselves sufficient for growth without the proper development of institutions and supporting structures.

\subsection{Supporting Infrastructures}

Wattanapruttipaisan (2002) proposes that competitiveness can be leveraged by factors other than location and natural resources such as: on-going access to global information and knowledge (market standards, marketing opportunities and technology); participation in clusters of firms, networks with suppliers, producers or complementary products; distributors and consumers; and on-going learning and improvements in efficiency and flexibility. This network relationship created a new information flow and knowledge base for SMEs that could be the model for the efficiency of resource distribution to SMEs by way of numerous policy packages from the state and the market.

\section{Methodology}

\subsection{Conceptual Framework}

Institutional theories referred to by Petri (1995), Assaf (1998), Brimble, Oldfield and Monsakul (2002), Harvie (2002), Tambunan (2005), Ha and Swierczek (2003), and Gibb and Lyapunov (1996) provide an understanding of the factors supporting SME development in developing countries. These authors infer that a well-defined support regime from the state can coordinate with existing market factors to provide policy support, external resources, and institutional infrastructure for the growth of SMEs.

A conceptual framework was applied to examine the evolving relationship between state and market and the impact of that relationship on local SMEs (see Fig.1 in the appendix). The conceptual framework included enabling or hindering factors associated with (1) the entrepreneurial role of the state through policies, resources and infrastructure, and (2) market factors.

\subsection{Research Methodology}

This paper uses qualitative data drawn from a number of semi-structured interviews held in Ho Chi Minh City, Vietnam. In order to identify key themes in this data, a content analytic approach was taken. 17 respondents were selected randomly and interviewed in June 2006. Semi-structured interviews were conducted mainly in Ho Chi Minh City.

Based on the conceptual model, a group - comprehensive questionnaire was developed to address the overall research issue of identification of the effectiveness of SME-related policies. Identified issues were analysed through applying NVivo-assisted themed qualitative analysis methods.

\section{Major finding}

\subsection{Business Support Services \& Human Resource Training and Professional Development}

There are shortages of good technical advisors and information. According to a respondent, he experiences difficulty in seeking qualified information and does not know where to seek advice. It seems that supporting agencies have failed to meet the demands of SMEs. Respondents have doubts about the roles of supporting agencies and the quality of technological consulting services. Information provided is too general and there is a shortage of necessary information about incentive policies and legal regimes available for SMEs. According to the findings, a common SME problem is the lack of formal linkages among businesses since most of the cooperation is through informal relationships. This has created no leap-frog approach for entrepreneurial development through which cooperation among potential businesses for production, sharing information, and supply chain and outbound value chain activities could evolve. In the absence of such an entrepreneurial culture, SMEs do not know where to seek advice and where there might be opportunities for cooperation: "Quality of technological consulting services is so poor. If we want to buy hi-tech equipment (for food processing) we have to learn ourselves since we do not know who to ask for advice" (F3-G1). As a result, SMEs find it risky to engage in international businesses with foreign partners. As claimed by respondents, the weak and unsynchronized role of supporting institutions in facilitating networking and cooperation also could be the reason for the slow growth of SMEs. On the other hand, the findings also indicate that there is a lack of cooperation among supporting institutions. Support in training is the government's indirect assistance to improve SMEs' managerial skills 
and to equip SMEs with professional skills. As a result, SMEs will have more chances to improve their products' quality, reducing the cost of production, and increasing their competitiveness.

The findings indicate that some government officers' inability to adapt to a market-oriented economy has created annoyance and difficulties for SMEs. According to interviewees, the insufficient skills and knowledge of executive officers has actually discouraged them from working with SMEs effectively and actively. Despite the fact that the government has tried to equip their staff with capabilities and knowledge in business management, it seems that the government officers who are currently involved with the private sector do not have enough skills and competency to adapt to the current economic development situation. As a result, SMEs are currently becoming the victim of red tape and corruption from those government officers. Furthermore, the implication of supporting policies would be invalidated due to the inadequate training of these officers: "Executive officers do not know clearly about the laws. They feel embarrassed in supporting and guiding SMEs to follow the laws. It could be seen that executive staff are incapable of helping SMEs effectively" (SMEs 1-G3). Surprisingly, all respondents claimed that the roles of these supporting agencies are still not strong in providing high quality advisory and training programs for SMEs. Training programs are not practically focused and are too general, as stated by a respondent: "The issue is how to select the most suitable training program that can satisfy SMEs' needs. Information is so general and there is no special information for food manufacturers in technology, corporate management, MKT" (F4-G1). In addition, as SMEs may not be able to pay for the qualified services that are offered by support agencies, they are neglected by consulting firms. Moreover, there is really a gap between SMEs' needs and advisory services' capability in satisfying SME demands: "SMEs do not know what to ask and advisors do not understand or fail to identify the need of SMEs" (R5-G2)

\subsection{Technology and Information Support Services}

A number of common technologically related issues were referred to by respondents such as legal barriers and ineffective policy regimes concerning property rights; patents and trademarks; technological transferring; and importation of used equipment. Also, there was a lack of formal network linkages and technological cooperation among technological research institutions, between SMEs and supporting institutions, and with other firms. "Technological transfer is mostly from SOEs to SOEs" (F2-G1). The shortage of funds for investment and for technological development and the existence of an ineffective legal framework have prevented SMEs and research institutions from cooperating with each other. Hence, the findings indicate that there is evidence of a deficient overall national technological research and development strategy. "The current intellectual and property laws are being implemented but still can not effectively handle any possible dispute. There are still some limitations in the legal framework such as limitations in importing used manufacturing equipment. The fact is that many SMEs can not afford to buy high-tech equipment" (F4-G1).

In regard to the low level of technological facilities of supporting institutions, one respondent comments that, "Technology is out of date, and there is a lack of motive power in innovation. The supporting capability of research institutions is vague. Equipment is out of date with a technology lag of 2-3 generations compared to regional countries" (SMEs1-G3).

\section{Discussion and conclusion}

\subsection{Business Support Services}

\subsubsection{Lack of legal framework to support consulting services for SMEs}

Tax for business consulting firms may be significantly different from a state-owned supporting and training agency to a non-state-owned firm. According to the results, key areas for advisory services, training programs and projects to support SMEs consist of legal consulting for start up firms, taxation reports, general market information, and marketing and business development support activities. Advisory activities for technological innovation and adequate provision of information have not been considered as a primary focus of those supporting institutions and business supporting services for SMEs. This observation is consistent with the statement of Pham (2002) that, in a survey conducted by VCCI, approximately $48.7 \%$ of interviewees have received advice from other business entrepreneurs. On the contrary, only $9.6 \%$ of the interviewees have received advice from professional advisors. SMEs found difficulties in accessing necessary information and advice for business developments. SMEs currently rely heavily on informal resources of information and public media rather than on formal sources of information from their supporting institutions and particularly from professional advisors.

\subsubsection{Lack of formal linkages among businesses}

In the absence of capable supporting institutions and regulatory regimes that can act as facilitators to encourage networking and linkages among SMEs and other business sectors, obviously strategic linkages for cooperation seem to be impossible. SMEs need networking and collaboration among important stakeholders to bridge the resource and capability gaps. The current infrastructure and regulatory regime have not been able to create market conditions that facilitate networking and mutual beneficial relationships. The findings demonstrate that there is poor linkage among 
academic and research institutions, government management entities, industrial and business associations, supporting services and SMEs. Under such an unfavorable environment, lending organizations are reluctant to lend capital to SMEs. Moreover, the legal system and inadequate support infrastructure have made the business environment more uncertain and risky. As a result, emerging SMEs find it difficult to attract capital from both local and foreign financial sources.

\subsubsection{Deficiency in the legal framework and weak roles of supporting agencies}

The instability of policies and frequent changes in regulatory and related policies has generated significant risks for SMEs. Those constraints have not encouraged SMEs to seek for cooperation opportunities, strategic alliances or industrial subcontracting. Despite being mentioned in trade laws, these activities have not been defined clearly. The regulatory framework for industrial subcontractors, supporting industries, business associations, and business advisory services does not adequately sustain SME development. Pham (2002) observed that no specific law provisions contain the necessary requirements for business consulting services such as the roles and responsibilities of advisory services, codes of ethics, professional knowledge, and principles of arbitrations of conflict of interest. There is also the unavailability of regulations and a tax policy for SMEs using advisory services. Hence, business supporting and advisory services have not been considered as a critical industry in the national lists of professional careers. It seems that there are no clear-cut definitions about business supporting services and even clear-cut definitions about SMEs. As stated by Pham (2002), some business supporting services were ranked in the group of "other financial intermediaries' supporting activities". Others were ranked in the lists as "other business trading activities". As result, the quality of services from private advisory and supporting agencies is still questionable. On the other hand, due to unclear definitions, some SMEs can receive much help from the assistance programs, while others who do not know clearly about the government's favorable policies can not approach or receive the benefits from those supporting programs.

\subsubsection{Poor Quality of Human Resource Training and Professional Development}

An unqualified and unskilled labor force is really a significant impediment for both the government and SMEs. The inadequate structures of skilled labor could be due to insufficient training and the educational system. The fact is that, while there is a redundancy of unskilled labor, skilled labor is rare. According to Pham, (2002), the percentage of those who have attended some business administration training programs was only about $37.8 \%$ of the interviewed SME directors. Having identified the importance of training programs for SMEs, the Vietnamese government has been conducting numerous corporate management projects. These supports are in the form of training, provision of information, marketing support, technological advice, and advisory services for business development. However, it should be emphasized that any public support for SMEs from the government should not be understood in the sense of free-of-charge or partly subsidized. It is because there will be no huge financial subsidies that can satisfy the needs of entrepreneurs for training. On the contrary, business development and supporting services will have to play a key role in facilitating the development of the private sector. Although the Communist Party and the Vietnamese government have made many efforts to train their executive officers, it seems that many of them are incapable of working in a marketoriented economy or of supporting private SMEs effectively. Inflexibility and resistance to change due to fear of the unknown, fear of losing power, and fear of losing interests are the most common problems. Many of them are not adequately trained in any basic business managerial skills and legal knowledge.

According to figures from the Organization Department of the Government in the survey of $2001,30 \%$ of executive officers failed to fulfill successfully their assigned tasks. An additional $30 \%$ of staff who were currently working in the public administration sector did not meet the civil service's requirements. At the local level, $60 \%$ of civil staff did not have university degrees. And, more importantly, many corrupt officers have been creating difficulties for SMEs and Vietnamese residents $(\mathrm{Vu} 2001)$. It is fair to say that there are gaps between the supporting policies and the implementations of these policies. This is due to the fact that managerial regimes and executive officers are unable to adapt to the rapid changes of the new market-oriented environment. It could be said that there is a shortage of an overall strategy for training civil staff effectively. It seems that the government has not successfully addressed the specific needs of training for their civil staff in terms of practical applications with basic skills of business and state management, information technology and foreign language courses. More importantly, this shows the defects of the current national education programs in updating their curricula to accord with market and economic development trends. And finally, the complex and overlapping management regimes with unclearly designed functions have added more difficulties.

According to Ho, Do and Chu (2002) only 5.13\% of private SMEs owners have college qualifications, 10-15\% SMEs owners have short-term managerial training (below 6 months) and $48.4 \%$ have no formal qualification. This example shows the SMEs' significant needs for managerial and professional skills training. There are two problems that need to be highlighted. First, the quality of the training services is still questionable. Second, SMEs face difficulties in accessing these training services due to a gap between SMEs' needs and advisory services' capability. Consistent with Pham (2002), only $9.6 \%$ of the interviewed SMEs in the VCCI 2001 study received advice from professional consulting firms while $48.7 \%$ of them have sought advice from informal sources. This example helps clarify why SMEs tend to focus on 
informal sources of advice rather than formal advisory services. Regarding the gap between SMEs' needs and advisory services' capability, supporting services do not pay attention to SMEs because SMEs may not be able to pay for the services. Unfortunately, business supporting and training services have formed in a disorganized way, and lack an overall developmental strategy and proper operational regimes. As a result, business supporting and training services are operating incoherently without mutual cooperation. Some services and training providers do not focus on quality of the services, which makes SMEs incredulous. Others fail to identify the necessary needs of SMEs.

\subsection{Technological Development and Information Services}

\subsubsection{The Elimination Of Technological Transfer Barriers And The Encouragement of R\&D}

According to Le (2006), Vietnamese entrepreneurs' demands for technological innovation were quite low. Vietnamese SMEs' expenses for technological innovation accounted for only $0.2-0.3 \%$ of total revenue, in comparison with $5 \%$ in Indian SMEs or 10\% in Korean SMEs. This figure indicates that SMEs are not proving able to upgrade their technology and equipment to high technological development levels.

\subsubsection{Problems of Legal Barriers and Ineffective Policy Regimes for Technological Transfer}

It could be said that the current policy for technological development is mostly focused on the management of technological transfer. Unfortunately, technological transfer activities are only occurring among

SOEs. Hence the policy is only on the supporting side of those SOEs and may not be profitable for SMEs. On the other hand, there are inadequacies in regulations and policies about tax, credits, customs, and investment. Furthermore, high commission expenses would be key barriers deterring technological transfer activities, as well as not creating favorable conditions for IT software technology to develop. There are several problems relating to policy regimes and legal barriers such as: there is no adequate competition legislation and anti-monopoly policies that can eliminate the privileges of SOEs and encourage SMEs to innovate in technological development. There are several defective rules and policy inconsistencies in patents and trade marking, technological transfer and research development, and in investment funds for risky business. Those inadequacies have turned out to be significant barriers for SMEs to overcome, as well as broadening the gap between demand and supply of technological development and supporting services. There are no specific technological support policies for SMEs. Although the government has been offering incentives for businesses that are applying modern technology; those incentives are not really suitable to SMEs' abilities. SMEs are poor in resources and can not successfully afford high-tech, while the incentives are for businesses in all sectors who actively conduct research and development activities as well as employing new modern technologies. As a result, there are big gaps between policy implications and policy design. Furthermore, most of the technological transfer activities are cases of horizontal conversion from business to business at the same level, rather than from large firms to smaller firms.

\subsubsection{The problems of poor technological development, and poor internal resources}

As stated by Le (2006), the results of a recent study conducted in 2003 show that $86 \%$ of the respondents complained about the inadequate technological market or the weakness of technological supporting services. The technological market has failed to meet the demands for technological research development and transfer. $32 \%$ of the respondents in this study claimed that technological researchers and suppliers did not know who would be their targeted customers for selling their technological research products, while $29 \%$ of respondents complained that they did not know where to buy those technological products and technologies. The other $26 \%$ revealed that there was no real technological market for SMEs, since only state-owned technological research institutions and state-owned technological supporting services were operating. About $43 \%$ of the total respondents in this survey claimed that there were not any or inadequate rules and policies for regulating and defining the methods of technological transfer activities in the technological market. For that reason, supporting technological development activities are underdeveloped for supporting SME growth. On the other hand, those supporting policies seem to pay more attention to SOE technological research and development rather than supporting and facilitating the sustainability and growth of SMEs in the private sector. Although facing an urgent need for technological innovations and improving their competitive advantages, private manufacturing SMEs in Vietnam do not have the capability of adopting new technology due to their inadequate labor force, inadequate capital and managerial skills. Most of SME equipment and production facilities are traditional technologies, manual or semi-automatic controls, and from SOEs and domestic sources which are already out of date by two to three or even four technological generations in comparison with regional countries and even with other larger Vietnamese businesses in the same industry. Backward equipment and facilities are disposed by SOEs and are then adopted by SMEs as their production facilities. There are quite a few private manufacturing SMEs who can actually import high-tech facilities from overseas apart from mature and large private manufacturers. Together with financial and human resource constraints that deter SMEs from further upgrading technological equipment, SMEs also face a numbers of obstacles such as the shortage of technological information, and lack of necessary supporting services and networking linkages for cooperation and resource utilization among SMEs and technological supporting entities. This is consistent with what 
we have found in our study about the problem of technological research and development services in Vietnam.

\subsubsection{Problem of poor networking, linkages for cooperation and poor technological supporting services for SMEs}

Supporting institutions are unable to identify and meet the actual needs of SMEs for technological research and development, and technological transfer activities. It is fair to say that, quite different from corporate management and business supporting services, technological supporting services are mostly provided by state-owned institutions because those organizations have stronger technological advantages and stronger resources for investment in technological innovation. Although many private and semi-private academic and research institutions have been established, they are not capable of helping SMEs. They are also dispersed in different areas. However, the connections, linkages and networking between those supporting institutions with SMEs, SMEs with SMEs and other large firms, and among those supporting institutions do not really exist. Obviously, there is a significant gap between the supply and demand sides for technological research and developments. According to Pham (2002), only 4\% of FDI firms had approval of technological transfer contracts from the state. An unexpected result was that most of the technological transfer was "under the table". This has led to many instances where SMEs did not choose a suitable technology for production and invested heavily in high-technology equipment or purchased backward equipment that can not help improve their competitive advantage. There is strong evidence to say that an imperfection between the formulation of technological support policy and its implications exists. During the interview process, some respondents did mention the recent introduction of a "technological incubation center". However, this concept has not actually being considered as critical to technological research and development support for SMEs from concerned parties. The reason is that technological incubation centers are not just the place to develop SMEs but also need numerous business support services to integrate and create a strong networking, linkage relationship to satisfy the diversified and increasing demands of SMEs in responding to globalization and economic development trends. On the other hand, the lack of coherent linkages between academic institutions, research institutions, SMEs and other business entities is partly caused by a shortage of the necessary regulatory framework. Business supporting services for market research, marketing, technological information, and business brokerage services are considered by the concerned parties as "usual intermediaries" for coordination. This is the reason why there are no strong linkages among business and institutional entities. Further, where a very high distrustful culture (due to strong social discrimination and the poor image of Vietnamese private SMEs) exists, it is very difficult to build mutual trust and seek cooperation to utilize technological and other resources efficiently.

To conclude, the current gap between the supply and demand sides for technological research and information, training and development, and business support services would be not easy to solve in the short term. The findings suggest that the state's entrepreneurial role is of special importance since it can coordinate existing market factors to provide support policies, infrastructure resources, and support institutions for SME development in Vietnam. This study highlights that inadequate policy regimes and inadequate market factors may become hindering factors instead of being enabling factors for SME growth if the Government and supporting institutions do not play a key role in acting as facilitators for the efficient distribution of resources. The proposed model could be a good example for further examination of the evolving relationship between the State and market factors in similar transitional and developing countries.

\section{Acknowledgements}

Our special thanks to the valuable contribution, Dr Jeffrey Keddie, Department of Management, Monash University made to the preparation of this paper. The earlier version of this refereed paper was accepted (on 3-3-2008) for presentation at the 5th International Conference on Service Systems and Service Management (ICSSSM'08), 2008, Melbourne, Australia.

\section{References}

Assaf, G.B. (1998). Enterprise restructuring in central and Eastern Europe (CEE) and the former Soviet Union: The roles of technical assistance. In Cook C, Kirkpatrick C., and Nixson F. (Eds), Privatization, Enterprise development and Economic reform: Experiences of developing and transitional economies, USA: Edwards Elgar.

Batra, G., and Mahmood, S. (2003). Direct support to private firms: Evidence on effectiveness. World Bank policy research working paper 3170 .

Brimble, P., Oldfield, D., and Monsakul, M. (2002). Policies for SME recovery in Thailand. In: Harvie, C., and Lee, B.C. (Eds), The role of SMEs in National Economies in East Asia. Singapore: Edward Elgar.

Dallago B., and. McIntyre, R.J. (2003). Small and Medium enterprises in Transitional economies, Basingstoke and New York: Houndmills, Palgrave Macmillan, 2003.

Gibb, A., and Lyapunov, S. (1996). Creating small business out of large enterprises", in Levitsky, , J. (Eds), Small business in transition economies: promoting enterprise in central and Eastern Europe and the former Soviet Union. UK: IT publication, 1996. 
Ha, T.T., and Swierczek, F.W. (2003). Motivation, entrepreneurship and the performance of SMEs in Vietnam. Journal of Enterprising Culture, vol 11(3): 47-68.

Harvie, C. (2002). China's SME: Their evolution and future prospects in an evolving market economy. In Harvie, C., and Lee, B.C. (Eds), The role of SMEs in National Economies in East Asia. Singapore: Edward Elgar.

Havie, C. (2001). Competition policy and SMEs in Vietnam. Working paper series 2001, WP 01-10, Department of economic, Department of economic University of Wollongong, 2001.

Ho, X.P., Do, M.T., and Chu, M.P. (2002). Financial supports for the development of SMEs:, Monographic book, Hanoi: Financial Publishing House.

Katz, S. (1995). Some key development issues for transitional economies-East and West” Konopielko, L., and Bell, J. (1997). Reinventing aid for SMEs in Eastern Europe: Lessons from the implementation of the Struder Programme. Policy review section.

Le, D.D. (2006). Businessmen, business entrepreneurs and economic reform, Ho Chi Minh City: The Youth Publishing House, Saigon Economic Times, p. 27.

McIntyre, R.J. (2002). Small enterprises in transition economies: Causal puzzles and policies relevant research". Economic science of contemporary Russia, vol 5,(1): pp. 121-141 (English version).

Petri, P.A. (1995). The lesson of East Asian Success: A primer for transitional economies, in in Naya, S.F., and Tan, J.L.H. (Eds), Asian transitional economies: challenges and prospects for reform and transformation. Singapore: Institute of Southeast Asian Studies.

Pham, T.H. (2002). Creating good jobs by the support policies to develop SMEs. Hanoi: The National Political Publishing House.

Tambunan, T. (2005). Promoting Small and Medium Enterprises with a clustering approach: A policy experience from Indonesia. Journal of Small Business Management 43 (2): 138-154.

Vu, Q.T. (2001). Business entrepreneurs in the market oriented economy. Hanoi: The National Political Publishing House, p. 441, 2001.

Wattanapruttipaisan, T. (2002). Promoting SME development: Some issues and suggestion for policy consideration". [Online]. Available: http://unpan1.un.org/intradoc/groups/public/documents/APCITY/UNPAN011410.pdf.

\section{Appendix}

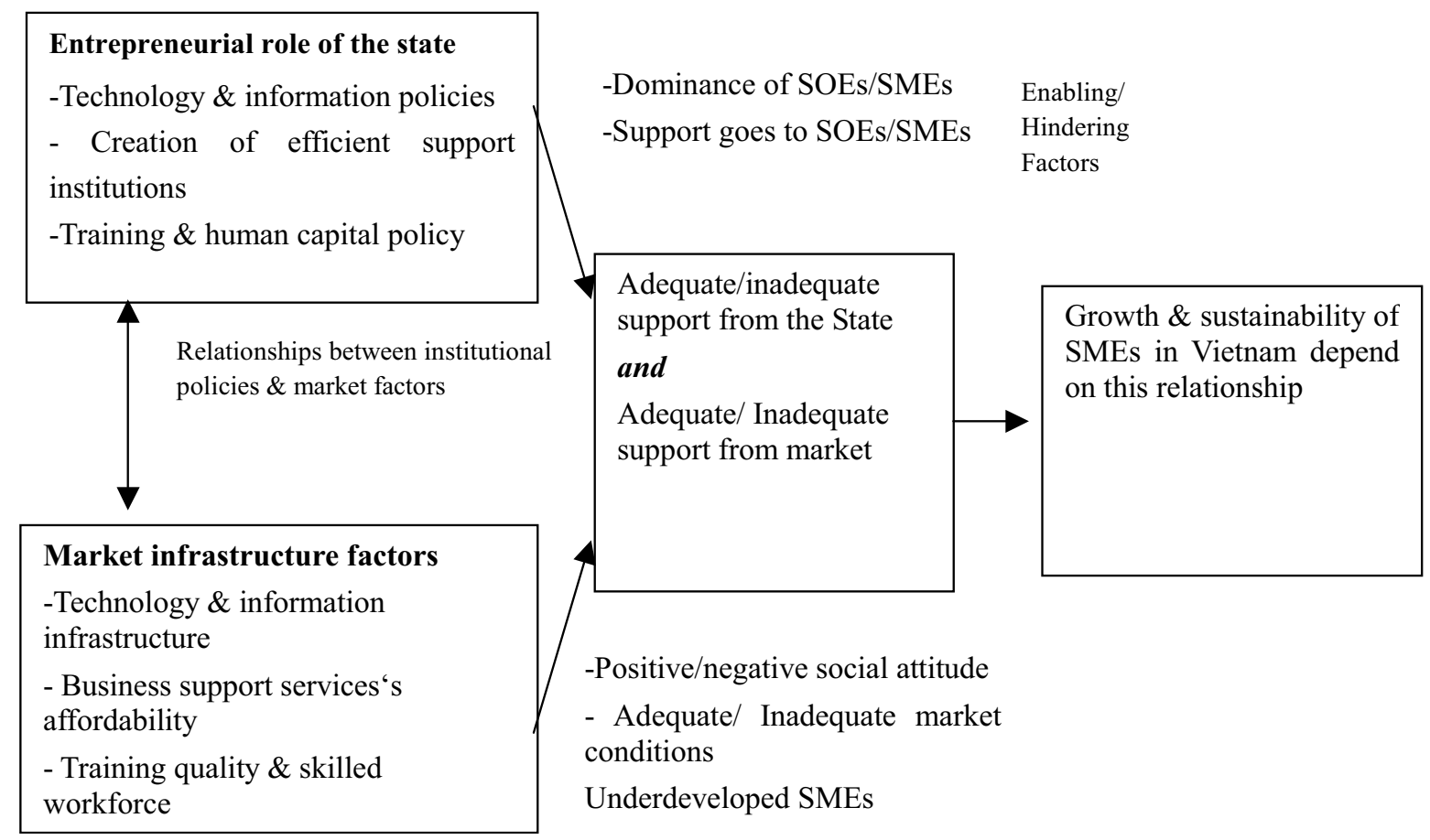

Figure 1. The Evolving Relationships between State and Market Factors impacting on SMEs in Vietnam 


\title{
Conducting Postgraduate Level Research: Selecting A Methodology- A Students' Perspective
}

\author{
Vlasios Sarantinos \\ Department of HRM, University of Strathclyde, UK \\ E-mail: vlasios.sarantinos@gmail.com
}

\begin{abstract}
In the vast majority of postgraduate research, an integral part of business students is to select an appropriate methodology to suit the particular research needs of each project. In this paper we present issues, problems and real-time practical issues from the perspective of a young researcher. Through a specific subject matter and two exemplary methodologies we present a concise review of the methodological dimensions to come up with an optimal solution that will maximize the potential of the project.
\end{abstract}

Keywords: Research project, Psychological contract, Methodology

\section{Introduction}

Undeniably, one of the most critical part of any postgraduate piece of work is the ability to select the methodology appropriate to the subject matter that will enable the researcher to develop the project adequately enough with the novel elements required to differentiate it from the existing pieces of work. In this paper we present an example of how a student can contemplate two research methods for a specific topic, not from a textbook perspective but from the framework of a student already in the actual making of his research project. Initially, we introduce the importance of selecting an appropriate methodology using a default subject matter from the area of human resources management. Continuing, we consider two potential methodologies survey type research and case-study creation for the particular research context, concisely discussing the pros and cons of each in terms of research philosophy, practicalities in research and inherent limitations.

\section{Choosing an appropriate methodology: Kicking of from the relevant literature}

An integral part in any critical piece of work is the methods used to formulate, substantiate and comment on the arguments usually found in the literature or conjectured at the beginning of the project. Depending on the project type, philosophy, scope and numerous other factors, the methodology adopted for data collection can take different forms and the researcher can use several different instruments dependent on the initial parameters decided on the outset of the project. The problem under scrutiny for our research area refers to the psychological contract and the element of trust in the employment relationship.

In particular we are trying to recognize the connections between employees and supervisors from the top levels of the hierarchy to line managers and common employees within the social healthcare section. Additionally, we are attempting to examine the line of intervention of top-level management to the every-day affairs between line managers and employees in terms of interest, practicality and capability of intervention. The psychological contract firstly coined by Argyris in 1960 has been thoroughly researched and argued. The various arguments in the field include questions about its nature, whether the term 'contract' is accurate or not especially when compared with written contracts (Arnold, 1996) whilst others attributed to this type of unwritten agreements significant enough powers to resemble in terms of validity and influence a standardised written contracts (Sparrow and Marchington, 1998; Deery, Iverson and Walsh, 2006).

Psychological contracts have been often defined according to their particular characteristics. For example, Rousseau (1995 and 2000) distinguishes between two types of PC:

- transactional contracts, which are structured with emphasis on material rewards that have a short-term duration and are relatively narrow in their scope; and

- relational contracts, which are structured around less tangible rewards, have a significant duration (often without an implied end-date) and are subject to the individual parties' beliefs.

Another interpretation of the PC was offered by Guest and Conway (1997, 1998 and 2004) representing overall the CIPD mentality on the PC (CIPD 2003, 2004 and 2005a). Whilst other researchers (Sparrow and Marchington, 1998; Rousseau, 1998) view the PC as an analytical tool to grasp the complex changes that occur throughout the organization when new employment practices are adopted, Guest and Conway (1998) view the PC as a means to understand the state 
of the employment relationship in an organization and for plotting corresponding changes. In terms of the various methodologies used, we can see a significant preference to questionnaire and interview type research (Robinson; 1996; Guest \& Conway, 2000; 2002)

\section{Considering the methodology}

On considering how to approach the subject matter, the most appropriate methodologies cannot skew significantly from the general trend towards questionnaires and interview-based methods. There are several reasons advocating the use of such instruments pertaining both to the inherent research philosophy and to practical considerations when conducting the data collection and analysis. On the other end, we shall examine the potential use of case-study creation as an alternative method. Considering each method individually, surveys are driven primarily by a positivistic paradigm,(Popper, 2002;2004) aiming to examine usually a set of predetermined hypotheses in a particular setting as is the case with our particular research question (Smith et. al 2002). The hypothetico -deductive framework also offers some important elements that fit the selected organizational setting to carry out the research.

Initially, the research question will be tested on a standardised organizational setting most likely a hospital where the researcher might be given access to conduct research but it is doubtful that he will have much or any capacity to actually becoming involved in the setting further from dispensing some questionnaires or carrying out some interviews. Consequently, the researcher needs to consider the overall research process as an objective reality in order to maximize the aims set at the outset. Given the conditions for operating in the specific research environment, a linear hypothetico-deductive method of testing a series of pre-determined questions appears quite suitable. As such, it is important for the research to adhere to the basic perception of objectivity in reality and the same should follow for the knowledge that is generated in the research process (Creswell, 1994).

Equally as we have already mentioned, survey type research is driven primarily be a positivistic stance emphasing in particular the quantitative strength in data collection and especially in the analysis stage with a linear principle at the forefront. As our research question contains specific variables we hypothesise about and which we seek to test in the healthcare section, the linearity in terms of methodology both in terms of philosophy and in terms of implementation further from applicable to the requirements of the organizational setting, it also operational in the actual facilitation of the research.

Essentially, this methodology offers a straightforward, adequate and practical manner in conducting our research. Straightforward as it allows to the researcher to immediately begin formulating the instruments for data collection firstly because the research environment is more adaptable in such an approach and secondly because the nature of the research question structure can be converted directly into a methodology (Buckingham \& Saunders, 2004). The latter is also evident through the previous research carried out in the field as we mentioned earlier, survey type research holds the preference of the most endeavours in the literature.

The alternative methodological approach we shall consider is case study creation for the purposes of our specific research question. In principle, case-studies usually examine more in-depth, at times over a longitudinal fashion of a smaller 'sample' or instance as termed by the word case to both generate and test hypotheses (Yin, 1993, 1994; Flyvbjerg, 2006). In the later sense, case-study can also fit with the prerequisite of our research question and the pre-determined questions we wish to examine. Due to its in-depth nature, contrasting to survey type research case-studies fall more into the qualitative spectrum rather than producing quantitative results without omitting the instance of co-existence (Yin, 1994).

In regards to data collection, typical instruments could include events such as interviews, archival records, participatory observation etc. For example, the interviews as we mentioned previously when considering the survey type research can also be used if a case-study method was adopted. The issue concerning the particular research question though is the size of the sample since there might be a difference in the context as survey-based interviews apart from the context also require a significantly larger sample than we would expect to find in a case-study as the objective is to obtain statistical information rather than qualitative texture.

The latter difference also pertains to the emphasis given in the research design and what is our primary objective in the data collection stage. If the interest is focused in obtaining sufficient enough sample for statistical substantiation then it is vital to obtain a significantly adequate sample of either questionnaire responses or interviewees or both. On the other end, if we are interested mainly on eliciting more in-depth information and delving perhaps deeper in the argumentology, than the case-study option might be more appropriate.

An additional factor we have to take into account are the practicalities when conducting the research and namely the various constraints that are bound to exist. For one, in our particular research environment we have constraints imposed by the organisation in terms of access and time. For example if we select the survey-type approach it is necessary to obtain permission first to conduct the research in the hospital and then to ensure we will have enough feedback. Equally, for the case-study option access to formulate the components of the case-study is required and secondly the information 
that will be collected must not impinge on any data-protection agreement or legal stipulation in order to be granted access to carry out the research. Similarly the are issues of time and scope that are inherent to any project so as not to be carried away and end up with a too small or to large sample for the purposes of the specific project and the relevant objectives.

Naturally, the pragmatics exist in any line of research as are the difficulties that arise from them. In order to surpass them, needs to be careful planning from the very start of the project. When drawing the research question and then onwards to formulating the research, design it is essential to carefully decide upon the research methodology that best fits the question, will provide the most optimal input for the analysis stage and at the same time minimises the practical obstacles. Essentially, at this stage we need to calculate all the parameters, taking into account the nature of the research question and of each method available, compare them against each other or in combination and adapt either our research question in a manner that does not compromise the objectives of the project or tweaking the methods' parameters to fit our research or even both. It is essential to point out that this is an ongoing process and most likely there will be several instances during every stage of the research that there will some level of review and potential change in the design, implementation and analysis phases of the examination and but this is an unavoidable and vital element to produce a novel, rigorous and in-depth outcome.

\section{Conclusions}

Selecting an appropriate methodology is a vital part for any postgraduate level research, from a simple thesis to a research paper in order to add the elements that will differentiate this piece of work from the previous tasks carried out in the field. The researcher needs to carefully weigh from the very early stages of the project all the information, the research question, the particulars of the methodologies available, the relevant philosophy, practical issues such as access, time and various other expected constraints coming finally down with an overall research mix that will allow to the student to progress and grow along with project raising both the academic merit of the project and individuals' own skills.

\section{References}

Argyris C. (1960). " Understanding organizational behaviour", Homewood, IL: Dorsey.

Arnold, J. (1996). 'The psychological contract: A concept in need for closer scrutiny?', Research Series Paper No. 17, Loughborough: Loughborough University Business School.

Buckingham, A \& Saunders, P (2004). " The survey methods workbook", Polity.

Creswell, J. W (1994). " Research design- Qualitative and quantitave approaches London: Sage.

Deery, S. J., Iverson, R. D., and Walsh, J. (2006) ' Towards a better understanding of psychological contract violation: A study of customer service employees', Journal of Applied Psychology, 91 (1), pp. 166-175.

Easterby-Smith, M., Thorpe, R. \& Lowe, A. 2002. “Management Research: An Introduction" (2 ${ }^{\text {nd }}$ ed.). London: Sage Publications.

Flyvbjerg B. (2006). “Five Misunderstandings About Case Study Research" Qualitative Inquiry, vol. 12, no. 2, pp. 219-245.

Guest D. and Conway N. (1997). 'Employee motivation and the psychological contract', Issues in People Management No. 21. Wimbledon: IPD.

Guest E. D \& Conway, N. (2000). " The psychological contract in the public sector" Research Paper, London: CIPD publishing.

Guest E. D. and Conway N. (2002). 'Communicating the psychological contract: an employer perspective', Human Resource Management Journal, 12 (2), pp. 22-38.

Guest E. D. and Conway, N. (2004). Employee well-being and the psychological contract, London, CIPD.

Guest, D., and Conway, N. (1998). Fairness at work and the psychological contract, London: IPD.

Popper, K.R. (2004). "The Logic of Scientific Discovery" ( $2^{\text {nd }}$ ed.). London: Routledge.

Popper, K.R. 2002. "Unended Quest: An Intellectual Autobiography". (5 $\left.5^{\text {th }} \mathrm{ed}\right)$ London: Routledge.

Robinson, S. 91996). "Trust and breach of the psychological contract" Administrative Science Quarterly. V. 41, No. 4: pp 574-599.

Rousseau, D. M. (1995). Psychological Contracts in organisations: Understanding written and unwritten agreements, Newbury Park, CA: Sage.

Rousseau, D. M. (1995). Psychological Contracts in organisations: Understanding written and unwritten agreements, Newbury Park, CA: Sage. 
Rousseau, D. M. (1998). 'The `problem` of psychological contract considered', Journal of Organizational Behaviour, 19, pp. 665-671.

Rousseau, D. M. (1998). 'The 'problem` of psychological contract considered', Journal of Organizational Behaviour, 19, pp. 665-671.

Rousseau, D. M. (2000). Psychological Contract Inventory: Technical Report, Heinz School of Public Policy and Graduate Industrial Administration, Carnegie MellonUniversity. http://www.andrew.cmu.edu/user/rousseau/0_reports/PCI.pdf retrieved 28/01/2008.

Rousseau, D. M. (2000). Psychological Contract Inventory: Technical Report, Heinz School of Public Policy and Graduate Industrial Administration, Carnegie Mellon http://www.andrew.cmu.edu/user/rousseau/0_reports/PCI.pdf retrieved 28/01/2008.

Yin, R. K. (1993). “ Applications for case study research” Newbury Park. CA: Sage.

Yin. R. K. (1994). “ Case study research: Design and Methods” ( $2^{\text {nd }}$ ed): Thousand Oaks: Sage. 


\title{
Strategies for Developing 'Red Tourism' : A Unique Tourism Activity in China
}

\author{
Bin Wang \\ School of Management, Dalian University of Technology \\ Dalian 116024, China \\ E-mail: dutpeter058@126.com \\ Chunyou $\mathrm{Wu}$ \\ School of Management, Dalian University of Technology \\ Dalian 116024, China \\ Haiyao Peng \\ School of International Tourism and Hospitality Management \\ Dalian University of Foreign Languages \\ Dalian 116002, China
}

\begin{abstract}
'Red Tourism', a newly developed tourism activity unique in China, has gained great popularity among tourists and keen attention from both tourism practitioners and researchers. However, its connotation has been narrowly defined and the policies to develop it in-depth at the regional level are insufficiently discussed. The paper firstly explains and redefines red tourism in a broader context. And then, taking Dalian, a Chinese famous tourist city, as a example, the paper analyzes the current situation and basis of red tourism resources, proposes marketing policies to promote red tourism, and finally expounds strategies to develop it in Dalian.
\end{abstract}

Keywords: Red tourism, Marketing, Strategy, Dalian

\section{Introduction}

'Red' in China is always related to the former revolution of Communist Party of China as far as tourism industry is concerned. Therefore, 'Red Tourism', a unique tourism activity originated from the 1990's in our country, stands for specialized tourism form with outstanding themes of organizing and receiving tourists of visiting, studying, and commemorating at the former revolutionary bases, remains, and landmark sites (Wang, 2005, pp.305). All of them are formed and left before the founding of People's Republic of China and after the birth of Communist Party of China, including the period of Red Army's Long March, Anti-Japanese Aggression War, as well as Civil Liberation War. However, in practice, the connotation of red tourism has been expanded to include a variety of tourism activities which could arouse patriotism and better understanding of revolutionary history in China. In this sense, we define red tourism as tourism activities conducted at revolutionary bases or historic sites which could contribute to a better understanding of national or revolutionary history, enrichment of tourists' knowledge about parties, history and revolution and arousal of patriotism.

Stimulated by 'Golden Week'( longest seven-day holidays around Labor Day, National Day and Spring Festival in China), mass tourism and holiday tourism prospered, which meanwhile boosted the development of Red Tourism(Mo, 2005, pp. 21-25). In February, 2004, at the National Tourism Conference held in Zhengzhou, at which Zhengzhou Declaration was announced by Shanghai, Beijing, Jiangxi, Fujian, Hebei, Guangdong, and Shaanxi Province in central China. They advocated "sharing resources, information, and market and benefit together", which unveiled the prelude of the great-scale Red Tourism development in China. Moreover, The General Office of the Central Committee of the Communist Party of China (CPC) and the General Office of the State Council has set six major goals for Red Tourism 
in their guidelines for the development of the nation's Red Tourism from 2004 to 2010, including developing 12 key tourist areas, improving 30 "selected traveling routes", cultivating about 100 "classic red tourist spots" in our country.

Dalian ,one of Chinese 10 best tourism cities, has attracted tourists from all over the world for its mild coastal climate, spectacular seascape, fascinating theme parks and festivities. Dalian is also known for its historical remains from the turn of $20^{\text {th }}$ century when Dalian was governed first by Russia then by Japan. A large number of war fields/fortresses/weapons etc. remained, many of which have been made into museums and exhibition centers to serve as tourist attractions. Besides, the old residence of Guan Xianying, a top leader in Chinese revolutionary history, was selected as one of 100 "classic red tourist spots" in our country (Li, 2005). It is expected that the design and exploitation of red tourism in Daian could greatly complement existing tourism products whose prevailing attraction consisting of seascape, squares and theme parks.

\section{Significance of Developing Red Tourism in Dalian}

It is believed that red tourism is a major project that could benefit both the Party, the nation and the people, either in the economic, cultural or political sense.

First of all, Red Tourism could reinforce the patriotism education of adolescents by coordinating the traditionally revolutionary education with the development of tourism industry. Former revolutionary bases, remains and war ruins are high in historical value and educational meaning. Visits to those sites will infuse national ethos and patriotic spirit into the youngsters. Combining teaching and fun with travel is also an improvement in the form of education.

Besides, red Tourism could be conducive to the development of Dalian economy and social culture. The glorious traditional culture deriving from fights to win national independence and anti-imperialists is valuable assets in both the revolutionary war periods and present-day efforts to realize the rejuvenation of the country. Red culture is a significant part of Chinese culture system, and is indispensable to the integrated, advanced culture of socialism with Chinese characteristics. To inherit and carry forward Red culture, seeking the gearing point with Dalian local culture and tourism will assist the development of Dalian economy. Red Tourism can effectively convert political advantage to economic advantage, and form a new growing point of Dalian tourism economy.

Lastly, red Tourism can be a great aid to Dalian tourism industry. For a long time, tourist products of Dalian remain at the relatively low level. High-grade tourist products are badly scarce. The single tourist product chain centering on the sea-sightseeing sea view, tasting seafood, fishing and shopping handicrafts about the sea, cannot meet tourists' diversified needs at cultural and spiritual level. However, Red Tourism fills the gap. Tourists are prone to learn historical and cultural knowledge, mould their sentiments and enhance their tastes.

\section{The Current Situation of Red Tourism Development in Dalian}

The main attractions of Dalian Red Tourism are the Former Residence and Memorial of Guan Xiangying in Jinzhou District, abundant war remains and some military buildings of former Soviet Union in Lvshun district.

At present, Dalian municipal government has been carrying forward the design and construction of Memorial of Guan Xiangying. Dalian Transportation has rebuilt the highway of 12.3 kilometers in Jinzhou in order to completely improve the transportation to the memorial (Liu, 2005). Some surrounding tourism resources are being developed to integrate an exquisite tourism program based on Red Tourism. Meanwhile, in order to expand more items on display in the memorial, the collection and disposal of historical relics and stories or anecdotes about Guan Xiangying are under way.

Patriotism education bases such as the former prison of Russian-Japanese War of 1905 has been well combined with annual important festivals to hold some seminars and other activities, which has attracted plenty of tourists, especially young students.

\subsection{Advantages}

(1) Rich and unique Red Tourism resources

The Memorial of Guan Xiangying in Jinzhou district, the national patriotism educational base, has been brought into national layout of Red Tourism. Lvshun represents an epitome of Modern History of China. Plenty of wars such as the Sino-Japanese War of 1894, and other significant historical events were closely related with Lvshun. Particularly, Lvnshun is the unique battle field of Russian-Japanese War of 1905, a lot of war ruins and military buildings are unique. They are live textbook as spreading patriotic spirit and national ethos. Thus, while reading the Modern History of China, people have to pinpoint Lvnshun.

\section{(2) Beneficial developing environment}

National and local governments have placed much emphasis on Red Tourism, and are making policies supporting travel agencies to manage Red Tourism routes. National Tourism Bureau is going to integrate Red Tourism resources and to establish Red Tourism system. 
Liaoning Province has set its aim and worked out the specific outline to develop provincial Red Tourism. One strategy is to design a series of exquisite itineraries and four key zones, including Lvshun in south Liaoning. In local Dalian, Red Tourism has been brought into the layout and many relevant infrastructures are under rebuilding.

\subsection{Disadvantages}

(1) Late start

Red Tourism originated in $90 \mathrm{~s}, 20^{\text {th }}$ century, whereas the development in Dalian began in recent years. A number of advantageous tourist products and itineraries need designing. However, some other renowned places outside Dalian have better basis and more experiences in developing Red Tourism.

(2) Competitive disadvantage in the region

Red Tourism is prevailing across China. Jinggangshan of Jiangxi, Shaoshan of Hunan and Yan'an of Shaanxi in central China developed Red Tourism early and are famous now. Their itineraries and scenic spots are overwhelming in the market. Furthermore, neighboring counterparts like Shenyang, Jinzhou and Fushun are also competing for market shares. Hence in order to catch up with and outdo them, Dalian has to highlight its strengths.

(3) Difficult to assimilate Red Tourism into Dalian tourism image

Dalian has promoted itself as an Romantic City and has gained much identification. Nevertheless, to speak of Dalian, tourists will associate with romantic squares and the sea. It needs a transition to change the first impression in the mind of tourists.

\section{Marketing of red tourism in Dalian}

\subsection{Market Position}

Red Tourism is positioned as a significant part of Dalian tourism economy. The general plan of developing Red Tourism is divided into two phases. The first phase mainly concentrates on the improvement of infrastructures and collections of historical and cultural objects. And the aim of the second stage is to make Red Tourism an essential part of Dalian tourism, extend and improve the industrial structure of Dalian tourism via Red Tourism.

Lvshun could be positioned as half of the history textbook of Modern History of China, and the Memorial of Guan Xiangying, war ruins in Lvshun and World Peace Park could be designed and promoted as the second classroom of patriotism education.

In terms of tourists' origins, the market of Dalian Red Tourism is mainly positioned domestically. The primary market consists of Dalian residents and people from neighboring areas. The secondary market should be extended to people in Liaoning province with which Dalian is affiliated. And the chance markets are those areas in the near vicinity of Dalian including parts of area of Shandong, Jilin and Heilongjiang provinces and Beijing. As far as tourists are concerned, red tourism in Dalian should be gearing to teenagers, school children who are required to study history or interested in chinese revolutionary cause.Much attention should also be given old people who are proved to be more interested in history.

The policies are to strengthen and retain the primary market, making efforts to strive for the secondary market and working hard to win the chance market.

\subsection{Design of tourist products}

Red tourism should be designed to helpful in blending teaching into travel, rereading the history textbook of wars to realize the importance of peace, in the form of travel and via actual deeds, is mutually effective. And it also could provide tourists with experiences of sightseeing and shopping in an romantic city, touring red scenic spots and recalling the history.

It is very important to add red tourism spots into existing mature itineraries, making red tourism spots indispensable parts of highlighting traveling routes. Designing routes in light of different themes is strongly recommended. Meanwhile, cooperation and coordination with neighboring regions and trying to link itineraries across regions will tremendously expand market. It is also advisable that travel agencies should reform the combinations of tourist products, pinpointing Red Tourism and design different itineraries in terms of tourists of different age, to meet their diversified needs, such as organizing a special trip to visit various former battle fields.

Red souvenirs should be designed with great care to infuse red culture into local handicrafts and artworks to deeply develop commercial value of red tourism in the way of, say, carving red scenic spots of Lvshun into glassware and shell sculptures or making badge of Guan Xiangying, publishing books about Guan Xiangying's anecdotes.etc.

\section{3 promotion}

Promotion can be done with unique features of red tourism and the collaboration with other forms of tourism taken into consideration. Firstly, make meticulous preparation, actively attend various cooperation conventions of red tourism in 
our country to promote Red Tourism products of Dalian and extend the popularity. Secondly, integratively take advantage of media, such as newspaper, television, and radio to enhance the promotion strength. Thirdly, promote via internet by adding columns of red tourism in the website of Dalian tourism, helping the tourist timely acquiring information about red tourism in Dalian. As regards the market of college students, the government and travel enterprises may set up a special column of red tourism on university websites and other popular websites. Fourthly, hold tourism festivals, e.g. Cultural Festival of Dalian Tourism. Combine patriotism education and the cultivation of 'national civilized city' together to spread the image of red tourism.

As regards college students, tourism bodies could cooperate with tourism education schools. For instance, by providing free internship base for students of tourism management school to let them promote red tourism at the university. On the other hand, travel enterprises may cooperate with university student bodies to organize activities to publicize red tourism products, e.g. sponsoring a photography competition, which is an effective and economical way to enhance the popularity of travel enterprises and scenic spots.

As to secondary school students and pupils, tourism enterprises could make the best use of holidays such as Labor Day, Children's Day and National Day to organize free trips to red tourism spots pinpointing theme activities of patriotism education, remembering national humiliation and studying for the reinvigoration of China etc. At the same time, patriotism education bases should enter schools to give lectures of and display pictures of Dalian Modern History to propagate patriotic spirit.

As for tourists of other ages, tourism organizations should take advantage of some commemorative days such as the $110^{\text {th }}$ anniversary of Sino-Japanese War of 1894 provide free visits for enterprises, government ministries, and military institutions to expand chance tourist markets. And innovation of display techniques should be emphasized.

\section{General development strategies}

\subsection{Make a master planning}

The municipal government must make the general strategic aim of the near future and then put it in practice stage by stage. The task of the first stage is to improve infrastructures and maintenance of war ruins, collect more historical objects, anecdotes and stories concerned by the end of 2007. At the second stage from 2008 to 2010, all parties concerned should implement the plan to initiate an all-round development of red tourism, making it a significant part of Dalian tourism industry.

\subsection{Make joint efforts from stakeholders}

Provincial and municipal governments hold the responsibility to bring stakeholders' initiative to full play. They are also responsible for rebuilding infrastructures, protecting ecological environment and providing sound conditions for the sustainable development of red tourism. Meanwhile, successful operation of red tourism involve tourism operators, tourism spots management, participation of local residents, and tourists themselves, whose common endeavors will enable red tourism to develop smoothly. Government will play the leading role in integrating efforts from various parts to propel red tourism to develop in line with the master plan.

\subsection{Provide product mix in which red tourism is highlighted}

Design 'red+ green+ blue' products, where 'red' refers to red tourism with 'green' and 'blue' representing the prevailing tourism products in market. 'Green' refers to green mountains and rivers like Bingyu Ice Valley, green squares and natural countryside sceneries. 'Blue' refers to the sea. It is necessary to bind those products together to enhance their general attraction and make better use of separate markets. As a famous tourist city of north China, Dalian is shielded by mountains and surrounded by seas, decorated by plenty of squares and lawns. Numerous tourists are deeply impressed by its superior natural environment and western style metropolitan design with many squares and buildings in Roman and Gothic Styles. Dalian's rich tourism resources, mainly consisting of Lvshun national scenic area, Golden Pebble Beach State Tourist Resort, Ice Valley, Pole Aquarium of Tiger Beach and Sun Asia Ocean World, are of great attraction for potential tourists. However, a sole dependence on natural sceneries is becoming less competitive in tourism market. It is imperative to complement natural attractions with new products rich in cultural and historical implications. Thus, the combination of red tourism with traditional sightseeing, and the blend of natural sceneries and historical as well as cultural resources, will greatly contribute to the improvement of comprehensive strength, economic benefits, and the sustainable development of Dalian tourism industry.

\subsection{Strengthen regional cooperation}

In order to avoid the repetitive construction and vicious competition with neighboring cities, it is necessary to seek regional cooperation to form a master frame for the whole region. A long term strategy is also essential for all the cooperators to follow in the long run. Tourism industry is a highly open and inclusive industry that has close connection with other industries such as communication, environment, trade and construction etc. moreover, tourists always travel across regions to finish a trip. Therefore, tourism industry usually depends on endeavors across industries and regions 
for smooth operation. Complementation and cooperation across departments and regions are the first choice for developing local tourism (Liao, 2005, 12-16). Dalian, the No.1 tourists destination in northeastern China, has great status in Chinese domestic markets, and as one of top destinations of Japanese and Korean tourists to China, it also plays a key role in Chinese inbound market. While enjoying the superiority of vast market, Dalian lacks competitive advantage in its red tourism development with abundant red tourism resources lying in the vicinity of but beyond management of Dalian. Under this circumstance, Dalian needs to seek help from neighboring regions which have good foundation and reputation of red tourism products, and as a reward, allowing those cities to take advantage of its large market and power in Chinese inbound markets. Regional cooperation can not only happen between cities within Liaoning province where Dalian is situated, but extend to neighboring provinces encircling Bohai Sea including Hebei, Shandong provinces and Beijing. Itineraries across regions could be designed with themes like "Commemoration of Anti-Japanese Aggression' to incorporate red tourism spots in neighboring cities of Shenyang, Jinzhou and Fushun. Mixed products combining red tourism with other traveling activities are also advised to extend beyond Liaoning province. Beijing, capital of China and known for its insurmountable attraction for overseas tourists, could be a big impetus for Dalian if it successfully links its itineraries with Beijing. Hebei province and Shandong province, both famous for their rich heritage, revolutionary remains and gorgeous seascape, could greatly enhance the overall glamour of Dalian if red tourism spots in those regions are elaborately designed and link together.

\subsection{Improve service}

Distinguished from most natural sceneries, scenic spots of red tourism are more meaningful in cultural and spiritual implications. Red tourism relies on competent workforce, e.g. tourist's guide, to convey and interpret its profound meanings. Hence the training of working personnel, including management and servicemen must be emphasized.

The interpretation of tour guides plays a significant role in spreading patriotism education and instilling patriotic spirit. Thereby, it is urgent to build a high-quality and high-level team of tour guides. Political science, of national and international affairs and situations, should be added to training program. In addition, the training of tour guides' language and skills is of great importance as well. Their infectious interpretation will naturally bring tourists back to the war period and consequently make them be aware of the significance of peace.

\section{Conclusion}

The development of red tourism in Dalian started late, but the resources are rich and distinctive, furthermore, they have great historical and cultural values, and great potential of development. Relying on superiority in policy and regional environment as well as existing foundation of tourism, Dalian should take the opportunity to make scientific plan develop red tourism in a sustainable way.

\section{References}

Li Fei. (2005). A take-off of 'red tourism' in Liaoning Province. http://www.eduhelp.com.cn/travel/hsly/.htm.

Liao Guoyi. (2005). Strategies for developing red tourism in Guangxi. Reform and Strategy. Vol,9,pp.12-16.

Liu Ming. (2005). Dalian initiate the project of 'red tourism' to incorporate Guan Xiangying Memorial into the plan. http://news.sina.com.cn/o/13405299298s.shtml.

Mo Zhongning \& Li Zhenyi. Thoughts of developing 'red tourism' in Baise City. Journal of college of Nanning Communist Party. Vol. 3, 21-25.

Wang Yucheng. (2005). Introduction to tourism culture. Bejing, Chinese Tourism Press.pp.307-317. 


\title{
Marxist or Feminist Approaches to Sports Management Are There Traits in A Modern Days Society
}

\author{
Ian Arnott \\ Teesside Business School, University of Teesside \\ Middlesbrough, Tees Valley, TS1 3BA, UK \\ Tel: 44-1642-342-809Ｅ-mail: i.arnott@tees.ac.uk
}

\begin{abstract}
Many scholars have attempted to apply various theories in the field of sport (Bordieu, $1984 \&$ Brainer 2007). This particular area looks at the relationship between Marxism to the sociology of sport and how it has influenced societal structures as well as the impact it has had on the economy. Though these theories are useful on exploring the general nature of sport, questions may be raised on have they influenced the way sports is managed today also? It is widely accepted that management theories have been influenced by industry and that many scholars have used Marxism and feminist approaches to form some sort of construct of this. However does one or two apply to all? And are they appropriate to areas such as the service industry that sport falls in too? This paper attempts to look at how Marxism may have had some influence on sports management through capitalists, masculinity and power and the weld it has had on females developing in such a field because of its deeply held roots. And more importantly possibly oppressed feminism in this field. There are also arguments made because of such oppression by the male domination that they have used sports as a vehicle to segregate society and influence the direction of sports management.
\end{abstract}

Therefore the discussion in its true entirety at most is a snapshot of how one theory dominates the area of sports management and how it impinges on others both on their application and development.

Keywords: Marxism, Feminism, Power, Masculinity

\section{Conceptual approach to management in the field of sport}

The term management is often confused, overused, and interchanged with words like administration, operations, business, and corporation (Mull, Bayless and Jamieson, 2005). What firstly must be adhered to and addressed is that management processes and practices are not the same with in all industries. Most theory is based around industry (Mayo etc) in such directional approaches as scientific management or human relations (Mullins, 1993). But as society is changing then so are the approaches to management, especially as they are so diverse in nature and also so are their industries in what they offer both as they maybe product orientated or a service provider dealing with consumer's day I and day out. One such area is the field of sport, a sector that employs millions of people around the globe, is played and watched by the majority of the worlds population, and at the elite level, has moved from being an amateur past time to a significant industry or a full time profession (Hoye, Smith, Westerbeck, Stewart and Nicholson, 2006). What can be clearly evident from such a particular and diverse industry, are present traditional management concepts and theories applicable to the service sector such as sport? Is management (business) transferable to an area such like sport that caters for people and not products or vast heavy industries where theories have been developed? Also from a society where principles have been underlined from capitalism and capitalists. From approaches that in some cases have suppressed societies under such rule like that of Carl Marx? Have these concepts further gone onto allow other theories to develop because of such suppression and rule. Liu, Srivastava and Wood (1998) attempted to make some relationship between skills transference and theoretical conceptualisation. There theorising, though useful was to address issues about management and the implementation approaches to enhance productivity and operational procedures. They also drew on some of the work conducted by Peters (1996) in discussing how a peer could help an executive in coaching. Most of this theory draws upon partnership working and does not discuss in any great detail the application of theoretical frameworks in its true entirety to the field of sport. What arises from Liu et al's (1998) work that draws upon Peters (1996) is the application of how unique the nature of sport is. This is a view also shared by Smith and Stewart (1999) who indicate that sports management requires the application of specific management techniques. Therefore if business requires a similar approach it could be argued that Liu et al's (1998) skill transference may be applicable after all in sport? However business does not as Hoye et al (2006) leads us to believe encapsulates irrational passions for sporting teams, competitions, or athletes. Sport has a symbolic significance in relation to performance outcomes, success, and celebrating achievement that does not occur in other areas of economic and social activity (Shank, 2007). 
Furthermore sport and its management is a competitive human physical activity that is governed by institutional rules (Snyder and Spreitizer, 1989). A view further supported Vanderzwagg (1998) who concludes the management processes of sport requires many types of physical activity, utilising specialised equipment and facilities with unique dimensions of time and space. Therefore what can be clearly drawn out from this is that the nature of sport is physical. But if sport is governed by institutional rules that it could be argued that it has developed some of its approaches from capitalism, way of rules and governance? Key writers in sport such as Blain et al (1993) stresses this relationship between governance and rules in domains of sporting and political discourse, particularly as it relates to the construction of national, characteristics and identities such as physical prowess. So it could be argued from the constructs and the routes that sport has developed from there have been elements of capitalist and political control, so some elements of a Marxist regime. However what ever theorists stress about the nature of sport and its evolution a strong element of business must be applied to it as it has to be managed in some way, and more significantly during its evolution under rules, to give it direction to follow. Went is clearly felt that sport must follow a business like approach. Pitts, Fielding and Miller (1994) support this as they recall that for the management of sport to be successful it must be innovative and practioners must adopt a business enterprise approach in all its aspects for it to be successful. Therefore linking into Liu te al's (1998) ideology of the process of management being a skill and not the view shared by Vanderzwagg (1998) where it is seen as a physical form and displays power and the traits of masculinity

Whatever approach or conclusion maybe applicable, there most be some type of management theory linked or applicable to the service industry upon which the field sport is placed in. We can see that from its routes it could be argued that did sport and its management evolve as a way of controlling and industrialised society with capitalist approaches to segregate people? This then would suggest that Blain et al's (1993) view as a way of developing national characteristics and physical prowess (healthier and fitter workforce). What is clearly evident that society has developed and shaped some of these characteristics and may be better understood through academics and discourse analysis. What must be developed and understood are what are some of those characteristics that have shaped the management of sport? Is it what Blain et al (1993) explains a way of controlling, health, workforce, governance or ruling? And what has shaped the elements and characteristics to management with in a service sector field.

\section{Characteristics of the Service Sector similar to those shared by business through a societal change}

Hoye et al (2006) goes onto to share a view about the characteristics of the service sector, and is that they do carry distinguishing features similar to business and other management fields that draw upon management theories. He goes on to say, "Some of these features are such things as strategy, structure and human resourcing".

What now is clearly evident from this that the service sector and more importantly sport has some important function or feature, as it needs a management approach, way of control, strategy, systems. This could perpetuate to some of the ideas such as those previously highlighted under rule or characteristics with in those which have been previously highlighted Marxist (some type order)! or what Coackley (2004) links to, "conflict theory". A view on society as a system or social structures which are shaped by ultimately economic forces like no other, Similar to that described by Shank (2007) and also Beech and Chadwick,(2004) in describing sport. What must be denoted before addressing theoretical approaches that sport has evolved from an amateur paternal situation which was dominated in the post war era (Critcher, Bramham and Tomlinson, 2001). The sport industry in the United Kingdom is growing rapidly, though this is so, some may argue it does not always follow management principles and warrant proper discourse approaches. Where as, whilst it has not always been so properly understood, sports management has played an important role in society for years. As in some cases formed social order at various levels developing particular systems of control in society in the eastern world. This is why to some extent the argument can be made that those that control the nature, practices and development of sport weld considerable power (Henry and Lee, 2004)? Therefore is this a view that could be described as control? Or is masculinity coming through and a form of male domination.

This is similar to a view shared by Arnott (2007) who conducted research into the structure of swimming in the United Kingdom who identified through this that for sport to move forward, new management practices, theoretical approaches need to be implemented need by those who weld power (male centralisation). Therefore Whannel (1983) in writing argued because of such a hold and in some cases the key players resisting to new management practices can sport move forward? Whannel (1983) goes onto say that because of this resistance only in the last twenty years has the state (Government) played much of a role, where as in eastern societies it has been evident for a number of years.

In the United Kingdom the DCMS through a white paper passed through the government by the then Prime Minister Tony Blair wanted state intervention. By doing so under the guidance of Sport England the governmental advisor in sport, they did so through the Game Plan; a strategy for delivering governments sport and physical activity objectives (DCMS/ Strategy Unit, 2002). It made clear that local government, in dealing with societal issues will continue to be a major provider of sport. (Robinson, 2004). Because of the governments intervention strategy in sport and the management of it could be contextualised into similarities to an Eastern Block approach under the control of society or element s of Marxism as previously discussed? However the rationale for this provision for the state to provide sport is 
based on two arguments. First, there is the market failure argument; Local authorities provide sport for those who cannot afford the opportunities offered by other sectors (Robinson, 2004). Gratton and Taylor (2000) provide a comprehensive overview of the efficiency- and equity related reasons for public provision, however Coalter (1998) and Stabler and Ravenscroft (1994) highlighted the key motivation for the state provision is to ensure access for all citizens to sport opportunities through price subsidies and targeted programming. What ever argument is put forward it should be concluded that, Gratton and Taylor (2000) Coalter (1998) or Stabler and Ravesncroft (1994) it is clearly apparent from this that the state is beginning to dictate, what way is should be managed? Will every community seek to be managed in the same way and do they share the same motives? If so is the elements of Marxism on a societal approach appropriate to this aspect of sports management? The Department for Culture, media and Sport (DCMS)(1999) feel that sport improves, health, reduces crime, brings about economic improvement and improves educational needs and contributes towards lifelong learning similar to those views shared under that of a Marxist/ societal controlled environment a view shared by Sage (1998). Does the practioner with in this field feel that this is an appropriate way to manage sport? This approach to the management of sport it could be argued, that it shows a Marx (1969) approach where sport is managed by capitalists approach and where the workers are not allowed express themselves and work becomes not a satisfying experience within itself because there are limitations with in the processes that it is controlled. But under this type of management approach as it is suggested by the DCMS (1999) there are satisfying external outputs, such as a reduction in crime and lifelong learning. Then is this approach a necessity and do the external outputs seem to support this? More importantly will the British Culture, in principle, historically who disapproves of the state officially ' interfering' in the way people either spend free time or more importantly the way it should be managed. Thus through this type of practise regulate how the use of free time is made(Malcolmson, 1973 ; Bailey, 1973). However this has traditionally been the case where they have moreover utilised their paternalistic powers (Mcnamee, Sheridan \& Buswell, 2000). The British Governments approach to sports management is not only to its key policies, it is greater, because its what they believe is called the 'rationalisation of recreation'. There justification for this is what they believe is that they are providing facilities on the grounds of social justice, economy and control, illustrated by the proliferation of multi-purpose sports facilities under social welfare principles. They base there argument on this through the characteristics as one on 'socially enforced dependency' (Kultgen, 1991).

Boyle and Haynes (2000) in contrast to the writings s of that of Rojeck(1992) and Kultgen (1991) who describe socially enforced dependency, highlights that the characteristics of society as a pluralistic system, in which individuals choice is the key in determining the way and the pattern in which sport should be managed.

Boyles and Haynes (2000) look at sport management with a Marxist analysis, which posits the activities of management with in this discipline they are determined by the economic and political contours of society. In short sport and the way it is managed has become a vehicle of social control which both exploits workers and expanded the hold of capital on all areas, influencing human activity. With in the United Kingdom it could be argued under its current government, are they adopting a Marxist approach to the way sport is managed and are they beginning to classify what Coackly (2004) described a system of class? Have we gone the full circle from and industrial revolution? Some would say, "Is this a drastic view to take"?

This was something similarly that was experienced on the National Governing Bodies of Sport (change agents with in specific sports, e.g. swimming, cycling etc) in Canada between 1984 - 1988. Sport Canada, the governmental arm of sport with in this country stipulated that all sports NGB's had to take a more professional approach to the way they deal with things, but also must embrace some of the current issues in society (improvement of health etc) (Slack \& Hinnings, 1992, Macintosh \& Whitson, 1990).

With in the United Kingdom, the government (Department of Culture, Media and Sport) leads us to believe was a view similar to the Game Plan. This document indicated clearly the key performance indicators that all sports (NGB's) and local authority providers of sport had address social issues in their provision. The document highlighted how through social control (Marxist approach) that the way sport is managed would have cost benefits on dealing with societal issues but also enable such providers to tap into funding. So was this the only means that government could adopt. This was further exemplified by the then Chief Executive of Sport England at that time who indicated that for every pound that was invested in sport there would be multiple returns (Brooking, 2001). So it could be argued by forcing this approach to the way sport is managed that the government with in the United Kingdoms saw this as an approach or a resolution of the contradiction in a capitalist system. And with the improvement of health and improved education would this be a way improving the economy and increase production creates transformation (Haralambos \& Holborn, 2000). By using such vehicles/ tools is this furthermore a resolution to what we are already begin to see a run down society a fix to create ownership and put pride back into society. Whatever the case maybe a Marxist approach is one worth looking at with in the context of sports management. Horne, Jary and Tomlinson, 1987, p188) state that it; It allows us to understand power relations with in sport; it emphasises the role of the state and the economy in structuring sports management in a contemporary society; and it applies and open ended approach to studies so the new developments with in this field can be examined in a non-dogmatic fashion 
Rojeck (1992) recognises this as a "cultural studies" approach. It is useful because of its recognition of sport and the deeply rooted social processes involved hear. But he also attacks this approach as being too deterministic and overtly concerned with class and capital. What ever Rojeck (1992) indicates about the approaches is that it helps us to, though academic discourse understand the field of sports management. Further more Hargreaves (1994) and Creedon (1994) have highlighted the importance and understanding of gender relations in shaping sports management. By doing so this it enables not only the elements of Marxist theory of power relations, and societal change it underpins possibly some of the oppression towards females in this field and the underpinning of of some of the approaches adopted.

\subsection{Feminist theory has this helped to develop management approaches with in the field of sport?}

Feminist theories are grounded in the awareness that women have been systematically devalued and oppressed in many societies under power/ mascultinity sometimes underpinned by a Marxist approach (Coackley, 2003). But in the field of general management and more importantly on the bearing of this paper sports management, there is a general need to develop political strategies to eliminate oppression which developed from, what it could be argued is capitalism and capitalists. The yield to strive for power and economic growth contributed by a Marxist society? But it has been identified by many scholars that the area of sport today is state of economic and also contributes education, society and more importantly the economy. So if this is the case is there an argument to be said that different approaches and theories should be tested? Or is it the values and experiences that women have faced from men to celebrate their attributes and skills associated by masculinity in society (Birrell, 2000; Brurstyn, 1999) that will win through and never allow feminism to be tested. Though this is an expressed view shared by most feminist theorists (Hartman, 1981 \& Barrett, 1984) it must be acknowledged that the area itself is useful for discourse analysis and also a clearer understanding for some marginal attempt in the direction for the future of sports management. Gruneau (1999) shares this view also in the criticism of Marxist and Neo-marxist approaches and interpretations on the contextualisation of sports management that occupies Guttmans (1993) work with in this field.

Sport undoubtly has along tradition of gender order and how it has contributed to social relations in management, by elevating the male experience over females, in particularly in the powerful, hierarchical and visible way (Collins \& Kay, 2003). Therefore it could be argued as Collins and Kay (2003) describe has this been the key factor in the development of women in management and subsequently held back different views and theories of management with in the sports profession? Moreover because of a capitalist society dominated by males, elevating them to being the powerful gender in management, has this been a theoretical approach accepted dating back as far the industrial revolution. A case where the female's

responsibilities were affected by the growth and pressure to raise a family than in men's, which then particularly influenced a women's participation in sport when their household contained young children (Collins \& Kay,2005). Notably what can be derived from such pressures, the opportunity for females to even display femininity in sport management, never mind sport and its management? This notion of feminism in a way of a theoretical approach to management or the attractiveness and sexual availability to men in management is once again to keep them from seeking real power (Goldman et al, 1991). Connell (2002) supports this view where he describes that the hegemonic forms of masculinity as the "most honoured or desired with in this particular context and more specifically as the configuration of gender and the practices with in management. This further embodies the currently accepted answer to the problem of which theory is most applicable in the field of sports management, Marxist approaches or the opportunity for Marxist- feminists? This role within gender is further stressed that males are in a more dominant position with in management and females are still subordinate (Pringle \& Makula, 2005). Connells (2002) work was inspired by Gramsici's (1971) understanding that masculinity with actions of ruling classes or groups, economic activities and hierarchical structure of power, which demonstrates Marxism in management. The bases for this was from the industrialisations of the nineteenth century (Coventry, 2004), during a time that transformed the institution of work creating a paid labour force mostly male. Some Marxist - feminists have argued that a women's position in society primarily benefits capitalism and capitalists (Haralambos \& Holborn, 1991)? Some Marxists further believe that women benefit capitalists and its systems in their capacities as the mother and housewives, by producing the labour force at no cost to the employers (Hartman, 1981). This would further create a view that is it women or women in management? Or will they ever be able to achieve such positions to develop theories and approaches which clearly, what some might say "not the done thing"!

Dramatic reductions in sex segregation occurred in the 1970's, as women began to such what has already been demonstrated a male dominated occupations in management (Resking \& Roo's, 1990, Jacobs 1989; Beller, 1984). Although declines continued in the 1980's and 1990's, the pace of decline did become slower and slower (Padavic \& reskin, 2002; Bianchi,1995; Cotler et al, 1995; Jacobs, 1989). More recently Wenner (1989), Blain et al (1993), Whannel (1992) \& Goldhurst (1987) examined the role of some of these issues mediated in sport management and how it plays a form of symbolic ritual in many modern industrialised societies. They examined the transformation of sports management and argue that the study provides a particularly incisive insight into the commodoification of popular 
culture by capital (Boyle and Haines, 2000). So if this is the case then, even in sports management there is a clearer link to Marxist approaches and suppressing on an even bigger substantive scale stressing the view that feminists and feminist theories will struggle to prevail with in this field? Whannel (1997) argues that there is a need to be business like and efficient in sport and it offers sites for the celebration of corporate capitalism. And because of this political arguments are against feminism. Blain et al (1993) stressed this once again that even in the field of something that is still in its infancy the relationship between sport and political discourse, particularly as it relates to the constructs of management approaches and identities. What also was identified in the early 1990's was the first comprehensive national "women and sport policy" (Sports Council, 1993 and the Brighton Declaration, Sports Council, 1994 from an International conference).It explicitly recognised female under representation in sports organisations as a fundamental barrier to gender equity, and advocated greater women's involvement in all aspects and all levels of sports management (Collins \& Kay, 2004).. However, in sport elsewhere formal policies do not guarantee effective action, as McKay's (1997) in depth analysis of resistance to affirmative actions in sport organisations in Australia, Canada and New Zealand displayed.

To date Collins \& Kay (2004) demonstrate that policies to promote gender equity have too often floundered in the face of organisational and societal cultures where capitalism and capitalists instead of a move towards addressing a wider gender issues that are entrenched in society. An extensive debate around gender equity in sport which subsequently impacts their positioning in management positions, where many writers have argued that only through making fundamental changes in sport to lessen maleness and give pwer with in it, will women have true access to these positions which will in turn allow opportunity for appropriate theories to be applied.

Hardgrave's (1994), Kay, (1996); Mckay (1994) at the beginning of the new millennium, most men and women are still segregated into, different occupations. So are we capable of allowing female hierarchical positions to prevail?. Or is it the case that Marxist theory, especially in management, essentially in sport in this case is insignificant? Hartman (1981) compares the situation to marriage in which the husband represents Marxism, the wife feminism, and it is the husband who has all the power (the male).

Scholars have long recognised the manipulation of gender relations in management and culture as a function of capitalist hegemony (Artz \& Murphy, 2000). Women and girls have been what, Lynn, Hardin \& Walsdorf (2004) call symbolically annihilated (i.e rendered powerless). The notion of feminity attractiveness and sexual availability to men is used to keep women from seeking real power via feminism (Goldman et al, 1991). Goldman et al (1991) like Hartman (1981) re emphasises this nearly a decade later that this is a commercial marriage of a Marxist application of feminism and feminity. The reinforcement of sexual difference and the capitalism ideal where the women is primarily and ideally feminine is integral to the capitalists control (Lynn, Hardin \& Walsdorf, 2004).It also remind them that their power is only in their ability to maintain the ideal (Powerless) feminine body. These findings though there is an attempt to appraise Marxism and feminism in the management, and more relevant to this paper, sports management it is clearly evident that there are deeper roots of capitalism hegemony and gender roles with in sport today. That is sport is actively, and sometimes aggressively, contributes to the continual reproduction of the gender order and maintenance of masculine hegemony (Yiannakis \& Melnick, 2001) from a profeminist perspective sports are still viewed as reinforcing the sexual division of labour and also society. Therefore carrying Marxism approaches, and perpetuating inequality and society, and contributing to the exploitation of ruling classes and males to females (Kidd, 9187).

To be sure those capitalist views are relevant in this in this particular field that they are supported by the ideals outputs (economic, political and educational) and practices, but it is the ideology of patriarchy (e.g. structured and ideological) systems of personal relationships that legitimate male power over women and the services they provide(Sage, 1998) . That it helps and perpetuates for feminist theories and gender inequalities in sports management and the larger society (Yiannakis \& Melnik, 2001). The very construct of feminity and masculinity reinforce patricical culture. As long as males and females are looked at in this way males will continue to be viewed as dominant and females will also be subordinates. This will subsequently impact the opportunity for feminist theories to break through from some historical grounding developed from Marxist bedding.

\section{Conclusion}

This article has attempted to look at some of the approaches to management using two theoretical concepts, e.g. Marxists and Feminist theories. The concepts some might say are so far apart and the rationale for applying such frameworks to sport could not be further from the truth. Marxism with in sport, it is felt has some foundations from this approach. Bairner (2007) attempted to use such constructs in the sociological context of sport. He linked it to the "return of Marxism". Though his research is underpin by aspects of Bordieu (1984), their constructs link very much to management with in the context of sport and its progress. They draw upon the position of relations of production, such as occupation, income or even educational level, which bare very much the similarities to the Government with in the United Kingdom where as they see sport a contributor to this to a better society. A few that has also been discussed in Hargreaves (1986) writings of the link the relationship between civil society and the state in a way consistent to other 
scholars such as Gramsci (1971). So some might argue that there is possibly a place for Marxist theories in sports management? Which clearly will have an impact on the development of other theories such as feminist approaches? Gramsci (1971) in Bairner (2007) goes onto describe this further in the power relation between these two also. The term shared Yiannakis and Melnik (2001) in the recreation of the "gender order and the maintenance of masculine hegemony".

However Hartman (1981) believes that Marxism on its own cannot explain inequalities, in other words how much Marxism exploits capitalists, masculine hegemony and power in sports management as a form of social control, but not only how it exploits women. Hartman (1981) and Barrett (1984) accept that Marxism can play an important construct for gender in equalities, similar to that of King (2005) who refers to it as a "theoretical toolkit". However Collins and Kay (2004) provide some direction in explaining for other theories to break through and provide an application to management, essentially sport then there needs to be more women with in senior positions with in this field of study to allow more enquiries.

Whatever the long term outcome the most important thing to address is that the field of sports management is still growing and developing, and what has been clearly demonstrated general theories, though useful do not fully explain this area of study.

\section{References}

Arnott, I.R. (2007). An understanding towards organisational change in swimming in the United Kingdom. Paper submitted for part of the assessment process for a Doctorate in Business Administration.

Bailey, P. (1975). Leisure and class in Victorian England, J. Hargeaves, from social democracy to authoritarian populism: state intervention in sport and physical recreation in contemporary Britain, Leisure Studies, 4 (2), 219-226.

Bairner, A. (2007). Back to basics: Class, social theory, and sport. Sociology of Sport Journal, 24 (1) 20-36.

Barrett, M. (1984). rethinking women's oppression; A reply to Brenner \& Ramas New Left Review. Women's oppression today, London.

Beech, J \& Chadwick, S (2004) The Business of Sports Management Prentice Hall.

Beller, A.H. (1984). Trends in occupational segregation by sex and race, 1960-1981 In B.F , Reskin (eds) Sex segregation in the workplace: Trends, explanations, remedies. Washington DC: National Academy Press.

Bianchi, S. (1995). Changing economic roles of women and men.

Birrell, S. (2000). Feminist theories of sport In handbook of Sports Studies 61-76.

Blain, N, Boyle, R \& O Donnell, S. (1993). Sport and National Identity in the European Media. Leicester University Press.

Blanin, N Boyle, R. \& Odonnell, H. (1993). Sport and National Identity in the European Media. Leicester, Leicester University Press.

Bordieu, P. (1984). Distinction. A social critique of the judgement of taste. London: Routledge and Keegan Paul.

Boyle, R \& Haynes., R. (2000). Power Play, Sporty, the media and Popular Culture, Pearson education.

Coalter, F. (1998). Leisure Studies, Leisure Policy and social citizenship: the failure of welfare or the limits of welfare? Leisure Studies, 17 21-36.

Collins, M.F \& Kay, T. (2004). Sport and Social Exclusion, Routledge.

Connell, R.W. (2002). Masculinities and globalisation In Hworth, A., Paris, I \& Allen L (eds) The life of Brian masculinities, sexualities and health in New Zealand.

Cotter, D.Am, Defore, J.M, Hermsen, J $>$ M, Kowalewski, B.M \& Vannemun, R. (1995). Occupational gender desegregation in the 1980's, Social Scinece research, 24, 439-455.

Coventry, B.T. (2004). On the sidelines: sex and racial segregation in television sport broadcasting. Journal of Sports Sociology, 2 (3) 322-341.

Creedon, P. (1994). Women, Media and Sport,: Challenging the gender order. London, Sage.

Critcher, C., Bramham, P \& Tomlinson, A. (2001). Sociology of Leisure, A Reader, Spon, London.

DCMS/ Strategy Unit. (2000). Game Plan; A strategy for delivering the governments sport and physical activity objectives, London; Strategy Unit.

DCMS. (1999). Policy Action Team 10: Report to the social exclusion unit - arts and sport. London; HMSO.

Goldman, R, Heath, D \& Smith, S. (1999). Commodity feminism, Critical studies in media communication, 8, 333-351. 
Goldhurst, J. (1987). Playing for keeps; Sport the media and society. Melbourne Longman.

Gramsci, A. (1971). Selections from the prison notebooks In Hoare, Q \& Nowell- Smith, G (eds) London: Lawerence and Wishart.

Gratton, C \& Taylor, P. (2000). The Economics of Sport and Recreation, : London: E \& FN Spon.

Guttman, A. (1993). From ritual to record. The nature of modern sports. In Gruneau, A (eds) Class, sports and social development. Champaign IL, Human Kinetics.

Haralambos, M \& Holborn, M. (1991). The origins of gender inequality Marxist and social perspective. Sociology: Themes and perspectives $\left(3^{\text {rd }}\right.$ ed) pg 322-341.

Hargreaves, J. (1994). Sporting females.; Critical issues in the history and sociology of women's sport. London, Routledge.

Hargreaves, J. (1986). Sport, power and culture. A social and historical analysis of popular sports in Britain. Cambridge, UK: Polity.

Horne., J, Jary D \& Tomlinson A. eds (1987) Sport, Leisure and Social Relations. London : Routledge \& Keagan Pail.

Hartman, H. (1981). The unhappy marriage marxisim and feminism; Toward a more progressive union. In Segeant (eds) Capitalism, patriarchy and job segregation by sex.

Hoye, R, Smith, A, Westerbeck, G, Stewart, and Nicholson, M. (2006). Sports Management; Principles and Application, Butterworth and Heinemann.

Jacobs, J.A. (1989). Long term trends in occupational segregation by sex. American Journal of Sociology, 95, $160-173$.

Kay, T.A. (1996). Just do it? Turning sports policy into sport practice. Managing Leisure.

Kidd, B. (1987). Sports and Masculinity. In Kaufman (eds) Beyond patriarchy: Essays by men on pleasure, power and change. New York; Oxford University Press, 250-265.

Kings, C.R. (2005). Cautionary notes on whiteness and sports studies. Sociology of Sport Journal, 22 (1) $397-408$.

Kultgen, J. (1991). Ethics and Professionalism, Philadelphia, University of Pennsylvania Press.

Liu, T., Sirvastave, A \& Seng Woo, H. (1998). Transference of skills between sports and business, Journal of European Industrial Training, 22 (3) 93-112.

Lynns, S, Hardin, M \& Walsdorf, K. (2004). Selling (out) the sporting woman; Advertising images in four athletic magazines. Journal of Sports Management, 18 (4) 335-349.

Macintosh, D \& Whitson, D.J. (1990). The game planners transforming Canada's sport system. Montreal \& Kingston: McGill-Queen University Press.

Malcolmson, R. (1973). Popular recreations in English society, J. Hargeaves, from social democracy to authoritarian populism: state intervention in sport and physical recreation in contemporary Britain, Leisure Studies, 4 (2), $219-226$.

Marx, K. (1969). The Notion of Alienation, in Mullins, L.J (1993) Management of Organisational Behaviour (4 ${ }^{\text {th }}$ Ed) Pitman Publishing.

Mckay, J. (1997). Managing gender: Affirmative action and organisational power in Australian, Canadian and New Zealand Sport, Albany NY: Stat University of New York Press.

McNamme, M.J, Sheridan, H \& Buswell, J. (2000). Paternalism, Professionalism and public sector leisure provision: the boundaries of a leisure profession. Leisure Studies, 19,199-209.

Mull, R.F, Bayless, K.G \& Jamieson, L.M. (2005). Recreational Sport Management (4 ${ }^{\text {th }}$ ed) Champaign IL, Human Kinetics.

Mullins, L. J. (1993). Management and Organisational Behaviour (4 ${ }^{\text {th }}$ ed), Pitman Publishing.

Padavic, I \& Reskin, B. (2002). Women and men at work $\left(2^{\text {nd }} \mathrm{ed}\right)$ Thousands Oak, CA.

Peters, H. (1996). Peer Coaching for Executives; Training and development, Vol 50. pg 39-42.

Pitts, B.G, Fielding, L.W \& Miller, L.K. (1994). Industry Segmentation theory and the industry; developing a sport industry segmentation model. Sports Marketing Quarterly; 3 (1) 15-24.

Pringles, R \& Markula, P. (2005). No pain in sane after all: A foucaualdian analysis of masculinities and men's experiences in rugby. Sociology of Sport Journal, 22 (4) 472-497.

Reskin, B.F \& Roos, P.A. (1990). Job queues, gender queues; explaining women's movement into male dominated occupations. Philadelphia: Temple University Press. 
Rojeck, C. (1985). Capitalism and Leisure Theory, London Routledge- (1992) The Field of Play in Sport and Leisure Studies. In Dunning E, Rojeck., C (eds) Sport and Leisure in the Civilising Process.

Robinson, L. (2004). The public sport and leisure context; Managing Public Sport and Leisure Services. Routledge.

Slack, T \& Hinnings, B. (1992). Understanding Change in National Sport Organisations; an integration of theoretical perspectives; Journal of Sport Management. (6), 114 -132.

Stewart, B., and Smith, B. (1999). Sports Management; a guide to professional practise, Sydney, Allen and Unwin.

Snyder, E.E and Spreitzer, E.A. (1989). Social Aspects of Sport, Englewood Cliffs, Prentice Hall.

Vanderzwagg, H.J. (1998). Policy Development in Sport Management $\left(2^{\text {nd }}\right.$ ed) West Port, CT Praegar.

Wenner, L.A. (1998). Playing the media sport game. In media sport (Wenner L.A ed) London, Routledge.

Whannel, G. (1992). Fields of vision, Television Sport and Cultural Transformation. London, Routledge.

Whannel, G. (1983). Blowing the Whistle, Pluto Press, London. 


\title{
Innovations in Trade Financing Process of Commercial Bank
}

\author{
Yijun Yuan, Xiaowei Dong \& Xiaoqing Lv \\ Department of Economics, Dalian University of Technology \\ Dalian 116024, China \\ Tel: 86-411-8470-7830Ｅ-mail: Lvxiaochong1111@yahoo.com.cn
}

\begin{abstract}
From the point of view of bank process reengineering theory, the paper focuses its discussion on definition and features of international trade financing based on the principles and requirements of financial innovation. Through the clarification for international trade financing process and comparison for ways of international trade financing under traditional trade settlement methods, trade financing process innovation has been fulfilled.
\end{abstract}

Keywords: Bank Reengineering, Trade Financing, Process Innovation

\section{Introduction}

International trade financing refers to credit support related to trade settlement in import and export, which commercial banks provide to importers and exporters. The constant development of international trade requires commercial banks to make substantial innovation for trade financing process. Therefore, based on the theory of bank reengineering, we studies and takes advantage of existing trade financing methods to fulfill trade financing process innovation, which becomes one of the most important channels to adapt to development of financial market and improve competitive ability for commercial banks.

At present, rapid growth of international trade brings huge market opportunity to the development of international trade finance. There are enormous opportunities for the financier in developing internal Chinese commodity sources. The potential for the trade financier is huge, not only in the field of commodity, but also the field of service.

Existing researches on trade financing innovation at home and abroad almost lie in the fields of financial product innovation; in contrast, trade financing process innovation is seldom concerned except in some researches on bank process reengineering. Thereby, it is very meaningful to study international trade financing process innovation based on the theory of bank process reengineering.

\section{Framework of Trade Financing Process Innovation: in Perception of Bank Reengineering}

As the process of finance liberalization, informationization and securitization, the theory of bank reengineering has developed as well since the second half of the 20th century. The rising of bank reengineering urged the theoretical development of finance innovation, and became a central issue, which was paid much attention by scholars home and abroad. Nowadays, the process design of commercial bank has not been suitable for the requirement of rapid development of finance industry, so it becomes an important channel to innovate trade finance through innovating trade financing process, combining the finance innovation with theory of bank reengineering.

The phrase bank reengineering came from the phrase enterprise reengineering. Through a long period exploration and practice, the theory of bank reengineering is summarized by international commercial bank, used to immerging creative reform for organization, product and process of bank. Bank process reengineering is the core content of bank reengineering. Its purpose is reengineering scattered task of every functional department and outsourcing non-value-added service to improve the operating efficiency, according customer category and operating process of customer value creation.

Applying effectiveness priority principle of bank process reengineering to trade financing process innovation is making operating process accepted by the market, which is designed for trade financing product. It is an efficiency issue of process reengineering. It must enable reengineered process to be suitable for either product nature or requirement of different customers.

In the meanwhile of improving efficiency, cost reduction is another requirement of trade financing innovation. The cost reduction oriented function virtual principle assimilates resources out of the organization into the organization to 
complete organizational function. This principle requires commercial bank to reserve critical and dominant services in the process of trade financing and outsourcing non-value-added or less-value-added parts to those professional agencies. Through this kind of mutual supplement, the value created in trade financing process is increased.

Resource integration principle is a theory of combine of labor in bank reengineering theory, on the contrary of theory of labor division. Based on utilization of information technology, this principle takes trade financing process restructure as breakthrough to assemble dilatory process reasonably.

\section{Carding of Trade Financing Process}

Prior to innovating trade financing process, we should be familiar with process of these services. Based on process carding, trade financing process innovation is completed. The text probes innovative methods of trade financing process, and its application and development in practice.

\subsection{Carding of Trade Financing Process with Three Participants Involved}

The participants, involved in this kind of trade financing process, include importer (exporter), importer's bank and exporter's bank. The representing services consist of Import Bill Advance, Forfaiting and so on.

The flow program is showed as Figure 1.

Forfeiting is a typical representative of this kind of trade financing services. Therefore, taking Forfaiting as an example, the text will introduce the specific process of this kind of trade financing service, which consists of six steps.

(1) Fix the purchasing bank. Firstly, exporter will make an inquiry to banks, and then fix a bank as the purchaser.

(2) Present the documents. The exporter will present materials to the purchaser, such as importer's details, goods and amount of money, in written form. After bank checking the documents, the exporter and the importer would sign the trade contract, in which Forfaiting is the method of trade financing.

(3) Acceptance of the importer. After getting acceptance of exporter's bank, the exporter would issue a time draft to the importer.

(4) Post the receipts. After dispatching the goods, the exporter will send all the cargo documents to the importer through banking system; and the importer will send accepted time draft to the exporter.

(5) Purchase the receivables. After getting the accepted time draft, the exporter will discount the draft to the forfeiter in a non-recourse way with agreed discount rate.

(6) Sign the Forfating agreement. After receiving the documents presented by the exporter, the purchasing bank will sign the Forfaiting agreement, and pay cash to the exporter.

\subsection{Carding of Trade Financing Process with Four Participants Involved}

The participants, involved in this kind of trade financing process, include importer, exporter, importer's bank and exporter's bank. The representing services consist of Export Discount, Packing Loan, Export Bill Purchase and so on.

The flow program is showed as Figure 2.

Figure 2 Flow Program with Four Participants Involved

Export Bill Purchase is a developed trade financing service. Therefore, take it as an example to introduce the specific process of this kind of trade financing service, which consists of five steps.

(1) Submit an application. The exporter submits an application for Export Bill Purchase to correspondent bank.

(2) Submit relative materials. The exporter provides the correspondent bank with trade contract, L/C, all receipts accompanied with $\mathrm{L} / \mathrm{C}$ and so on.

(3) Examine the materials and pay the cash. After all the materials are verified, an agreement will be signed, and then the bank will pay cash to the exporter.

(4) Present the receipts. The exporter's bank presents all the receipt accompanied with $\mathrm{L} / \mathrm{C}$ to the importer's bank (usually opening bank). After all the receipt are verified, the importer's bank will present for payment to the importer.

(5) Withdraw the money. When $\mathrm{L} / \mathrm{C}$ expires, the importer will pay the number of money listed on the $\mathrm{L} / \mathrm{C}$ to the opening bank, and then the opening bank will cover draft the money to the exporter's bank.

\subsection{Carding of Trade Financing Process with Five Participants Involved}

The participants, involved in this kind of trade financing process, include importer, exporter, importer's bank, exporter's bank and shipping company (or insurance company). The representing services consist of Shipping Guarantee, Credit Insurance under the Trade Financing and so on.

The flow program is showed as follow. 
For the purpose of avoiding risks, the insurance part is more and more introduced in trade financing service. Take Credit Insurance under the Trade Financing as an example to introduce the specific process of this kind of trade financing service, which consists of six steps.

(1) Insure export credit insurance. The exporter insures short-term export credit insurance for the trade settlement. After getting credit line, submit the financing application to the bank, which has business contact with the exporter.

(2) Fill in tripartite agreement. The exporter and the bank fill in Indemnity Transfer Agreement of triplicate. Afterward, the exporter takes one of them to negotiate with the bank. (Figure 3)

Figure 3 Flow Program with Five Participants Involved

(3) Submit the receipts. When the exporter is negotiating with the bank, he should submit the financing application and all the relative receipts.

(4) Check the receipts and pay the cash. After all the materials are verified, the bank will sign the agreement with the exporter and pay the cash to the exporter.

(5) Present the receipts. The exporter's bank presents all the receipts to the importer's bank. After all the receipts are verified, the importer's bank will present to payment to the importer.

(6) Withdraw the money. When L/C expires, if the importer does not pay the money back to his bank, the insurance company will pay the indemnity to the bank.

\section{Trade Financing Process Innovation}

Based on the carding of trade financing process with different participants above, the paper will carry out process innovation in three aspects as follow, using the principles of bank reengineering as guidance.

\subsection{Effectiveness Priority Principle and Carding of Trade Financing Process}

No matter which kind of trade financing services, there is something identical. Selecting the identical or similar operating process in trade financing process, and then identify these parts with each other. In this way, the similar parts of every kind of trade financing services are not need to be charged by specialized person respectively, but by a single clerk or a service team. This is the main thought of lateral spreading of trade financing process. This kind of lateral spreading does not only simplify the processing steps of trade financing services, but also reduce the cost and improve the efficiency.

These three kinds of trade financing services mentioned above have the same steps, such as submitting the application and presenting the receipts. Although different kinds of trade financing services need to submit different application and receipts, but what these function departments need to do is receiving all kinds of applications and receipts. After carrying out lateral spreading, what the service team need to do is just clarifying and checking different applications and receipts, and then sending them to different function department to do further processing.

It is very important to standardize trade financing process. However, because of the service feature of trade financing, the customers and environment are of variety. Therefore, the design for business process should focus on requirement of flexibility. Through clarifying different kinds of customers and conditions of environment, trade financing process is designed. Based on the standardization, use the flexible principle to handle complicated situation. This is the main thought of flexible design of trade financing process.

For example, according the credit line of single trade financing service, commercial bank could establish different approving mechanism. Bank could carry out sub-management, and set up different approving standard for every credit line, even use the automatic approval mechanism.

\subsection{Function Virtual Principle and simplification of trade financing process}

There existing some redundant or non-value-added steps. Only if they are removed from trade financing process, the value creation advantage could be displayed further. Through selection to specific trade financing steps, remove those steps which can not reduce the cost by the way of specialization, and keep those critical steps which can increase value significantly. This is the main thought of internal simplification of trade financing process. In this way, commercial banks overcome the defect of large and all-inclusive to own a path of value creation advantage.

All kinds trade financing services mentioned above exist step of checking receipts. In practice, customer managers do preliminary check and then regional data processing center do further and thorough examination. In fact, customer managers' checking could be removed, because the substantial mistakes could only be found by those professional clerks from regional data processing center. Therefore, this kind of internal simplification is the way of getting value-added advantage.

External expansion takes internal simplification as the foundation, that is to say, the purpose of internal simplification is for conducting external expansion efficiently. As the weakening of some trade financing steps inside the commercial 
bank, the bank should search the resources outside, and assimilate them inside. This is the main thought of external expansion of trade financing process. The purpose of this kind of innovation method is to reduce the cost and enhance competitiveness of commercial banks.

For now, most of risk control of trade financing is feed forward control, that is to say, commercial banks only control risks that happen before financing funds' deliver. There is no such a risk control mechanism, which identifies and control risks during the whole process of trade financing. However, this would increase managing cost remarkably. Therefore, commercial banks could utilize resources outside to reduce the cost, as well as get professional services.

\subsection{Resource Integration Principle and Integration of Trade Financing Process}

Trade financing belongs to financial services. Financial services should base on resources integration and fulfill the organic combination of technical resources, organizational resources and capital resources to form core competitive strength. The purpose of resource integration is to get more effective financial services.

The application of resource integration in trade financing innovation should be multi-level and omnibearing. Generally, resource integration should carry out in four levels; those are personal level, team level, single enterprise level and virtual enterprise level. Resource integration of trade financing mainly focuses in the first two fields.

Only if resources are integrated in the whole chain of trade financing, commercial banks could improve efficiency and embody the principle of maximizing customers' value. The main thought of customers' value exemplification of trade financing is taking the customer as the core process design, not the banks themselves in a traditional way.

At present, the steps, needing to contact with customers, are scattered in different functional department, which makes customers feel difficult in this procedure. However, if taking the customers as the core of process innovation, commercial banks should integrate all those customers-contact links together and provide a sequence services to the customers. In the meanwhile of increasing customers' utility, the efficiency of commercial banks is improved.

\section{Conclusion}

Taking the theory of bank process reengineering as the analyzing framework, the text cards the general process with different participants. Combining the principles of bank reengineering, commercial bank should carry out the simplification, expansion and integration for trade financing process. Trade financing process innovation would fulfill the purpose of customers-centralized and market-oriented, and embody the value-added advantage.

\section{References}

Andrew M. Moravcsik. (1989). Disciplining Trade Finance: The OECD Export Credit Arrangement. International Organization. Vol. 43, No. 1, Oct., pp. 173-205.

C. Bram Cadsby \& Elizabeth Maynes. ( 1998). Laboratory Experiments in Corporate and Investment Finance: A Survey.Managerial and Decision Economics.Vol.: 19, No. 4/5, Jun. - Aug., pp. 277-298.

Charles Tennant \& Yi-Chieh Wu. (2005). The application of business process reengineering in the UK.The TQM Magazine. Volume: 17, Issue: 6, June, pp: 537 - 545.

Helen E. S. New Institutional Architecture Evolving Structures for Managing Trade, Financial, and Security Relations. The Political Economy of the Asia Pacific.

Jonathan Eaton \& Samuel Kortum. (2002). Technology, Geography and Trade.Econometrica, Vol.: 70, issue: 5, Sep., pp. 1741-1779.

Laurence Weiss. (1980). A Model of International Trade and Finance. Vol.: 95, issue: 2, Sep., pp. 277-292.

Mike Burkart \& Tore Ellingsen. (2004). In-Kind Finance: A Theory of Trade Credit. Vol. 94, No. 3, Jun., pp. 569-590.

Namchul Shin \& Donald F. (2002). Jemella.Business process reengineering and performance improvement: The case of Chase Manhattan Bank. Business Process Management Journal.Volume: 8, Issue: 4, April, pp: 351 - 363.

Olaf Weber \& René Beeler. (1999). Incorporating sustainability aspects in structured trade and commodity finance.Journal of Applied Accounting Research. Volume: 5 Issue: 1, Jan., pp: 97 - 111.

Paul Reding \& Jean-Marie Viaene. (1995). Capital controls and international trade finance in a dual exchange rate regime: The Belgian experience post-mortem. Review of World Economics. Vol. 131, No. 1, March. 


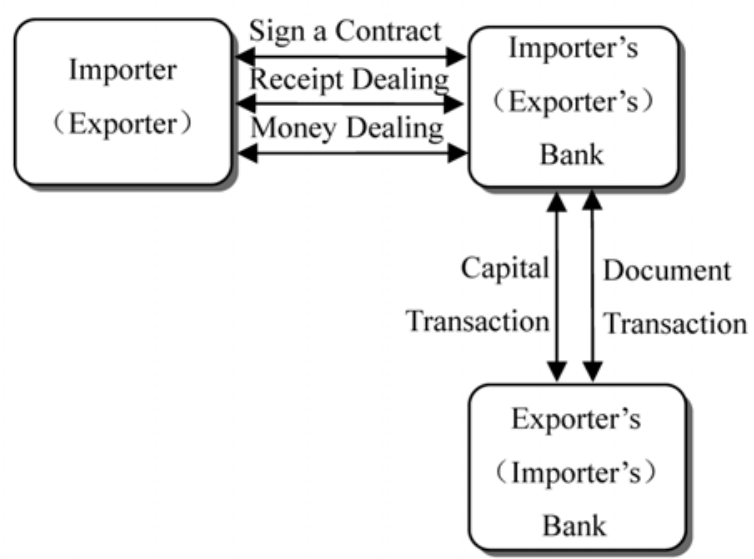

Figure 1. Flow Program with Three Participants Involved

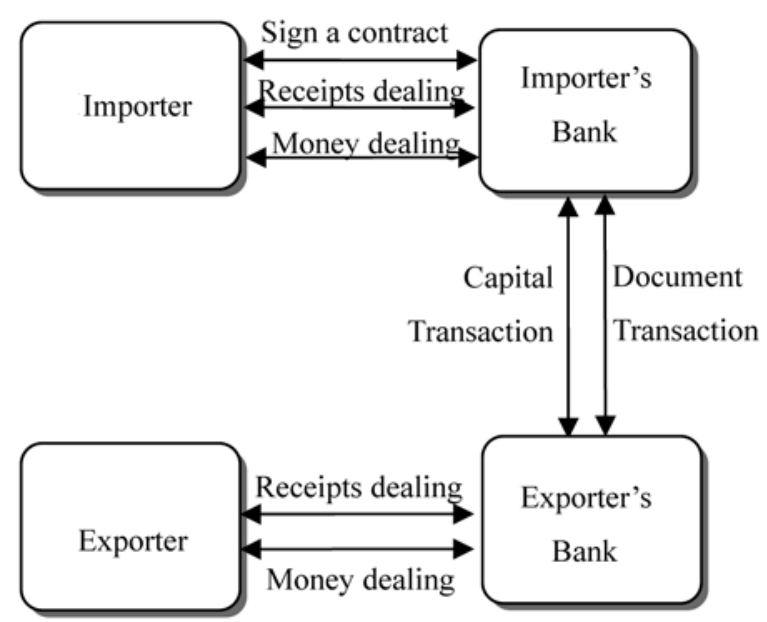

Figure 2. Flow Program with Four Participants Involved

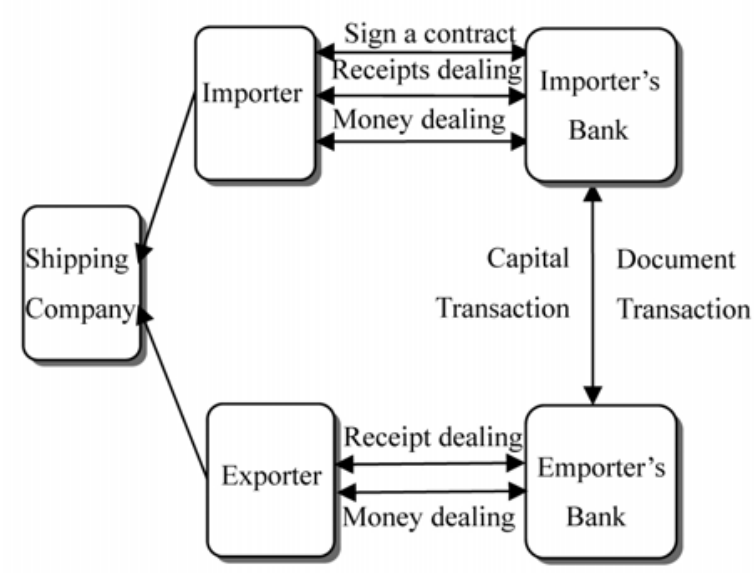

Figure 3. Flow Program with Five Participants Involved 


\title{
Audit Delay of Listed Companies: A Case of Malaysia
}

\author{
Ayoib Che-Ahmad \\ College of Business, Universiti Utara Malaysia \\ 06010 UUM Sintok, Kedah, Malaysia \\ Tel: 60-4-928-3942 E-mail: ayoib@uum.edu.my \\ Shamharir Abidin \\ College of Business, Universiti Utara Malaysia \\ 06010 UUM Sintok, Kedah, Malaysia \\ Tel: 60-4-928-3943_E-mail: sham1202@uum.edu.my
}

\begin{abstract}
It is important to understand factors that influence audit delay since it directly affects the timeliness of financial reporting which is one of the most important qualitative attributes of financial statements (Ashton et. al., 1987; Carslaw \& Kaplan, 1991; and Johnson, 1998). A number of studies have investigated audit market research including the issue surrounding audit delay within the context of developed countries. However, audit market research in the developing countries is very limited despite calls in the literature to expand the scope of market studies to those nations (see for example, Simon et al. 1992; Walker and Johnson 1996; Che-Ahmad and Houghton 1996; Taylor 1997). This study extends previous research by examining the determinants of audit delay in a developing country. Malaysia is one such country that provides a rich setting for audit market research. It seeks to provide empirical evidence concerning audit delay of Malaysian public listed companies.

The findings indicated that the mean audit delay of Malaysian companies to be much longer than the delay in Western countries. The multivariate analysis showed that director shareholdings, total assets, number of subsidiaries, type of audit firms, audit opinion and return on equity to be important determinants of audit delay. The regression results for non-banking and finance sectors were very similar. However, only director shareholding variable was found to be strongly significant in banking and finance sub-sample suggesting the importance of ownership structure in influencing audit lag in this sector. The differences in regulatory framework for both sectors could be a significant reason for the differences in the findings and warrant further research.
\end{abstract}

Keywords: Audit Delay, Audit Report, Malaysia

\section{Introduction}

The importance of timely financial reporting by corporate entities is of interest to policymakers. In the United States, Financial Accounting Standard Board (FASB), for example addresses its importance in the Statement of Financial Accounting Concepts No. 2 as an "ancillary aspect" of relevance. The statement also suggests that "a lack of timeliness can rob information of relevance it might otherwise have had" (paragraph 56, FASB, 1980). In Malaysia, the Bursa Malaysia (Malaysia Bourse) demands timely financial reporting through the provision of Chapter 2 (2.03-2) and Chapter 9 (9.01-3) of the Listing Requirements of Bursa Malaysia Securities Berhad.

Previous studies have examined the issues of timeliness of information from different angles. Ashton, Willingham and Elliott (1987, p. 275) contended that “... the timeliness of information release can affect the level of uncertainty associated with decisions based on the reported information." Feltham's (1972) analytical model shows that a decision-maker's action choices and expected payoff are affected significantly by the timeliness of information release. Further, Givoly and Palmon (1982) and Kross and Schroeder (1984) found that delayed announcements of earnings are associated with lower abnormal returns than those of timely announcements. They also concluded that the timing of such announcements is significantly affected by the lag of audit report, i.e. the length of time from a company's financial year-end to the date of auditor's report (Ashton et al., 1987; Carslaw \& Kaplan, 1991; and Johnson, 1998).

While a number of researchers have investigated the issue surrounding audit delay within the context of advanced countries, little has been done to investigate the same issue in developing countries. This is especially true in the case of 
countries with new capital markets and regulatory enforcements. This is continuing despite calls in the literature to expand the scope of market studies to those nations (see for example, Simon et al. 1992; Walker and Johnson 1996; Che-Ahmad and Houghton 1996; Taylor 1997). Further, Newton and Ashton (1989) suggested that a more refined analysis is needed to understand the cause of audit delay especially in different industries. Bamber et al. (1993) added a variable that classified companies into two namely financial and non-financial companies. They contended that financial sector represents a less complex auditee and therefore should experience shorter audit delay. It is also well known that financial companies are subject to different regulation and acts and are monitored closely by the regulators. The primary purpose of this study is to provide empirical evidence concerning audit delay of publicly listed Malaysian companies. Specifically, this study investigates factors that could influence the timeliness of annual reports and provides further evidence on the effect of client industry (i.e. financial vs. non-financial) on audit delay.

The remainder of this paper is structured as follows. The next section provides the background to regulatory requirements concerning financial reporting timeliness by critically reviewing prior studies. The third section considers the research design employed for this study. The fourth section discusses the empirical results. The final section suggests possible limitations of the paper and concludes the study.

\section{Background and Prior Studies}

The Malaysian Companies Acts 1965 requires the accounts of all public companies to be audited by a qualified accountant. In addition, the Bursa Malaysia also requires companies to comply with Chapter 9 the Listing Requirement. This section stipulates that the interval between the close of the financial year of the company and the issue of the printed annual report to the company's shareholders and the exchange shall not exceed six months. Companies breaching this section can be publicly reprimanded. The Bursa Malaysia views the delay of issuing audited annual report seriously and cautions directors of the companies about their responsibility to maintain appropriate standards of corporate responsibility and accountability. The delay of the report to be furnished to company's shareholders is of interest since it has a close association with the audit functions. This is because the financial statements cannot be issued until an audit has been duly performed and concluded (Johnson, 1998).

Weygandt, Kieso and Kimmel (1998, p. 518) explained that financial information is relevant to users if it can influence or make a difference to their decision. For the information to be relevant it must be timely, i.e. it must be available before it looses its capacity to influence a user's decisions. Ashton et al. (1987) examined a sample of 488 companies that were Peat Marwick Mitchell \& Co, US clients for 1981. Using 14 variables (some of which are not publicly available), they found that the length of audit delay is significantly longer for companies that i) are categorized as nonfinancial, ii) have received qualified audit opinion, iii) have a fiscal year-end in December, iv) are non-listed companies, v) have poor internal controls, vi) rely on less complex data-processing technology, and vii) have a greater relative amount of audit work performed after year-end. Overall, the mean audit delay for the sample was reported at 62.5 days.

Ashton, Graul and Newton (1989) found that mean audit delays are associated with the type of industry, in that the financial clients have been found to have a shorter audit delay than the non-financial clients. This finding is consistent with Ashton et al. (1987). Ashton et al. (1989) also found that longer audit delay has a positive relationship with financial losses and the existence of extraordinary items. Surprisingly, Ashton et al. (1989) found that clean audit opinions were associated with longer audit delay. Although, the result is contrary to Ashton et al. (1987), they did not offer any explanation for the unexpected result.

Newton and Ashton (1989) studied the relationship between audit delay and audit firm structure for 300 Canadian firms. They found that longer audit delay was significantly associated with smaller clients, non-financial clients, existence of extraordinary items and structured audit firms. On average, the delay of audit report was recorded at 54 days. Carslaw and Kaplan (1991) examined New Zealand public listed companies using a model that is based on Ashton et. al (1987). In the study, they tested two hypothesis variables, namely, company ownership and debt proportion. Although the results were in the predicted directions for both variables, the results were not consistent for different datasets in terms of statistical significance. Debt proportion for example, was significant in 1988 but not in 1987 . With respect to company ownership, a significant effect was only found for 1987, but not in 1988 .

Whittred (1980) examined the effect of audit qualification on the timeliness of corporate annual report by using a univariate relationship test approach. The result of the study indicated that "first time" qualifications delay the release of companies' preliminary profit and the distribution of corporate annual report. This is due to an increase in the year-end time taken to complete the audit and also an increase in auditor-client negotiation time as a result of impending qualification. In general, the study concluded that "... the more serious the qualification, the greater the delay" (Whittred, 1980, p. 576).

\section{Research Design}

The sample considered in this study consists of all publicly held Malaysian companies, which were listed on both the 
Main Board and the Second Board of the Bursa Malaysia (formerly known as Kuala Lumpur Stock Exchange), as at 31 December 1993. Data are extracted from corporate annual reports with the financial year ending in the same year. The year 1993 was chosen since the economic and political environments were stable during the period.

Analysis of the dataset was conducted using the following model of audit delay. The model is replicated and extended from the one employed by Carslaw and Kaplan (1991).

\section{LDELAY $=\alpha+\beta_{1}$ FIN $+\beta_{2}$ LASSET $+\beta_{3}$ LSUBS $+\beta_{4}$ INVREC $+\beta_{5}$ LEV $+\beta_{6}$ ROE + $\beta_{7}$ DIRSH $+\beta_{8}$ BSIX $+\beta_{9}$ BUSY $+\beta_{10}$ COPINION $+\beta_{11}$ CHANGE $+\varepsilon$}

Where (expected sign in parenthesis):

\begin{tabular}{|c|c|}
\hline LDELAY & $\begin{array}{l}=\log _{10} \text { of number of days from the financial year-end to the date of audit } \\
\text { report. }\end{array}$ \\
\hline FIN (-) & $\begin{array}{l}=\text { Industry classification represented by a dummy variable: " } 1 \text { " for } \\
\text { financial (banks, finance, insurance, and securities and investment } \\
\text { sectors) and " } 0 \text { " for non-financial companies. }\end{array}$ \\
\hline LASSET (-) & $=\log _{10}$ total assets of company as a proxy to measure company size \\
\hline LSUBS $(+)$ & $=\log _{10}$ number of subsidiaries +1 (including the holding company) \\
\hline $\operatorname{INVREC~}(+)$ & $\begin{array}{l}=\text { Total of inventory and receivables divided by total assets. Note that for } \\
\text { financial companies, this includes trade bills, bills receivables, advances } \\
\text { to customers and lendings. }\end{array}$ \\
\hline $\operatorname{LEV}(+)$ & $=$ Proportion of long-term debt (excluding deferred tax) to total equity. \\
\hline ROE (-) & $=$ Proportion of net profit to shareholders' equity \\
\hline DIRSH (+) & $\begin{array}{l}=\text { Ratio of client's directors' shareholding (based on the number of } \\
\text { common shares held by the directors divided by the total number of } \\
\text { common share outstanding). }\end{array}$ \\
\hline BSIX (-) & $\begin{array}{l}=\text { Type of company auditor, represented by a dummy variable: " } 1 \text { " for the } \\
\text { Big-Six auditors and " } 0 \text { " for others. }\end{array}$ \\
\hline BUSY $(+)$ & $\begin{aligned}= & \text { A dummy variable coded " } 1 \text { " for companies with financial year date } \\
& \text { between } 31 \text { December to } 31 \text { March, "0" otherwise. }\end{aligned}$ \\
\hline COPINION $(+)$ & $\begin{array}{l}=\text { Audit opinion issued by auditor, represented by a dummy variable: " } 1 \text { " } \\
\text { for companies with qualified opinion and " } 0 \text { " for those with unqualified } \\
\text { opinion. }\end{array}$ \\
\hline CHANGE $(+)$ & $\begin{array}{l}=\text { A dummy variable coded " } 1 \text { " if the incumbent auditor is a new auditor } \\
\text { and " } 0 \text { " otherwise. }\end{array}$ \\
\hline & $=$ Error term assumed to be normally distributed with constant variance. \\
\hline
\end{tabular}

\subsection{Variable discussion}

Unique aspects of different industries are likely to affect the relative length of time to complete an audit. Financial companies are expected to experience shorter audit delay due to the fact that such companies have little or no inventory (Ashton et. al. 1989; Carslaw and Kaplan, 1991). In addition, the accounting systems of the financial services industry are generally highly centralized and automated (Bamber et. al. 1993). In the case of Malaysia, it was found that more than $70 \%$ of financial companies depend heavily on computer in their day-to-day operations (Basariah, Mahamad and Shamharir, 2000). These two facts (i.e. less inventories and highly automated system) reduce the audit coverage as the inventory segment represents the most difficult area to audit (Carslaw and Kaplan, 1991) and the centralized and automated accounting systems mean less diverse transactions. In addition, the banking industry is also governed separately by the Bank Negara (Central Bank).

Another important determinant of audit delay is company size. Normally, total assets have been used to measure size of company in previous studies of audit delay. The variable was found to have a negative relationship with audit delay (see for example, Carslaw and Kaplan, 1991; and Newton and Ashton, 1989). It was contended that several factors account for this relationship. For example, it is commonly known that big companies normally have reliable internal control, which in turn would reduce the propensity for financial statement error. Hence, auditors are likely to rely more on the 
client's internal control, which in turn will reduce the extent of audit substantive test.

Similar relationship is expected between complexities of the companies and timeliness of financial reporting. Due to a client's diversified business operations, an auditor of a client-company with a large number of subsidiaries is expected to utilize additional time. It is expected that as complexity of the client increases, the auditor will spend more time to complete the audit task.

Another measure of complexity is the ratio of inventory and receivables to total assets. The variable should be positively related to audit delay. A larger proportion of receivables and inventory requires more audit effort for verification of balances in the balance sheet and hence a need for longer time.

Carslaw and Kaplan (1991) suggested that auditing of a company with a high proportion of debt to assets consumes more time than a company with a relatively low proportion of debt. One of the reasons is the fact that a company with a high proportion of debt to total assets tends to be associated with financial distress and ultimately the greater likelihood of bankruptcy. In this study, the proportion of long-term debt (excluding deferred tax) to total equity is included in the model. The amount of long-term debt may also raise the agency costs as suggested by Jensen and Meckling (1976) and this is likely to increase the audit efforts and hence, the length of the audit engagement.

The auditor is likely to perform his audit task more cautiously if the profitability of the client is low due to higher business risk. As the auditor performs the audit cautiously and thoroughly, the audit delay is expected to be longer as compared with the audit of companies with higher profitability. ROE is used to proxy for profitability in this study.

Audit delay literature (see for example, Ashton, et al. 1987; Carslaw and Kaplan, 1991; and Bambers et al. 1993) suggests that companies with a high level of manager ownership are likely to experience longer lag due to less pressure for timely information release. This is because the owner managers already have easy access to the information.

The size of audit firms is likely to affect audit delay. Large audit firms have a greater propensity to complete audits in a shorter time due to their greater resources compared with smaller firms (Carslaw and Kaplan, 1991). These firms are likely to develop audit specialization and expertise in certain areas and industries, which in turn will result in audit works being performed more efficiently. Following previous studies, a dichotomous variable is used to identify large audit firms (previously defined as Big Six, but now Big Four auditors).

A company that has a financial year-end similar to the others is expected to experience longer audit delay. This is due to the fact that a large number of audits with the same financial year-end date may cause scheduling problems for the auditor (Carslaw and Kaplan, 1991) and also a shortage in audit personnel to be assigned in each audit engagements.

Bamber et al. (1993) argued that the qualified opinions are not likely to be issued until the auditor has spent considerable time and effort in performing additional audit procedures. Moreover, companies always view audit qualified opinion as "bad news" and might not respond to the auditor's request promptly. It is a symptom of auditor-management conflict that would also increase audit delay (Carslaw and Kaplan, 1991).

Similar relationship is expected when companies change their auditor. The new auditor is likely to spend more time on audit work in order to study and understand their new clients compared with existing clients.

\section{Results}

There were 413 companies listed on the Bursa Malaysia as of 31 December 1993. However, after excluding several companies for various reasons, only 343 companies were selected to form the final sample. (Note 1)

The next section reports the descriptive statistics related to the sample companies followed by a section that explains the results of the multivariate test. Further, we provide additional tests by splitting the sample into two sub-samples namely, financial companies and non-financial companies.

\subsection{Descriptive statistics}

Table 1 shows the descriptive statistics for sample companies during the period under study. The mean audit delay was 114 days with a minimum delay of 20 days. The longest delay was reported to be 442 days. Only nine companies were found to have audit lag of more than 180 days and this might violate the Bursa Malaysia rule with regards to the minimum submission period of six months. Compared with the delays in other countries, namely, the USA; 62.5 days (Ashton et al., 1987), Canada; 54 days (Newton and Ashton, 1989) and New Zealand; 87.7 days (Carslaw and Kaplan, 1991), the mean period of audit delay for Malaysian companies seems to be longer. Part of the reason could be due to lack of auditors in Malaysia and/or perhaps weak enforcement from the regulatory bodies. Meanwhile, the mean total asset was MYR1.14 billions with the standard deviation of about MYR3.81 billions.

As expected, the Big-Six audit firms were dominant in the Malaysian audit market for public listed companies. The market-share of these "first-tier firms" was reported to be $77.3 \%$, leaving less than $25 \%$ of companies to the non Big-Six firms. More than $70 \%$ of the companies were audited during the busy season, i.e. December through May. Meanwhile only $4.1 \%$ of the companies changed their auditor in 1993 and the same percentage of companies was 
reported to receive qualified audit opinion.

\subsection{Multivariate results}

To investigate the multivariate relationship between independent and dependent variables, we performed an OLS regression. Following the method of previous studies, audit delay, total assets and numbers of subsidiaries were transformed using the natural log function. Table 2 exhibits the regression results for all variables. (Note 2)

Six out of eleven independent variables were significantly associated with LDELAY in the predicted directions. Four variables (LASSET, DIRSH, LSUBS and ROE) were highly significant at the one-percent level. Large companies tend to have strong internal control systems that are relied upon by auditors and this is reflected by less audit work. Similarly, less profitable companies are more risky and need additional audit work. The same can be said for complex companies that need additional scrutiny. As expected, the higher the directors' interest in the company, the higher the audit delay. This is because timely financial reports are less crucial for companies with high director shareholdings since the directors are likely to have easy access to the company information. The result is consistent with that of Carslaw and Kaplan (1991). COPINION and BSIX were significant at the five-percent significance level. (Note 3) As indicated earlier, auditors need more time to audit companies that are issued qualified opinions. As expected large audit firms (BSIX) were associated with less audit delay. This may be due to greater resources owned by large firms such as adequate qualified staff that reduce the time taken to complete the audit works. Although the direction of the association between FIN variable and the delay is as expected, the model however, shows no significant relationship between financial companies and the audit delay. Note that the model $\mathrm{R}^{2}$ is $19.5 \%$ and the F-Ratio is significant at less than one-percent. (Note 4)

\subsection{Financial and non-Financial Companies}

To provide further evidence on the role of FIN on audit delay, we split the sample into two sub-samples and performed multiple regressions on each sample. Table 3 below presents the descriptive statistics of the non-financial and financial subsamples. The mean audit delay of 105.97 days of the financial sector is approximately a week shorter than that of the non-financial subsample. Financial subsample companies were found to own more assets as well as greater ROE. The Big Six audited $72 \%$ of the financial companies and $78 \%$ of non-financial companies while $82 \%$ of the financial companies were audited during the busy season as opposed to $69 \%$ in the non-financial sector. Additionally, the non-financial companies have recorded fewer inventories and receivables as well as fewer ROE. They also received fewer qualified audit opinions and experienced fewer auditor changes.

Table 4 exhibits the results of OLS regressions of the two subsamples. For the non-financial subsample, the six variables that significantly affected audit delay in the overall sample were also significantly affected audit delay during the year under study in the predicted directions. In fact, the results were identical to the results of the full sample in terms of statistical significance. Note that the $\mathrm{R}^{2}$ is about $20 \%$ and the F-ratio is significant at less than one-percent significant level.

On the other hand, the result for the financial subsample is somewhat different. Except for DIRSH, LSUBS and COPINION, the other variables were no longer significantly associated with audit delay. Only DIRSH was statistically significant at the one percent level while LSUBS and COPINION were weakly significant at the ten-percent level. Interestingly, the $\mathrm{R}^{2}$ is relatively high with about $28 \%$ of the variations are explained by the model. The F-ratio is also significant at less than four percent. The results suggest that there may be other variables that are not incorporated in the model for financial companies and that may have resulted in omitted variable errors. As well, the differences in regulatory framework for both subsamples could be one reason for the differences in the findings and this warrant further research.

\section{Conclusions}

The present study has sought to explain the determinants of audit delay in a Malaysian environment. The results were broadly consistent with previous studies done in Western countries. Size, complexities, directors' shareholdings, the size of auditor, audit opinion and the profitability of the companies are the major determinants of audit delay. The same results were also found in non-banking and finance sector. However, only directors' shareholdings was found to be significantly associated with audit delay at a one-percent significant level while client complexities and audit opinion were significant at the ten-percent level. Differences in regulatory framework were offered as one of the possible causes for the differences.

There are possible limitations to the design described in this study, especially regarding the measurement of directors' interest. The interests of the directors are disclosed in the director's report. However, the data may not reflect the accurate percentage of ownership as both direct and indirect shareholdings are included in total interests in many cases. Furthermore, the presence of institutional shareholders and the use of nominee companies to register shareholdings may also add noise to the analysis. However, the new amendments to the Companies Act 1965 provide clear definitions of what constitutes the "interest(s) in shares" (Cheong, 1990). Substantial penalties imposed for nondisclosure or 
inaccurate financial disclosures are likely to minimise the inaccuracy of the data.

\section{References}

Ashton, R., J. Willingham, and R. Elliott, (1987) Empirical Analysis of Audit Delay. Journal of Accounting Research (autumn). pp. 275-292.

Ashton, R., P. Graul, and J. Newton. (1989) Audit Delay and the Timeliness of Corporate Reporting. Contemporary Accounting Research (Spring). pp. 657-673.

Bamber ,E., L. Bamber, and M. Schoderboek. (1993) Audit Structure and Other Determinants of Audit Report Lag: an Empirical Analysis. Auditing: A Journal of Practice \& Theory, 11(1): pp 1-23.

Basariah, S, T. Mahamad, and A. Shamharir (2000) Computer Crime and Security: A Survey of Financial Institutions in Malaysia, Paper Presented at Seminar on Accounting and Information Technology, 13 - 14 November 2000, Convention Centre, Universiti Utara Malaysia.

Carslaw, C. and S. Kaplan. (1991). An Examination of Audit Delay: Further Evidence from New Zealand. Accounting and Business Research (Winter). pp. 21-32.

Che-Ahmad, A. and K.A. Houghton. (1996). Audit Fee Premiums to Big Eight Firms: Evidence from the Medium-Size UK Auditees. Journal of International Accounting, Auditing and Taxation, 5(1): pp. 53-72.

Cheong, S. (1990). Corporate Groupings in the KLSE. Petaling Jaya, Malaysia: Modern Law Publishers \& Distributors.

Cook, R. D. and S. Weisberg. (1982). Residuals and Influence in Regression. New York: Chapman \& Hall.

Financial Accounting Standards Board. (1980). Statement of Financial Accounting Concepts No. 2, Qualitative Characteristics of Accounting Information. Stanford, CT: FASB.

Feltham, G.A. Information Evaluation. Studies in Accounting Research, no. 5, Sarasota, Fla,: American Accounting Assn., 1972.

Givoly, D., and Palmon. (1982) Timeliness of Annual Earnings Announcements: Some Empirical Evidence. The Accounting Review (July). pp. 486-508.

Jensen, M. C. and W. H. Meckling. (1976). Theory of the Firm: Managerial Behavior, Agency Costs and Ownership Structure. Journal of Financial Economics, 3(4), (October): 305-360.

Johnson, L, E. Further Evidence on the Determinants of Local Government Audit Delay. (1998). Journal of Public Budgeting, Accounting and Financial Management, 10(3), pp. 375-379.

Kross, W., and D.A. Schroeder (1984). An Empirical Investigation Of The Effect Of Quarterly Earnings Announcement Timing On Stock Returns. Journal of Accounting Research (Spring). pp. 153-76.

Newton, J. and R. Ashton. (1989). The Association Between Audit Technology and Audit Delay. Auditing: A Journal of Practice and Theory (Supplement). pp. 20-37.

Ramsey, J. B. (1969). Tests For Specification Error In Classical Linear Least Squares Regression Analysis. Journal of the Royal Statistical Society. Series B 31, pp. 350-371.

Simon, D.T., S. Teo and G. Trompeter. (1992). A Comparative Study of the Market for Audit Services in Hong Kong, Malaysia and Singapore, International Journal of Accounting, 27: pp. 234-240.

Taylor, M.H. (1997). The Market for Audit Services in Japan, Pacific Accounting Review, 9(2): pp. 59-74.

Walker, K.B. and E.N. Johnson. (1996). A Review and Synthesis of Research on Supplier Concentration, Quality and Fee Structure in Non-U.S. Markets for Auditor Services, International Journal of Accounting, 31 (1): pp. 1-18.

Weigandt, Kieso and Kimmel. (1998) Accounting Principles, $5^{\text {th }}$ ed., John Wiley and Sons , Inc.

Whittred, G. (1980). Audit Qualification and the Timeliness of Corporate Annual Reports. The Accounting Review (October), pp 563-577.

\section{Notes}

Note 1 . Out of 70 companies excluded, 44 were newly listed companies, 15 changed the corporate financial year-end, one company was under suspension from the Bursa Malaysia, and 11 companies did not have sufficient data for the study.

Note 2. The (robust) results were corrected for heteroscedasticity based on the method of Cook and Weisberg (1993). Note that the results were almost identical to the (uncorrected) original regression results in terms of significant variables and the signs of variables. The R-squared and the F-Statistics were also similar. The regression specification error test (Ramsey, 1969) indicated no specification problem. 
Note 3. The variables Inflation Factor (VIF) for all variables were not more that 2.5 and were not likely to pose a multicollinearity problem. However, since LSUBS and LASSET were found to be correlated with 0.55 and significant (1-tailed) at $1 \%$, additional regressions were carried out by first dropping the variable LASSET and then the variables LSUBS. The results suggested that there was no change in signs, size or significant levels of the remaining variables. Hence, multicollinearity should not pose any problem in interpreting the results.

Note 4 . The robust estimate of the regression results using STATA statistical software did not produce adjusted $\mathrm{R}^{2}$.

Table 1. Descriptive statistics for the dependent and variables $(\mathrm{n}=343)$

\begin{tabular}{|l|r|r|c|}
\hline \multicolumn{1}{|c|}{ Variable } & \multicolumn{1}{c|}{ Mean } & \multicolumn{1}{c|}{ SD } & \% \\
\hline AUDIT DELAY (days) & 114.45 & 39.06 & \\
\hline TOTAL ASSETS* & $1,135,707.74$ & $3,808,087.57$ & \\
\hline DIRSH & 0.36 & 0.36 & \\
\hline LEV & 0.07 & 0.09 & \\
\hline LSUBS & 0.93 & 0.52 & \\
\hline INVREC & 0.29 & 0.23 & \\
\hline ROE & 0.25 & 0.33 & \\
\hline FIN & & & 11.40 \\
\hline COPINION & & & 4.10 \\
\hline BSIX & & & 77.30 \\
\hline BUSY & & & 70.30 \\
\hline CHANGE & & & 4.10 \\
\hline
\end{tabular}

*The figure is stated in RM ' 000

Table 2. Results of OLS Regression (Robust) for 1993 ( $n=343$ )

\begin{tabular}{|l|c|r|c|rl|}
\hline Variable & $\begin{array}{c}\text { Expected } \\
\text { Sign }\end{array}$ & Coef. & $\begin{array}{c}\text { Robust } \\
\text { Std. Error }\end{array}$ & t-statistics \\
\hline FIN & - & -0.005 & 0.039 & -0.123 & \\
\hline LASSET & - & -0.058 & 0.019 & -3.074 & \\
\hline LSUBS & + & 0.061 & 0.020 & $3.020 \quad * * *$ \\
\hline INVREC & + & -0.021 & 0.038 & -0.535 & \\
\hline LEV & + & -0.013 & 0.081 & -0.155 & \\
\hline ROE & - & -0.075 & 0.022 & $-3.408 \quad * * *$ \\
\hline DIRSH & + & 0.073 & 0.022 & $3.375 \quad * * *$ \\
\hline BSIX & - & -0.033 & 0.017 & -1.944 & \\
\hline BUSY & + & 0.003 & 0.016 & 0.170 & \\
\hline COPINION & + & 0.077 & 0.036 & $2.130 \quad * *$ \\
\hline CHANGE & + & 0.038 & 0.039 & 0.989 & \\
\hline Constant & $+/-$ & 2.311 & 0.098 & $23.501 \quad * * *$ \\
\hline F-ratio & $9.00^{* * *}$ & & & \\
\hline R-squared & 0.195 & & & \\
\hline
\end{tabular}

*** Significant at 1 percent level (one-tailed where signs are expected, two-tailed otherwise)

** Significant at 5 percent level (one-tailed where signs are expected, two-tailed otherwise)

* Significant at 10 percent level (one-tailed where signs are expected, two-tailed otherwise) 
Table 3. Descriptive statistics for the dependent and explanatory variables for the non-financial and financial subsamples

\begin{tabular}{|l|r|r|r|r|r|r|}
\hline & \multicolumn{2}{|c|}{ Non-Financial Sector $(\mathrm{n}=304)$} & \multicolumn{3}{|c|}{ Financial Sector $(\mathrm{n}=39)$} \\
\hline Variable & \multicolumn{1}{c|}{ Mean } & \multicolumn{1}{c|}{ SD } & \multicolumn{1}{c|}{$\%$} & \multicolumn{1}{c|}{ Mean } & \multicolumn{1}{c|}{ SD } & $\%$ \\
\hline AUDIT DELAY (days) & 115.53 & 38.01 & & 105.97 & 46.09 & \\
\hline TOTAL ASSET* & $658,318.97$ & $1,670,070.48$ & & $4,856,892.00$ & $9,604,128.29$ & \\
\hline DIRSH & 0.37 & 0.38 & & 0.27 & 0.29 & \\
\hline LEV & 0.07 & 0.09 & & 0.07 & 0.11 & \\
\hline LSUBS & 0.94 & 0.51 & & 0.90 & 0.53 & \\
\hline INVREC & 0.29 & 0.20 & & 0.32 & 0.39 & \\
\hline ROE & 0.23 & 0.31 & & 0.39 & 0.45 & \\
\hline COPINION & & & 3.95 & & & 5.00 \\
\hline BSIX & & & 78.00 & & & 72.00 \\
\hline BUSY & & & 69.00 & & & 82.00 \\
\hline CHANGE & & 4.00 & & & 5.00 \\
\hline
\end{tabular}

*The figure is stated in RM ' 000

Table 4. Results of OLS Regression (Robust) for the non-financial and financial subsamples

\begin{tabular}{|c|c|c|c|c|c|c|c|c|}
\hline & \multicolumn{4}{|c|}{ Non-Financial $(\mathrm{n}=304)$} & \multicolumn{4}{|c|}{ Financial $(\mathrm{n}=39)$} \\
\hline Variable & Coefficient & $\begin{array}{c}\text { Robust } \\
\text { Std.Error }\end{array}$ & \multicolumn{2}{|l|}{ t-statistics } & Coefficient & $\begin{array}{l}\text { Robust } \\
\text { Std.Error }\end{array}$ & \multicolumn{2}{|l|}{ t-statistics } \\
\hline DIRSH & 0.055 & 0.021 & $2.594 *$ & $* * *$ & 0.285 & 0.101 & 2.822 & $\star \star \star *$ \\
\hline LASSET & -0.061 & 0.018 & -3.376 & $* * *$ & -0.022 & 0.082 & -0.264 & \\
\hline LSUBS & 0.048 & 0.019 & 2.523 & $* * *$ & 0.137 & 0.101 & 1.355 & * \\
\hline INVREC & -0.025 & 0.038 & -0.653 & & 0.019 & 0.122 & 0.156 & \\
\hline LEV & 0.010 & 0.090 & 0.112 & & -0.023 & 0.307 & -0.073 & \\
\hline ROE & -0.085 & 0.022 & -3.855 & $* * *$ & -0.052 & 0.111 & -0.466 & \\
\hline BSIX & -0.038 & 0.017 & -2.159 & ** & 0.050 & 0.111 & 0.453 & \\
\hline BUSY & -0.003 & 0.016 & -0.167 & & 0.033 & 0.112 & 0.294 & \\
\hline COPINION & 0.069 & 0.038 & 1.821 & ** & 0.205 & 0.134 & 1.529 & * \\
\hline CHANGE & 0.038 & 0.040 & 0.950 & & -0.033 & 0.161 & -0.202 & \\
\hline Constant & 2.355 & 0.090 & 26.165 & $* * *$ & 0.848 & 0.528 & 3.498 & *** \\
\hline F-ratio & \multicolumn{4}{|l|}{$9.06^{* * *}$} & \multicolumn{4}{|l|}{$2.00 * *$} \\
\hline$R$-squared & \multicolumn{4}{|l|}{0.200} & \multicolumn{4}{|l|}{0.282} \\
\hline
\end{tabular}

Significant at 1 percent level (one-tailed where signs are expected, two-tailed otherwise)

** Significant at 5 percent level (one-tailed where signs are expected, two-tailed otherwise)

* Significant at 10 percent level (one-tailed where signs are expected, two-tailed otherwise) 


\title{
Data Enriched Voice Service Analysis and Forecast
}

\author{
Qiaohong Zhou \\ School of Economics and Management, South West Jiaotong University \\ Jiu Li Ti Campus, Juan Cheng Zhai 13-107 \\ Chengdu 610031, China \\ E-mail: qiaohong.zhou@gmail.com \\ Guohua Zhou \\ School of Economics and Management, South West Jiaotong University \\ Tel: 86-28-8763-4066Ｅ-mail: ghzhou@126.com
}

\begin{abstract}
In this article, we compare the traditional call model and the new call model where voice and data are united together in a globally interoperable way, and analyze the data enriched voice service via call personalization, call-to-browse, and call-to-advertise. This work aims to better understand the characteristics and current situations of voice service in the telemarketing industry and forecast its market potential.
\end{abstract}

Keywords: Voice service, Data personalization, Call- to -browse, Advertisement

\section{Introduction}

3GSM World Congress 2007 in Barcelona has marked a turning point in the availability, or at least announcement of, multimedia enhancements to Caller ID and Call Alerts. As would be expected for such a new area, there are many ideas about how to proceed. Some offers are positioned as extensions to "ringtone", while others have a broader vision of how rich media can be added to the telephone call. Some service requires either calling parties to be on each other buddy lists; or both calling parties to install client software, while others do not. Some platforms are SIP/IMS/VoIP oriented, while a small number can be implemented in standard $2.5 \mathrm{G}$ and $3 \mathrm{G}$ environments. Some use relatively sophisticated service platforms while others are quite basic point products. Most are launched on the web independent of operators while some only work with operators' network infrastructure. Some claim "patents pending" while others have granted patents, though in quite diverse areas and sometimes rather late.

\section{The Call model}

\subsection{The traditional call model}

The traditional call model (Figure 1) only makes the benefit for the operator by charging a fee during the in-call, there are no commercial activities during pre-call and post-call.

\subsection{The new call model}

The new call model (Figure 2) brings new and diverse commercial activities during the pre-call and post-call periods, which in turn generate new business value.

\section{Call Personalizations}

\subsection{Mobile music service market}

From the table 1,we find that a huge share of mobile music revenue and consumers come from personalized services, among them ringback tone is the largest, full-track download still marginal, ringtone ARPU is decreasing while ring back tone ARPU is still increasing within next 3 years. Other studies from OVUM even foresee a decrease of total revenues from ringtones and wallpaper download in APAC during the same period. While ringtone service revenue is expected to decrease, it leaves room for the growth of new music and personalization services.

\subsection{Innovation in the ring tone personalization area (Figure3)}

Major innovation is happening in the call personalization area, mainly coming from start-up companies highly invested by venture capitals looking for the next ringtone application.

The competitors listed here typically have early Skype implementations or private beta tests: 
$\diamond$ Gizmoz allows to create 3D animated avatars based on user pictures. It raised $\$ 6.5$ million recently from investors, including DoCoMo. It announced a partnership with AOL for talking 3D avatars ${ }^{[1]}$. (Figure4)

$\diamond \quad$ Vringo allows to create a community of users with whom you can share content as a ringtone when you call them. Portfolio of licensed music and video content is available ${ }^{[2]}$. (Figure5)

$\diamond$ Comverse has developed Klonies as a customizable avatar service for mobile and Internet calls. Currently its service is available to Skype users ${ }^{[3]}$. (Figure6)

$\diamond \quad$ Emotive has an application called Ringjam which allows callers to customize Internet call alert with purchasable licensed music and video content. Ringjam is currently available on Skype ${ }^{[4]}$. EMotive has raised $\$ 7.7$ million from investors including Warner Music Group ${ }^{[5]}$. (Figure7)

$\diamond \quad$ Monikker starts as the next Generation of Ringtone and Caller ID, as the caller can choose for each call, multimedia - sound, image and text message, same across fixed, mobile or broadband (VoIP, SIP, IMS...) ${ }^{[6]}$. (Figure8)

$\diamond \quad$ Innovation is also driven by major Internet players aiming to move towards the mobile world through their IM and community pages. Key Internet players are Google, Yahoo, MSN, AOL, Skype, Facebook, etc; while they come to compete with carriers, innovation in personalization servers as a key differentiator.

\section{Call - to - Browse Experience}

While $76 \%$ of mobile users in developed countries have Internet through their mobile phones, only $32 \%$ use the service

[7]. Technology is giving more possibilities, more choice, but also more complexities. Placing or answering a voice call or a SMS is still what most people can or are willing to do. Simplification of the end-user experience is required to bring any enhanced service to the mobile world. Operators have shown reluctance in bringing content to their subscribers. New mobile players are actively exploring this opportunity.

The operator uses the SMS simple interface to request for premium content (weather, stocks, addresses, etc), which is limited in content size (due to SMS) and fastidious in navigation. (Figure9)

The mobile phone camera can be used as a 2D barcode reader. Pictures can be decoded into 400 bytes information such as the contact details or the URL. End users just need to take a picture of a magazine or the billboard instead of typing complex URL address, and do not require to handle printing media. (Figure10)

New devices such as iPhone include direct access buttons on phone menu to embedded online applications such as Maps, Weather, Stocks, etc. Often portal services can create new widgets coming directly on the phone interface (i.e., Facebook). (Figure11)

Yahoo Go! offers a one-stop-shop for mobile client to select from all of Yahoo Internet world: email, news, flick pictures, maps, finance, RSS feeds, etc and a mobile browser that adapts Internet content to mobile screen size. (Figure12)

Keying in a URL or clicking on a hyperlink works conveniently on a PC, but not so on a mobile device. Many attempts have tried to replace the trigger of a data session by a simpler action: SMS, barcode, specific mobile client, or even RFID tags. But attempts resulted in either a limited experience or more complicated end-user experience. Coupling or triggering a data session before or after a voice call could be a more natural way to proceed as every mobile phone owner knows how to place a phone call.

Many start-up targets this function such as one Australian company Monikker which sets up their network market as: Figure13

Value Proposition:

$\diamond \quad$ Consumers can 'make it mine' if they like a call based on Monikker and order the music or image.

$\diamond \quad$ Content owners get a new 'viral' distribution channel - consumers promoting their content at no cost!

$\diamond$ Scenario

$\diamond \quad$ Business pays MSP to deliver a call

$\diamond$ monikkers and receives customer feedback.

$\diamond \quad$ Parties

$\diamond \quad$ Party A chooses a monikker, knowing that it is available to others

$\diamond \quad$ Party B chooses to "make it mine" and pays

$\diamond \quad$ Content provider chooses this distribution option and MSP serves as the intermediary

$\diamond \quad$ Business Model

$\diamond \quad$ MSP earns a share of every sale from unique platforms 
$\diamond$ Has lower advertising and promotion costs than other media. New platform for "Hits"

$\diamond \quad$ Call monikker can be free, but full song paid for - customers become advocate

\section{Call-to- advertise}

\section{1 market view}

The average consumer spends 3 hours daily watching TV, on which advertisers spend \$79 billion yearly, 1 hour using their mobile, on which advertisers spend \$2 billion in 2007.Mobile advertisement global market revenue is $\$ 1.5$ billion in 2006 , i.e., $0.2 \%$ of the $\$ 435$ billion spent for advertisement on any media ${ }^{[8]}$. Mobile advertising revenue is projected to reach $\$ 11.3$ billion in $2010^{[9]}$, $\$ 13.8$ billion in $2011^{[10]}$; In Japan, mobile marketing was as big as $\$ 850$ million already in 2006.

Multimedia and interactive technologies have been adopted on mobile (Multimedia devices, MMs, Mobile TV, 3G, etc), and Mobile operators possess huge data about their subscriber profiles and behaviors, that other media may not have. Among all mobile users, $34 \%$ of them are ready to accept mobile advertisement in exchange of free content ${ }^{[1]}$. All these will make this market grow very fast.

According to a survey from $\mathrm{OPA}^{[7]}, 50 \%$ of mobile users in developed countries use their mobile device the same brand as their computer. Big Internet players represent most of the mobile traffic as well. Google, Yahoo and MSN are introducing key assets on the mobile Internet to take further control. Applications are currently free of charge, free of advertisement. But it can be easily extended to include advertisement, their first source of revenues. (Figure14)

\subsection{Advertisement insertion on mobile}

Mobile advertisement can be improved by using user profile and behavior information, providing the user with advertisement of goods \& services which he likes, when he needs. Mobile Advertisement could reach higher efficiency by associating multimedia advertisement with voice calls and SMS. Voice call is still the first killer application for mobile users. The figure below compares the efficiency of different mobile advertisement options. (Figure 15)

\subsection{Advertising and Sponsored Service (Figure 16)}

\section{Value Proposition}

$\diamond \quad$ Businesses provide branded but interesting monikkers to customers at no charge (Sponsored mode)

$\diamond$ Consumers option in to receive advertisements as call alerts (for calls without monikkers) and post-call advertisement time or location based alerts possible. Can leave material in address book and on time line.

$\diamond$ Scenario

$\diamond \quad$ Business pays Intermediary or MSP - new advertising platform with measurable delivery.

$\diamond$ Parties

$\diamond \quad$ Party B - Consumer receiving calls, may opt in for advertising

$\diamond \quad$ Party A- Gets interesting monikkers at lower price in sponsored mode

$\diamond$ Business Model

$\diamond \quad$ Business pays for the new option to promote brand and leave messages with customers

$\diamond$ Can include "click to call", click to "make it mine"

$\diamond \quad$ Pay for exposure, pay for results

\section{Opportunity \& Revenue forecast}

\subsection{Market potential evaluated in APAC}

Data enriched voice service market, from four streams (advertising, entertainment, information, communication), will grow to $€ 80$ billion in revenue by 2010 in APAC. The figure attached presents revenue forecast for call personalization service in APAC for the period of 2007 through $2010^{[12]}$. (Figure 17)

\subsection{Market potential for China}

TD-SCDMA 3G subscribers China will jump to 28 million by 2011, up from 1.1 million subscribers in 2007, and estimated 6.4 million in 2008. A key revenue driver in China will come from the applications that will be enabled by $3 \mathrm{G}$. Chinese consumers will be able to access the Internet, download music, stream Internet video, use mobile mailboxes, pay bills online and engage in mobile blogging and interactive 3D gaming through their mobile phones. China $3 \mathrm{G}$ value-added services market will grow to $\$ 19.5$ billion in revenue by 2011 , maintaining a Compound Annual Growth Rate (CAGR) of $17.4 \%$ from $\$ 8.8$ billion in $2006^{[13]}$., which shows the grand opportunities for call personalization service in china. 
The figure 18 attached presents revenue forecast for $3 \mathrm{G}$ value-added services in China for the period of 2006 through $2011^{[13]}$.

However, blocking points needs to be addressed to go further in business evaluation such as: low penetration of capable devices on the Chinese Market compared to other countries; difficulty to protect patents in China; lack of local structure and operations in china to provide local support as requested by Chinese operators; maturity of the product for quick commercial launch with required feature (advertisement).

\section{Conclusions and suggestion}

Voice and data united in a globally interoperable enhanced call model, and the customer can use any handset type VoIP, 3G, Smartphone, Softphone, Hardphone and any network as common as CLI (command line interface), are integral to enrich more personal communications.

In the future, VoIP will be a grand threat to the mobile operator for voice service, because the cost of VoIP is much lower. But data enriched voice service is a benefit, as mobile operators can still charge at the same price for voice: valued service provided for a monthly subscription fee plus per call charges for some applications and all of the Internet business models, and keep on being attractive as they offer data services on top of voice.

For such a new area there are many ideas about how to proceed. Some claim "patents pending" while others have granted patents, though in quite diverse areas and sometimes rather late. However potential investors should make their own assessment.

\section{References}

Gizmoz. (Online) Available: http://biz.yahoo.com/prnews/080317/aqm047.html?.v=42 (March 1, 2008).

(Online) Available: http://www.vringo.com/ (January 10,2008).

(Online) Available: http://skype.klonies.com/ ((January 12, 2008).

(Online) Available: http://ringjam.com/ (January 12, 2008).

(Online) Available: http://www.monikker.com/home.php (March 1, 2008).

(Online) Available: http://64.13.250.16/newsletter.php?newsId=52\&newsType = pr((January 20,2008).

Emarket. (September 18, 2006). Mobile Ad Market on a Roll, (Online) Available: http://www.emarketer.com/Article.aspx?id=1004165 (November 25,2007).

(Online) Available: http://www.zenithoptimedia.com/home/ (September 25,2007).

Emarketer. Mobile Advertising Exposure Rising (March 7,2008). (Online) Available: http://www.emarketer.com/SiteSearch.aspx?arg=Mobile+Advertising+Exposure+Rising\&src=search_go_articles (March 20,2008).

Online Publisher Association (March, 2007), Available: http://www.online-publishers.org/media/176_W_opa_going_mobile_report_mar07.pdf (March 12, 2008).

(Online) Available: http://alcatel-lucent.com (March 6, 2008).

Jonathan Cassell. (25/07/2007). Government Drives 3G Wireless Transition in China, (Online) Available: http://www.isuppli.com/news/default.asp?id=8237\&m=7\&y=2007, (March 6, 2008).

RafatAli. (April 2007). Warner Music And Other Invest \$7.7 Million In "Push Ringer" Firm emotive, (online) Availabl: http://www.moconews.net/entry/warner-music-and-other-invest-77-million-in-push-ringer-firm-emotive/ (January 20,2008). 
Table 1. APAC (excl Japan) Mobile Music Service Revenues \& Forecast

\begin{tabular}{|c|c|c|c|c|c|c|c|}
\hline & 2006 & 2007 & 2008 & 2009 & 2010 & 2011 & $\begin{array}{l}2006-2011 \\
\text { CAGR(\%) }\end{array}$ \\
\hline Total mobile subscribers $(M)$ & 782.2 & 966.4 & $1,108,50$ & $1,239.20$ & $1,334.90$ & $1,432.20$ & 12.9 \\
\hline \multicolumn{8}{|l|}{ Ringtone customers } \\
\hline Ringtone customers at year-end $(M)$ & 182.1 & 242.1 & 295.5 & 348.9 & 401.5 & 453.6 & 20 \\
\hline Share of total mobile subscribers $(\%)$ & 20 & 30 & 30 & 30 & 30 & 30 & \\
\hline Ringtone revenue(US\$M) & 927.4 & $1,267.40$ & $1,521.50$ & $1,735.80$ & $1,918.00$ & $2,061.20$ & 17.3 \\
\hline Monthly ARPU(\$) & 0.5 & 0.5 & 0.5 & 0.5 & 0.4 & 0.4 & -4.1 \\
\hline \multicolumn{8}{|l|}{ Ringback tone customers } \\
\hline Ringback tone customers & 244.5 & 347.2 & 416.1 & 476.7 & 533.9 & 598 & 19.6 \\
\hline Share of total mobile subscribers $(\%)$ & 30 & 40 & 40 & 40 & 40 & 40 & \\
\hline Subscription & 477.4 & 889.4 & $1,259.80$ & $1,658.90$ & $2,076.90$ & $2,522.80$ & 39.5 \\
\hline Content & 672.6 & $1,122.80$ & $1,569.70$ & $1,998.20$ & $2,356.10$ & $2,693.20$ & 32 \\
\hline Total & $1,150.00$ & $2,012.10$ & $2,829.40$ & $3,657.00$ & $4,433.00$ & $5,216.00$ & 35.3 \\
\hline Monthly ARPU(\$) & 0.5 & 0.6 & 0.6 & 0.7 & 0.7 & 0.8 & 8.9 \\
\hline \multicolumn{8}{|l|}{ Mobile full-track music customers } \\
\hline $\begin{array}{l}\text { Total Mobile full-track music } \\
\text { customers }(M)\end{array}$ & 2.8 & 7.9 & 14.8 & 24.9 & 39.5 & 55.7 & 82 \\
\hline Share of total mobile subscribers $(\%)$ & 0 & 0 & 0 & 0 & 0 & 0 & \\
\hline Total revenue & 44.9 & 156.6 & 391.1 & 776.3 & $1,468.90$ & $2,466.20$ & 122.8 \\
\hline Monthly ARPU(\$) & 1.34 & 1.65 & 2.20 & 2.60 & 3.10 & 3.69 & \\
\hline
\end{tabular}

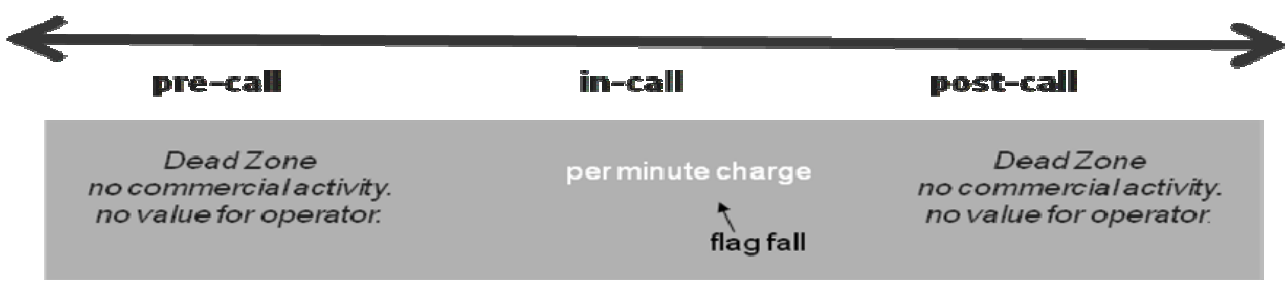

Figure 1. Traditional call model

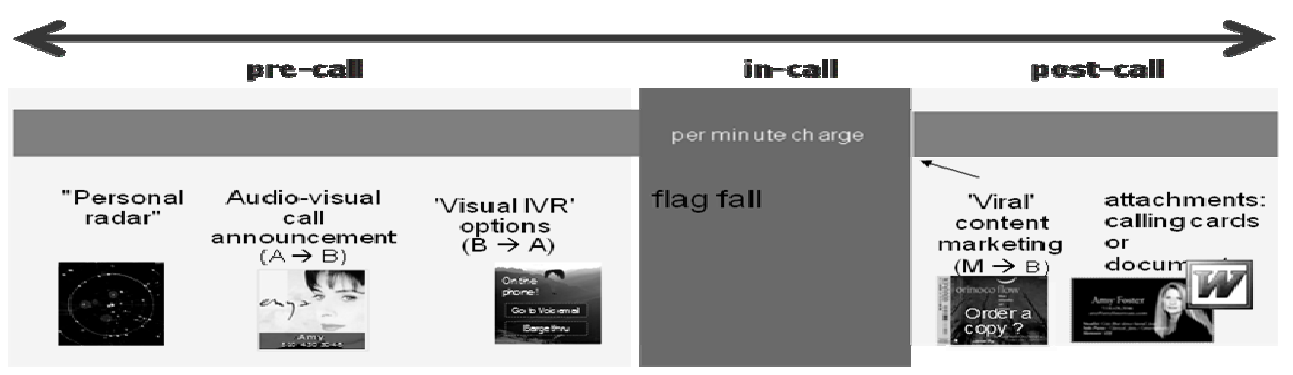

Figure 2. New call model

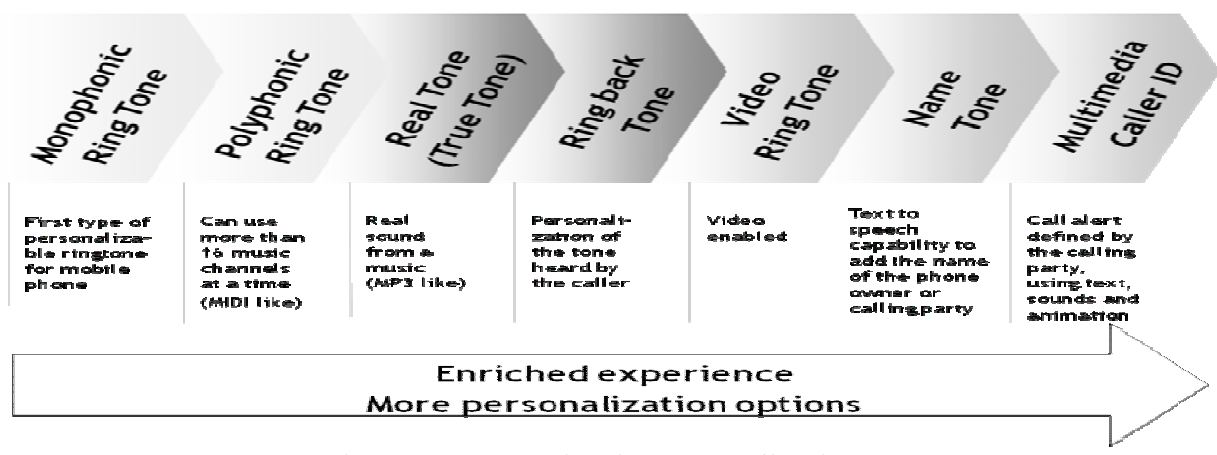

Figure 3. Innovation in personalization 

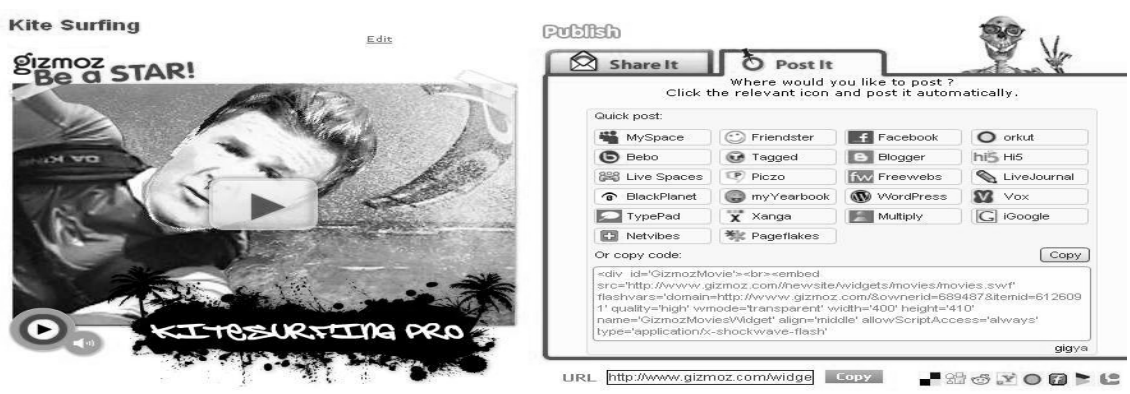

Figure 4. Gizmoz application

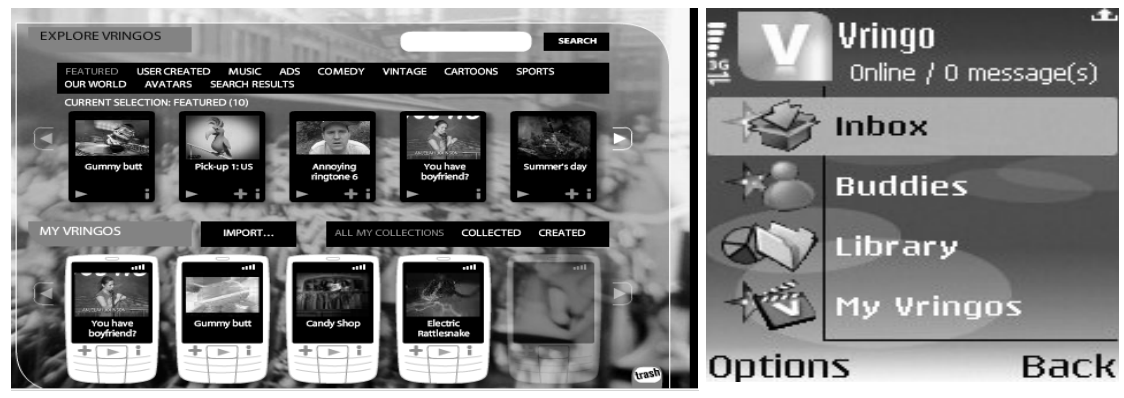

Figure 5. Vringo application

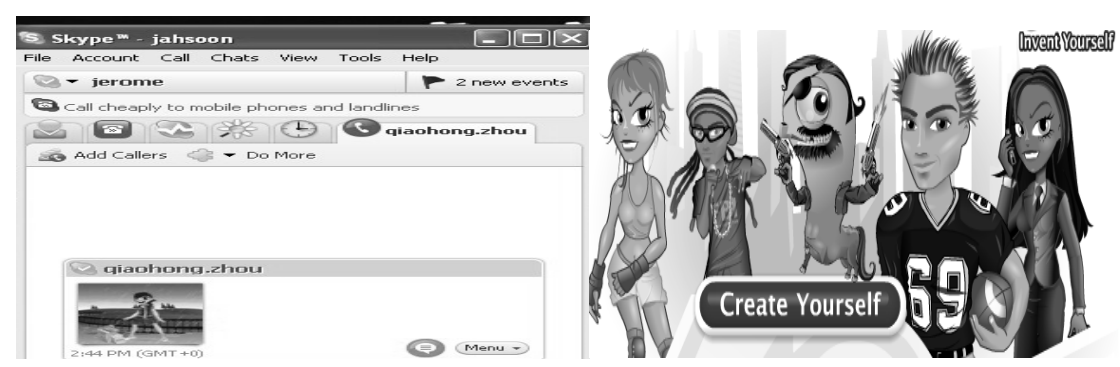

Figure 6. Klonies application

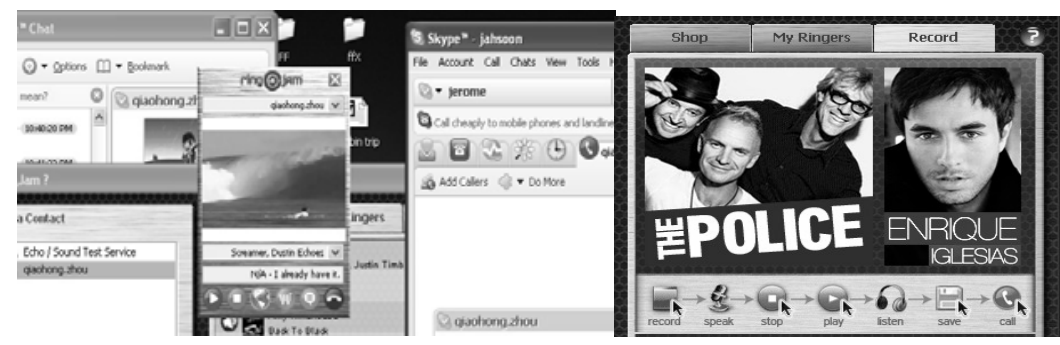

Figure 7. Ringjam application
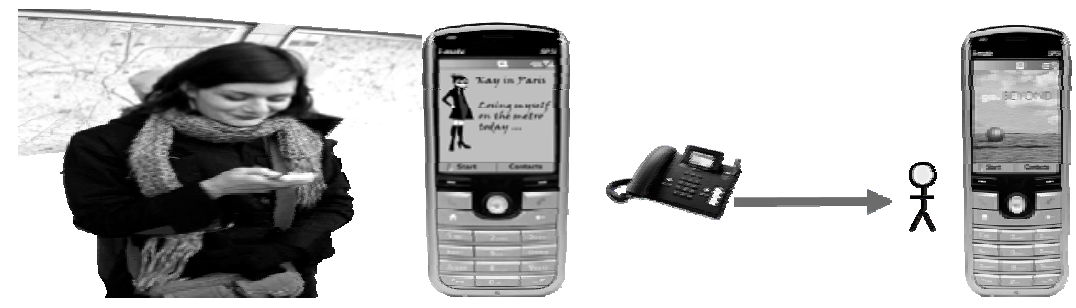

Figure 8. Monikker application 


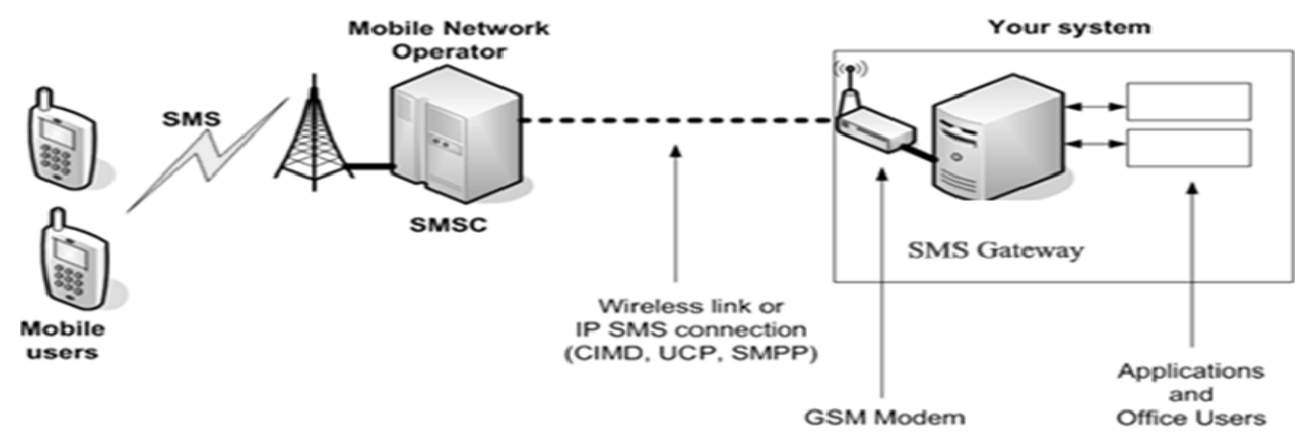

Figure 9. SMS portal

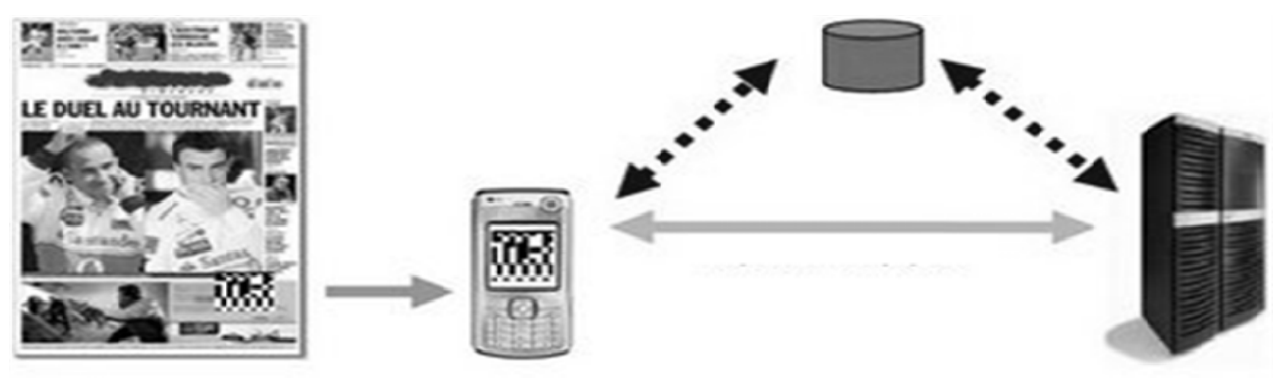

Figure 10. 2D bar code

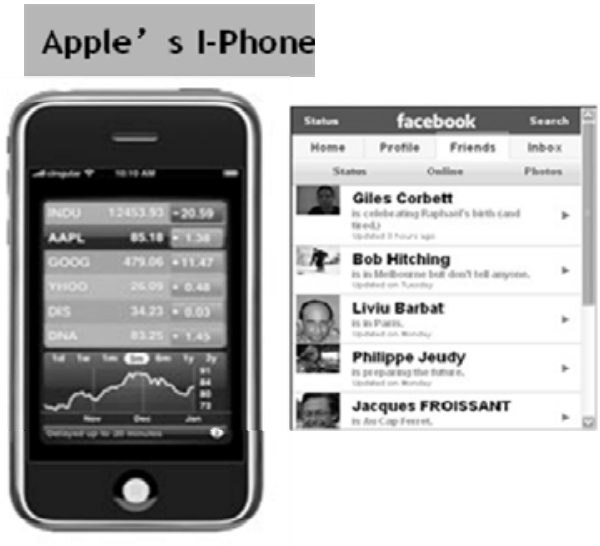

Figure 11. Apple's I-Phone

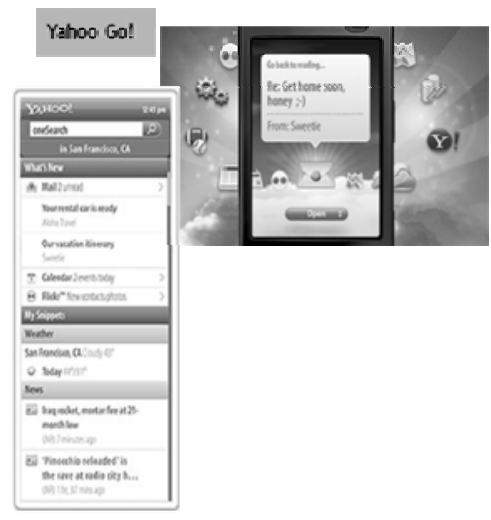

Figure 12. Yahoo Go

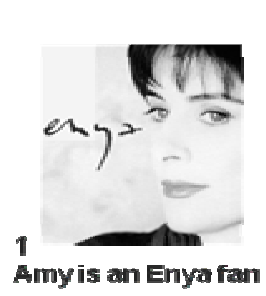
-..

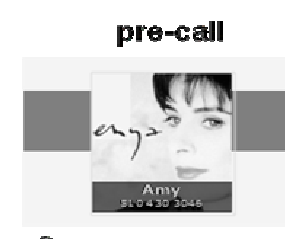

2

mo hercalls are announced with an Enya based monikker (sound and shortmusic clip)

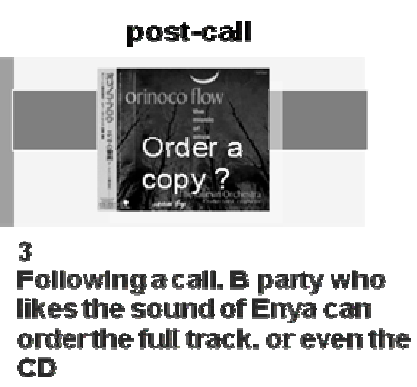

Figure 13. Monikker Network Marketing 

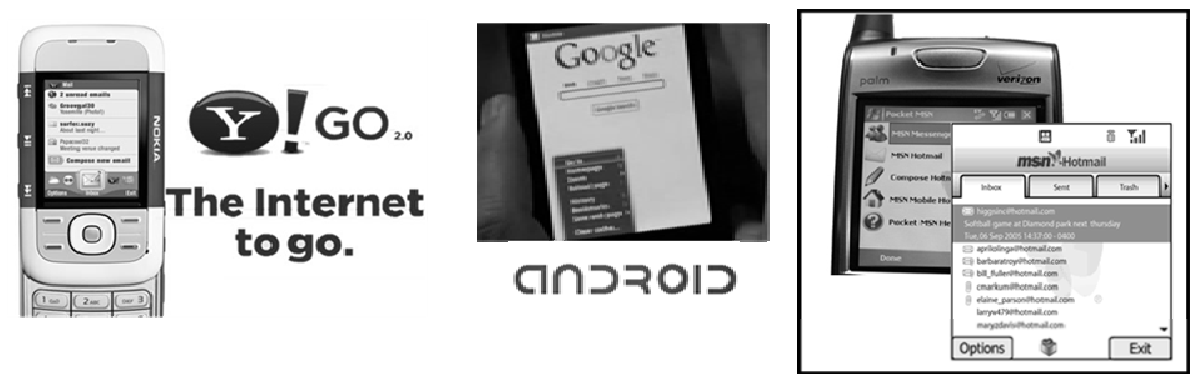

Figure 14 .Yahoo Go advertisement

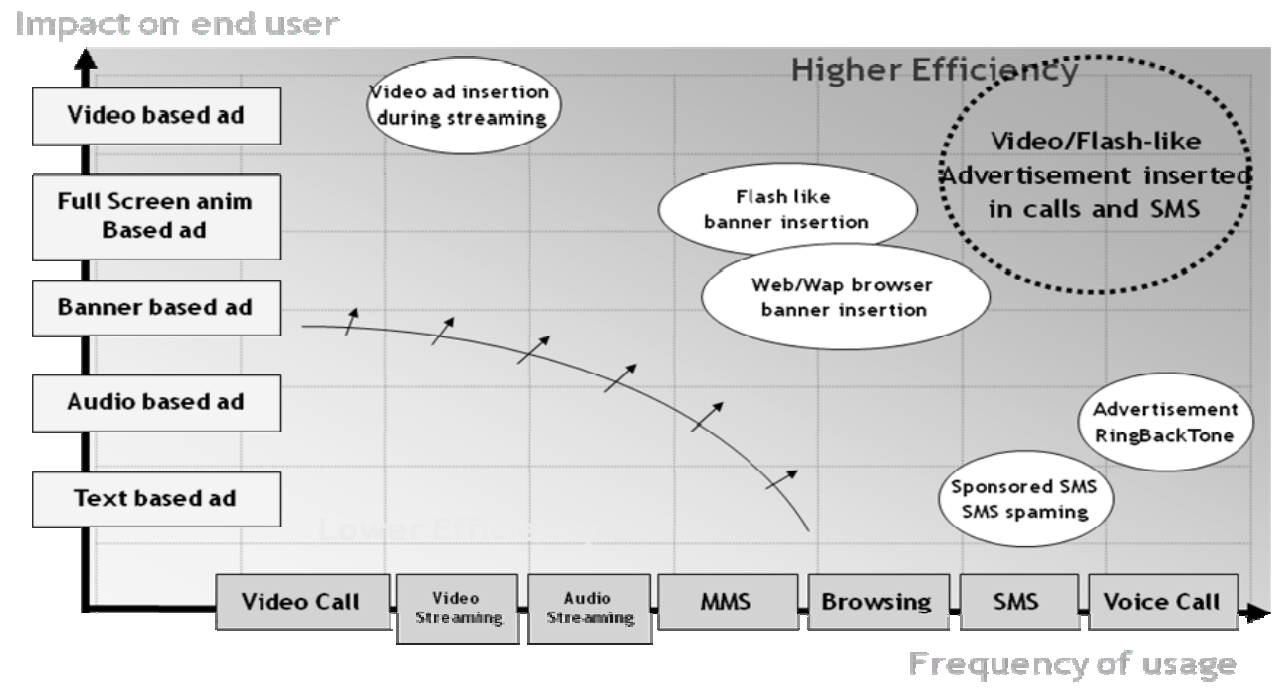

Figure15. Efficiency of the different mobile advertisement options

pre-call

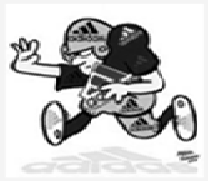

Audio-visual call announcement call

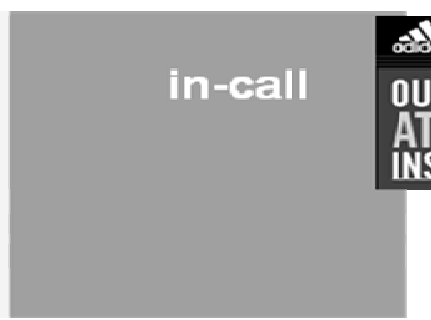

end of call

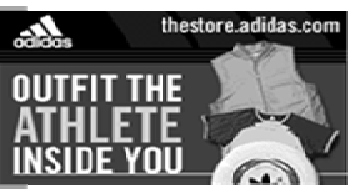

Postcall Advertisement post-call

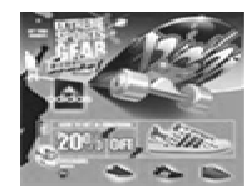

Address Book Update

Figure 16. Call model for advertisement 

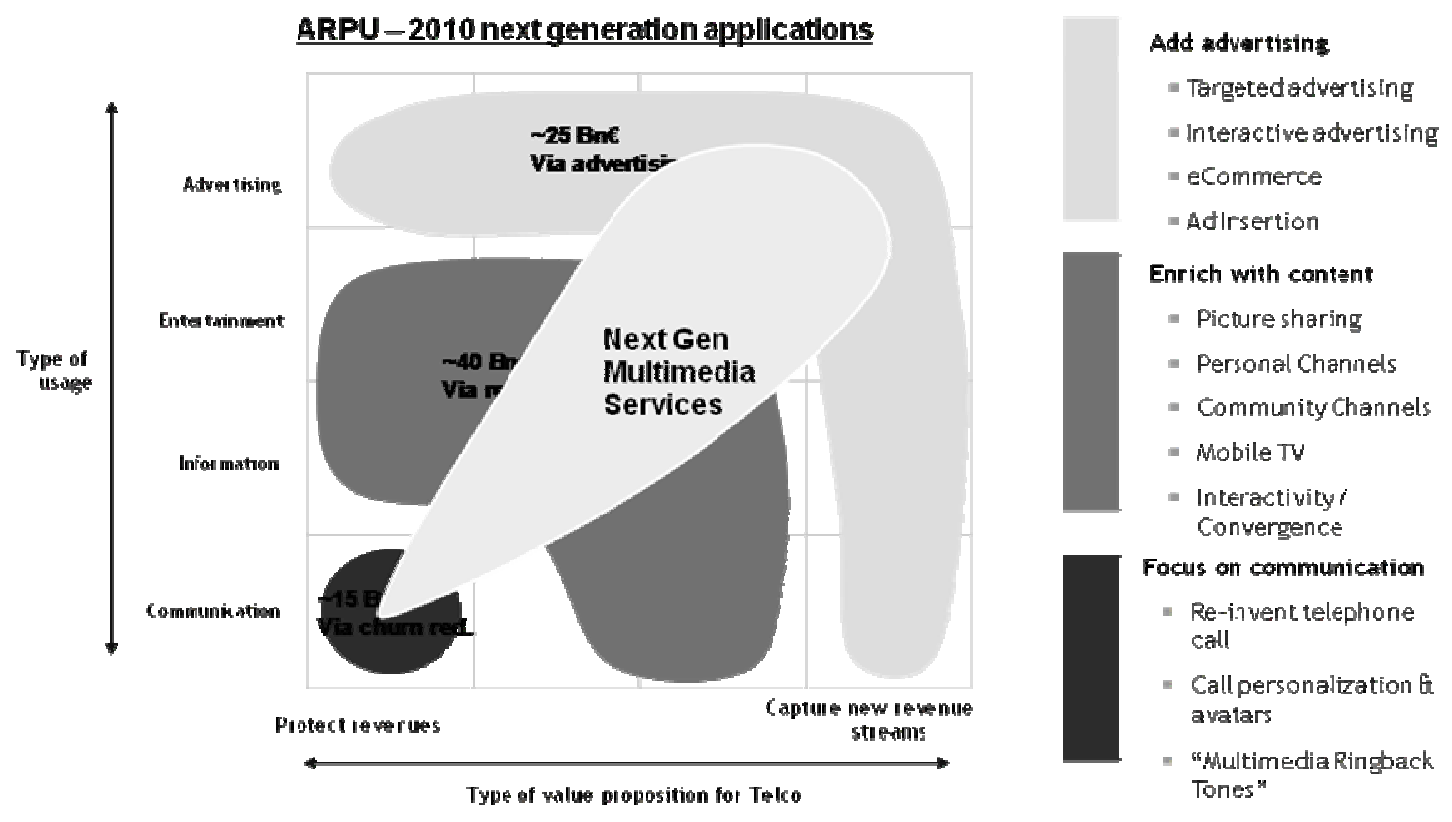

Figure 17. Personalization of Calling Experience - Fits in 1st wave of revenue growth

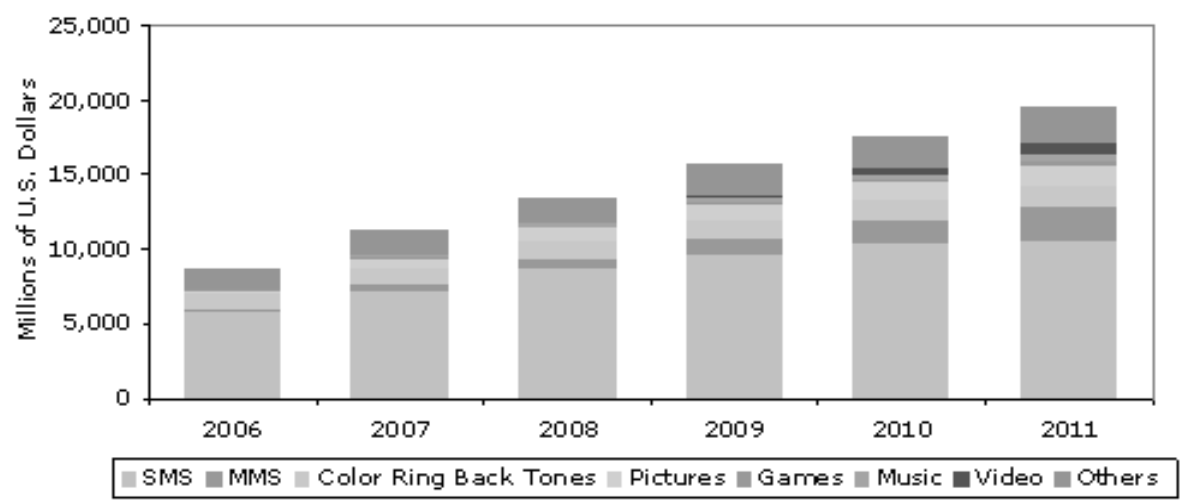

Figure 18. China's $3 \mathrm{G}$ value added service forecast 


\title{
Bayesian Approach for ARMA Process and Its Application
}

\author{
Chongjun Fan \\ Business School, University of Shanghai for Science and Technology \\ Shanghai 200093, China \\ E-mail: cjfan@sh163.net \\ Sha Yao \\ Business School, University of Shanghai for Science and Technology \\ Shanghai 200093, China \\ E-mail: yaosha126@126.com
}

The research is financed by the key research project of Shanghai Municipal Education Commission of China. No. $06 Z Z 34$ (Sponsoring information)

\begin{abstract}
There have been a lot of works relating to time series analysis. In this paper, the Bayesian analysis method for ARMA model is discussed and an application example is given. Firstly, the Bayesian theoretic results about AR model and the determination approach for model order are obtained. Then, the approach are presented for Bayesian analysis of MA and ARMA models. As its application, the forecasting model for Shanghai real estate price index is set up and the digital result shows well performance.
\end{abstract}

Keywords: Bayesian analysis, ARMA, Economic forecsting, Real estate price index

\section{Introduction}

The past few decades have seen the main results of research on Bayesian time series analysis method (Chongjun Fan, 1993). It has a short history. However, since its special significance of the method for fitting economics data, research in this aspect has seen a vigorous development and progress very soon.

The Bayesian approach of ARMA model which is given by Broemeling and Shaarawy (1986) is particularly appropriate. With conditional likelihood function and base on normal-Gamma prior distribution, they educed that both the posterior distribution of model parameters and the one-step-ahead predictive distribution of AR model are t-distribution, and then apply the results to MA and ARMA model. Meanwhile, they have shown arithmetic to determinate the order number of the models under generalized prior.

In this paper, above methods are reorganized, simplified and expanded, particularly the problem of the model order number under normal - gamma prior distribution is discussed.

\section{The results about $A R$ model}

In this section, we consider following p-th auto-regressive (AR) model

$$
Y(t)=\Phi_{1} Y(t-1)+\cdots+\Phi_{p} Y(t-p)+e(t)
$$

Where, we assume that $\mathrm{Y}(t)$ is observation at time $t$, and $\mathrm{e}(\mathrm{t}), \mathrm{t}=0, \pm 1, \cdots$ are i.i.d. $\mathrm{N}\left(0, \tau^{-1}\right)$. Let

$$
\Phi=\left(\Phi_{1}, \cdots, \Phi_{p}\right)^{\prime}
$$

Then $\Phi$ and $\tau$ are unknown parameter of the modeling.

If we suppose on $n$ observation are available, denote $\mathrm{Y}(1) \ldots \mathrm{Y}(\mathrm{n})$, and let

$$
\mathrm{S}_{\mathrm{i}}=(\mathrm{Y}(1), \cdots, \mathrm{Y}(\mathrm{i}))^{\prime} \quad \mathrm{S}_{(\mathrm{n}-\mathrm{i})}=(\mathrm{Y}(\mathrm{i}+1), \cdots, \mathrm{Y}(\mathrm{n}))^{\prime}
$$


Then the condition density of $S_{(n-p)}$ when $S_{p}$ is given is as follows:

$$
\begin{aligned}
f\left(S_{(n-p)} / S_{p} ; \Phi, \tau\right) \propto \tau^{\frac{n-p}{2}} \exp \left\{-\frac{\tau}{2} \sum_{i=p+1}^{n}(Y(t)\right. & \left.-\sum_{i=1}^{p} \Phi_{i} Y(t-i)^{2}\right\} \\
& \propto \tau^{\frac{n-p}{2}} \exp \left\{-\frac{\tau}{2}\left(S_{(n-p)}-X \Phi\right)^{\prime}\left(S_{(n-p)}-X \Phi\right)\right\}
\end{aligned}
$$

where

$$
X=\left[\begin{array}{ccc}
Y(p)^{\prime} & \cdots & Y(1)^{\prime} \\
\vdots & & \vdots \\
Y(n-1)^{\prime} & \cdots & Y(n-p)^{\prime}
\end{array}\right]
$$

We can use this condition likelihood function instead of the exact likelihood function when $n$ is large relative to $p$ (Priestley M B., 1981). In this section, the discussions are based on function (2.2).

In the model, we consider the group of conjugated prior distribution: normal-Gamma distribution. It can be proved that the Bayesian analysis method for AR model equates to the following Bayesian multivariate regressive analysis:

$$
S_{(n-p)}=X \Phi+E \quad E \sim N\left(0, \tau^{-1} I\right)
$$

with the prior density:

$$
\left\{\begin{array}{c}
\phi / \tau(\text { condition prior density of } \phi \text { given } \tau) \sim N_{m, r}\left(\mu,(\tau \Delta)^{-1}\right) \\
\tau(\text { marginal prior density of } \tau) \sim \Gamma\left(\alpha-\frac{p}{2}, \beta\right)
\end{array}\right.
$$

The following result can be obtained easily by the results of Bayesian multivariate regressive model:

Theorem 1. Combining (2.2) with (2.4), It can be obtained the marginal posterior densities of $\Phi$, $\tau$, and one-step-ahead predictive $\mathrm{Y}(\mathrm{n}+1)$ are multivariate t-distribution, Gamma distribution and univariate t-distribution respectively, namely

$$
\begin{gathered}
\Phi \sim t_{p}(\hat{\Phi}, Q, n+2 \alpha-2 p) \\
\tau \sim \Gamma\left(\frac{n}{2}-p+\alpha, \beta+\frac{1}{2} S S_{e}\right) \\
\mathrm{Y}_{(\mathrm{n}+1)} \sim t\left(\hat{Y}_{(n+1)}, D, n-2 p+2 \alpha\right)
\end{gathered}
$$

Where,

$$
\begin{aligned}
& \qquad \widehat{\Phi}=\left(X^{\prime} X+\Delta\right)^{-1}\left(X^{\prime} S_{(n-p)}+\Delta \mu\right) \\
& S S e=S_{(n-p)}^{\prime} S_{(n-p)}+\mu^{\prime} \Delta \mu+\left(X^{\prime} S_{(n-p)}+\Delta \mu\right)^{\prime} \\
& \left(X^{\prime} X+\Delta\right)^{-1}\left(X^{\prime} S_{(n-p)}+\Delta \mu\right) \\
& Q=\left(\alpha+\frac{n}{2}-p\right)^{-1}\left(\beta+\frac{1}{2} S S e\right)\left(X^{\prime} X+\Delta\right)^{-1} \\
& \mathrm{~L}=\left(\mathrm{Y}_{(\mathrm{n})}, \cdots, \mathrm{Y}_{(\mathrm{n}-\mathrm{p}+1)}\right)^{\prime} \\
& \hat{Y}_{(n+1)}=L^{\prime} \hat{\Phi} \quad D=\left[1+L^{\prime}\left(X^{\prime} X+\Delta\right)^{-1} L\right](n-2 p+2 \alpha)^{-1}\left(2 \beta+S S_{e}\right)
\end{aligned}
$$


The following four corollaries can be obtained easily from theorem 1 , that is

Corollary 1. With the square loss, Bayes estimation of $\Phi$ is the weighted average of least square estimator

$$
\widehat{\Phi}_{L S}=\left(X^{\prime} X\right)^{-1} X^{\prime} S_{(n-p)}
$$

and prior mean $u$, that is

$$
\widehat{\Phi}=\left(X^{\prime} X+\Delta\right)^{-1} X^{\prime} X \widehat{\Phi}_{L S}+\left(X^{\prime} X+\Delta\right)^{-1} \Delta \mu
$$

Proof: It can be proved from equations (2.5) and (2.8)

Corollary 2. With the square loss, the Bayes estimation of random error variance, $\tau^{-1}$ is

$$
\tau^{-1}=\left(\frac{n}{2}-p+\alpha-1\right)^{-1}\left(\beta+\frac{1}{2} S S_{e}\right)
$$

Proof: It follows from (2.6) that the marginal posterior densities of $\tau^{-1}$ is athwart Gamma distribution, then we can obtain (2.10) from the results about the expected value of athwart- Gamma distribution (See page 395 of Berger J. O., 1980).

Corollary 3. One-step-ahead predictive $\mathrm{Y}(\mathrm{n}+1)$ can be divided to two parts as:

$$
V=\tau^{-1}+L^{\prime}\left(X^{\prime} X+\Delta\right)^{-1} L \hat{\tau}^{-1}
$$

where $L^{\prime}\left(X^{\prime} X+\Delta\right)^{-1} L \hat{\tau}^{-1}$ is posterior variance of $L^{\prime} \Phi$.

Proof: Combining (2.7) and the results about variance of $t$ distribution (See page 394 of Berger J. O., 1980), we can obtain the equation

$$
V=(n-2 p+2 \alpha)[(n-2 p+2 \alpha)-2]^{-1} D
$$

Then we obtain this Corollary from (2.9) and (2.10).

Corollary 4. When suppose $\Delta=0, \alpha=0, \beta=0$, the equations (2.5), (2.6) and (2.7) are the same with the results of generalize prior density $\pi(\Phi, \tau) \propto \tau^{-1}$ in Jeffreys no-information condition.

Equation (2.7) gives the distribution of one-step-ahead $Y_{(n+1)}$. It can be proved distribution of $Y_{(n+2)}$ is also univariate t-distribution when one-step-ahead $Y_{(n+1)}$ is given. But for the joint predictive distribution of $Y_{(n+1)}, \ldots, Y_{(n+k)}$ and sole multi-step-ahead distribution $Y_{(n+k)}$, we need make use of digital algorithm. We will not make further discussion in the paper.

\section{The determination of model order number}

Inference on the order number of the model, we need use the following results:

Theorem 2. It follows with the result of Theorem 1, that

$$
\mathrm{Q}_{p}^{-\frac{1}{2}}\left(\Phi_{p}-\hat{\Phi}_{p}\right) \sim t(0,1, n+2 \alpha-2 p)
$$

where

$$
\hat{\Phi}=\left[\begin{array}{c}
\hat{\Phi}_{1} \\
\vdots \\
\hat{\Phi}_{p}
\end{array}\right] \quad Q=\left[\begin{array}{ccc}
Q_{1} & \cdots & * \\
\vdots & \ddots & \vdots \\
* & \cdots & Q_{p}
\end{array}\right]
$$

(2) Piecemeal make the matrix above

$$
\Phi=\left[\begin{array}{l}
\Phi_{(1)} \\
\Phi_{(2)}
\end{array}\right] \quad \hat{\Phi}=\left[\begin{array}{l}
\hat{\Phi}_{(1)} \\
\hat{\Phi}_{(2)}
\end{array}\right] \quad Q=\left[\begin{array}{ll}
Q_{11} & Q_{12} \\
Q_{21} & Q_{22}
\end{array}\right]
$$


Where, $\Phi_{(1)}, \hat{\Phi}_{(1)}$ are $p_{1} \times 1$ order matrix, $Q_{11}$ is $p_{1} \times p_{1}$ order matrix respectively, and $p_{1}+p_{2}=p$. Then the posterior distribution of $\Phi_{(1)}$ when $\Phi_{(2)}=0$ is given is as follows:

$$
\begin{aligned}
& \Phi_{(1)} / \Phi_{(2)}=0 \sim t_{p_{1}}\left(\hat{\Phi}_{(1)}-Q_{12} Q_{22}^{-1} \hat{\Phi}_{(2)},\right. \\
& \left(n+2 \alpha-2 p+p_{2}\right)^{-1}\left(n+2 \alpha-2 p+\hat{\Phi}_{(2)}{ }^{\prime} Q_{22}^{-1} \hat{\Phi}_{(2)}\right) \\
& \left.\left(Q_{11}-Q_{12} Q_{22}^{-1} Q_{21}\right), n+2 \alpha-2 p+p_{2}\right)
\end{aligned}
$$

Proof: It can be obtained from the property of multivariate t-distribution and (2.5).

If the model order number is $p_{1}$, not $p$, the prior distribution (2.4) can be adjusted to express when $\Phi_{2}=0$ is given as follows:

$$
\left\{\begin{array}{c}
\Phi_{(1)} / \tau \sim N\left(\mu_{(1)}-\Delta_{11}^{-1} \Delta_{12} \mu_{(2)},\left(\tau \Delta_{11}\right)^{-1}\right) \\
\tau \sim \Gamma\left(\alpha-\frac{p_{1}}{2}, \beta+\frac{1}{2} \mu_{(2)}^{\prime}\left(\Delta_{22}-\Delta_{21} \Delta_{11}^{-1} \Delta_{12}\right) \mu_{(2)}\right)
\end{array}\right.
$$

where

$$
u=\left[\begin{array}{l}
u_{(1)} \\
u_{(2)}
\end{array}\right] \quad \Delta=\left[\begin{array}{ll}
\Delta_{11} & \Delta_{12} \\
\Delta_{21} & \Delta_{22}
\end{array}\right]
$$

and where $u_{(1)}$ is $p_{1} \times 1, \Delta_{11}$ is $p_{1} \times p_{1}$.

Discussion about the order number determination of model AR is as follows.

It can be shown that there are two kinds of recursion algorithms from Theorem 1about the posterior distribution of coefficient parameter, which is

$<1>$ We Suppose that the real order number of the model is not bigger than an integer N. since the posterior distribution of $\Phi$ when $p=N$ is given, then we can test by using (3.1). Suppose $H_{0}: \Phi_{p}=0$, and opposing $H_{1}: \Phi_{p} \neq 0$, if accept $H_{0}$, it means that the value of $\mathrm{p}$ can be descended, so make $p=N-1$, and then adjust the prior distribution by (3.3). It can be calculated recursively until the value of $\mathrm{p}$ can not be descended.

$<2>$ When $\Phi_{p}=0$ is accepted, we can use (3.2) to take the next test directly, then also by this way we can determine the order number finally.

It can be shown the relation between two kinds of recursion algorithms by the following Theorem 3 .

it is similar with the FPE rule of traditional method. By using the Corollary 3 to set up a step of predictive error criterion to determinate order number:

Suppose that $\mathrm{N}$ is bigger than or equal to the model real order number. Equation (2.11) shows that we can calculate the value of $V$ when $p=1, \ldots, N$, and we also can adjust to the prior distribution using by (3.3). If the value of $V$ is the smallest at $p=\hat{p}$, then we can make $\hat{p}$ as the estimator of $p$.

Theorem 3. If the order number of AR model is $p_{1}$, let $Y_{\left(p_{2}+1\right)}, \ldots, Y_{(n)}$ denote available observations, with the prior distribution (3.3), then the posterior distribution of $\Phi_{(1)}$ is (3.2).

\section{The analysis method of MA model}

Generally $q$-th moving average (MA) model can be represented as

$$
Y(t)=e(t)-\theta_{1} e(t-1)-\cdots-\theta_{q} e(t-q)
$$


where we also assume that $e(t), t=0, \pm 1, \ldots$, are $i . i . d . N\left(0, \tau^{-1}\right)$ correspondingly with likelihood function

$$
L\left(\theta, \tau / S_{n}\right) \propto \tau^{\frac{n}{2}} \exp \left\{-\frac{\tau}{2} \sum_{i=1}^{n}\left[Y(t)+\sum_{j=1}^{q} \theta_{j} e(t-j)\right]^{2}\right\}
$$

If $e(t)$ is given, then equations (4.2) and (2.2) are the same in the form. Then we known all equitation above is also suitable in the model. Replaced $\theta=\left(\theta_{1}, \ldots \theta_{q}\right)$ by $\Phi, n$ by $n-p, S_{n}$ by $S_{n-p}$, Correspondingly we can recast the model. For example we can obtain

$$
X=\left[\begin{array}{cccc}
e(0) & e(-1) & \cdots & e(-q+1) \\
e(n-1) & e(n-2) & \cdots & e(n-q)
\end{array}\right]
$$

and so on.

Therefore, the key of analysis method of MA model is how to assess the value of $\{e(t)\}$. In Shaarawy and Broemeling (1984), the Box-Jenkins analysis method particularly appropriated. Estimation $\hat{\theta}_{*}=\left(\hat{\theta}_{*_{1}}, \ldots, \theta_{* q}\right)^{\prime}$ of $\theta$ can be calculated firstly, then we can get the estimation by using the following formulas.

$$
\left\{\begin{array}{cc}
\hat{e}(t)=Y(t)+\sum_{j=0}^{q} \hat{\theta}_{*_{j}} \hat{e}(t-j) & t=1,2, \ldots, n \\
\hat{e}(t)=0 & t=0,-1, \ldots,-q+1
\end{array}\right.
$$

Then in the context of the Bayesian analysis approach above we can deduced the posterior distributions of $\Phi \theta$ and $\tau$ Obviously, the analysis approach of MA model combined traditional methods with Bayesian approach and the results are approximately. A common approach assessment for $e(t)$ shown by when we see estimation as observations, There is, however, on how to get the estimation of $e(t)$ only by Bayesian analysis approach is relatively little research and unsolved.

\section{The analysis method of ARMA model}

The analysis method of ARMA model ARMA similar with the analysis method of MA model.ARMA model can be recast into the following

$$
Y(t)=\Phi_{1} Y(t-1)+\cdots+\Phi_{p} Y(t-p)+e(t) \sqrt{2}-\theta_{1} e(t-1)-\cdots-\theta_{q} e(t-q)
$$

Now firstly we also consider about the likelihood function of $S_{p}$

$$
L\left(\Phi, \theta, \tau / S_{n}\right) \propto \tau^{\frac{n-p}{2}} \exp \left\{-\frac{\tau}{2} \sum_{i=p+1}^{n}\left[Y(t)-\sum_{i=1}^{p} \Phi_{i} Y(t-i)+\sum_{j=1}^{q} \theta_{j} e(t-j)\right]^{2}\right\}
$$

The difficulties are also how to get $\{e(t)\}$. Firstly we can get $\hat{\Phi}_{*}$ and $\hat{\theta}_{*}$ by Box-Jenkins analysis approach, then from following equation we can estimate $\hat{e}(t)$ :

$$
\left\{\begin{array}{cc}
\hat{e}(t)=Y(t)-\sum_{i=1}^{p} \hat{\Phi}_{*_{i}} Y(t-i)+\sum_{j=0}^{q} \hat{\theta}_{*_{j}} \hat{e}(t-j) & t=p+1, \ldots, n \\
\hat{e}(t)=0 & t=-q+p+1,-q+p+2, \ldots, p
\end{array}\right.
$$

Therefore, It can be obtained the value by equation (5.1). Base on above equation (5.1), we can obtain the posterior 
distributions of $\Phi \theta$ and $\tau$.

Similarly Box-Jenkins analysis method helps to get the estimation of $e(t)$. And we can draw the conclusion from the discussion above that it is the point to make well the model of MA.

\section{An application}

As we known, economical system is a complex system and in change frequently (Chongjun Fan, 2008). There is always not enough history data for setting up the forecast model. Therefore, how to make use of Bayesian approach to improve the forecast precision by the relevant data and information is a meaningful topic. Here we discuss the application of Bayes analysis approach to the following case.

The general analysis on real estate by using price index has been carried out for many years in China. The price index is composed by the data from the market research. These data which keep track of the quotations on the market all the times are come from different estates and become a dynamic graph used to observe the quotation on the market. The quantitative research and the precise description and forecast on the orbit track of price index play a major role in real estate research. This paper constructs the forecast modeling on Shanghai Composite Index of Chinese Restate from January in 2005 to May in 2008. The data are deseasonized and normalized first.

First, we get the prior distribution by using Beijing Composite Index of Chinese Restate from October in 2005 to March in 2008, then set Shanghai model up.

The calculations: the order number of the model is $\mathrm{p}=3$, and we can see Shanghai composite index of Chinese restate by Table 1 as below. It is can be seen from table 1 that error rate for one step forecasting of April, May and June in the year 2008 respectively is $-0.49 \%,-0.34 \%, 0.09 \%$. Better precision and well performance can be drawn form results. (Insert Table 1 here)

\section{Conclusions}

This paper mainly at studying the Bayesian approach for ARMA models and illustrating the methods for forecasting Shanghai composite index of Chinese restate as an application. Since our insufficient economy data, it takes us difficulties to forecast just by setting up a model, however, in the view of an introduction of a new solution thought which we can use the prior distributed, it has common significance. The application results do show that the methods we proposed are effective.

\section{Acknowledgements}

This research was supported by the key research project of Shanghai Municipal Education Commission of China (No. 06ZZ34). Expresses the thanks.

\section{References}

Broemeling, L. \& Land M. (1984). On forecasting with univariate autoregressive processes. Communications in Statistics, 13.

Broemeling, L. \& Shaarawy. (1986). A Bayesian analysis of time series. Bayesian Inference and Decision Techniques, Goel, P., Zellner, A. eds..

Berger J. O. (1980). Statistical Decision Theory. Springer- Verlag, New York.

Fan, Chongjun. (1993). The Bayesian methods in Time series analysis. Journal of Xi'an statistical college, 1.

Fan, Chongjun \& Hui Xu. (2008). The Review on Non-linear Analysis and Forecasting Methods of the Real Estate Market in China, Asian Social Science, 11.

$\mathrm{Hu}$, Zhang-ming. (2007). Research on forecasting real estate price index based on neural networks, Academic Journal of Zhongshan university, 27 (2): 100-115.

Priestley M B. (1981). Spectral analysis and time series, Academic Press, London.

Shaarawy S. \& Broemeling, L. (1984). Bayesian inferences and forecasts with moving average processes. Communications in Statistics, 13.

Shaarawy S. \& Broemeling, L. (1985). Inferences and prodiction with ARMA processes. Communications in Statistics, 14.

Huiming Zhu, Yuqin Han \& Jincheng Zheng. (2005). The Bayesian forecasting for AR (p) model based on normal - Gamma with conjugation prior distribution, Statistics \& decision, 2. 
Table 1. Predicted result of Shanghai composite index of Chinese restate

\begin{tabular}{|c|c|c|c|}
\hline Year/Month & $\begin{array}{c}\text { Shanghai } \\
\text { composite index } \\
\text { of Chinese restate }\end{array}$ & $\begin{array}{c}\text { One step } \\
\text { forecasting }\end{array}$ & $\begin{array}{c}\text { Error rate for one } \\
\text { step forecasting }\end{array}$ \\
\hline $08 / 04$ & 2008 & 1998 & $-0.49 \%$ \\
\hline $08 / 05$ & 2034 & 2027 & $-0.34 \%$ \\
\hline $08 / 06$ & 2068 & 2070 & $0.09 \%$ \\
\hline
\end{tabular}




\title{
A Strategic Competitive Advantage Perspective on Management Development
}

\author{
Law Kian Aun \\ School of Graduate Studies, UCSI \\ E-mail:kalaw@ucsi.edu.my
}

\begin{abstract}
This paper attempts to evaluate relevant literature related to management development, competitive advantage as well as the links between management development and competitive advantage. This will be done through assessing the emerging role of management development in organizations, the dynamics of competitive advantage and conceptual model on linkage between management development and competitive advantage. The focus is on the link between management development and competitive advantage by comparing and contrasting two representative models through cross referencing and to suggest a conceptual model that fundamentally integrates both models. The findings of this review indicate that there are several aspects of the management development and competitive advantage models which are mutually inclusive especially in the areas of corporate vision and strategy, learning and knowledge as well as skills. Other integrated areas which were observed, are decision making, behavioural and cognition development. The proposed conceptual model suggests a methodological guideline and recommendation for implementation and practice of management development.
\end{abstract}

Keywords: Competitive advantage, Management development, Cross-referencing

\section{Introduction}

Management development (MD) and competitive advantage (CA) are fields that have been researched by personnel in academia and in industry. Despite the considerable research in both fields, there has been surprisingly, little done to show the links between the two fields. Luoma (2000) argued that the relationship has received amazingly scant attention whilst McClelland (1994) asserted that many organizations do not consider management development to be linked to their corporate competitiveness. Recent changes in the global competitive environment, for example, the formation of Asia Pacific Economic Cooperation (APEC) in 1989 and ASEAN Free Trade Area (AFTA) in 1992 has forced corporations, from small to big scale across industry types, to rethink their competitive strategies. As a result, organizations needed to build their competitive edge through MD activities in order to retain talented, experienced and adaptable managerial personnel. This is because capable management is perceived as one of the organizational resources to build corporate competitiveness. MD assumed an important role in realigning the organizations internal resources and functions for organizational success (Atkinson \& Meagher, 1986; Schuler, 1989). Millett and Leppanen (1991) further argued that MD's basic function is to help organizations to ensure that competent and knowledgeable managers are able to implement successfully the corporate strategies in facing anticipated business challenges.

Likewise, McClelland (1994) suggested that MD needs to be realigned with competitive strategy in order to ensure the availability of skills for effective strategic implementation.

It is meaningful to attempt to discover how MD is associated with the strategic competitiveness of organizations. In this context, Hussey (1985) agreed that MD should be integrated with organizational strategies and objectives. Berry (1990) further linked MD to business strategies by suggesting that skilful and capable managers assist in better decision making and strategy implementation. Moreover, Mann (1990) pointed out that MD enhances organizational competitive advantage by defending and progressing an organization's market position in the competitive market place. However, very little has been discussed about the practical methodological links between MD and CA (McClelland, 1994). Identification of this literature gap drives the purpose and aim of this study.

The main objective of this study is to establish if MD and CA could be linked in a conceptual framework and translated into a practical methodology to serve as a pedagogical guideline to improve organizational performance. In attempting to address the answer, this paper will conduct an assessment and evaluation of MD and CA and their possible linkages using a proposed conceptual framework by comparing the existing MD and CA models.

The findings of this study ought to shed light on organizations that practice MD, to recommend ways to broaden and improve organizational horizons and avoid misconceptions about practicing MD. The framework constructed in this 
paper serves as practical means to understand the potential of MD in relation to CA.

\section{Literature Review}

In evaluating the emerging role of MD in organizations, it is appropriate to define the concept of MD before proceeding to examine its emerging role in organizations. Lees (1992) conceptualised MD as the intersection of three variables, namely, the individual career, organizational succession and organizational performance. He reaffirms that the intersection of these three variables represents an entire system of corporate activities with the espoused goal of improving performance in the context of consistent environmental and organizational changes. Hence, MD is seen as a whole complex process by which individuals in the organizations learn, grow and improve their abilities to perform tasks related to management in organizational development activities. For example, performance appraisal, job rotation, career planning, and participation in teamwork are some organizational development activities.

Dikken and Hoeksema (2001) defined five major aspects of MD. They are (1) opportunity of learning at job; (2) controlling and managing learning process of managers; (3) learning on the job for career success; (4) conscious use of developmental instruments to influence managers' behaviour; (5) recommendation for managers and organizations to improve organizational performance and bottom-line results.

Likewise, Storey (1989a, 1989b) argued that MD represents an organizational process that enhances the capability of managers while leaving scope for creativity and interdependency. Jansen, van der Velve and Mul (2001) classified MD into four types which are (1) administrative MD which emphasizes lifetime employment for managers, including promotional opportunity based on the length of service and age; (2) dependent MD, which is dependent on organizational chosen strategy; (3) leading MD which concentrates on prior adequate selection than on latter training and development; and (4) partnership MD, which stresses filling key positions within an organization. These four types of MD suggest the importance of context in trying to understand the different definitions of MD. Thus, MD is perceived as the system of manpower practices by which an organization tries to place the right candidates at the right place at the right time.

Similarly, Taylor and Gordon (1984) claimed that MD is a part of a well coordinated organizational developmental programme which should be interlinked with corporate policies and strategies. They emphasized that it is imperative to develop managers for strategic thinking in the wake of organizational development and this is in line with current developments in the field of management development studies.

Similarly, Torrington and Hall (1998) suggested that MD is a system that focuses on developing the future roles of managers rather than what they are currently doing. Different definitions are used to describe MD. McClelland (1994) defined MD as one of the key organizational processes aimed at delivering successful organizational adaptation and renewal while Hitt (1987) refered to MD as a unified process that is coherent and integrates the organization's philosophy, mission, vision, business goals and human resource strategy across all functions and hierarchies.

Mumford (1993) set forth a more comprehensive definition of MD. He contends that MD can be categorised into three approaches, namely, the informal accidental process which should include the activities of informal and unconscious learning; the integrated managerial opportunistic process that encompass planned learning experiences and the formalised development planned process that focuses on structured learning activities. These approaches could be seen as a holistic ever-changing perspective of organization.

In understanding the stages of MD in an organization, Burgoyne (1988) identified six levels of maturity of MD progression within an organization. Level one represents no systematic practice of MD, level two shows an isolated and tactical style of MD, level three conclude with integrated and coordinated structured MD, level four sees MD strategy input to corporate policy, whereas level five conceives MD strategy input to the formation of corporate policy and eventually level six captures the strategic development of the management of the organization. These six levels of maturity of MD include both the structural and conceptual dimensions that are closely intertwined within an organizational design that provides an MD process.

Furthermore, Doyle (1994) suggested a system approach of studying of MD through an integral part of a wider organizational system that is linked to the context and reality of managerial work. He noted that MD is an open system that consists of the interplay of interrelated elements that directed towards common goals. Likewise, Morgan (1986) revealed that a system approach of MD exhibits the synthesising, integrative and relational qualities of an organization with its internal and external environment. It also fosters the awareness and pattern of causal relationship among the elements and their complex interactions. Such a perspective implies that MD as an open system is both a system and process that interacts with other organizational and environmental subsystems and activities.

In understanding MD from the investment rationale perspective, Lees (1992) suggested that there are ten rationales for investing in MD. According to him, MD is driven by these rationales that aim to improve managerial functioning and the overall corporate performance. The rationales are (1) functional performance, which aims to directly improve managerial functioning and corporate performance; (2) agricultural development, which focuses on the perceived needs 
of organizations to cultivate and develop managers internally; (3) functional defensive, where MD is perceived as an element of the core organizational strategic and management control process; (4) socialization, where MD is seen as a socialization of managers to share a common corporate value system; (5) political reinforcement, where MD acts as a political tool to reinforce the belief of controlling managers; (6) organizational inheritance, where MD is perceived as a crucial factor in corporate succession planning and career development; (7) environmental legitimacy, which advocates the rationale of internalizing the organizational legitimacy by conforming to environmental reality and its constituencies; (8) compensation, which advocates that MD should offer compensation at work to prevent employee alienation; (9) psychic defence, where MD serves as a social system against work anxiety; and (10) ceremonial, where MD is viewed as a ceremony designed to legitimise the social progression of managers. Quinn (1988) shared a similar view and further suggests that MD rationales represent a system of competing values in the organizations, both meant for the purpose of MD itself and the overall organizational objectives.

In other words, the differences in the definition of MD tend to occur between various researchers as a result of their different approaches towards the study of MD. For instance, the traditional definition tends to focus on the deliberate aspects of MD, which emphasizes the structured, planned and formal side of MD whereas the contemporary perspectives see MD as generic, which constitutes both formal and informal aspects of MD. In the systems approach of MD, emphasis is placed on seeing MD as neither fragmented nor piecemeal, but an integrated approach towards organizational competitiveness.

It follows therefore that the understanding of the need and emerging role for MD practices in the corporate sector is crucial especially under growing and intensified globalized competition. The Asia Pacific region, especially South East Asia, has been forecasted to achieve high rates of economic growth for the next decade (Asean Economic Bulletin, 1991), thus it is in this economically promising scenario that the future role of MD in building and sustaining organizational competitiveness lie.

There are other sources of MD literature which have extensively focused on selection, analysis of MD needs, managerial competencies, choice of delivery methods and evaluation of MD. A review of the literature is given below.

Sisson and Storey (1993) observed that success of managerial work is a function of possession of social skills and the individual personal qualities; hence, attention should be focused on selection in order to ensure the appropriate filling of managerial positions.

Doyle (1994) noted that effective MD requires systematic needs assessment based on the holistic approach. Mumford (1993) further described that performance appraisal is an effective mechanism to identify the skills and knowledge required for organizational performance. This means that systematic needs analysis is perceived as a fundamental procedure that should be realigned with the agreed management development plan, which, in turn, should be periodically reviewed and adapted to situational contexts.

Storey (1989a, 1989b) suggested that the competency-based approach to MD plays a major role in any successful MD initiative. Jones and Woodcock (1985) identified the competencies needed. They include the traditional categories of knowledge, skills, attitude and behaviour. Boyatzis (1982) shared a similar view and defined competency as the underlying qualities of a manager that ensures job success and performance. This emphasis on the emerging role of competency-based approach is in line with the current development in the field of MD (Jansen \& van der Velve, 2001; Paauwe \& Williams, 2001; Taylor \& Gordon, 1984;).

The literature of MD is further discerned in the choice of delivery and evaluation tenets. According to Mumford (1993), the integrated approach to on-the-job development has been successfully seen as a delivery method that places emphasis on both task performance and developmental opportunity.

On the other hand, Beddowes (1994) concluded that the emphasis on the MD evaluation is a result of clarity of organizational objective reflected through the MD design. However, Easterby (1994) cautioned that it is difficult to make causal relations between investment in MD and organizational performance. Constable and McCormick (1987) shared the same view and warned that it is difficult to establish a statistical link between MD and organizational performance.

All of the above definitions suggest that there is a possibe link between MD and competitiveness in organizations. The concept of MD is a practical approach to organizational improvement and performance. Mumford (1993) stressed on the systemic perspective which involves a continuous or unplanned and informal process of learning. This echoes Dikken and Hoeksema (2001) five aspects of MD which are significant to the understanding of the MD concept in this study. The five aspects are (1) opportunity of learning at job; (2) controlling and managing learning process of managers; (3) learning on the job for career success; (4) conscious use of developmental instruments to influence managers' behaviour; and (5) recommendation for managers and organizations to improve organizational performance and bottom-line results.

It is also helpful to understand the concept of CA with regard to its definitions and impact on organizational 
effectiveness. Different definitions are used to describe CA. Generally, there are two perspectives and views in defining CA, namely the outside-in perspective and the inside-out perspective. A leading outside-in theorist, Porter (1985) argued that as a firm's efficiency of strategic business unit (SBU) is mainly determined by industry attractiveness based on the five forces model, which is represented by (1) the rivalry among the competing firms; (2) bargaining power of suppliers; (3) bargaining power of consumers; (4) threat from potential entrants; and (5) threat from potential substitutes. As a result, the competitive position of SBU or its positional advantage can be achieved through cost and differentiation position. As a result, CA will be built for organizational success and performance. According to Porter (1985), firms should continuously adapt to the external environment when determining their strategies. Such a positioning approach ensures the market position for sustained profitability. In other words, insight into markets and industries is crucial as the general structure of markets and industries including the specific demands, strengths, positions and intentions of all five forces will be determined in response to external structural changes. However, Porter (1985) readily acknowledged the importance of firm resources as market opportunities will only be seized with the availability of such resources in order to ensure the implementation of the best market strategy.

By looking from the inside-out perspective, Foss (1996) shared a similar view but described CA in a different way. He defined CA as the art of accumulating and deploying organizational resources as opposed to Porter's definition which stressed the positional advantage derived from the analysis of industry structure. Castanias and Helfat (1991) echoed Foss's definition by saying that CA is derived from company resources owned by organizations.

Day and Wensley (1988) futher elaborated that organizations achieve positional advantage through investment in company assets and managerial capabilities. They contend that investment will result in a CA by leveraging sources which are valued by the customer through differentiation strategy. This concept of CA is uniquely identified from a capability-based perspective. It implies that learning skills which emphasize service quality, cost control, innovation and business speed will eventually form a competitive business position (Hamel \& Prahalad, 1994).

It is noted that although capability or learning skill is considered a source of organizational competency, the focus of CA has recently been diverted to resource-based view (RBV) or inside-out perspective (Smith, Vasudevan \& Tanniru, 1996). RBV emphasizes the critical importance of organizational internal resources for sustaining CA as opposed to the belief of positional advantage. In this regard, many researchers argue that organizational performance or the creation of CA is dependent on how well the companies resources that are rare (Barney, 1991), immobility (Peteraf, 1993), inimitability (Dierickx \& Cool, 1989; Godfrey \& Hill, 1995; Lippman \& Rumelt, 1982; Reed \& DeFillippi, 1990; Rumelt, 1984; ), valuable and lack of possibility of substitute (Rumelt, 1984; Teece, Pisano \& Shuen, 1997). CA is also dependent on social complexity (Barney, 1991; Dierickx \& Cool, 1989; King \& Zeithaml, 2001), causal ambiguity (Arthur, 1996; Badaracco, 1991; King \& Zeithaml, 2001; Lippman \& Rumelt, 1982; Mosakowski, 1997) and skills and knowledge (Polanyi, 1967; Reed \& DeFillippi, 1990) that are built by managers. They contend that the more the advantages of these characteristics, the better the sustainability of CA through the interaction and intermediation of organizational competency.

In identifying factors that lead to measuring $\mathrm{CA}$, some researchers tend to express concern over the elusive concept of CA from the RBV perspective. Smith, Vasadevan and Tanniru (1996) alleged that building a CA is time consuming, RBV's static perspective has over focused on the result rather than on the process of constructing CA. As a result, the potential contribution of RBV to CA is limited and ignored as measuring CA based on a point of time is less dynamic and non realistic to reflect the actual strength of organizational CA.

Empirical evidence suggests that strong and sustainable CA has a positive influence on organizational effectiveness (McClelland, 1994). A sustainable CA promotes organizational performance and the outcome is high productivity in terms of better resource allocation and utilization. It thus suggests that a sustainable CA does have a positive impact on overall organizational performance. However, a sustainable CA could be considered effective if it manages to assist in achieving organizational goals and objectives.

Given that the objectives of both MD and CA are organizational efficiency and effectiveness, it seems logical for MD to be perceived as a strategic resource in helping organizations to achieve the goals and objectives.

However, current literature fails to link both fields in an integrated conceptual model. McClelland (1994) argued that MD has assumed a more important role in the internal alignment of resources and functions. Millett and Leppanen (1991) further claimed that MD ensures that organizations have identified and mobilized the capable managers in implementing the corporate strategy. Likewise, Hussey (1985) and McCall (1992) asserted that MD should be closely integrated with organizational objectives and strategies.

Furthermore, Mann (1990) found that organizations have instituted MD to enhance their CA in order to maintain and progress their market position in the industries. Consistent monitoring of MD activities thus is needed to ensure better managerial performance and effiency as a result of improved CA. Yet, very little has been done to integrate and link the two concepts (Luoma, 2000; McClelland, 1994). 
It is noted that there remains a gap in the link between MD and CA despite the above arguments. While the literature is helpful in emphasising aspects of MD and CA, what seems to be lacking is the conceptual framework linking the two areas of study in terms of organizational transformation (action approach) and not only on organizational description (narrative approach). Thus, a conceptual model is developed to explore the

links and also to simplify the theme (the strategic role of MD) that is identified in the literature.

\section{Discussion: Links between Management Development and Competitive Advantage}

\subsection{Conceptual framework}

Much of the literature focuses on the strategic role of MD in situational context, for instance, Catalanello and Redding (1989) stated that the strategic role of management developmental function should be emphazised by organizations. Torraco and Swanson (1995) discussed the importance of MD in supporting and shaping corporate strategies.

On the other hand, Mabey and Salaman (1995) viewed the relationship between MD and strategy as a means to assess and identify skill deficiencies in organizations. In this regard, Pettigrew, Henry and Sparrow (1988) pointed out the importance of skill performance for MD activities. Buller (1988) and Argyris (1989) suggested that MD could be part of the corporate strategic planning process. According to them, the strategic planning process should be seen as learning experiences or reflection for problem solving.

While these arguments are useful in illustrating aspects of MD and CA, there is still weakness in the literature in assessing and linking MD and CA. This piece-meal approach to understanding the links has pressured the development of a more integrated approach in connecting the two conceptual dimensions of MD and CA.

\subsection{Method}

The CA models by Hill and Jones (1998) and Smith, Vasudevan and Tanniru (1996) were taken to represent the CA conceptual model (Appendix A). The MD model by Garavan (1997) was taken to represent the MD model.

The methodology used to assess and ascertain the links between MD and CA and organizational performance involves comparing and contrasting these two models through cross referencing. The following steps were employed:

1) The main corresponding criteria in the CA model were identified and matched to each characteristic of the MD model.

2) For each of the three criteria of the CA model, the corresponding number of similar references in the MD model were identified and matched.

\subsection{Results}

Table 1 shows each characteristic of the MD model with the number of corresponding references in the Hill and Jones (1998) and Smith et al.(1996) CA models. The results show that the characteristics of the MD model most frequently referred to in the Hill and Jones (1998) and Smith et al. (1996) model are aligned with vision and strategy, peer learning, improved problem solving, skill building, skill and effectiveness as well as inter and intra personal skills and life skill. Key areas of proactive-related MD described under the MD model such as the manager potential, future role, interaction with the environment (inside out and outside in) and continuous change are not covered to large extent by the Hill and Jones (1998) and Smith et al. (1996) CA models.

Further investigation of the elements in the Hill and Jones (1998) and Smith et al. (1996) CA models criteria are shown in Table 2. The criteria which are referred to the most in the comparison are the more proactive elements of the model. These criteria cover the company skills, people skill, interaction and cooperation, control system as well as cognitive and behavioural development. Organizational structure and tangible assets are the least covered criteria.

In brief, MD provides a mechanism for organizational development which facilitates the creation and sustainability of $\mathrm{CA}$. Hence, it is adequate to indicate that MD has an impact on corporate renewal and success. It is considered to be a means in the process of building CA.

The findings from mutual cross referencing derived from Table 1 and Table 2 above verify that the suggested model to link MD and CA can be established. The conceptual model may add complementary strength to both the effectiveness and efficiency dimensions of organizations.

Figure 2 shows a suggested model of applying MD and CA concurrently towards organizational transformation and performance. Thus, it is adequate to indicate that MD has many common criteria with $\mathrm{CA}$ in terms of organizational success and performance. MD is considered to be a strategic mechanism, a catalytic reinforcer and an effective and efficient system in the process of building organizational competitiveness (Mann, 1990; McClelland, 1994; Millett \& Leppanen, 1991)

\section{Conclusion}

This study indicates that although the underlying definitions of MD and CA are different there have been some 
aspects of convergence or complementary similarity which support commonalities between the two concepts.

The findings of this study are the result of an attempt to compare and contrast the MD and CA models to identify the mutual corresponding criteria. Overall, there seems to be adequate indication to suggest that the MD model corresponds to a large extent with the CA model and that both share common theoretical understanding which concentrates on organizational knowledge and expertise, vision and strategy, learning as well as skill development. Based on the finding in general, it is observed that although the MD and CA models represent individual aspects of study, to a large degree, they are complementary in many similar dimensions particularly on aspects of organizational knowledge and expertise, vision and strategy, learning and skill development.

As a result, in order to strengthen the needs and convince the organizational emancipation of effective participation and practicing of $\mathrm{MD}$, the synergistic and holistic understanding of $\mathrm{MD}$ and $\mathrm{CA}$ can provide a better guideline and methodological framework which serve as overall directive and reference to implement MD initiatives within organizations.

The conceptual framework is recommended to serve as a methodological technique to guide overall business processes to better improvement and help companies become performing organizations especially in terms of implementing and practicing MD.

\section{References}

Argyris, C. 1989. 'Strategic implementation: An experience in learning', Organizational Dynamics, Autumn, pp.5-15.

Arthur, W.B. 1996. 'Increasing returns and the new world of business', Harvard Business Review, vol.74, no.4, pp.100-109.

Asean Economic Bulletin. 1991. vol.8, no.1, pp.104-106.

Atkinson and Meagher. N. 1986. 'Changing patterns of work:How companies introduce flexibility to meet changing needs', Institute of Manpower Studies, London.

Badaracco, J.L. 1991. The Knowledge Link, Havard Business School Press. Boston, MA.

Barney, J.B. 1991. 'Firm Resources and Sustained Competitive Advantage', Journal of Management, vol.17, pp.99-120.

Beddowes, P.L. 1994. 'Management Development', Journal of Management Development, vol.13, no.7, pp.40-47.

Berry, J. 1990. 'Linking Management Development to Business Strategies', Training and Development Journal, vol.44, no.8, pp.20-2.

Boyatzis, R. 1982. The competent manager: A model for effective performance, Wiley, New York, NY.

Buller, P.F. 1988. 'For successful strategic change: Blend OD practices with strategic management', Organizational Dynamics, Winter, pp.42-55.

Burgoyne, J. 1988. 'Management development for the individual and the organization', Personnel Review, vol.20, June, pp.20-24.

Castanias, R.P. and Helfat, C.E. 1991. 'Managerial resources and rents', Journal of Management, vol.17, no.1, pp.155-71.

Catalanello, R. and Redding, J. 1989. 'Three strategic training roles', Training and Development Journal, vol.73, no.12, pp.51-54.

Constable, L. and McCormick, T. 1987. The Making of British Managers, BIM, London.

Day, G.S. and Wensley, R. 1988. 'Assessing advantage: a framework for diagnosing competitive superiority', Journal of Marketing, vol.52, pp.1-20.

Dierickx, I. and Cool, K. 1989. 'Asset stock accumulation and sustainability of competitive advantage', Management Science, vol.35, no.12, pp.1504-11.

Dikken, L. and Hoeksema, L. 2001. 'The palette of management development', Journal of Management Development, vol.20, no.2, pp.168-179.

Doyle, M. 1994. 'Organizational transformation and renewal: A case for reframing management development', Personnel Review, vol.24, no.6, pp.6-18.

Easterby, S.M. 1994. Evaluation of Management training, education and development, Gower, Aldershot.

Foss, N. 1996. 'Research in strategy, economics, and Michael Porter', Journal of Management Studies, vol.3, no.1, pp.1-24.

Garavan, T.N. 1997. 'Training, development, education and learning: different or the same?', Journal of European Industrial Training, vol.21, no.2, pp.39-50. 
Garavan, T.N., Costine, P. and Heraty, N. 1995. Training and Development in Ireland, Context, Policy and Practice, Oak Tree Press, Dublin.

Godfrey, P.C. and Hill, C.W.L. 1995. 'The problem of unobservable in strategic management research', Strategic Management Journal, vol.16, no.7, pp.519-533.

Hamel, G. and Prahalad, C.K. 1994. Competiting for the future: Breakthrough strategies for seizing control of your industry and creating the markets of tomorrow, Havard Business Press, Boston, MA.

Hill, C.W.L. and Jones, G. R. 1998. Strategic Management: An Introduction, Houshton Miffun Co., New York.

Hitt, W. 1987. 'A unified development programme', Journal of Management Development, vol.6, no.1, pp.43-53.

Jansen, P., van der Velve, M. and Mul, W. 2001. 'A typology of management development', Journal of Management Development, vol.20, no.2, pp.106-120.

Jones, J. E. and Woodcock, M. 1985. Manuals for MD, Strategy Design and Instruments for Programme Improvement, Gower, Aldershot.

King, A. W. and Zeithaml, C.P. 2001. 'Competencies and firm performance: Examining the causal ambiguity paradox', Strategic Management Journal, vol.22, pp.75-99.

Lees, S. 1992. 'Ten faces of management development', Journal of Management Development, vol.23, no.2, pp.89-105.

Lippman, S.A. and Rumelt, R.P. 1982. 'Uncertain imitability: An analysis of interfirm differences in efficiency under competition', The Bell Journal of Economics, vol.13, pp.413-38.

Luoma, M. 2000. 'Investigating the link between strategy and HRD', Personnel Review, vol.29, no.6, pp.769-790.

Mabey, C. and Salaman, G. 1995. Strategic Human Resource Management, Blackwell, Oxford.

Mann, R. 1990. 'A Building Blocks Approach to Strategic Change', Training and Development Journal, vol.44, no.8, pp.23-5.

McCall, M. 1992. 'Executive Development as a Business Strategy', Journal of Business Strategy, vol.13, no.1, pp.25-31.

McClelland, S. 1994. 'Gaining competitive advantages through strategic management development', Journal of Management Development, vol.13, no.5, pp.4-13.

Millett, S. and Leppanen, R. 1991. 'The Business Information and Analysis Function: A New Approach to Strategic Thinking and Planning', Planning Review, vol.19, no.3, pp.10-15.

Morgan, G. 1986. Images of organizations, Sage, London.

Mosakowski, E. 1997. 'Strategy making under causal ambiguity: Conceptual issues and empirical evidence', Organization Science, vol.8, pp.414-442.

Mumford, A. 1993. Management Development: Strategies for Action, IPD, London.

Peteraf, M.A. 1993. 'The cornerstones of competitive advantage: A resource-based view, Strategic Management Journal, vol.14, no. 3, pp. 179-91.

Paauwe, J. and Williams, R. 2001. 'Management Development Revisited',Journal of Management Development, vol.20, no.2, pp.180-191.

Pettegrew, A., Henry, C. and Sparrow, P. 1988. 'The role of vocational education and training in employers' skills supply strategies', Sheffield Training Agency report in conjuction with Coopers and Lybrand.

Polanyi, M. 1967. The Tacit Dimension, Anchor, Garden City, NY.

Porter, M.E. 1985. Competitive Advantage: Creating and sustaining superior performance, The Free Press, New York.

Quinn, R.E. 1988. Beyond Rational Management, Jossey-Bass, San Francisco, CA.

Reed, R. and DeFillippi, R. 1990. 'Causal ambiguity, barriers to imitation, and sustainable competitive advantage', Academy of Management Review, vol.15, no.1, pp.88-102.

Rumelt, R. P. 1984. 'Toward a strategic theory of the firm', in Lamb, R.(Ed.), Competitive Strategic Management, Prentice-Hall, Englewood Cliffs, NJ, pp.556-570.

Schuler, R. 1989. 'Strategic Human Resource Management and Industrial Relations', Human Relations, vol.42, no.2, pp.157-84.

Sisson, K. and Storey, J. 1993. Managing human resources and industrial relations, Open University Press, Milton Keynes. 
Smith, K. A., Vasudevan, S.P. and Tanniru, M.R. 1996. 'Organizational learning and resource based theory: An integrative model', Journal of Organizational Change, vol.9, no.6, pp.41-53.

Storey, J. 1989a. 'Management development: A literature review and implications for future research', Personnel Review, vol.18, no.6, pp.3-19.

Storey, J. 1989b. 'Management development: A literature review and implications for future research- part 2', Personnel Review, vol.19, no.1, pp.3-11.

Taylor, B. and Gordon, L. 1984. Management Development and Training Handbook, McGraw-Hill, New York, pp, 31-32.

Teece, D. Pisano, G. and Shuen, A. 1997. 'Dynamic capabilities and strategic management', Strategic Management Journal, vol.18, no.7, pp.509-533.

Torraco, R.J. and Swanson, R.A. 1995. 'The strategic roles of human resource development', Human Resource Planning, vol.18, no.4, pp.10-21.

Torrington, D. and Hall, L. 1998. Human Resource Management, $4^{\text {th }}$ ed., Prentice Hall, London.

Table 1. Cross referencing of MD to CA

\begin{tabular}{|c|c|}
\hline $\begin{array}{l}\text { Management development model } \\
\text { characteristics }\end{array}$ & $\begin{array}{l}\text { Number of corresponding competitive advantage } \\
\text { model references }\end{array}$ \\
\hline 1. Align with vision $\&$ strategy & $9($ mainly criterion part $1 b, 2 a$ and $3 a)$ \\
\hline 2. Peer learning & $8($ mainly criterion part $1 \mathrm{a}, 2 \mathrm{~b}$ and $3 \mathrm{e})$ \\
\hline 3. Improved problem solving & 7 (mainly criterion part $1 \mathrm{c}, 2 \mathrm{~b}$ and $3 \mathrm{~d})$ \\
\hline 4. Skills building & 7 (mainly criterion part $2 a, 2 b$ and $3 a$ ) 7 (mainly \\
\hline 5. Skills \& effectiveness & criterion $2 \mathrm{a}, 2 \mathrm{~b}$ and $3 \mathrm{~d})$ \\
\hline 6. Interpersonal skills & 7 (mainly criterion part $2 \mathrm{a}$ and $3 \mathrm{a}$ ) \\
\hline 7. Intrapersonal skills & $6(3 e)$ \\
\hline 8. Life skills & $6(3 c)$ \\
\hline 9. Decision making & $6(3 a)$ \\
\hline 10. Personal competence & $5(3 b)$ \\
\hline 11. Continuous change & $5(3 c)$ \\
\hline 12. Inductive strategy & $2(3 b)$ \\
\hline 13. Outside in & $2(3 b)$ \\
\hline 14. Inside out & $1(3 b)$ \\
\hline 15. Manager potential & $1(3 b)$ \\
\hline 16. Maximising potential & 0 \\
\hline 17. Future role & 0 \\
\hline
\end{tabular}


Table 2. Cross referencing of CA to MD

\begin{tabular}{|l|l|}
\hline Competitive advantage model criteria & $\begin{array}{l}\text { Number of corresponding references in } \\
\text { management development model }\end{array}$ \\
\hline 1. Distinguish knowledge & 12 \\
2. Distinguish expertise & 11 \\
3. Company skills & 10 \\
4. Interaction and cooperation & 7 \\
5. People skills & 6 \\
6. Control system & 6 \\
7. Cognitive development & 3 \\
8. Behavioural development & 2 \\
9. Decision making & 2 \\
10. Organizational structure & 0 \\
11. Tangible assets & 0 \\
\hline
\end{tabular}

\section{Model comparisons:}

CA Model MD Model

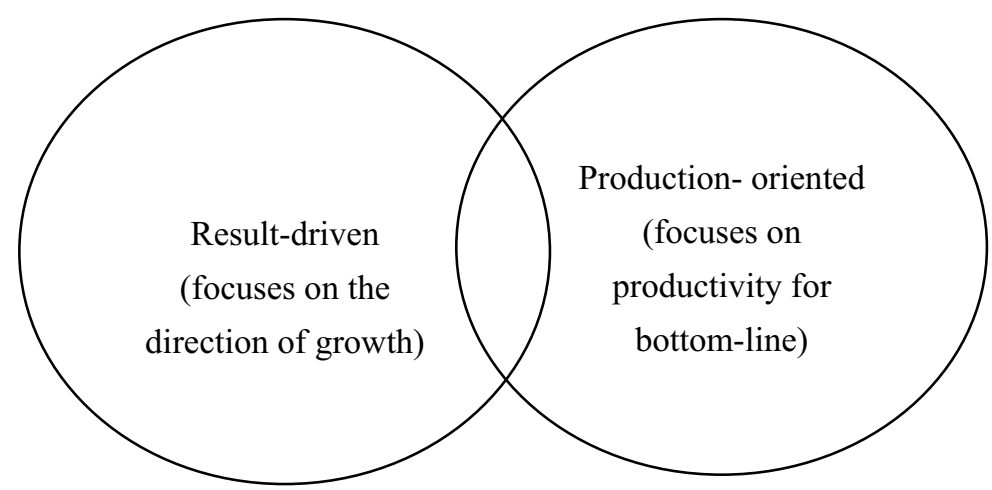

Figure 1. Interaction between management development and competitive advantage

(A proposed conceptual framework)

Figure 1 depicts the suggested model that shows the interaction between CA and MD. Both are not mutually exclusive, rather, they are mutually inclusive in certain aspects. Interaction thus can be expressed through commonality of result-driven and production-driven criteria for effectiveness and efficiency. Therefore, in order to test the suggested model, existing CA and MD models were compared and contrasted

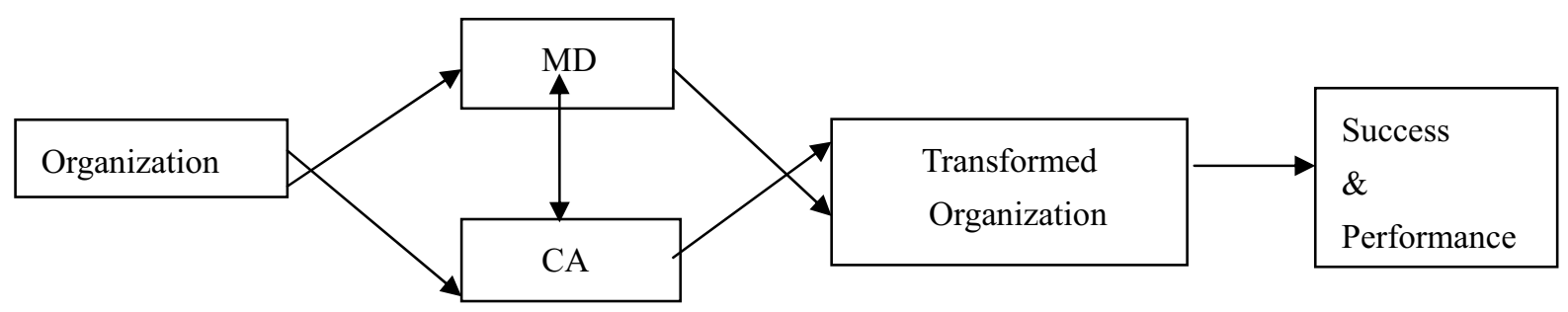

Figure 2. Applying MD and CA methods concurrently to organizational transformation 


\title{
E-collaboration: A Universal Key to Solve Fierce Competition in Tourism Industry?
}

\author{
Caiwei Ma \\ Economy \& Management Department, Tianhua College of Shanghai Normal University \\ No. 1661 North Shengxing Rd, Jiading District \\ Shanghai 201815, China
}

Tel: 86-21-3996-6301Ｅ-mail: macaiwei@yahoo.com.cn

\begin{abstract}
E-collaboration is a new strategy to compete in today's business world. Cooperation, collaboration, alliance and etc are the words companies are now focusing on. These companies are looking towards friendliness instead of hostility. This paper analyzes the previous literature on Internet, e-business, and collaboration, looking at the emergency of e-collaboration in the tourism industry. The applications of e-collaboration are often mentioned in the fields of international trading and e-business. The paper aims to apply those theories of collaboration, internet and e-business from other industries to tourism and hospitality industry. It also analyzes the e-collaboration situation in this particular area and tries to find a way to help today's tourism industry players to create and guide thriving e-collaboration strategies. E-collaboration provides a very efficient strategic option with low cost, easy access, large market, reputation and resources sharing. It brings geographically dispersed teams together, supporting communication, coordination and cooperation. But problems like unbalanced management and power between collaborators, unequal resource commitments, quality maintenance, culture differences exist in e-collaboration. In the end of the paper, the author highlights the advantages of e-collaboration and suggests the way to e-collaborate properly to contribute to strategic management.
\end{abstract}

Keywords: E-collaboration, E-business, Internet, Tourism

\section{Introduction}

The development of Internet technology and the dramatic spread of its use throughout the world in the past decade brought business into a new stage, a stage known 'e-time'.

Before ' $\mathrm{e}$ ' time, tourism industry players mainly maintained workable vertical relationships with its suppliers and their sales force (Appleman \& Go 2002). The walls of each company's office were not just physical bricks; they were also the spiritual boundaries isolating the company from its horizontal neighbours who do similar business. While drivers in the business environment such as globalization, regionalization, information technology and e-commerce decreased barrier effect of brick walls (Timothy 2003). Consumers are becoming more experienced. Competition between organisations by throwing bricks to each other can no longer lead to success (Stern \& Hicks 2000).

This article starts with relevant definitions of e-collaboration and the description of the change in the business environment and then analyzes these motivations, advantages and the problems of e-collaboration in the tourism industry. Multinatinational enterprise (MNE) and small business/tourism organisations are tending to adapt e-collaborative strategies. Gartner (2001) predicts that $70 \%$ of firms will have a coherent e-business strategy within a year. However, this is not a universal key if being used improperly. Addressing the theories of collaboration and e-business in other industries and trying to find a way of applying them to today's tourism industry players to create and guide thriving e-collaboration strategies is the main aim of this article.

E-collaboration bridges national borders and continents. E-collaboration and collaborative systems bring geographically dispersed teams together, supporting communication, coordination and cooperation. Indeed, it has become a cornerstone of global competition (Doz \& Hamel 1998; Timothy 2003). It is a logical and timely response to the quick change in the economic and IT world and split organizations into two competition divisions: one for the global market, one for the future development.

\section{Relevant definitions}

\section{E-business}

This field of activity is relatively young and evolving rapidly, and as such no single definition of the term has become 
accepted as the universal norm (Clegg et al 2001). E-business was initially limited to the financial transactions online. It was coined with a meaning of conducting business on the Internet by IBM back in 1997 as part of an advertising campaign. For the purposes of this essay, both business-to-business (B2B) and business-to-consumer (B2C) transactions and relationships are considered. Thus, e-business here is defined as the transaction of commercial activities on global open networks between an ever-increasing number of corporate and individual participants (Richmond et al. 1998).

\section{Collaboration}

According to Cambridge Advanced Learner's Dictionary (2003), collaboration means working jointly with others or together for some purpose or achieve the same thing. Words like strategic alliance, collaborative partnership, collaborative form, collaboration, partnership, and coalition are interchangeable utilized ( Fyall \& Spyriadis 2003).

E-collaboration is an extension from the old collaboration type in e-age. It is Internet-based cooperation/collaboration with exchange of information, materials, or cash among entities (Brown \& Sappenfield 2003).

\section{The changing of the business environment}

Information is the "lifeblood" of tourism. Since the tourism products can not be pre-tested, the access to accurate, timely and relevant information is therefore essential to consumers. Before the spread of Internet, telephone, fax, letter and face-to-face meeting were the main communication channels between suppliers and buyers. The generation, gathering, processing, application and communication of information was time consuming (O'Connor et al 2002). Consumers almost completely relied on representation and description to make an appropriate choice (Go and Pine 1995). Intermediaries played a very important role between disciplines and end-customers. Collaborations between horizontal tourism players were very rare.

While technology can act as a 'creator, enhancer, focal point and/or destroyer of the tourism experience' as O'Connor (2002 p332) indicated, the development of IT brought the business world a revolution of electronic. Business-related "dot-com" Web sites emerged all over the virtual world. A matching between buyer and seller was set up. Andy Grove, the chairman of Intel, predicted in 1999 that, within five years, all companies will be Internet companies or they will not exist.

As web-based technologies expanded, core back-office processes, including order management, procurement, logistics, financial management, and supply chain planning was incorporated (Gould 2004). The barriers and distance competitors were reduced. Information flows among the client, intermediaries and each of the suppliers involved in serving the client's needs. New relationships with customers, new relationships between competitors and suppliers and buyers, new business process, new information and communications technologies came into being and empowered employees are required (E-business Management Consultants 2003; Timothy 2003).

\section{Motivations for Collaboration}

Globalisation and regionalisation are emerging worldwide. This macro environment stimulates the development of IT; and the development of IT enhances the integration inversely. Hastings (1993) states that the need for 'quality, as well as the high costs and complexity of servicing global markets' is forcing organisations into collaborating with their clients, their suppliers and with their competitors in many new ways.

The power of IT allows information to be managed more effectively, and transported worldwide almost instantly (Frew and Pringle 1995). The physical boundaries between brick walls or territories can't block the information flow. Smaller countries, organisations, in particular, can benefit by gaining access to a much larger market than that in their own territories; large economic regions become available to them for sale of their goods and services (Timothy 2003).

From horizontal view, market is limited, the more ratio one company occupies, the less other companies occupies. But competitors in well-matched strength always exist. It's time for antagonists to begin to use the bricks to build something useful instead of throwing bricks at one another (Stern \& Hicks 2000). Collaboration offers a way to pursue business development, revenue increase, cost reductions in promotions and marketing and enhance market image and reputation (Fyall \& Spyriadis 2003). A partnership of collaboration is a tailored business relationship based on mutual trust, openness, shared risk and shared rewards that yields a competitive advantage, resulting in business performance greater than would be achieved by the firms individually (Lambert et al 1996; Cooper 1993; Oliver 1990).

In an executive report, META pointed that by 2001/02, high-performing enterprises will recognize the value of business collaboration to achieve flexibility, speed, and agility. By 2004, more than $30 \%$ of G2000 companies will have developed a collaborative competency and will use collaborative tools to extract superior value from their collaborative efforts (Passori 2000).

\section{Types of collaboration}

There are three types of collaboration: vertical relationships, horizontal relationships and diagonal relationships. (Fyall \& Spyriadis 2003) This is a classifying according to the different structure of collaboration and could suit 
e-collaboration.

\subsection{Vertical relationship}

Vertical relationship is the collaboration between suppliers and buyers e.g. travel operator and travel agency, travel agency and hotel. There is growing emphasis in modern supply chain literature on the importance of forming collaborative strategic partnerships with select trading partners (Kolluru \& Meredith 2001). The official site of Scotland's tourism board is one example. The links to travel agencies which sales its products can be found in this website. It offers you the service of journey booking while not owning a travel agency itself.

\subsection{Horizontal relationship}

Horizontal relationship is the collaboration between competing companies selling similar products or services, e.g. hotel and hotel (Bernal et al 2002). In tourism industry, horizontal collaboration happens more often than other two types with the spread of IT. This collaboration can be either inter-organisational which refers to licensing, franchising, sub-contracting and etc under one brand or alliance between different brands. Whichever horizontal collaboration the tourism industry players join, they are separated organisations by law (Fyall \& Spyriadis 2003; Stern \& Hicks 2000; Timothy 2003). Orbitz.com, for instance, was initially started by five airlines - American, Continental, Delta, Northwest and United to serve customers better and only sell flight tickets of these five owners. To gain more "click", it encourages other airlines to sell their tickets through its website. At the same time, other airlines are seeking for multi-distribution channels to explore market. Now Orbitz's inventory has hundreds of choices of airlines for customers. Marriott International has just signed a deal with Hotels.com. As part of the agreement, Marriott will have a direct link to the websites from its own central reservation systems. It will make its inventory of hotel rooms available to the sites. (Hotel Report 2003)

\subsection{Diagonal relationship}

Diagonal relationship is the relation where companies in different industries and sectors are working jointly. It's a dynamic structure and is growing follow closely to the other two types of e-collaboration (Brenner 2004). Grandheritage.com can illustrate this type of collaboration. Grandheritage.com is an online hotel booking website, but it has collaboration with Currency Converter, BBC Weather, Multi Map, British Tourist Authority (a site for events \& general information), British Airports Authority, London Transport, UK Genealogy (a site for tracing UK ancestry), Festivals.com(festivals and events in Europe), BITOA(The British Incoming Tour Operators Association), www.wellwellwell.co.uk(suppliers of water to hotels), and www.holidayautos.co.uk (low cost car hire). The collaboration is not just limited to the vertical supplier and buyer's relationship and horizontal relationship with competitors, but extends to other industries.

\section{The Influence of e-collaboration}

\subsection{Advantages}

6.1.1 Wider market and better competitive position.

Collaborative partners share common reservation system and customer databases. In this way tourism destinations, hotels, travel agencies and etc. can access to worldwide markets despite of the territory boundaries (Fyall \& Spyriadis 2003). The collaborated members can market as a whole sometimes (Teye 2000). Hospitality industry is witnessing the growth of technology-based collaboration best. An example of this is the Hilton International (UK based unit of Ladbroke Plc.) and Hilton Hotel Corporation (US based) alliance. These companies have entered into a relationship that involves sharing customer databases throughout the world. According to Hilton, the objective of this collaboration is to grow the brand to be able to compete on a global basis. Hotels.com is another good example for global market. It is one of the fastest growing hotel booking sites on the Internet. It offers savings of up to $70 \%$ off regular hotel rates in some of the world's most popular and expensive cities. What's more, the collaboration of the hotels guarantees traveler a room when cities are sold out. As Bruce Wolff, Marriott's senior vice president of sales and e-commerce strategy, said on Marriott's collaboration with expedia and hotel.com:' We want to ensure the travelers have access to Marriott properties no matter how they prefer to plan and book travel.'

This advantage is especially helpful to small and medium size tourism industry players. Collaboration through Internet enables them to source components and raw materials so as to widen their market and reputation (Gani 2001). E-collaboration offers the opportunity for companies to increase the numbers of potential suppliers, and for smaller companies to reach a larger trans-national client base (Leadbetter 1999)

'Through a close collaboration between hotels, restaurants, tourism and commerce, we can cater for anyone who wants to arrange their meeting or conference in Kristianstad or the surrounding area,' says Gunnel Ahlbeck of Turism Kristianstad (2003). When cross-border collaboration and cooperation in tourism promotion are formed, the global competitive advantage is likely to increase (Timothy 2003). 


\subsubsection{Value creation.}

Collaboration between competing firms may create favourable conditions for "inter-partner" learning (Dussage et al. 1999), allowing one firm to acquire capabilities that they lack from a partner, particularly when partners from different geographic region. Each partner will bring its product markets, technology, and experience to the collaborated group. A high-speed search and accurate results can be offered to customers with the sharing resources contributed by collaborators (O'Connor et al 2002). This caters for the increasing business-to-business or business-to-consumer demands for products and services with a wider resource of combination of each partner's limited resource.

What's more, value creation and its role in business network relationships is becoming an area of increasing interest (Blankenburg-Holm et al. 1998 in Bernal 2002) and enables firms to focus on combining internal and external resources in innovative ways.

\subsubsection{Inventories reduction.}

The closer, long-term, collaborative buyer-supplier relationships, i.e. partnerships, are enabled through seamless integration and transfer of information up and down the chain (Kolluru \& Meredith 2001). Strategic SCM can lower inventory risks and costs, improve customer service and satisfaction, increase customer retention and more effective marketing. (Horvath 2000) As distributors enter the same web, data on sales and inventories are received; forecasts are much easier to be made. With the forecasting and planning ability's improvement, collaborators will get benefit to know what to do next clearly. For example, Depkon's Hilton properties use a software application called Birch Street that manages the procurement and inventory at the property level. It allows the properties real-time access to suppliers' inventory. The sound e-collaboration makes the hotel managers focus on the day-to-day issues more and saves the hotel 8 percent to 15 percent (Higley 2004).

\subsubsection{Better communication.}

E-collaboration enhances inter-organizational relationships (O'Connor and Galvin 1998; Guide to the Use of Information Technology in the Supply Chain 1999; Song 1999). Though reduction in face-to-face contact and an increase in the opportunities for dispersed or paperless offices and people-less factories that have proved to be largely unfounded (Clegg et al 2001), e-collaboration does allow managers/staff to share information dynamically and far more quickly than previously. It enhances the gain from face to face meetings and other types of communication.

\subsubsection{Fewer cultural conflicts.}

As more collaborations are made, defining company culture is critical, especially when companies come from different countries. The social cultural environment will impact the company. While e-collaboration is based online, whether to customers or managers, it is more virtual than physical. Communicating while not working and meeting face to face day to day. Emotion and behavior interference will be less (Stern \& Hicks 2000).

\subsection{Key Problems}

Collaboration offers a way out of the fierce competition but it is not a universal key. Without good understanding and preparation, e-collaboration can also damage business. Not all collaboration or alliances or cooperation are successful. America's Tribune newspaper (2003) has reported a trend of hotel operators breaking away from their franchises and going it alone without big brand backing. The following are several key problems exist in e-collaborative relationship.

\subsubsection{Unequal resource commitments}

Perhaps the most critical thing in collaboration is the degree to which the partners' contributions are committed and complementary (Stern \& Hicks2000). Timothy (2000) pointed that the commitment on the part of individual nations to giving up absolute control in some areas is lack, because national interests nearly always outweigh cross-national interests when he talked out the collaboration between countries. It is a common problem throughout the world where collaboration is being undertaken no matter it is a horizontal collaboration, vertical collaboration or diagonal one.

\subsubsection{Unbalanced management and power}

Unbalanced management and power results from unequal commitment. But no party wants to be at a disadvantage in cooperation. The unbalanced situation sometimes leads to inefficient if dealt wrong.

\subsubsection{Different maintenance of quality standards between partners}

Every tourism industry player has different internal needs for different technological and organizational systems and external needs for connectivity and share-ability of messages, data, applications and processes (Stern \& Hicks 2000). But once collaborated, the reputation and services of each collaborator are bounded together. One comparatively worse website or service will lead to the poor impression of the whole group to customer. And also because of the collaboration of huge database, the difficulty of maintenance is increasing (Bernel et al 2002). 


\subsubsection{Losing the opportunity for a creative solution}

Problems are sometimes unavoidable no matter what product and what life stage. When an enterprise meets conflicts or problems entering a market, it might find its own way to solve itself. E-collaboration may need certain managers to negotiate with those who have been in the market and link their websites and database to bridge the markets.

\section{Suggestions and conclusions}

E-collaboration is a very vital strategy for tourism industry players in today's business world. Vertical and horizontal e-collaboration is more often to see in tourism industry than diagonal collaboration. But this type of e-collaboration will be a trend when vertical and horizontal collaboration have developed well. Cooperation between different industries will enhance each other and help each industry's development.

Smartly using this strategy can avoid the fierce competition between hotels, travel agencies and travel operators. As discussed above, e-collaboration can help to widen market, enhance competitive position, add value, reduce cost, bridge communication and lessen cultural conflicts. It is a great strategy more SME to compete with stronger competitors. But Zaid Ismail (2003), senior director of the National Chamber of Commerce and Industry of Malaysia (NCCIM), said though many small and medium size companies have their own websites, not all of them are aware of the benefits of e-business and fully utilize this tool.

Either to small business/tourism organisations or multinational enterprise, to take successful e-collaboration strategy to compete in the global market, the following suggestions should be considered:

- Choose your partner carefully. Every enterprise should know clearly its own strengths and weaknesses before collaborating, and then smartly look for partners that can fit its wants.

- Necessary information technology. The information that an organization communicates with its supply chain partners is among the most critical of its assets. Powerful, integrated collaborative technology is the backbone of an e-collaboration (Vlachopoulou and Manthou 2003). Protection must be provided against external threats and from internal abuse (Kolluru \& Meredith 2001). The data that is shared between the partners and customers engaged in these different types of relationships varies widely in its criticality, thus requiring different levels of security.

- Managing the balance of power and dependence. Normally a partner who brings differentiating contributions of a more sustainable nature --- such as a leading brand--- will enjoy a more sustained influence. And the smaller partner is comparably more dependent. The dependence comes from commitments. As the commitments are irreversible, more specific commitments should be done so that every partner is very clear about its role and contribution, for example, the service standard, price, credit policy, service level performance, response time, image and etc. The trust between partners should be well set up as the basis of enduring collaborative relationships (Donington 1995, Richmond et al. 1998).

- Monitoring the quality. Quality is the life core in any industry. Service, price, credit policy, response time, and legal issue warranties and so on detailed things should also be considered carefully. Online service and face-to-face service should be both monitored. Keeping a sustainable good quality can enhance customer's loyalty and then raise the company's reputation.

- Hiring intelligent and empowered employees. Managing e-collaboration will be more difficult than traditional management activities, as the systems become potentially more complex, more tightly coupled, and increasingly involve complex interrelations between people, organizations and technology (Timothy 2003). Companies need more than just good technology to make the most of the Internet (Cairncross 2000).

Evaluation can also not be forgotten while using e-collaboration strategy. Individually, jointly and publicly evaluation all are important to keep the process on its way to success.

This paper addresses the relevant theories on e-business and internet to the specific tourism industry. But as time and resources are limited, no particular case study is offered to support the researcher's ideas. E-trading is the industry witnesses the technology information development first and reacts first. The theories and practice in this industry can be studied more to contribute to tourism. A further research of comparing and analyzing the similarities and differences between these two industries, especially the e-market place and online travel agencies can be carried out. What's more, the research of the trend of diagonal e-collaboration in tourism industry is also worth researching.

\section{References}

Allisat, B. (2004). At a drop of hat (the definition of internet).(online)Available: http://www.gtld-mou.org/gtld-discuss/mail-archive/05134.html (Feb,2004).

Appleman,J. \& Go,F. (2002).Transforming Relationships Between Airlines and Travel Agencies: Challenges for Distribution and the Regulatory Framework. Tourism Distribution Channels: Practices, Issues and Transformations. London: Continuum. 
Bafoutsou,G. \& Mentzas,G. (2002).Review and functional classification of collaborative systems. International Journal of Information Management. 22;4, pp. 281-305.

Bernal,S.,Burr, C. \&Johnsen, R. (2002).Competitor networks: international competitiveness through collaboration: The case of small freight forwarders in the High-Tech Forwarder Network. International Journal of Entrepreneurial Behaviour and Research. 8;5, pp. 239-253.

Brenner, B. (2004). Diagonal Collaborations: Dazzling or Dangerous? Chaco Canyon Consulting.(online)Available:http://www.chacocanyon.com/pointlookout/010516.shtml (April,2004).

Brown, M. \& Sappenfield, D. (2003). Collaborative. (online)Available:Http://www.intelligentententerprise.com (Feb,2004).

Buhalis, D. \& Laws, E. (2002). Tourism Distribution Channels: Practices, Issues and Transformations. London: Continuum.

Chathoth, P. \& Olsen, M. (2003). Strategic Alliances: A Hospitality Industry Perspective. Hospitality Management. 22; 4, pp.419- 434.

Clegg, C. W. , Icasati-Johanson, B. \& Bennett,S. (2001). E-business: boom or gloom?Behaviour and Information Technology. 20;4, pp. 293-298.

Donington,J. (1995). Electronic Data Interchange in the Automotive Industry: Managing Information Flows for Greater Profitability. Financial Times Management Reports. London: Pearson Professional Ltd.

Doz,Y. \& Hamel,G. (1998). Alliance advantage: the art of creating value through partnering. Boston: Harvard Business School Press.

Dussage,P., Garrete,B., \& Mitchel,W. (1999). Learning from competing partners: outcomes and durations of scale and link alliances in Europe, North America and Asia. Strategic Management Journal.24;3, pp.231-242.

E-business Management Consultants. (online) Available: Http://www.quickredfox.co.uk/ebusiness-explained.htm (Feb, 2007).

Frew, A. \& Pringle, S. (1995). Multi-media Marketing Across ATM Broadband Networks - A Hospitality and tourism Perspective: Part One. The Hospitality Information Technology Association Worldwide Conference.

Fyall, A. \& Spyriadis, A. (2003). Collaborating for Growth: the International Hotel Industry. Journal of Hospitality and Tourism Management. 10;2, pp. 108-123.

Gani,H. (2001). Enhancing Product Quality. New Straits Times. Malaysia. 26July 2001.

Go,F. \& Pine, R. (1995). Gobalisation Strategy in the Hotel Industry. New Yourk: Routledge.

Gould, L. (2004). What's in an Online Marketplace? (online) Available:Http://www.autofieldguide.com (Feb,2004).

Guide to the Use of Information Technology in the Supply Chain: Making Technology Pay. (1999). London: Price Waterhouse Coopers.

Horvath, L. (2001). Collaboration: the key to value creation in supply chain management.

Supply Chain Management: An International Journal. 6; 5, pp. 205-207.

Higley, J. (2004). Supply-chain Policies Help Hoteliers Save Time, Mondy. Hotel \& Motel Management. 219; 3, pp. 26-27.

IBM and E-collaboration. IBM.com. (online)Available:http://www-5.ibm.com/e-business/pl/e-collaboration/intro/ (Feb,2007).

Independence Day for Franchise Operators. (2003). Hotel Report. 6;12,pp.1.

Jaquith, A. (2002). Securiting Avallable:

Http://www.stake.com/research/reports/acrobat/atstake_securing_ecollabor...(Feb,2004).

Knudsen, D. \& Sweden, L. (2003). Aligning corporate strategy, procurement strategy and e-procurement tools. International Journal of Physical Distribution\& Logistics Management. 33;8, pp.720-734.

Kolluru, R. \& Meredith, P. H. (2001).Security and trust management in supply chains. Information Management \& Computer Security. 9;5, pp. 233-236.

Le, T. (2002). Pathways to Leadership for Business-to-Business Electronic Marketplaces. Electronic Markets. 12;2, pp.112.

Leadbetter, C. (1999). Living on Thin Air. London: Penguin.

Marriott Joins third Party sites for Online Management. (2003). Hotel Report. 6;12, pp. 6. 
O’Connor, P., Buhalis, D. \& Frew, A.J. (2002). The Transformation of Tourism Distribution Channels Through Informaion Technology. Tourism Distribution Channels: Practices, Issues and Transformations. London: Continuum.

O’Connor, J. \& Galvin, E. (1998). Creating Value through eCommerce. Management Briefings: General Management. London: Financial Times Management.

Oz, E. (2002). Foundations of E-commerce.U.S.A.: Prentice Hall.

Passori, A. (2000). Executive Direction. Stamford: META Group In.

Richmond, C., Power, T. \& O'Sullivan, D. (1998). E-business in the Supply Chain: Creating Value in a Networked Marketplace. London: IBM.

Song, S. (2004). Guidelines on the Use of Electronic Networking to Facilitate Regional or Global Research Network. (online) Available:Http://www.idrc.ca/books/focus/890/15aSong.html (Feb,2007).

Stern, A. \& Hicks, T. (2000). The Process of Business/ Environmental Collaborations. USA: Quorum Books.

Timothy, D. J. (2003). Supranationalist Alliances and Tourism:Insights from ASEAN and SAARC. Current Issues in Tourism. 6;3, pp. 250-167.

Tourism collaboration and partnerships: politics, practice, and sustainability. (2000). Clevedon: Channel View.

Trends \& Indicators: Collaboration. (2002). Business Intelligence Market Watch. 13; 2, pp. 28.

Vlachopoulou, M. \& Manthou, V. (2003). Partnership alliances in virtual markets.

International Journal of PhysicalDistribution \& Logistics Management. 33; 3, pp.254-267. 


\title{
The Relationship between Ownership and Performance:
}

\section{A Review of Theory and Evidence}

\author{
Yabei $\mathrm{Hu}$ \\ College of Economics, Hebei University \\ Wusi-east Road 180, Baoding, Hebei 071002, China \\ Tel: 86-312-501-3646, Fax: 86-312-591-5108 \\ E-mail: huyabei2004@yahoo.co.jp \\ Shigemi Izumida \\ Graduate School of Economics and Management, Tohoku University \\ Kawauchi 27-1, Aoba-ku, Sendai 980-8576, Japan \\ Tel/Fax: 81-2-2795-6277 \\ E-mail: izumida@econ.tohoku.ac.jp
}

\begin{abstract}
This paper surveys the theoretical basis for, and empirical evidence on the relationship between ownership structure and corporate performance from two perspectives: ownership concentration and managerial ownership. We pay special attention to see reasons for discrepancies among previous empirical research, such as corporate governance environments, data issues, variable measurements, and estimation methods. General directions for future work are discussed as well.
\end{abstract}

Keywords: Ownership concentration, Managerial ownership, Corporate performance

\section{Introduction}

What ultimately matters for companies, policy makers and economists alike is whether ownership structure affects corporate performance, and if so, how. The fundamental insight into the issues dates back to Berle and Means (1932), who argue that the separation of ownership and control of modern corporations naturally reduces management incentives to maximize corporate efficiency. Their concerns were later developed by Jensen and Meckling (1976) into that has subsequently become known as "agency theory", which has been characterized as "a theory of the corporate ownership structure" and the guiding framework for ownership-performance studies. The central premise of the theory is that self-interested managers (controllers or agents) can engage in decision making and behaviors that may be inconsistent with maximizing value of shareholders (owners or principals). Ownership structure is often thought as an important instrument for corporate governance to resolve the conflict of interests between shareholders and managers. The past 30 years have witnessed the rapidly growing literature on this topic. Early work was largely descriptive. The empirical research appeared in the mid-1980s and has gotten a lot of attention recently.

The purpose of this paper is to survey the theory and evidence on the relationship between ownership structure and corporate performance. We divide the current literature in this area into two streams, one concerning the efficacy of concentration of ownership; the other revealing the distinctive motivations, abilities, and effectiveness of managerial ownership to influence corporate value. Although the ownership-performance relationship has been a hot topic for decades, scholars have not reached an agreement with it. Generally speaking, theoretical and empirical researches supplement each other. Since the ownership-performance relation is subject to controversy in theory, empirical research becomes more important to examine which of the logically possible explanations is the most probable. This paper emphasizes the consistency between theory and empirical evidence in this field. We take a step further to analyze the reasons for discrepancies among previous research. The most important reason is that the ownership-performance relation varies with the realities of corporate governance environments in which firms are embedded. The disagreement is also a reflection of differences in estimating technique applied - weather and how to account for the endogeneity of ownership, and a reflection of limitations on the ownership and performance measurements, data quality and selection bias. 
The remainder of this paper is organized as follows. Section 2 summarizes main competing views and empirical findings on the relationship between ownership concentration and corporate performance. Section 3 examines the distinctive roles of managerial ownership on performance. Reasons for discrepancies among previous empirical findings are discussed in section 4. Finally, conclusions and suggestions for further research are provided in section 5.

\section{Concentration of ownership and performance}

\subsection{Efficacy of ownership concentration: monitoring vs. expropriation}

Until the 1980s, the agency conflict between shareholders and managers has been the main concern of the literature on corporate governance. It is widely accepted that ownership concentration has the potential to limit the agency problem, and then generate improved corporate performance. This positive effect of ownership concentration can be explained by the efficient monitoring hypothesis, which contends that higher concentration of ownership gives large shareholders stronger incentives and greater power at lower cost to monitor management. Grossman and Hart (1986) argue that shareholders with a large stake in the company show more willingness to play an active role in corporate decisions because they partially internalize the benefits from their monitoring effort. The methods used by large shareholders to monitor and intervene are range from informal conversations with management to formal proxy contests (Shleifer and Vishny, 1986, 1997). Even when they cannot monitor the management themselves, large shareholders can facilitate third party takeovers by splitting the large gains on their own shares with the bidder.

Since the late 1990s, the potential conflict of interest between controlling shareholders and minority investors has become a focus of academics' attention. Concentrated ownership structure may permit dominant shareholders expropriate minority investors, known as the expropriation-of-minority-shareholders hypothesis. Large shareholders represent their own interests, which need not coincide with the interests of other stakeholders in the firm. Pyramidal control structure, cross shareholding, and super-voting rights allow the controlling shareholders to secure control rights without commensurate cash flow rights (La Porta et al., 1999; Claessens et al., 2000). The divergence between control rights and cash flow rights induces the pervasive problems of controllers' expropriation (Denis and McConnel, 2003; John C. Coffee, 2005). Johnson et al. (2000) use the term "tunneling" to describe the transfer of resources out of firms for the benefits of controlling shareholders. Small investors' fear of being expropriated may induce the high cost of capital to firms, so it follows inefficient investment.

\subsection{Empirical evidence}

Theoretical arguments alone cannot unambiguously predict whether benefits of monitoring outweigh costs of expropriations at the given level of concentration. The link between concentration and corporate value is thus an empirical matter. Demsetz and Lehn (1985) were the first to empirically analyze the relationship. They argue that ownership concentration is determined by firm size, control potential, regulation and amenity potential, and then estimate linear regressions of accounting profit rate on concentration - the fractions of shares owned by the five, the twenty largest shareholders, and a Herfindahl measure for 511 U.S. firms. No significant relationship between ownership concentration and accounting profit rate is found (Table 1). Holderness and Sheehan (1988) compare 101 pairs of listed firms and reach the same conclusion of no systematic performance difference associated with large U.S. shareholders.

In contrast, in Continental Europe and East Asian economies, studies suggest that block ownership per se might often have a positive effect on firm performance for better monitoring. Claessens and Djankov (1999) find a 10 percent increase in concentration leads to a 2 percent increase in short-term labor productivity and a 3 percent increase in short-term profitability in the Czech Republic. Earle et al. (2005) imply that the size of the largest block increases profitability and efficiency strongly and monotonically in Hungary over 1996 to 2001. Xu and Wang (1999) find a positive relation between concentration and performance in China.

\section{Managerial ownership and performance}

\subsection{Efficacy of managerial ownership: alignment vs. entrenchment}

Some shareholders may be entirely passive investors, whereas others are more active and do perform an important monitoring service. Various motivations and abilities of different types of shareholders may result in their distinctive effectiveness to influence major corporate decisions and value. Managerial ownership (insider ownership) is the most popular topic that has been extensively studied. Jensen and Meckling (1976) formalize the relation between managerial ownership and corporate value. They propose the convergence-of-interest hypothesis to explain the positive effect of managerial ownership. That is, a sufficiently high level of managerial ownership helps align the interests of managers and shareholders resulting in superior performance. A manager's claim on the performance outcomes and burden on the costs associated with non-value maximizing behavior increase with his fraction of the equity. Thus, a high level of managerial ownership increases the probability that the manager devotes significant effort to creative activities and immunizes himself from misappropriating the corporate resources. The manager will act to maximize firm/shareholder value due to his own interests. 
However, Demsetz (1983) and Fama and Jensen (1983) propound offsetting costs of significant management ownership - the managerial entrenchment hypothesis. According to this hypothesis, the firm will be less valuable when managers with a significant equity have enough voting power to ensure their position inside the firm or to allow their free from outside checks. A manager held smaller shares can be disciplined toward firm value maximization by the market forces, while a manager controlled a substantial equity can entrench himself from the market restriction, such as the takeover threat or the managerial labor market. Consistent with this, Stulz (1988) develops a model of firm valuation to explain how large shareholdings help managers to be entrenched and decrease the monitoring of external control mechanisms. The impact of managerial ownership on performance therefore is a double-edged sword.

\subsection{Endogeneity of ownership}

The initial argument about the endogeneity of ownership structure is formulated by Demsetz (1983). He contends that ownership structure should be thought of as an endogenous outcome of decisions that ought to be influenced by the profit-maximizing interests of shareholders. An optimal ownership level is likely to vary with certain firm characteristics. Some factors (firm size, industry, investor protection, etc.) that determine ownership structure probably also have significant effects on performance. It is complicated to evaluate the effects of ownership structure which is itself endogenous to the system that includes performance goals. For example, that the presence of concentrated ownership has a positive influence on performance may mean that firm value is higher due to better monitoring by large shareholders. However, it could also arise because concentration is more common in a particular industry which is high-valued, on average. Thus, endogeneity may lead researchers to see a relationship which does not actually exist - a spurious regression, or fail to find a relationship which actually exists. The central issue is to isolate the ownership-performance relation from a complex set of interrelationships.

Since Jensen and Meckling (1976), ownership has been supposed to be a determinant of corporate performance, i.e. the causality runs from ownership to performance. Recent studies argue the causation between ownership and performance could, in some circumstances, run in the opposite direction. Holderness (2003) raises a reverse-causation problem: corporate performance may be a determinant of the ownership structure, but not vice versa. It is conceivable that outside shareholders often choose to reward the insiders for good past performance, such as the performance-based compensation in the form of stock options. Moreover, the insider information may create the incentive for managers to change their holdings according to their expectation of future firm performance (Demsetz and Villalonga, 2001). High performance will therefore lead to higher levels of insider ownership. In contrast, when share prices are high relative to expectations, there are large immediate gains and low expected future gains. Insiders may be more tempted to sell parts of their shares in a particular firm at high share prices due to the high risk and opportunity cost of holdings (Pedersen and Thomsen, 2000). This argument indicates a negative effect of performance on managerial ownership. The theoretical discrepancies have resulted in various empirical methods used to analyze the issues.

\subsection{Empirical evidence}

\subsubsection{Managerial ownership as a function of performance}

Morck et al. (1988) examine the relationship between management ownership, as measured by the combined stake of all board members, and market value of the firm, as measured by Tobin's Q, for a 1980 cross-section of 371 Fortune 500 firms. To test two hypotheses of the convergence-of-interest and entrenchment, they estimate piecewise linear regressions allowing for slopes to change at two turning points, 5 and 25 percent. The results show that in some ranges of ownership (below 5 percent and over 25 percent), Tobin's Q is positively related to board ownership, but in others, a negative relation is found.

Following Morck et al. (1988), McConnell and Servaes (1990) and Holderness et al. (1999), among others, find significantly inverse U-shaped relationship in the similar way (Figure 1). The results suggest that the convergence-of-interest effect is more important at both low levels and high levels of managerial ownership, but the entrenchment effect is dominant at the medium levels of shareholdings.

\subsubsection{Simultaneous equation studies}

Recently an ongoing proliferation of research applies the simultaneous equation method to deal with the endogeneity problem of managerial ownership. Cho (1998) introduces investment as an intermediate variable between ownership and corporate value. Based on a sample of 326 Fortune 500 manufacturing firms in 1991, ordinary least squares regression (OLS) results suggest that there are significant non-monotonic relations between ownership and Tobin's Q, and between ownership and investment. To address the endogenous effect, he estimates a 3-equation model simultaneously determining ownership, Q-values and investment (capital and R\&D expenditures). The two-stage least squares regression (2SLS) results suggest that investment affects corporate value which, in turn, affects ownership structure, but the effect of ownership on Q becomes insignificant (Table 2).

Demsetz and Villalonga (2001) examine the relationship when ownership is treated as not only an endogenous variable but also an amalgam of shareholdings owned by persons with different interests (the fractions of shares owned by 
management and by outside shareholders) for 223 U.S. firms. OLS results suggest that ownership is significant in explaining performance. However, when endogeneity is taken into account, 2SLS results show no effect of ownership on performance (Table 3).

Another way to solve the endogeneity problem of ownership is to use panel data and control fixed individual effect. Himmelberg et al. (1999) argue that both managerial ownership and performance are endogenously determined by exogenous changes in the firms' contracting environment, i.e. observable and unobservable firm characteristics. The unobserved firm heterogeneity may induce a spurious regression. Using unbalanced panel data from the Compustat universe over the period 1982-1992 and controlling both for observed firm characteristics and firm fixed effects, they find no evidence to suggest that managerial ownership affects firm performance. They also explore the use of instrumental variable as an alternative to fixed effects to control the endogeneity of ownership. It is difficult to find suitable instruments that are correlated with ownership, but not with the error terms of equations. Without a more suitable candidate, they select firm size and stock price volatility as instruments and find a significant inverse- $U$ relation between ownership and firm value. However, due to the weakness of the instruments, the evidence of a causal link seems to be tentative.

\section{Reasons for discrepancies among previous research}

In the field of corporate governance, empirical results appear to provide different, even conflict evidence on the effects of ownership on performance (Appendix). What accounts for such disagreement? We think it may be a result that researchers apply different estimation methods, performance and ownership measures, samples, and more importantly, whether and how they are concerned with corporate governance environments in which firms are embedded.

\subsection{Corporate governance environment}

One important reason of that the existing evidence fails to establish a convincing link between ownership structure and corporate performance is that the relation may be diverse according to the realities of the corporate governance environment - communities, political environments, cultures and ideologies, industry organization, and more generally financial markets and laws which particular absorb scholars. Comparing across countries, it is useful to distinguish and contrast two categories of national systems of corporate governance: a market-oriented (Anglo-American) system and an insider/control-oriented (European-Japanese) system. Both systems are broadly associated with various developments of financial markets and law systems. Consistent with the section 2.2, empirical studies are likely to show that blockholders have a positive effect on corporate performance in insider-oriented countries, such as Continental Europe and East Asian economies; while the overall impact of blockholders on performance seems to be insignificant in the market-oriented system, such as the USA and UK. This line of reasoning would suggest that ownership structure matters, but its impact is contingent on a specific governance environment. In the market-oriented system, ownership concentration is very low, stocks are frequently traded and shareholder rights are well protected. In principle ownership does no matter much to a company, because management is largely held in check by external forces of market competition and laws/regulations, rather than shareholders. But in the rest of the world, the insider-oriented system, ownership is much more concentrated, many stocks are illiquid and investor protection is weak. Ownership structure is likely to be more important to a company due to the essentiality of shareholders' monitoring role.

A possible failure of existing studies is that they generally ignore the influence of environmental context, especially the extent to which corporate governance environments influence the ownership-performance relation. In a specific economic environment, different ownership (diffused or concentrated) and types of shareholders (stable shareholders or market investors) bring various benefits and costs to firms. The actual trade-off between the benefits and costs is contingent on economic environments. That is, a specific corporate governance environment may determine whether the ownership-performance relation is positive, negative or insignificant. Placing the ownership-performance relation within a broader economic environment may thus yield additional insight into this field.

\subsection{Estimation method}

Different conclusions regarding the relationship between ownership and performance are partially owing to model specification and estimating technique applied. Endogeneity of ownership structure is the most important reason for the divergent estimates. With the assumption that ownership structure is exogenously determined, a common approach for estimating the relation is single equation of regressing corporate performance on such variables as the percentage of equity ownership. While the single equation studies do not agree upon detailed results, most report significant effects of ownership on performance. However, if ownership is endogenously determined, single-equation estimation will produce biased results. Simultaneous equation models and the instrumental variable regressions will result in better estimates. The equations for the most general case of ownership and performance being jointly determined are as follows:

Performance $=f$ (ownership, financial leverage, firm size, investment, industry, etc.)

Ownership $=g$ (performance, firm size, investor protection, risk, liquidity, industry, etc.) 
It is also possible that there is no systematic relation between ownership and performance at all. A statistically significant relationship found in empirical studies may be attributed to unobservable heterogeneity among firms. Thus, using panel data and controlling for fixed individual effect is a way to solve the endogeneity caused by the spurious relation. However, the methodology is questioned by Zhou (2001) who argues that fixed effects may not allow detecting an effect of ownership on performance even if one exists due to stability of ownership over time.

Contrary to the single equation models, the simultaneous equation models or fixed effect models have generally found the impact of ownership on performance to be insignificant. Whether ownership is an endogenous variable, of course, has important implications as to which method should be used. When securities markets are less liquid, it is difficult for shareholders to alter their portfolios based on the firms' recent performance. Ownership might be exogenous or at least predetermined with respect to performance, and therefore single regression estimates are defensible. When securities markets are well developed and ownership can vary with performance, simultaneous equation models may help overcome the endogeneity problem. Unfortunately, the test for endogeneity of ownership is not clear-cut so far.

\subsection{Measurements of corporate performance}

Existing research employs three alternative criteria for performance in corporations. First is a market based measure Tobin's Q, the market value of the firm over its replacement cost. Since it can provide a viewing window into the firm through the market's valuation of the securities and capture the long-term impacts of corporate actions, Tobin's $Q$ is a well-accepted proxy for firm valuation and widely used in the literature of corporate governance. However, the way in which Tobin's Q is computed suffers from some problems. Demsetz and Villalonga (2001) argue that Q distorts performance comparisons of firms with different intangible capital, because the numerator of Q (market value) partly reflects a firm's intangible assets; but the denominator (replacement cost) includes the firm's tangible assets only. Furthermore, it incorporates Q into accounting artifacts that many studies substitute the depreciated book value of total assets for replacement cost as the denominator of Q.

Secondly, accounting performance measures, such as return on asset (ROA) and return on equity (ROE), are employed in many empirical studies solely or as a complement of Tobin's Q. While primarily accounting information reflects the short-term profitability of the firm's operations, it also induces many problems, including not reflecting all agency costs and long-term returns, easily manipulated by insiders, and affected by accounting practices. Accounting data is not thought as eligible variables in measuring a firm's performance in countries where the accounting standards are imperfect, especially in developing countries.

Finally, productivity analysis is also used to explore the effects of ownership structure on performance. Total factor productivity (TFP), usually based on Cobb-Douglas production function, addresses any effects in total output not caused by capital and labor inputs, and is a general accepted measure of technical efficiency, which is seen as the real driver of long-term growth and forward-looking performance in corporations. It is nature that the studies using different performance measures often present different results.

\subsection{Measurements of ownership structure}

A number of studies that came after Demsetz and Lehn (1985) measure concentration of ownership with respect to a group of blockholders, frequently as the fraction owned by the five, ten, or twenty largest shareholders. Earle et al. (2005) contend that the group measure may obscure some important aspects of interactions among large shareholders and the pattern of concentration, which may crucially influence the estimate of the effect of concentration on performance. For example, if a dominant owner presents in a firm, additional small blockholders might make little marginal contributions to monitoring, and serve even to increase costs of concentration. In this situation, measuring concentration by the largest holdings seems to be better than using the joint holdings. Earle et al. (2005) believe that the lack of attention to the limitation of the group measure could explain partially the conflicting findings of previous studies.

Another issue that draws researchers' attention is whether the fraction of shares owned by insiders is the appropriate measure to be representative of the strength or incentives of professional management. Demsetz and Villalonga (2001) argue that a board member, for example, who has large holdings of the company's stock, often has interests identical to those of outside investors, rather than professional management. A large level of management shareholdings, therefore, is not so reliable an index of the ability of professional management to ignore shareholders. Thus, it is especially important that we understand: which is the better measure of incentives to management.

\subsection{Data issues}

Discrepancies may arise from data quality, including inconsistent statistical criteria, accuracy, and selection bias. The data from various sources suffers from the inconsistent issue. There is not, for example, a standard definition used for ownership. Kole (1995) compares three widely-used sources for ownership data in the U.S.: proxy statements of corporations (PROXY), Corporate Data Exchange (CDE) Stock Ownership Profiles, and Value Line Investment Survey (VALUE LINE). The three data sources are in considerable disagreement in definition of ownership: "PROXY includes 
officers and directors as a group; $\mathrm{CDE}$, all board members that individually are beneficial owners of at least 0.2 percent of their company's equity; and, VALUE LINE reports the 'largest group of shareholders or insiders'." (p.420) Although Kole prove that differences in ownership data cannot explain contradictory empirical evidence, the ownership coefficients in the separate regressions for the same sample from the three data sources are different and their statistical significance varies dramatically.

Dlugosz et al. (2006) highlight that the large shareholder data in Compact Disclosure (CD) Database of Standard \& Poor's, a widely used commercial product in the United States, has many mistakes and biases: overlaps, misrepresentation of preferred shares, and other problems. In a representative analysis of outside blockholders and firm value, they find that using the uncorrected blockholder data as an independent variable leads to significant biases for the blockholder coefficients. Thus, if the blockholder effect is the key independent variable, it is necessary to work with "clean" block data.

Furthermore, most studies use data from large enterprises, particularly listed companies, due to the enormous difficulties in collecting data for smaller enterprises. Large enterprises are thus overrepresented in empirical analysis. Kole (1995) demonstrates that divergences in the effect of ownership on performance are attributable to differences in the size of sample firms. Similarly, developed countries, especially the U.S., are overrepresented also because disclosure of information is much less in most developing countries.

\section{Conclusions and further research}

Our reading of the extant literature on the relationship between ownership structure and corporate performance suggests the following conclusions:

- Concentrated ownership is associated with the benefits of better monitoring and the costs of the expropriation by large shareholders. However, in Continental Europe and East Asian economies, with a high average ownership concentration, empirical studies find similar results that blockholders have a positive effect on corporate performance.

- Some empirical research has tended to find that the relationship between firm value and managerial ownership would be inverse U-shaped, suggesting the convergence-of-interest and entrenchment effect of insider ownership. But the effect has tended to become insignificant when attempts are made to control for the endogeneity of ownership structure.

- One important reason for discrepancies among previous research is that the ownership-performance relation varies with the realities of corporate governance environments in which firms are embedded.

- The disagreement is also owing to model specification and estimating technique applied. Single equation models, simultaneous equation models, and fixed effect models report different results, because of their divergence of controlling for the endogeneity of ownership. Moreover, variable measurements and data issues could explain partially the discrepancies.

While much has indeed been learned about the relation between ownership and performance, there are several important areas that need further research. We believe that, in particular, three aspects are required to be understood much better.

One avenue of research would be to more closely examine the endogenous issues. It requires that empirical tests are carefully designed and the results carefully interpreted. While more recent work attempts to control for this endogeneity in one way or another, it is very tentative up to now.

The second vital area of research is to investigate the indirect relationship between ownership and performance via corporate governance mechanisms. Ownership structure has important implications for corporate strategy, e.g. investment decision, takeover, compensation schemes, management successions, dividend policy, and long- or short-term orientation of managers, which in turn, influence corporate performance. Up to now, research has focused on the direct relationship between ownership and performance. It is also of interest to find how owners use the mechanisms to control managerial discretion, and then affect the value of firms.

Finally, further examining the cross-national differences in corporate governance environments will be an interesting topic of research. As mentioned above, the ownership-performance relationship varies across countries and over time. A particular ownership structure that is valuable for one economy may have no impact on another, making it difficult to pick up a definite relation. Thus, it is well worth contextualizing ownership-performance relation within a more comprehensive perspective (Figure 2).

\section{References}

Berle, A. A., \& Means, G. C. (1932). The modern corporation and private property. New York: Macmillan.

Cho, M.-H. (1998). Ownership structure, investment and the corporate value: An empirical analysis. Journal of Financial Economics, 47, 103 - 121.

Claessens, S. \& Djankov, S. (1999). Ownership concentration and corporate performance in the Czech Republic. 
Journal of Comparative Economics, 27, 3, 498-513.

Claessens, S. Djankov, S., \& Lang, L. H. P. (2000). The separation of ownership and control in East Asian corporations. Journal of Financial Economics, 58, 1-2, 81-112.

Demsetz, H. (1983). The structure of ownership and the theory of the firm. Journal of Law and Economics, 26, 375-390.

Demsetz, H. \& Villalonga, B. (2001). Ownership structure and corporate performance. Journal of Corporate Finance, 7 , $209-233$.

Demsetz, H. \& Lehn, K. (1985). The structure of corporate ownership: Causes and consequences. Journal of Political Economy, 93, 6, 1155-1177.

Denis, D. K. \& McConnell, J. J. (2003). International corporate governance. Journal of Financial and Quantitative Analysis, 38, 1, 1-36.

Dlugosz, J., Fahlenbrach, R., Gompers, P. \& Metrick, A. (2006). Large blocks of stock: Prevalence, size, and measurement. Journal of Corporate Finance, 12, 594-618.

Earle, J. S., Kucsera, C. \& Telegdy, Á. (2005). Ownership concentration and corporate performance on the Budapest stock exchange: Do too many cooks spoil the goulash. Corporate Governance, 13, 2, 254-264.

Fama, E. F. \& Jensen, M. C. (1983). Separation of ownership and control. Journal of Law and Economics, 26, 301-325.

Grossman, S. J., \& Hart, O. D. (1986). The costs and benefits of ownership: A theory of vertical and lateral integration. Journal of Political Economy, 94, 4, 691-719.

Himmelberg, C. P., Hubbard, R. G. \& Palia, D. (1999). Understanding the determinants of managerial ownership and the link between ownership and performance. Journal of Financial Economics, 53, 353-384.

Holderness, C. G. (2003). A survey of blockholders and corporate control. FRBNY Economic Policy Review, 9, 1, 51-64.

Holderness, C. G., Kroszner, R. S. \& Sheehan, D. P. (1999). Were the good old days that good? Changes in managerial stock ownership since the great depression. Journal of Finance, 54, 435-469.

Holderness, C. \& Sheehan, D. (1988). The role of majority shareholders in publicly held corporations: An exploratory analysis. Journal of Financial Economics, 20,317-346.

Jensen, M. \& Meckling, W. (1976). Theory of the firm: Managerial behavior, agency costs, and ownership structure. Journal of Financial Economics, 3, 305-360.

John C. Coffee, Jr. (2005). A theory of corporate scandals: Why the U.S. and Europe differ. Columbia Law and Economics Working Paper No. 274.

Johnson, S., La Porta, R., Lopez-de-Silanes, F. \& Shleifer, A. (2000). Tunneling. American Economic Review, 90, 2 , $22-27$.

Kole, S. R. (1995). Measuring managerial equity ownership: A comparison of sources of ownership data. Journal of Corporate Finance, 1, 413-435.

La Porta, P., Lopez-de-Silanes, F. \& Shleifer, A. (1999). Corporate ownership around the world. Journal of Finance, 54, 471-517.

McConnell, J. \& Servaes, H. (1990). Additional evidence on equity ownership and corporate value. Journal of Financial Economics, 27, 595-612.

Morck, R., Shleifer, A. \& Vishny, R. (1988). Management ownership and market valuation: An empirical analysis. Journal of Financial Economics, 20, 293-315.

Pedersen, T. \& Thomsen, S. (2000). The causal relationship between insider ownership, owner identity and market valuation among the largest European companies. Copenhagen Business School, Working Paper.

Shleifer, A. \& Vishny, R. W. (1986). Large shareholders and corporate control. Journal of Political Economy, 94, 3, 461-488.

Shleifer, A. \& Vishny, R. W. (1997). A survey of corporate governance. Journal of Finance, 52, 2, 737-783.

Stulz, R. (1988). Managerial control of voting rights. Journal of Financial Economics, 20, 25-59.

$\mathrm{Xu}, \mathrm{X}$. \& Wang, Y. (1999). Ownership structure, corporate governance in Chinese stock companies. China Economic Review, 10, 75-98.

Zhou, X. (2001). Understanding the determinants of managerial ownership and the link between ownership and performance: Comment. Journal of Financial Economics, 62, 559-571. 


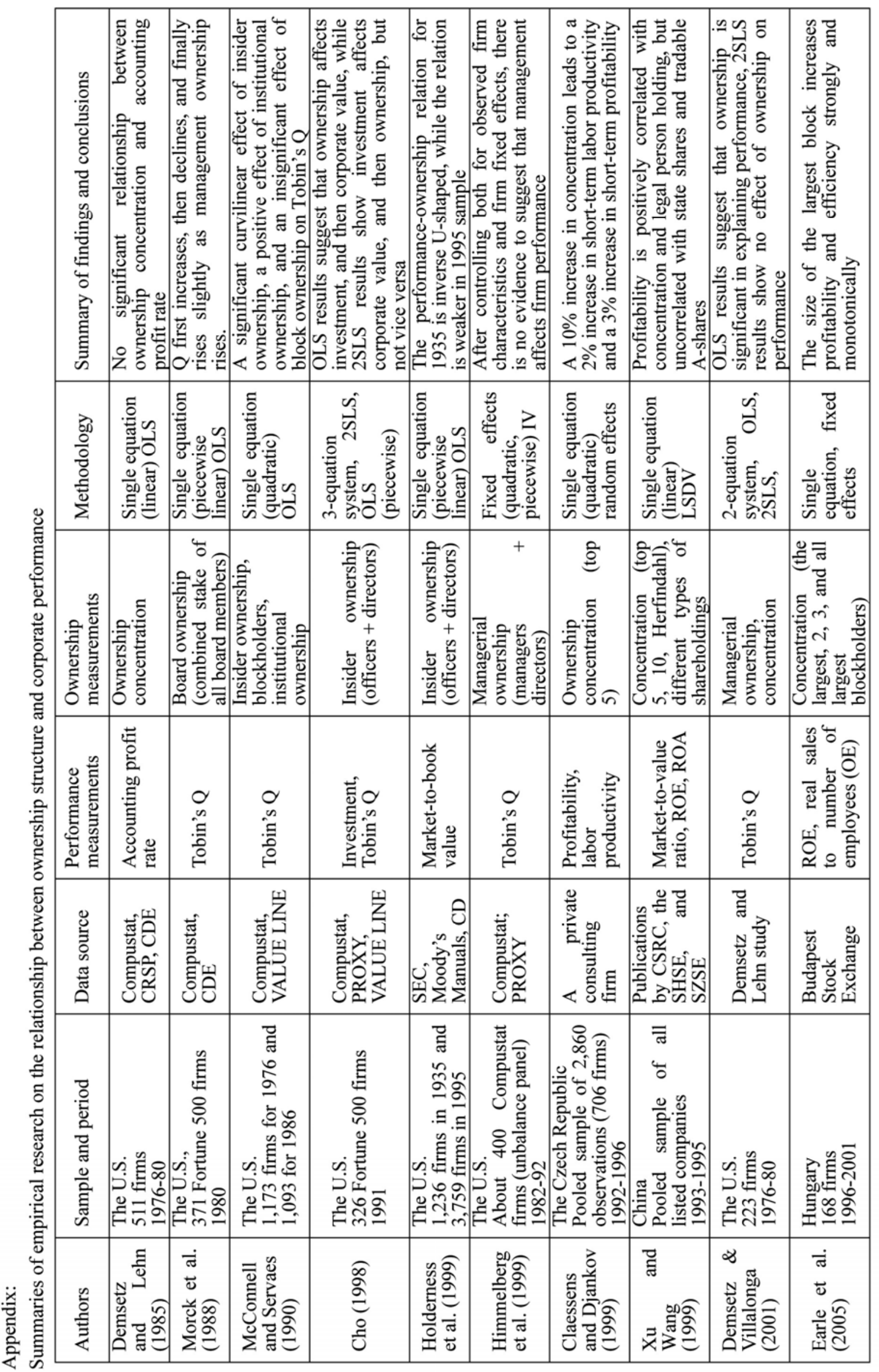


Table 1. Regression results, Demsetz and Lehn: for a sample of 511 U.S. firms 1976-80.

\begin{tabular}{llllll}
\hline Equation & LA5 & LA20 & LAH & $\ldots \ldots$ & $R^{2}$ \\
\hline$(1)$ & $-0.02(0.9)$ & & & & 0.10 \\
$(2)$ & & $-0.004(0.2)$ & & & 0.10 \\
$(3)$ & & & $-0.02(0.9)$ & & 0.10 \\
\hline
\end{tabular}

Source: Demsetz and Lehn, 1985, table 9.

The dependent variable is the mean value of accounting profit rate for the 5-year period. LA5, LA20, and LAH are logistic transformation to the percentages of shares owned by top 5 and top 20 shareholders, and to the Herfindahl measure. t-statistics are in parentheses.

Table 2. Simultaneous regression results, Cho: for a sample of 326 Fortune 500 firms in 1991.

\begin{tabular}{lllllll}
\hline & \multicolumn{2}{l}{ Capital expenditures model } & \multicolumn{3}{l}{ R\&D expenditure model } \\
\cline { 2 - 7 } & $\begin{array}{l}\text { Insider } \\
\text { ownership }\end{array}$ & $\begin{array}{l}\text { Corporate } \\
\text { value }\end{array}$ & Investment & $\begin{array}{l}\text { Insider } \\
\text { ownership }\end{array}$ & $\begin{array}{l}\text { Corporate } \\
\text { value }\end{array}$ & Investment \\
\hline Tobin's Q & 0.202 & & 0.033 & 0.188 & & 0.033 \\
& $(2.67)$ & & $(2.04)$ & $(2.60)$ & & $(2.87)$ \\
INS1 & & 1.087 & -0.123 & & -1.774 & -0.084 \\
& & $(0.45)$ & $(-1.26)$ & & $(-0.60)$ & $(-0.80)$ \\
INS2 & & 0.957 & -0.060 & & 1.370 & -0.091 \\
& & $(0.44)$ & $(-1.53)$ & & $(0.54)$ & $(-0.73)$ \\
INS3 & & 1.431 & -0.124 & & 2.613 & -0.065 \\
& & $(0.61)$ & $(-1.03)$ & & $(0.93)$ & $(-0.44)$ \\
Investment & -5.377 & 22.987 & & -3.385 & 23.614 & \\
$\ldots . .$. & $(-1.01)$ & $(4.46)$ & & $(-1.23)$ & $(3.12)$ & \\
$\bar{R}^{2}$ & & & & & & \\
& 0.046 & 0.171 & 0.183 & 0.076 & 0.189 & 0.285
\end{tabular}

Source: Cho, 1998, table 4.

Using 2SLS to estimate the following equations:

Insider ownership $=f$ (Market value of common equity, Corporate value, Investment, Volatility of earnings, Liquidity, Industry),

Corporate value $=g($ Insider ownership, Investment, Financial leverage, Assets size, Industry $)$,

Investment $=h$ (Insider ownership, Corporate value, Volatility of earnings, Liquidity, Industry).

Definitions of insider ownership (INS1, INS2, and INS3) are similar to Morck et al. (1988) with different breakpoints of 0.07 and 0.38 . t-statistics are in parentheses.

Table 3. Regression results, Demsetz and Villalonga: for a sample of 223 U.S. firms 1976-80.

\begin{tabular}{|c|c|c|c|c|}
\hline Equation & LAvMH & LA5 & AvQ & $\bar{R}^{2}$ \\
\hline (1)AvQ (OLS) & $0.0298(2.14)$ & $-0.0566(-1.98)$ & & 0.36 \\
\hline (2)AvQ (2SLS) & $0.0287(0.47)$ & $-0.0721(-1.24)$ & & $* * *$ \\
\hline (3)LAvMH (OLS) & & & $0.1093(0.37)$ & 0.36 \\
\hline (4)LAvMH (2SLS) & & & $-2.3916(-3.21)$ & $* * *$ \\
\hline
\end{tabular}

Source: Demsetz and Villalonga, 2001, table 6.

Ordinary and two-stage least squares regress Tobin's Q (AvQ) and managerial shareholdings (LAvMH) on ownership concentration (LA5), and other control variables. $t$-statistics are in parentheses. 

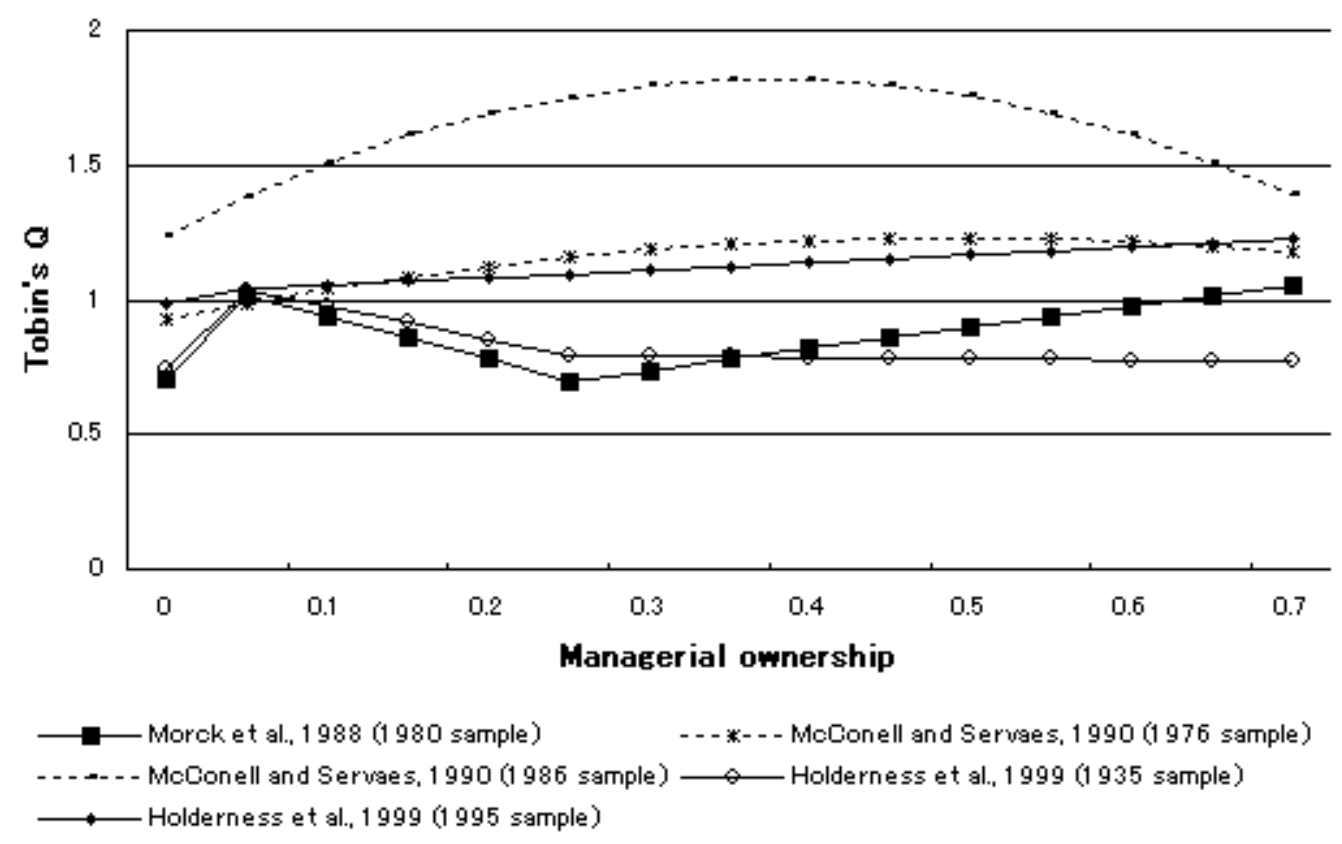

Figure 1. Previous studies of effects of managerial ownership on Tobin's Q

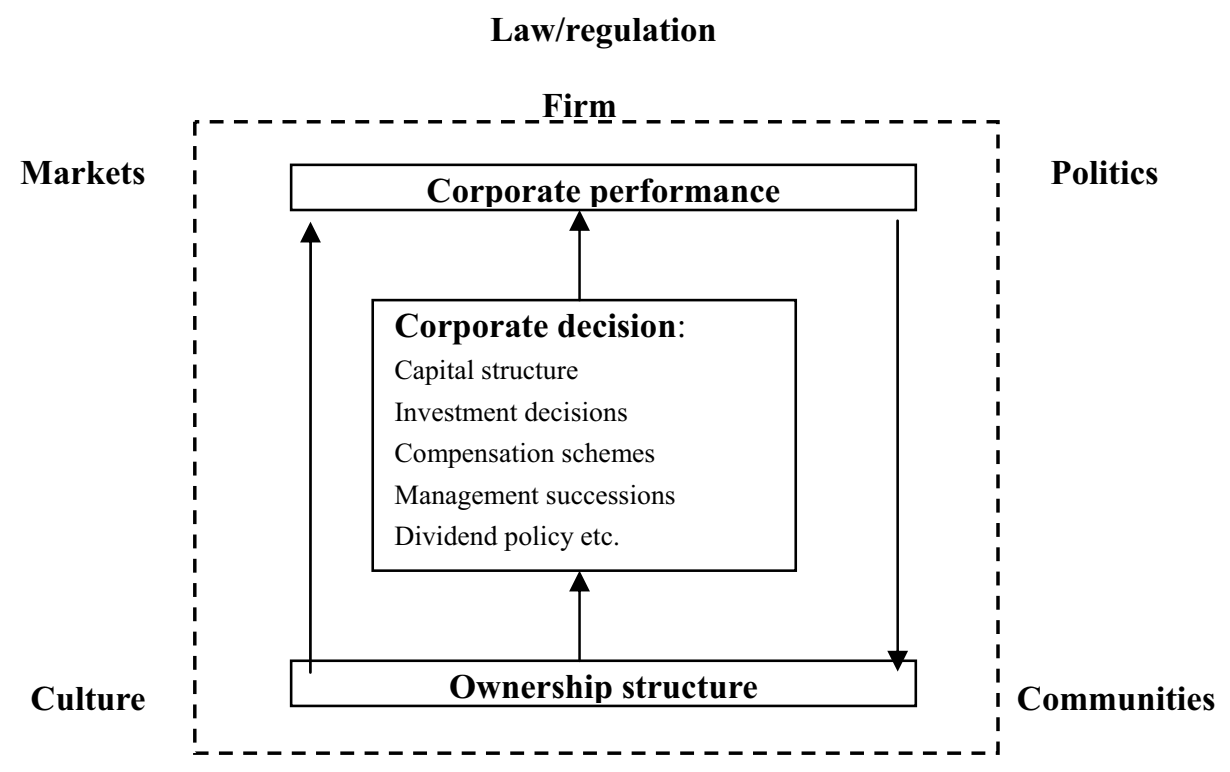

Figure 2. Framework of ownership-performance research 


\title{
Linkage between Money and Prices: A Causality Analysis for Malaysia
}

\author{
Mohd Fahmi Ghazali \\ Labuan International School of Business and Finance \\ Universiti Malaysia Sabah, Labuan International Campus \\ Jalan Sg. Pagar, 87000 W.P. Labuan, Malaysia \\ Tel: 60-87-466-715 E-mail: mohdfahmi_ghazali@yahoo.com \\ Hanudin Amin \\ Labuan International School of Business and Finance \\ Universiti Malaysia Sabah, Labuan International Campus \\ Jalan Sg. Pagar, 87000 W.P. Labuan, Malaysia \\ Tel: 60-87-466-718 E-mail: hanudin@mailkal.ums.edu.my \\ Mohd Zulkifli Muhammad \\ Labuan International School of Business and Finance \\ Universiti Malaysia Sabah, Labuan International Campus \\ Jalan Sg. Pagar, 87000 W.P. Labuan, Malaysia \\ Tel: 60-87-460-498 E-mail: zulrider@yahoo.com \\ Siti Hajar Samsu \\ School of Business and Economics \\ Universiti Malaysia Sabah \\ Locked Bag 2073 \\ 88999 Kota Kinabalu, Sabah, Malaysia \\ Tel: 60-88-320-000 Ext. $1551 \quad$ E-mail: sitihajar@ums.edu.my
}

\begin{abstract}
The main purpose of this paper is to examine the relationship between money and prices in Malaysia. This research considers monthly data of money supply M1, M2 and M3 and consumer price index (CPI) from January 1974 to September 2006. The Johansen cointegration method suggests that there is a long-run equilibrium relationship between money supply with prices. Toda-Yamamoto causality tests find that there is uni-directional causality running from money supply to CPI. Therefore, the empirical evidence from Malaysia supports the quantity theorist's view.
\end{abstract}

Keywords: Causality, Money, Prices, Malaysia

\section{Introduction}

This paper investigates the relationship between money supply and prices in Malaysia using monthly data over the period January 1974 to September 2006. Nowadays, empirical analysis on money and prices relationship has received greater attention, as there is a move to assign the single objective to the central bank. Among likely candidates of monetary policy objective, price stability is the single most important objective. Assignment of price stability as the single objective of monetary policy hinges on the empirical strength of money-consumer price index $(C P I)$ relationship. If empirical result show a strong and robust relationship between money supply and $C P I$, then the central bank an opt for price stability as its single objective.

Over the past two decades, policy makers have become more aware of the social and economic cost of inflation and more concerned with a stable price level as a goal of economy policy. Price stability is desirable because a rise in price level (inflation) creates uncertainly in the economy, and that may hamper economy growth. Not only do public opinion surveys indicate that the public is very hostile to inflation, but also a growing body of evidence suggests that inflation leads to lower economic growth (Fisher, 1993). 
There is a strong positive correlation between changes in money supply and aggregate prices. The direction of causality, however, has long been a matter of controversy. The widely accepted quantity theory of money argues that inflation is caused by exogenous changes in the money supply. A minority 'structuralist' view holds that inflation, develops from pressures arising in economic growth in economies with institutional rigidities, particularly in agriculture and international transactions. Monetary and fiscal authorities choose to expand the money supply, ratifying the inflationary pressures, rather than face unemployment or disruptions in consumption and investment. Underdeveloped financial markets and a weakly independent central bank can contribute to the likelihood of money supply growth. Under this view, money supply expansion is a consequence of, and therefore caused by, structural inflation (Pinga and Nelson, 2001).

The motivation of this study is the need for a further empirical work analyzing the relations between money and prices in Malaysia to reassert that causality exist. More technically, this research applies the modified-Wald test (MWald) test approached by Toda and Yamamoto (1995) to reinvestigate the causal relations between money supply and price. In addition, this study will also use the most appropriate monetary target, $M 1, M 2$, and $M 3$ for curbing inflation and applied to a longer and more recent period.

The rest of the paper is organized as follows. In the next section, we review some empirical studies and the main findings. Section three gives a brief discussion about the data set used in the present paper and outlines the methodology employed. In section four we discusses the empirical results, while section five we provide concluding remarks.

\section{Literature review}

The direction of causality between money and prices have been tested in Malaysia over various periods of time. The results have yielded conflicting evidence. For example, Tan and Baharumshah (1999) has examined the dynamic causal chain among money (M1, M2 and M3), real output, interest rate and inflation in Malaysia using monthly data from 1975 to 1995. They found that price does Granger cause $M 2$ through short-run channel. In addition, the error correction model has provided evidence that real income, interest rate and price do jointly lead $M 2$ in the long run, and the real output, interest rate and $M 2$ do jointly cause price. The study, however, did directly not tell the causal relations between money and price rather than joining the other variables.

Masih and Masih (1998) investigated the causality between money (M1 and M2) and prices in four Southeast Asian developing countries, namely Thailand, Malaysia, Singapore, and the Philippines from January 1961 to April 1990. They found that money supply lead prices which are in agreement with the monetarist view.

Pinga and Nelson (2001), on the other hand, examined the relationship between money supply and aggregate prices for 26 countries, and found that no causal relationship between prices and money (M1 and M2) in Malaysia. They also found that aggregate prices cause money supply in Chile and Sri Lanka, which are in agreement with the structuralist view. Evidence of money supply exogeneity was found to be strongest in Kuwait, Paraguay, and the US. Most countries exhibited mixed evidence of money supply endogeneity, with bi-directional causation between money supply and aggregate prices a common result.

Using modified Wald test, Tang (2004) examined the causality between money (M2) and prices in Malaysia from 1970:Q1 to 1998:Q4. He found that there is a uni-directional causality running from money to prices, and it supports the monetarist view.

Research on other countries has found both bi-directional causality and uni-directional causality. Jones (1989) examined the causality between money and prices in the US over the period 1959:Q1 to 1986:Q2. The results, however, show feedback relationship between the measures of money growth (M1 and $M 2)$ and inflation (CPI and wholesale price index $(W P I)$ ). On the other hand, Darrat (1986) examined the direction of causation between money and prices for Morocco, Tunisia and Libya over the period 1960:Q1 and 1980:Q2. The results show a uni-directional causation running from money to prices without feedback for all the three countries concerned. Darrat (1986) concluded that the results support the monetarist view that money causes inflation.

Monetary Division, Research Department, Nepal Rastra Bank (2001) found that there is a feedback interaction in Nepal from 1975:Q3 through 1999:Q2. Recent study by Benbouziane and Benamar (2004) on the three Maghreb countries found that there was a uni-directional causation from money to prices in the case of Morocco and Tunisia, supports Darrat's (1986) finding. On the other hand, the results also show the apparent absence of causality between money and prices in the case of Algeria, which is not easy to explain.

\section{Data and methodology}

\subsection{Data}

In order to perform the causality analysis, we use monthly data for $M 1, M 2$, and $M 3$ (in millions of ringgit). The $C P I$ (in 2000 prices) is used as proxy for price. The data set was drawn for the period from January 1974 to September 2006, which comprises 393 observations in total. The variables are obtained from various issues of the International Financial 
Statistics (IFS) published by the International Monetary Fund (IMF) and transformed into natural logarithm scale prior to analysis.

\subsection{Johansen Cointegration Tests}

A preliminary issue regarding the methodological procedure is related to the fact that the data generating process for most of the economic series exhibits a unit root. Time series properties, namely order of integration and cointegration, have been examined by applying the full information multivariate procedure proposed by Johansen (1988).

The cointegration methodology basically characterizes the existence of a long-run relationship. According to Johansen (1988), a $p$-dimensional vector autoregression (VAR) of order $k$ [VAR $(k)]$ can be specified as follows:

$$
Z_{t}=d+\prod_{1} Z_{t-1}+\ldots+\prod_{k} Z_{t-k}+\omega_{t}(t=1 \ldots T)
$$

We can rewrite this expression as,

$$
\Delta Z_{t}=d+\prod_{k} Z_{t-k}+\sum_{i=1}^{k-1} \theta_{i} \Delta Z_{t-i}+\omega_{t}
$$

Here $\Delta$ is the first difference operator, $\Pi$ and $\theta$ are $p$-by-p matrices of unknown parameters and $\omega_{t}$ is a Gaussian error term. Long-run information about the relationship between money and prices in Malaysia is contained in the impact matrix $\Pi$. When the matrix $\prod$ has full column rank, it implies that all variables in $Z_{t}$ are stationary. When the matrix $\Pi$ has zero column rank, the expression is a first differenced VAR involving no long-run elements. If, however, the rank of $\Pi$ is intermediate meaning that $0<\operatorname{rank}(\Pi)=r<p$, there will be $r$ cointegrating vectors that make the linear combinations of $Z_{t}$ become stationary or integrated.

There are two Johansen cointegration tests. First, the maximum likelihood estimation procedure provides a likelihood ratio test, called a trace test, which evaluates the null hypothesis of, at most, $r$ cointegrating vectors versus the general null of $p$ cointegrating vectors. A second, likelihood ratio test is the maximum eigenvalue test, which evaluates the null hypothesis of $r$ cointegrating vectors against the alternative of $(r+1)$ cointegrating vectors.

\subsection{Granger Causality Tests based on Toda and Yamamoto levels VAR}

To examine the issue of causations, we have employed a modified version of the Granger causality test, which is robust for the cointegration features of the process. This procedure was suggested Toda and Yamamoto (1995) with the objective to overcome the problem of invalid asymptotic critical values when causality tests are performed in the presence of non-stationary series. Zapata and Rambaldi (1997) explained that the advantage of using the Toda-Yamamoto procedure is that in order to test Granger causality in the VAR framework, it is not necessary to pre-test the variables for the integration and cointegration properties, provided the maximal order of integration of the process does not exceed the true lag length of the VAR model. According to Toda and Yamamoto (1995), Toda-Yamamoto procedure however does not substitute the conventional unit roots and cointegration properties pre-testing in time series analysis. They are considered as complimentary to each other.

The Toda-Yamamoto procedure basically involves the estimation of an augmented VAR $\left(k+d_{\max }\right)$ model, where $k$ is the optimal lag length in the original VAR system, and $d_{\max }$ is the maximal order of integration of the variables in the VAR system. The Toda-Yamamoto procedure uses a modified-Wald test (MWald) test for zero restrictions on the parameters of the original VAR $(k)$ model. The remaining $d_{\max }$ autoregressive parameters are regarded as zeros and ignored in the VAR $(k)$ model. This test has an asymptotic chi-squared distribution with $k$ degrees of freedom in the limit when a VAR $\left(k+d_{\max }\right)$ is estimated. The dynamic causal relationship between prices and money supply would be as follows:

$$
\begin{aligned}
& L M_{t}=\alpha+\sum_{i=1}^{k+d} \beta_{i} L M_{t-i}+\sum_{j=1}^{l+d} \gamma_{j} L C P I_{t-j}+u_{t} \\
& L C P I_{t}=a+\sum_{i=1}^{m+d} b_{i} L C P I_{t-i}+\sum_{j=1}^{n+d} c_{j} L M_{t-j}+v_{t}
\end{aligned}
$$

Where $L M$ and $L C P I$ are, respectively, the logarithm of money supply (M1, M2 and M3) and of general price level, $t$ is time period, $k, l, m$, and $n$ is the optimal lag length, $d$ is the maximal order of integration of the series in the system and $u$ and $v$ are error terms that are assumed to be white noise. The initial lag lengths $k, l, m$ and $n$ are chosen using the Schwarz Information Criteria. However, the initial lag lengths are augmented with extra lag(s) depending on the likely order of integration (d) of the series $L M_{t}$ and $L C P I_{t}$. If $L M_{t}$ and $L C P I_{t}$ is likely to be I (1) (as it is with most macroeconomic data) 
then one extra lag is added to each variable in Equations (3) and (4). If both variables are assumed I(0), no extra lag is added in the equation, and the Toda Yamamoto test is equivalent to the Granger causality test. Wald tests are then used to test the direction of causality. For example, in Equation (3), the lags of $C P I_{t}$, excluding the extra lag added to capture maximum order of integration, are tested for their significance. If the null hypothesis that the lags are jointly equal to zero is accepted, then $C P I_{t}$ does not cause $M_{t}$. Testing for the joint significance of $M_{t}$, excluding the extra lag added, in Equation (4) allows tests for uni-directional or bi-directional causality.

\section{Estimation results}

The first stage involves establishing the order of integration using the Augmented Dickey-Fuller (ADF), with and without a deterministic trend. Table 1 presents the results of the unit root tests for the four variables, $M 1, M 2, M 3$ and $C P I$. The results indicate that all the variables are not stationary in their levels. On the other hand, all data are stationary at first difference and therefore indicating that all variables are I (1).

Table 1. Results of the Unit Root Tests

\begin{tabular}{|l|l|l|l|l|}
\hline \multirow{2}{*}{ Variables } & \multicolumn{2}{|l|}{ ADF Unit Root Tests at Level } & \multicolumn{2}{l|}{ ADF Unit Root Tests at First Different } \\
\cline { 2 - 5 } & $\tau_{\mu}$ & $\tau_{\tau}$ & $\tau_{\mu}$ & $\tau_{\tau}$ \\
\hline$L M 1$ & $-0.8949(16)$ & $-2.8132(16)$ & $-4.1927(15)^{* * *}$ & $-4.2306(15)^{* * *}$ \\
\hline$L M 2$ & $-1.3166(12)$ & $-2.6210(12)$ & $-3.4090(11)^{* *}$ & $-3.5702(11)^{* *}$ \\
\hline$L M 3$ & $-2.3671(16)$ & $-1.5282(16)$ & $-2.8800(15)^{* *}$ & $-3.6160(15)^{* *}$ \\
\hline$L C P I$ & $-1.8753(16)$ & $-1.4908(13)$ & $-3.8310(12)^{* * *}$ & $-3.9130(12)^{* *}$ \\
\hline
\end{tabular}

Notes: The null hypothesis is that the series is non-stationary, or contains a unit root. The rejection of the null hypothesis for ADF tests is based on the MacKinnon critical values. Values in parentheses are optimal lag lengths. $\tau_{\mu}$ and $\tau_{\tau}$ are constant and trend and constant, respectively. Asterisk $(* * *)$ and $(* *)$ denotes that a test statistic is significant at the $1 \%$ and $5 \%$ significance level, respectively.

Given the variables are I(1), the cointegration hypothesis between the variables is examined using the methodology developed in Johansen (1991) in order to specify the long-run relationship between the variables. The results of the cointegration tests are reported in Table 2. The null hypothesis of no cointegrating vector $(r=0)$ are rejected. Thus, the money supply $(M 1, M 2$ and $M 3)$ and the price level $(C P I)$ are cointegrated, indicated that there is a long-run relationship.

Table 2 . Testing for Bivariate Cointegration

\begin{tabular}{|l|l|l|l|l|l|l|l|}
\hline$H_{0}$ & $H_{l}$ & Eigenvalue & Trace Statistics & $\begin{array}{l}5 \% \text { Critical } \\
\text { Value }\end{array}$ & $\begin{array}{l}\text { Max-Eigen } \\
\text { Statistics }\end{array}$ & $\begin{array}{l}5 \% \text { Critical } \\
\text { Value }\end{array}$ & VAR \\
\hline LMI-LCPI \\
\hline$r=0$ & $r=1$ & 0.2150 & $98.2382^{* * *}$ & 19.96 & $94.3903^{* * *}$ & 15.67 & 2 \\
\hline$r \leq 2$ & $r=2$ & 0.0098 & 3.8479 & 9.24 & 3.8479 & 9.24 & \\
\hline$L M 2-L C P I$ \\
\hline$r=0$ & $r=1$ & 0.2184 & $99.7122^{* * *}$ & 19.96 & $96.0781^{* * *}$ & 15.67 & 2 \\
\hline$r \leq 2$ & $r=2$ & 0.0093 & 3.6341 & 9.24 & 3.6341 & 9.24 & \\
\hline$L M 3-L C P I$ &
\end{tabular}

Notes: VAR is order of the variance. ${ }^{* * *}$ denotes statistically significant at the $1 \%$ level. $H_{0}$ and $H_{l}$ denote the null and alternative hypothesis respectively and $r$ denotes the number of cointegrating vectors.

The Toda-Yamamoto causality test results are presented in Table 3. Since all the variables are in levels, the results provide information about the long-run causal relationships among non-stationary variables in the system. The results indicate that the null hypothesis that $C P I$ do not Granger cause $M 1, M 2$ and $M 3$ cannot be rejected. These suggest that the money supply does not respond to lagged changes in $C P I$ in the system. On the other hand, the hypothesis that money supply do not Granger causes $C P I$ can be rejected at the 1 percent significance level for $M 1$ and $M 3$ and 5 percent significant level for $M 2$. These indicate that there is only a uni-directional causality running from money supply to $C P I$ in the case of the Malaysia, but not the reverse. Therefore, the empirical evidence from Malaysia supports the quantity theorist's view. 
Table 3. Test of Causality, Toda-Yamamoto Approach

\begin{tabular}{|c|c|c|c|c|c|}
\hline \multirow{2}{*}{$\begin{array}{l}\text { Dependent } \\
\text { Variables }\end{array}$} & \multirow{2}{*}{$\begin{array}{l}\text { Independent } \\
\text { Variables }\end{array}$} & \multirow{2}{*}{$\begin{array}{l}\text { Lag } \\
\text { Structure }\end{array}$} & \multirow{2}{*}{ VAR Order } & \multicolumn{2}{|c|}{$\begin{array}{l}\text { Joint Test of Zero Restrictions of Variables } \\
\text { Added in Column } 2\end{array}$} \\
\hline & & & & MWald statistics & $p$-values \\
\hline \multicolumn{6}{|l|}{$L M 1-L C P I$} \\
\hline$L M 1$ & $L C P I$ & 1 & (2) & 0.0991 & 0.7530 \\
\hline$L C P I$ & $L M 1$ & 4 & (5) & $4.9200 * * *$ & 0.0007 \\
\hline \multicolumn{6}{|l|}{$L M 2-L C P I$} \\
\hline$L M 2$ & $L C P I$ & 1 & (2) & 1.7906 & 0.1816 \\
\hline$L C P I$ & $L M 2$ & 2 & (3) & $4.4023^{* *}$ & 0.0129 \\
\hline \multicolumn{6}{|l|}{$L M 3-L C P I$} \\
\hline LM3 & $L C P I$ & 2 & (3) & 2.1878 & 0.1136 \\
\hline$L C P I$ & $L M 3$ & 2 & (3) & $4.8836^{* * *}$ & 0.0080 \\
\hline
\end{tabular}

Notes: The $[\mathrm{k}+\mathrm{d}(\max )]$ th order level VAR was estimated with $\mathrm{d}(\max )=1$ since the order of integration is 1 . The lag length selection was based on Schwarz criterion test results (not reported in this paper). ${ }^{* * *}$ and ${ }^{* *}$ denotes statistically significant at the $1 \%$ and $5 \%$ level respectively.

\section{Conclusions}

This paper examined empirically the relationship between prices and money for Malaysia. We employed monthly data and applied cointegration using the Johansen approach and application of the Toda-Yamamoto causality approach to study the money and prices interaction. Using Johansen cointegration approach, our results show long-run association between prices and money, in line with previous research in other countries (see for example Benbouziane and Benamar (2004)). This mean that prices and money move together in the long-run. Using the powerful causality testing procedure developed by Toda and Yamamoto (1995), we found evidence of a uni-directional link from money to prices without significant feedback. This tends to support the quantity theorist's view that the causal relation between money and prices is from the former to the latter, in line with Masih and Masih's (1998) and Tang's (2004) work.

Thus, the monetary authorities can consider control of the money supply (M1, M2, and M3) to influence and control inflation. This is well known that the objective of Malaysian monetary policy is to maintain price stability in the form of low inflation in order to create a stable environment for sustainable economic growth. As suggested by monetarists, this can be best achieved by maintaining a steady rate of growth of the money supply, roughly corresponding to the long-run growth of the real output in order to achieve price stability and economic disturbances.

This study also suggests that the monetary policy should be conducted with care. Money supply can cause domestic price, and the latter variable plays an important role in determining Malaysia's import demand in the long run. An increase in domestic price might make imported goods become cheaper. Consequently, it might deteriorate the Malaysia external balance because of increasing demand on imported goods.

The above results provide evidence support the quantity theorist's view that postulate a uni-directional causation that runs from monetary aggregates to prices. We, however, suggest that the significant of our results could possibly be improved upon by applying a control variable to avoid possible bias of using bivariate framework in causality analysis as highligted by Al-Yousif (1999), that bivariate framework is potentially misspecified and maybe flawed due to the ommission-of-variable phenomenon. Thus, we suggest by adding domestic real activity and/or real exchange rate into the bivariate VAR framework between money and price.

\section{References}

Al-Yousif, Y. K. (1999). On the Role of Exports in the Economic Growth of Malaysia: A Multivariate Analysis. International Economic Journal, 13, 67-75.

Benbouziane, M. \& Benamar, A. (2004). The Relationship between Money and Prices in the Maghreb Countries: A Cointegration Analysis, The $11^{\text {th }}$ Annual Conference of the Economic Research Forum (ERF) Beirut - Lebanon December 16-28, 2004.

Brillembourg, A. \& Khan, M. S. (1979). The Relationship between Money, Income and Prices: Has Money Mattered Historically. Journal of Money, Credit and Banking, 11, 358-365.

Darrat, A. F. (1986). Money, Inflation and Causality in the North African Countries: An Empirical Investigation. Journal of Macroeconomics, 8, 87-103. 
Fisher, S. (1993). The Role of Macroeconomic Factors in Growth. Journal of Monetary Economics, 32, $485-512$.

Johansen, S. (1988). Statistical Analysis of Cointegration Vectors. Journal of Economic Dynamics and Control, 12 (2/3), 231-254.

Johansen, S. (1991). Estimation and Hypothesis Testing of Cointegration Vectors in Gaussian Vector Autoregressive Models. Econometrica, 59 (6), 1551-1580.

Jones, J. D. (1989). A Comparison of Lag-Length Selection Techniques in Tests of Granger Causality between Money Growth and Inflation: Evidence for the US, 1959-86. Applied Economics, 21 (6), 809-822.

Jones, J. D. \& Uri, N. (1987). Money, Inflation and Causality (Another Look at the Empirical Evidence for the USA, 1953-84. Applied Economics, 19 (5), 619-634.

Masih, A. M. M. \& Masih, R. (1998). Does Money Cause Prices, or the Other Way Around? Multi-Country Econometric Evidence Including Error-Correction Modelling From South-East Asia. Journal of Economic Studies, 25 (3), $138-160$.

Monetary Division, Research Department \& Nepal Rastra Bank (2001). Money and Price Relationship in Nepal: A Revisit. Economic Review: Occasional Paper, 13, 50-65.

Pinga, V. E. B. \& Nelson, G. C. (2001). Money, Prices and Causality: Monetarist versus Structuralist Explanations Using Pooled Country Evidence. Applied Economics, 33 (10), 1271-1281.

Tan, H. B. \& Baharumshah, A. Z. (1999). Dynamic Causal Chain of Money, Output, Interest Rate and Prices in Malaysia: Evidence Based on Vector Error-Correction Modeling Analysis. International Economic Journal, 13 (1), $103-120$.

Tang, T-C. (2004). Causality between Money and Price in Malaysia: A Revisit. Labuan Bulletin of International Business \& Finance, 2 (1), 71-81.

Toda, H. Y. \& Yamamoto, T. (1995). Statistical Inference in Vector Autoregressions With Posibbly Integrated Processes. Journal of Econometrics, 66 (1/2), 225-250.

Turnovsky, S. J. \& Wohar, M. E. (1984). Monetarism and the Aggregate Economy: Some Long Run Evidence. Review of Economics and Statistics, 66 (4), 619-629.

Zapata, H. O. \& Rambaldi, A. N. (1997). Monte Carlo Evidence on Cointegration and Causation. Oxford Bulletin of Economics and Statistics, 52 (2), 285-298. 


\title{
Study on the Employee Training for China State-owned Enterprises Based on Harmony Concept
}

\author{
Shengming Hou \\ College of Business Administration, North China Electric Power University \\ Beijing 102206, China
}

Tel: 86-10-5196-3675 E-mail: kangwei63@yahoo.cn

\begin{abstract}
The harmonious development of China state-owned enterprise and employees is the essential approach to develop state-owned enterprise. The development of enterprise is the premise of employees' developments, and only harmonious enterprise can ensure employees' complete development and bring up better employees. At the same time, employee's quality decides the development level of enterprise, and employee's survival and complete development are the bases for the harmonious development of enterprise. In this article, we study the employee training for China state-owned enterprises based on harmony concept, and further discuss the harmonious development between enterprise and employees. The contents of the article include the comprehension of harmony concept in the development of China state-owned enterprise, the main contents and the main modes of employee training embodying harmony in the principal of employee training, which can offer primary theoretic base and implementation frame for the work of employee training, and possess the function of reference for the employee training of state-owned enterprise.
\end{abstract}

Keywords: State-owned enterprise, Harmonious development, Employee training, Employee quality

\section{Introduction}

The mutual development of China state-owned enterprise and individual employee embodies the harmony concept, which is the basic approach to enhance employee quality and realize employee value and enterprise value. The development of enterprise is the premise of employee development, and with the quick development of state-owned enterprise, enterprise offers wide stage and plenteous development space to create and realize individual values for employees. The system training that can offer various skills for employees and enhance employees' comprehensive quality is the basic approach for individual development (Cao, Peixi, 2008). The training mechanism can offer more material and spirit returns for employees and make employees be pride because of the rapid development of enterprise and the enhancement of individual value, which can effectively promote the harmony between the whole benefit of enterprise with employees' benefits.

\section{The state-owned enterprise management based on harmony concept}

The harmony concept of state-owned enterprise is to realize the harmony between the quick development of enterprise with the urban development, the harmony between the whole benefit of enterprise with the employee benefit, the harmony between enterprise leader with employees, the harmony among departments of enterprise, and the harmony between the hardware construction of enterprise with the enhancement of employee quality. To realize five objectives of enterprise harmony, enterprise emphasizes the mutual and gradual development between enterprise and employees, establish the harmonious environment of mutual growth of enterprise and employees, and make the harmony embody the development of enterprise and individual at every place.

Through continual and systematically scientific training, every employee in enterprise can be continually enhanced, and not only employees' values can be gradually realized, but also the development of enterprise can be droved. The employee training can inspire employees' potentials and make their ideas open and enhance their own values, and it is the concrete embodiment of people-oriented idea of enterprise, and the impetus to realize the harmonious development of enterprise. At the same time, various training can optimize the study atmosphere in the interior of enterprise, help to establish learning enterprise and organization, and make enterprise realize sustainable harmonious development $(\mathrm{Wu}$, Wei, 2008).

\section{Taking the harmonious development of enterprise as the training objective}

The objective of ability construction for state-owned enterprise is to completely enhance the quality of all employees and form a composite team adapting the demands of new position and new task, accordingly enhance the core competition force of enterprise, and realize quite great developments of enterprise advancement and employee growth. 
To realize this objective, we need acquire breakthroughs from following aspects.

\subsection{The transformation of concept}

The state-owned enterprises of China are still in the key term of historical development, and the interior and exterior environments continually change, and the opportunity and the challenge coexist, which all produce more objectives and requirements for us. The concept is the premise of action, and the implementation of concrete system also carries out the concept. The important objective of quality construction is to transform employees' concepts and open the "shell" restraining employees' ideas (Wang, Jinling, 2008), and make employees accord with the requirements of social and enterprise development from their ideas and consciousnesses.

\subsection{The advancements of individual brand and organizational brand}

The team has brand, and the individual also has his own brand. Only enterprise can establish good enterprise brand, employees can be better trained. With the rapid development and continual grandness of enterprise, enterprise offers wide stage and sufficient development space to create and enhance individual brand for employee. At the same time, only every employee's ability is continually enhanced and his value is gradually realized, he can create harmonious enterprise environment and return enterprise and drive the development of enterprise. Therefore, the individual brand and the organization brand supplement each other and both synchronous enhancements should be realized (Wang, Wenbin, 2008). So the enterprise should try to create the amused work environment and the stage bringing up business, implement employees' occupational layout according to employees' growth demands, implement planned cultivation and actual exercise, inspire employees' potentials, make their ideas open, and accordingly enhance their own values.

\subsection{Developing enterprise and training employees}

State-owned enterprise is the main strength in the national economy. Except for economic responsibility, enterprise also undertakes political responsibility. To keep and increase state-owned assets, ensure investors' benefits and the leading function of state-owned economy to the national economy and the people's livelihood, are all obligatory responsibilities of state-owned enterprise.

Employees are the most precious fortune of state-owned enterprise. Only employees and enterprise grow together, the state-owned enterprise can be developed. And only to continually create more development environments, offer more study and training opportunities, continually enhance employees' welfares and salary treatments, provide more material and spiritual returns, and let employees be pride because of the rapid development of enterprise and the enhancement of individual value can offer powerful impetus for the sustainable development for the state-owned enterprise.

\section{Embodying harmony in the principle of employee training}

\subsection{Paying equal attention to organizational ability and individual ability}

According to the people-oriented strategic deployment to establish harmonious enterprise, the state-owned enterprise should apply itself to enhance employees' various abilities and offer wide development space for employees. When the individual ability is emphasized, the integration of individual ability should also be strengthened and so the team resultant force can be formed for the organization. Employees should not only "study", i.e. increasing their knowledge repertories and enhancing their integrated abilities through classroom training, knowledge competition and special topic discussion, but also "learn", i.e. applying learned knowledge and skills into the work, increasing the whole competition force of enterprise and create real learning organization.

\subsection{Paying equal attention to integrated ability and professional ability}

The professional ability that employees possess to be competent for the post enough is the condition for the survival of enterprise, and the confirmation and enhancement of professional ability is the base for the development of enterprise, so the construction of professional quality ability should be strengthened continually. The urgent position that enterprise reforms system and implements quick development should not only need employees possess familiar and exquisite professional ability, but also need employees develop sustainable and comprehensive integrated abilities. The formation of sustainable competition for enterprise needs composite talents with strong ideas, exquisite operation, high quality and strong ability, so state-owned enterprise should fully develop trainings with multiple layers and angles, so employees' professional ability and comprehensive ability should be enhanced synchronously.

\subsection{Paying equal attention to schooling education and post training}

The state-enterprise should lead employees to implement self-occupational design, support and encourage employees to implement schooling education, strengthen the association with various educational colleges, and offer more possible opportunities for employees to enhance their basic abilities. At the same time, the incumbency educations with multiple orientations and angles such as the post skill training, the expert lecture and the interior central training should be developed to optimize the training project, enhance training quality and enhance employees' professional abilities and skills. So the schooling education and the incumbency education for employees are the base to enhance employees' 
integrated ability and professional ability.

\subsection{Paying equal attention to training efficiency and training mode}

In the construction of ability, the high efficiency of training and the diversity of training mode should be emphasized together. In the design of training, the layer and pertinence should be recognized, and different concrete training projects should be designed aiming at different employees on different posts and different layers to achieve better training effect. The study modes such as classroom lecture, view and visit, group discussion and knowledge competition can enhance employees' theoretical knowledge and practical skills, and the modes such as expert lecture, experience training and foreign view can widen employees' views and let them fully feel the time breath.

\section{Main contents of employee training}

The employee training includes cultivation, education and training for employees in many aspects such as enterprise cultural concept, occupational moral culture, management knowledge, professional technology knowledge, operation skills and work skills according to the requirements of the development plan of state-owned enterprise and the model of employee quality. Its objective is to fully enhance employees' quality and ability, make them better adapt the requirement of post quality ability, and lead them to realize their individual occupational layout objectives in the frame of the whole strategic plan of enterprise (Wang, Xialiang, 2004). The concrete employee training is implemented mainly from five aspects including fresh employee training, professional technology ability training, integrated management ability training, post ability training and culture ability training.

\subsection{Ability training of fresh employee}

The training of fresh employees is the training to make fresh employees can quickly know well the basic situations about the work and the enterprise, such as the strategic perspective, the mission, the core concepts, and the work procedure of the enterprise and relative employee obligation, responsibility, and performance evaluation system.

\subsection{Ability training of professional technology}

The professional technology training includes schooling education and professional technology development training. The schooling training is to acquire higher education level and enhance employees' basic quality level for all employees of the enterprise through adult education, self-study exam or incumbency study. The professional ability development training is to let employees study other professional knowledge, develop their knowledge views and completely enhance their quality and ability.

\subsection{Ability training of integrated management}

The integrated management ability means management knowledge, management skill and individual quality that should be possessed in the management activities or the work process with characters of management. To different posts, the integrated management abilities needed and the corresponding grades of same management ability are different. The training of integrated management ability is implemented aiming at employees on different layers including grass roots employee, general manager, middle-level leader and enterprise leader. The integrated management ability should be constructed from five aspects including self-management ability, professional knowledge ability, security consciousness, communication ability and the ability of exertion, judgment and management.

\subsection{Post ability training}

The post ability construction mainly means the construction of professional quality ability, i.e. the construction of the special professional knowledge and skills needed by special posts or works. The training of professional quality ability is respectively implemented according to different specialties and different layers, and it mainly includes the professional quality ability of human resource, the professional quality ability of client relationship management, the strategic ability, the professional quality ability of finance management, the professional quality ability of security supervision, and the professional quality ability of operation management.

\subsection{Cultural ability training}

The enterprise culture reflects mutual willing, mission and value view of all employees of state-owned enterprise, and it is the reference of value tropism to adapt future development environment and solve enterprise management, the mutual action creed of all employees, the permanent impetus for the sustainable development of state-owned enterprise. The culture ability construction is to make employees continually recognize enterprise culture and strengthen the leading function of enterprise culture to employees through the special topic lecture or the discussion about enterprise culture.

\section{Main modes of employee training}

The main modes of employee training are seen in Table 1 (Yang, 2008).

\section{Conclusions}

The mutual development of China state-owned enterprise and employees embodies the harmony concept, which is the 
basic approach to enhance employee quality and realize employee value and enterprise value. The employee training is a complex engineering, and the specific construction objective and orientation, clear layout and approaches and good relationship among various aspects are all guarantees to realize the anticipated effects of ability construction.

\section{References}

Peixi Cao. (2008). The New Ambit to Exploit the Harmonious Development for State-owned Enterprises. Seeking Truth. No. 5.

Jinling Wang. (2008). Establishing Harmonious State-owned Enterprises in Development and Innovation: Some Considerations about Developing Northeast Old Industrial Base. Theory Horizon. No.2.

Na Wang. (2008). Analysis of China Enterprise Employee Training. Consume Guide. No.1.

Wenbin Wang. (2008). The Promotion of the Harmonious Development for State-owned Enterprises in Northeast China. Journal of Changchun University of Science and Technology (Social Sciences). No.1.

Xialiang Wang, Xiaohua Zhang, Chaorong Hu, Jianhua Yan \& Xiaodong Mo. (2004). Thinking of Employee Training System for China State-owned Enterprises. Neijiang Keji. No.1.

Wei wu. (2008). The Countermeasures and Advices for the Employee Training of State-owned Enterprises. China Economist. No. 6.

Ningsheng Yang, Qinghong Dong \& Xuzhu Chen. (2008). Establishing the Long Efficiency Mechanism of Employee Training. China Power Enterprise Management. No.1.

Jianyou Zhao, Zhenxiang Zhang \& Xudong Wen. (2008). Some Problems Need to Be Clarified in Employee Training. Coal Economic Research. No.1.

Table 1. Modes of employee training

\begin{tabular}{|c|c|c|c|}
\hline \multicolumn{2}{|c|}{ Training mode } & Features & Application range \\
\hline \multirow{3}{*}{$\begin{array}{l}\text { Classroom } \\
\text { training }\end{array}$} & $\begin{array}{l}\text { Schooling } \\
\text { training }\end{array}$ & $\begin{array}{l}\text { The intention of schooling training is to } \\
\text { enhance the group construction of } \\
\text { employees and enhance employees' } \\
\text { basic quality level }\end{array}$ & $\begin{array}{l}\text { Entire employees of state-owned } \\
\text { enterprise }\end{array}$ \\
\hline & Skill training & $\begin{array}{l}\text { Studying other professional knowledge } \\
\text { and developing employees' knowledge } \\
\text { view }\end{array}$ & Employees at the core post \\
\hline & Expert lecture & $\begin{array}{l}\text { Adopting the mode of centralized school } \\
\text { teaching, and employees can accept } \\
\text { much knowledge and low costs in short } \\
\text { time }\end{array}$ & $\begin{array}{l}\text { The training project that the centralized } \\
\text { school teaching can acquire good } \\
\text { effects }\end{array}$ \\
\hline \multirow{4}{*}{$\begin{array}{l}\text { Non-classroom } \\
\text { training }\end{array}$} & $\begin{array}{l}\text { Self-study } \\
\text { exam }\end{array}$ & $\begin{array}{l}\text { Employees study themselves and review } \\
\text { the study effects by the form of exam }\end{array}$ & $\begin{array}{l}\text { The study content is not suitable for the } \\
\text { centralized school teaching, and the } \\
\text { self-study can complete the project }\end{array}$ \\
\hline & Discussion & $\begin{array}{l}\text { Employees discuss or invite relative } \\
\text { experts to communicate front to front }\end{array}$ & $\begin{array}{l}\text { The construction project tying up } \\
\text { practice and needing experience } \\
\text { communication to achieve better } \\
\text { effects }\end{array}$ \\
\hline & Competition & $\begin{array}{l}\text { Mobilizing employees' study enthusiasm } \\
\text { and activity }\end{array}$ & $\begin{array}{l}\text { The project needing comprehension } \\
\text { and memory }\end{array}$ \\
\hline & $\begin{array}{l}\text { Experience } \\
\text { training }\end{array}$ & $\begin{array}{l}\text { Widening views and studying advanced } \\
\text { experiences }\end{array}$ & Middle and high layer managers \\
\hline
\end{tabular}




\title{
The Design of Knitting Dress and the Development Orientation of Knitting Enterprises
}

\author{
Tianpeng Liu \\ College of Art and Appareluages \\ Tianjin Polytechnic University \\ Tianjin 300160, China \\ Tel: 86-22-2641-4423 E-mail: Tianpengliu@yahoo.cn
}

\begin{abstract}
At present, in the fashion domain, the uniform advantage of tatting products have been broken by knitting products which suddenly rise and partly occupy the market, so the situation that knitting products and tatting products occupy the market together begins to form. Because of their own characters of knitting dress or tatting dress, they can not be replaced. But in future, the knitting dress should not isolate itself even if it possesses the character of knitting dress. Aiming at future fashion trend, in this article, we put forward the problems of knitting enterprises in future design and development orientation for knitting dress, and the solution advices for corresponding problems. And the author hopes the article can offer helps for the design of knitting dress and the knitting enterprises.
\end{abstract}

Keywords: Knitting dress, Fashion trend, Enterprise development

The knitting dress possesses important status in the dress domain, and it is one force which can not be ignored in the commodity of dress. From 1980s, people increasingly begin to pay attention to knitting dress which has deserved consumers' favors in the world. The character of making craftwork makes knitting dress possess not only general commonness of dress, but also un-imitable individuality. Many good performances such as comfort, pliability and elasticity make knitting dress form its own special style. Aiming at the status and character presenting in the industrial development of knitting dress design and the problems which should be noticed in the future development process of knitting dress enterprise, in this article, we put forward opinions, hope to reduce the difference with developed countries and promote the further development of China industry of knitting dress.

\section{The characters of design and production for knitting dress}

In the world domain of dress, the development trend from tatting dress to knitting dress occurs. According to the report of International Wool Secretariat Annual Meeting, the knitting dress in the world was increasing by the speed of 5\%-8\% year after year, but the global knitting dress was increasing only by the speed of $2 \%$. The first reason is that the knitting dress is mainly represented by the matching. The matching of knitting dress and tatting dress is easier than the matching of two pieces of tatting dress, because the latitude of size is large and the knitting dress is not limited by the season comparing with tatting dress. Second, as viewed from the technology, the knitting dress such as sweater is fixedly knitted and dyed, and the risk in the slopwork process is easier than the tatting dress. Concretely speaking, the texture of sweater, i.e. the flower pattern, is easier to produce the design of difference. Comparably, it is much easier to weave the sweater with different textures than to develop tatting jacquard fabric with same form. In addition, the design and production of knitting dress can live up to multiple styles and few quantities, and the manufacture speed is quicker than the knitting. So the first order form will have few quantities, and the risk of the market is much lower. According to the character of knitting dress, more market risks are avoided furthest from the design and production of products.

\section{What functions the knitting dress play in the design of suit-dress? What is the development foreground of this} function in future?

The function of knitting dress in future suit-dress still gives priority to assistant matching. For example, the sweater is the common matching in the fashion design. In future, the knitting sweater is still used to match the tatting dress, and because it is easy to operate, so it will become into main fashion. The limitation of sweater character rests with that it is designed as the pattern of frock to match tatting under most situations. Many characters of knitting dress make it develop very extensively, and its development depends on its easy design, manufacture and difference. The dress mainly lies on the difference operation of products, and the tatting is very difficult, but the corresponding matching of knitting and tatting is much easier, and this matching has been a tide. The consumers of knitting dress have extensively adaptive market, the operation is easy, the market has good reaction, and the risk of knitting can be shared in production and 
distribution, so businessmen commend knitting well. Based on the forces of two aspects, this matching tide of knitting and tatting will keep on developing in future.

\section{The future popular tendency of knitting dress}

In recent years, the industry of knitting dress develops quickly. According to the statistic of China National Textile and Apparel Council, the output of knitting dress was about 14.5 billion pieces in 2003, with year on year increase of $15 \%$, and the export increases $27 \%$, and the increase extent fully exceeds the knitting dress. The knitting dress has displayed large development space in domestic and foreign markets, and with complete abolishment of global textile quota, the knitting dress must meet the opportunity with quick development. For example, the proportion of knitting dress and tatting dress in developed countries such as US and Japan has achieved 45:55. In china, the knitting dress is one of important supports of textile industry all along. In ten years, with the increasing quick development trend of knitting dress and the continual extension of knitting dress demand to domestic and foreign markets, the industry of knitting dress in China is in the term of quick development. The market of future knitting dress is large, and the knitting dress would more extensively invade the domain formerly belonging to the tatting dress, and the pattern and the type will be more extensive, but in short time, it will not replace the biggest status of tatting.

\section{Which aspects should be noticed by China enterprises when they study foreign enterprises?}

The present knitting enterprises in China has entered into the mistake overly emphasizing the significance of design. Blindly studying design to foreign enterprises, domestic enterprises even crazily copy foreign designs. In fact, though the significance of design is at the first position, but the knitting dress rests with the development of yarn and the opening of computer-controlled flat knitting machine except for layout and knitting stitch. The development of yarn and the opening of computer-controlled flat knitting machine are needed to be developed first. The reason is that the handmade and machine manufacture mode of tatting dress is different, and the knitting dress is mainly knitted, and because most foreign computer-controlled flat knitting machines are programmed by the computer, so the design and manufacture in foreign enterprises are better than domestic enterprises. For domestic enterprises, the developments of stitch and jacquard are not more important than the developments of yarn and machine. The development of yarn is not a negligible important part, and it is the direction of product difference, because the pattern is easy to be imitated, but the material can not be imitated. The combination of different materials in textile is difficult to develop, but in foreign enterprises, the tatting material has 7 or 8 sorts of material combination for foreign wool spinning material. One design of yarn needs various tests in different aspects, which is more complex than the design of one pattern. So to save costs, many enterprises give up the development of yarn. In fact, it is false, because if the corporation monopolizes the yarn, it will monopolize the profit. The design without the matching of yarn material has not any values. Good matching of design and yarn material can really monopolize the design, and the combination of good design and yarn is flawless, and the use of other yarns can not make this, and the enterprise develops the good variety, it will monopolize the operation and profits. That is the most effective method of anti-pirate in the domain of dress.

As a whole, the industry of knitting dress in China develops well and it is in the period of rapid development. But we can clearly see that the knitting dress of China has large differences with developed countries, and these differences include not only the software difference of concepts such as originality, design and distribution, but also the hardware difference of technologies such as yarn, machine and dying, so the competition of knitting dress is more intense in future. To quicken technical advancement, to adjust product structure, to enhance product added values, to push brand strategy and to completely enhance industrial competitive force are future development directions of knitting dress undoubtedly.

\section{References}

Gui, Jilie. (2001). Design Base of Knitting Dress. Beijing: China Textile \& Apparel Press. January, 2001.

Ma, Dali. (2005). Management of Commodity. Beijing: China Textile \& Apparel Press.

Ma, Dali \& Wang, Xiucai. (2006). The commodity is the king, the commodity management to win the market. Beijing: China Textile \& Apparel Press.

Mao, Lili \& Wang, Xingjia. (2005). The actuality analysis of the Industrial Development for China Knitting Dress. Knitting Industries. No.3.

Shenlei. (2005). Design and Arts of Knitting Dress. Beijing: China Textile \& Apparel Press. January, 2005. 


\title{
Partnering Project Success Criteria in Malaysia
}

\author{
Hj. Kamaruzaman Jusoff \\ Yale University, Yale's School of Forestry \& Environmental Studies \\ 205 Prospect St, New Haven, CT 06511-2104, USA \\ Tel: 203-676-7761Ｅ-mail: kjusoff.kamaruzaman@yale.edu
}

Hamimah Adnan \& Nurul Fatanah Nazli

Faculty of Planning, Architecture and Survey

Universiti Teknologi MARA

Shah Alam Selangor, Malaysia

Tel: 60-3-5544-4935 E-mail: hamimah689@salam.uitm.edu.my

\begin{abstract}
Partnering is used as an approach in the procurement system as it could lead towards improving the performance of the construction industry. Organizations which used the partnering approach in their past construction projects are now reporting favorable results, which include decrease in project costs, delivery of project to program, time quality and buildability. Despite these benefits, there remain are still risks associated with this mode of procurement. Risk management process and partnering are critical to the succession of the construction project. Three (3) case studies were looked into to support this study. The opinions and techniques of risk mitigation were gathered. It was found that the most critical construction partnering risk is the partner's financial resources, the clients' problems and economic conditions and financial problems with one of the partner. It is hoped that the risk management programme will help to reduce such risks.
\end{abstract}

Keywords: Succession, Risk management, Partnering, Malaysian, Construction industry

\section{Introduction}

Partnering is an arrangement where the players are encouraged to work efficiently together. All parties in a construction project work together in an environment of trust and openness towards the efficiency of the project without conflict. Partnering has been popularly used as a procurement method since the Latham "Construction the Team" report was published (Latham, 1994). The report recommended partnering as a means of improving inter-firm relations. It is one of several strategies being proposed by practitioners, academics and managers (Cook and Hancher, 1990) and draws heavily upon lessons from Japanese manufacturing. Organisations which have used partnering for construction projects are now reporting favourable results, which include the decreased costs, quality improvement and delivery of project to programme. Partnering is becoming increasingly well understood in the building industry as a way of working with clients to jointly deliver vastly improved construction performance.

Partnering is a management approach used by two or more organisations to achieve specific business objectives by maximising the effectiveness of both parties. The approach was based upon mutual objectives, an agreed method of problem resolution and active search for continuous measurable improvements (Reading Construction Forum, 1995). It is only recommended where the management teams of all parties involved display a fundamental commitment to partnering and where companies share a common culture (Smircich, 1985). The partnering process involves allocating time to agreed objectives, establishing an open style of communication, developing a mechanism for problem resolution and identifying measures designed to monitor and help improve performance (CIB, 1997). It attempts to create an environment where trust and teamwork prevent disputes, foster a co-operative bond to everyone's benefit and facilitate the completion of successful project. Organizations which have used partnering for construction projects are now reporting favorable results, which include decreased costs, improved quality and delivery of project to program. This management concept attempts to prevent issues such as the dissatisfaction of a customer or contractor filing a claim and in most cases, it can be traced back to issues related to the three C's - communication, coordination, and conflict management. It is a planned effort by all stakeholders of a construction project to establish an environment of mutual trust, open communication, cooperation, and teamwork to encourage everyone to succeed by achieving mutually agreed upon goals and objectives. 
Risk is a function of the interaction of uncertainty and the magnitude of the potential loss or gain. Construction work involves risks due to the complex nature and uncertainties inherent in the construction process. Consequently, the construction industry suffers due to several factors, which act as barriers of a partnering approach to procurement. The client, consultants, contractor and sub-contractors of a construction project all have a role to play in delivering quality project. Failure by any party will seriously affect the quality of the final project. Risk management is a discipline to protect the asset, reputation and profits of the partnering method by reducing the possible losses or damages before they occur. It works with risk analysis and assessment to ensure proper financing controlled. In order to mitigate the risks in partnering projects, it is essential that management practitioners need to develop proven technique such as risk simulation techniques. The construction industry is plagued with by risk (Flanagan and Norman 1993), but often not dealt adequately, resulting in poor performance with increased cost and time delays (Thompson and Perry 1992). Construction projects are becoming increasingly complex and dynamic in their nature and the introduction of new procurement methods means that many contractors have to rethink their approach to the way risks are treated within their projects and organizations. The Malaysian construction industry is a conglomeration of diverse sub-industries loosely lumped together as a sector of the economy. The industry is primarily concerned with building and civil engineering, and its main activities relate to the planning, regulation, design, manufacturing, construction, fabrication and maintenance of buildings, infrastructure facilities and process plant. The building sector of the industry encompasses the construction of commercial, industrial and housing (high, medium and low-cost) projects; infrastructure facilities includes the construction of roads and highways, drainage, sewerage, industrial structures, dams and water retaining structure projects; whilst process process-plant construction ranges from sewerage, water treatment, energy to fertilizer and food projects.

Malaysia has a fast developing economy with a growing population. Since independence in 1957, the economy has expanded from a predominantly agriculture to a broad-based economy, diversified into manufacturing, oil and gas, tourism and heavy industries. The industry is the vital sector that has enabled the government to facilitate this change. It is of enormous economic and social significance as it continues to provide the impetus for stimulating development and growth. It provides and maintains the much needed infrastructure facilities for the growing population, and forms the base for the other segments of the industry to function. The construction of buildings, and infrastructure facilities such as roads and highways, leads to the creation and growth to new township and industrial zones. The transportation network, which links these newly developed areas, further opens up rural areas surrounding these areas. This in-turn promotes economic growth, employment and social activities within these regions. The issue arising in this paper is regarding risk factors associated in construction Partnering. Risks constitute a barrier to the successful adoption of this procurement method in construction and one needs to come out with risk management techniques although formal risk analysis and management techniques are rarely used due to lack of knowledge and doubts on their suitability in construction industry activities. The aim of this research is therefore to identify effective risk management measures applied to mitigate the risks faced by the construction industry using the partnering procurement method.

\section{Research methodology and data analysis}

Case studies were conducted based on the risks associated within partnering project and the effective risk management measures used to mitigate the risk. Case studies were conducted based on various construction companies' registered under the Malaysian Construction Industry Board (CIDB). For the purpose of this research, the researcher had examined and conducted three (3) projects implemented by Contractor AXA, BXB and CXC to determine the problems and the most effective management of risk applied in each of the projects. The succession criteria accounted for in Partnering projects are based on whether the projects are within budget and profit, whether they cater to the client satisfaction and goodwill if they are on/ahead of schedule, of quality standard and whether they enhance the partner reputation and if they meet up to the team's satisfaction. The main characteristics of the three cases are summarized in Table 1.

$<$ Table 1: Main Characteristics of Partnering Cases $>$

\subsection{Case Studies}

\subsubsection{Case Study 1: Civil Works}

The project was a civil engineering work which involved excavating, deepening, straightening the alignment of the river and building a slope protection. The client was a local government organization responsible for maintaining the river in Malaysia. The partner, hereafter referred to as DD, was a construction company. Company AXA acted as the other partner company and the Partnering is hereafter referred to as AXA - DD Partnering. The share distribution between AXA and D was to be $70 \%$ and $30 \%$ respectively. After the project was awarded in October 2000, problems slowly emerged. The project was stagnant due to financial problems in DD. The project was far behind schedule and the work was of poor quality. The client was dissatisfied and the relationship between the partner and the client deteriorated. Serious negotiations were then held among the directors from the two parties and they agreed that the project would not continue in the same manner. The project was beyond the financial capability of DD as DD was undertaking other 
projects at the same time with lacked in sufficient capital limited workforce and equipment. It was decided that Company AXA would take over the entire project and thereafter DD was terminated.

\subsubsection{Case Study 2: Building Works}

Company BXB entered into Partnering with EE on a Design and Build basis with both companies holding 75: 25 shares respectively. The project was divided into two parts in which Company BXB was responsible to construct the main hospital building while EE contractor was responsible for the construction of staff accommodation. This was done to ensure undisrupted operations. Although, disagreements between the staff surfaced occasionally, they were resolved as they arose between the parties involved. The progress was satisfactory and this project was expected to finish within the allocated budget and time.

\subsubsection{Case Study 3: Building Works}

This Partnering was formed by CXC and FF that has a strong record in the construction market, particularly in the field of building, civil works and infrastructure. Each partner held joint and individual responsibility for the partnering work and would accept the loss or profit according to their shares. The share distribution of CXC and FF was 60: 40 respectively. The contract was based on the Public Works Department Form as conditions of contract. This project ran smoothly and by April 2006 the project was at the end stage. The cost was expected to be within budget and the completion of the project would be on time. All partners were satisfied with this alliance. The interview regarding the case studies was based on eight (8) risk management measures which consist of: (1) Partner Selection; (2) Agreement; (3) Sub-contract; (4) Engineering Contract; (5) Employment; (6) Good relationships; (7) Control and; (8) Others. The risk management process must go through (1) Identification; (2) Analysis; and (3) Control.

The risk management process to identify the risks is based on the sources of the risks which are categorized into three groups: (1) Internal; (2) Project-specific; and (3) External. Under these groups there are several factors associated within the Partnering. These most critical factors are analyzed during three stages of Partnering: (1) Start-up (2) Operation; and (3) Dismantle. Once a risk is identified and defined, it becomes a management problem (Flanagan and Norman, 1993).

\subsection{Analysis of risk mitigation measures}

Risk management must be carried out as earliest as possible to mitigate any negative impact on the project's progress and profitability. In the early stage of a Partnering, selecting a suitable partner, drafting a good agreement, formulating correct personnel policies and adopting a suitable operational structure are the most effective management measures for future risk avoidance or mitigation. The first step towards the risk management process is risk identification, which may consist of the systematic and continuous task of identifying, classifying and assessing the importance of project risks. The identification of risks and the creation of a risk list are dependent upon many factors such as past experience, personal tendency and possession of the information. The aim is to generate a comprehensive list of the relevant risks and to document what each one involves. For these case studies, the researchers had classified the risk factors into three main groups.

\section{Results and discussion}

\subsection{Internal risk factor: Partner's Financial Resources and Managerial Competence}

In Case Study 1, the most critical factor affecting the Partnering was the financial problem with DD contractor. The financial status of DD contractor was at critical stage. This was happened because at the same time DD contractor was taking on other projects. This could be labeled as lack of management competence and resource. The result was the project was far behind schedule and the workmanship of low quality.

\subsection{Risk analysis}

For the three case studies, the researchers had analyzed the risk factors identified in each project into three stages which consist of: start-up, operation and dismantle. The researchers found that the internal risk factors in Case study 1 falls into the Operation Phase. In the operation phase, the partner had a large numbers of issues pertaining to financial status and responsibility. Conflicts arose during the execution of project. The conflict was unavoidable and this had a negative impact on the Partnering performance.

\subsection{Risk Control/Treatment}

An interview was conducted based on the previous questionnaire. A summary of the important measures are shown in Table 2 in which the researcher believe the person involved in the three case studies had taken in order to mitigate the risks in their Partnering project.

$<$ Table 2 Risk Mitigation Measures $>$ 


\subsubsection{Partner selection}

Partner selection for a Partnering is a risk in itself becaus Risk Mitigation Measures e is directly affects the outcome of the Partnering. Essentially, the company should analyze the various attributes of the potential partners and choose one that can complement them most in terms of needs. Companies usually search for partners who have compatible objectives, who are experienced in Partnering projects, specialize in technical skills with suitable management styles and are trustworthy and financially credible. Companies with existing relationship with each other may find it easier to form a Partnering. In the three cases, the companies of AXA and BXB (Case 1 and 2), BXB (Case 2) and CXC- FF (Case 3) had strong financial capabilities. In addition to financial aspects, management competence and complementary skills are essential ingredients of prospective partnerships. In Case study 2 and 3, each of the partners was qualified technically in his respective area and was competent in management. A good relationship with the client is also important for the success of a project. The three projects in this research were developed by government agencies.

\subsubsection{Agreement}

Most of the researchers on partnering have concluded that a good Partnering agreement is an important success factor that can prevent a great deal of trouble and conflict in future partnering operations. A good Partnering agreement must be drafted in clear terms with conditions that can be easily understood by all partners as well as the working staff, and each partner's authority is well defined. In three cases, all parties regarded their agreement as clear and the scope was well defined. In Case 1 and 2, they made new agreement and it is being drafted well, bound and registered between the partners. All of the terms and conditions were recorded. The third cases were developed from the previous agreements used in successful Partnering. In terms of work distribution, the projects were broken into packages and works were allocated to the respective partners. In Case Study 1 the work for excavation, straighten, and deepening the river was split vertically into two parts between the partners. It is also the same for the second case study, whereby the works were divided into two packages which are constructing the hospital main building and staff accommodation. This allowed both partners to concentrate their resources and defined the works.

\subsubsection{Employment}

The characteristic of a successful staffing policy in Partnering is that the staff must be committed to the Partnering and unbiased towards different partners. In Case Study 1 and 2, the AXA - DD and AXA - DD contractors employed most of the staff from the local manpower market through advertisement. They chose their critical staff based on good qualifications, previous experiences and their good records in previous types of procurement or Partnering projects. All the staff involved in the three cases was encouraged by the directors to commit themselves to the Partnering. The other effective risk mitigation measure was to carefully organize the operation structure so that the responsibilities and rights of all the positions did not overlap. The probabilities of conflicts could be reduced as the staff could perform their work without unnecessary disturbances.

\subsubsection{Management Control}

One management style was adopted in the three cases it was controlled. In the three cases, the decision-making was given to the bigger shareholder. Nevertheless, discussions were made between the partners before any decisions were made. The other important factor was the allocation of work between partners. In Case 2, the work was divided into two parts, in which AXA was responsible for the construction of hospital main building while BXB had to construct staff accommodation. The scope of works was managed by each party independently. The employees from both parties had limited contact with each other and this subsequently reduced conflict.

\subsubsection{Sub-contracting}

Sub-contractor selection is very critical for the success of a construction project. Much research work has been conducted to study the relationship between the main contractor and their sub-contractors. Setting up a strategic alliance with sub-contractors was recommended by Kwok and Hampson (1997). For Case 1 and 2, the sub-contractors and suppliers were from the local Malaysian market. The agreement was between each partner and their sub-contractors. Their services were obtained through advertisement done by each partner. Unfortunately, the co-ordination within D contractor became difficult and progress was not achieved for the project. That was one of the main causes for the initial failure of this Partnering project. In case 3, CXC owned several sub-contractors and they had a good relationship for a long period of time with the parties' parent companies.

\section{Conclusion}

The analysis of the risk mitigation measures have shown that the risk management model could be a useful process for implementing a successful construction Partnering. The critical risk factors must be systematically studied from the internal perspective, Project-specific, and External risk groups in combination with the Partnering development stages. The three case studies show that the important measures must be adopted when a company decides to enter into Partnering. It must consider the local partner's financial and management capability, it must insist on a good drafting of 
Partnering agreement that clearly defines each partner's responsibility and liability. It is also necessary to ensure that critical staffs are unbiased and experienced in joint management. It is preferable to adopt a one-partner-dominant style of management where one partner is capable enough to handle major construction works. It is critical for the partner to choose experienced and familiar sub-contractors and suppliers to strengthen the Partnering operation.

The risks of Partnering are different in each project involving different participants. However, the most critical factors exist in the financial aspects of Partnering, government policies, economic conditions and project relationships. Although formal risk management has not yet been implemented in most cases or projects, the efforts of the construction personnel in a Partnering project to respond to risks by means of training and education with the risk model provider is the best way of understanding the importance of risk management.

\section{References}

Construction Forum. (1995). Trusting the Team: The Best Practice Guide to Partnering in Construction,' Centre for Strategic Studies in Construction, Reading University.

Cook, L and Hancher, D.E. (1990). Partnering Contracting for the Future, Journal of Management in Engineering.

Flanagan, R and Norman, G. (1993). Risk Management and Construction, Blackwell Publishing.

Kwok, T.L \& Hampson, K.D. (1997). 'Strategic Alliances Between Contractors and Subcontractors - A Tender Evaluation Criterion for the Public Work Sectors,' School of Engineering, Griffith University, Queensland.

Latham. (1994). Constructing the Team. Department of the Environment, pp. 14-85.

Smircich, L. (1985). 'Is the Concept of Culture a Paradigm for Understanding Organization and Ourselves,' Organization Culture.

Thompson, P \& Perry, J. (1992). Engineering Construction Risks - 'A Guide to Project Risk Analysis and Risk Management', Thomas Telford, London.

Table 1. Main Characteristics of Partnering Cases

\begin{tabular}{llll}
\hline Characteristics & \multicolumn{1}{c}{$\begin{array}{c}\text { Case Study 1 } \\
(\text { AXA-DD) }\end{array}$} & $\begin{array}{l}\text { Case Study 2 } \\
(\text { BXB - EE) }\end{array}$ & $\begin{array}{l}\text { Case Study 3 } \\
(\text { CXC - FF) }\end{array}$ \\
\hline Project Type & Civil Works & Building & Building \\
Location & Malaysia & Malaysia & Malaysia \\
Project Value & RM 98,000,000.00 & RM 170,000,000.00 & RM 230,000,000.00 \\
Project Duration & 3 Years & 3 Years & 1 Year 4 Month \\
Shareholding (\%) & $70: 30$ & $75: 25$ & $60: 40$ \\
Opening Structure & Integrated with local partner & Integrated with local partner & Integrated with local partner \\
\hline
\end{tabular}


Table 2. Risk Mitigation Measures

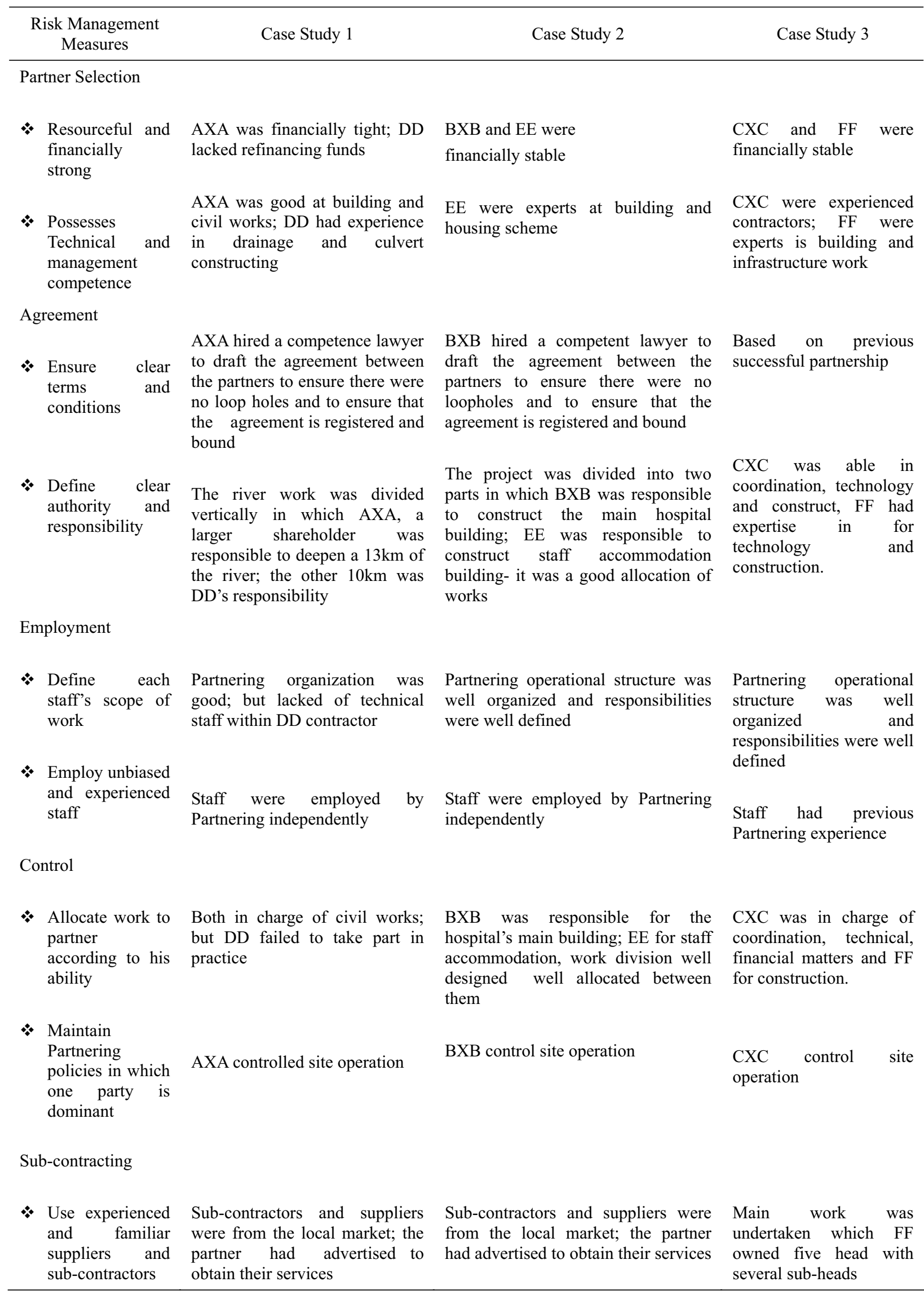




\title{
The Market Orientation and 4P Strategies of Ailing River Drifting Scenic Spot
}

\author{
Jin Zhang \\ School of Tourism, Guilin University of Technology \\ Guilin 541004, China \\ E-mail:koiohjkl@qq.com
}

\begin{abstract}
Based on a feasibility analysis on the product and source market orientation of the Ailing River Drifting Scenic Spot, this article explores its product quality as well as market strategies in four aspects including product, price, promotion and place.

Keywords: Ailing River drifting, Market orientation, 4P strategies

Drifting tourism refers to a variety of tourism activities organized by some drifting enterprises in which tourists take boats, rafts, dinghies and so on in a certain water area. As one of the four permanent travelling programs, including recreation, camping, picnic and drifting, it is a surprising instead of dangerous outdoor activity in which tourists can take an active role. Actually, its adventurous, challenging, surprising but not dangerous features appeal to modern tourists, especially middle-aged and young ones' psychological demands for excitement and adventures. As a result, this activity is quite popular in China and has bright future in terms of market development.
\end{abstract}

\section{Survey of Ailing River Drifting Scenic Spot and Its Source Market Orientation}

Ailing River Drifting Scenic Spot, located in an area spreading from Huangniao Unit of Nitang Village to Ailing Unit of Jianxin Village in Jiangdi of Longsheng County in Guilin City of Guangxi Province, is 119 kilometers from Guilin. Its drifting river extends for 4.5 kilometers and has a drop of 79 meters as well as an average 15/1000 falling gradient. This scenic spot is an organic whole with ecological, entertainment and cultural functions propped up by Longsheng Hot Spring and characterized by light and night drifting.

In order to get a better understanding of the distribution of potential source market of this scenic spot, its market department organized a survey in Datangwan Ethical Village, Longsheng Hot Spring( including Center Hotel and Longfu Mountain Villa) on May 24 and May 26, 2007. In 200 questionnaires sent out to potential tourists, 187 ones were valid and 11 were not, with the returning rate of $99 \%$ and the validity rate of $94.44 \%$.

It is shown in this survey that $30 \%$ of the tourists are from Guangxi, $64.29 \%$ of them are from Guilin and others come from Nanning, Liuzhou, Wuzhou and some other areas. Besides, there are also a great number of tourists from Guangdong and Hunan, accounting for $27 \%$ and $16 \%$ respectively of the total tourists. $17 \%$ are from Yangtze Delta, in which Jiangsu accounts for $8 \%$, Zhejiang $5 \%$ and Shanghai $4 \%$. There are also a small number of tourists from Beijing, Tianjin, Yunnan, Guizhou, Sichuan and Hubei.

Based on the above survey, the distribution of tourists to Longsheng Hot Spring, the geographical features, tourism resources and current situations of Ailing River as well as an objective analysis on domestic and foreign tourism markets, we establish the market orientation of Ailing River Drifting Scenic Spot as follows: inside Guangxi, cities and regions surrounding Longsheng, especially Guilin, Nanning and Liuzhou should be regarded as key markets, while outside Guangxi, Hunan and Guangdong should be focused on and Beijing, Tianjin, Tangshan as well as the Yangtze Delta should be developed. A more specific scheme comes next:

First-class target market: Guilin, Nanning, Liuzhou and Hunan, Guangdong (focused on the Pearl River Delta)

Second-class target market: Beijing, Tianjin, Tangshan, the Yangtze River Delta

Chance source market: other developed areas in China and their neighboring provinces.

\section{Feasibility Analysis of Source Market Orientation}

\subsection{Analysis on the Tourism Development Background of Longsheng and Its Hot Spring Scenic Spot}

Tourism in Longsheng began in 1985. Since "relying on tourism to aid the poor" was put forward in Longsheng County in 1993, tourism has been developed as a pillar industry in the local economy. During the past two decades, its tourism 
has made great advance. At present, this industry is achieving rapid development in Longsheng. In 2006, it received 660,000 tourists, increased by $14 \%$ compared with the same period last year, and gained 274,000,000 yuan as profit, increased by $44 \%$ compared with the same period last year. Among the total tourists, there were 102,494 inbound tourists, increased by $65 \%$ compared with the same period last year.

As one of the key scenic spots in Longsheng as well as a major one to earn profit, Hot Spring Resort has gained rapid development during the recent years. Table 1 shows the number of tourists as well as tourism revenue during 2000 to 2006 based on its annual business statistics these years.

According to the above table, 2004 was a dividing line in the number of tourists to Hot Spring Resort, in the three years before which it remained on the rise while after which there was a decline in the number of tourists due to the rise of entrance fares caused by the establishment of Center Hotel. In 2005 the number came back to 154,000 and it set a new record of 166000 tourists in 2006. Luckily, the revenue has been on the rise during the past years, even in 2004 with declined number of tourists.

The prosperity of hot spring tourism can have strong radiating function on the tourism of Jianxin Village in Jiangdi Country in that it will provide some tourists for this area and reinforce the publicity of this area's tourism image. In order to develop tourism in this area, this hot spring market should be relied on, whose tourists can be attracted to other scenic spots and will stay longer than planned, hence spending more money there.

\subsection{Analysis on Competitors}

Currently, there are two companies dealing with drifting tourism near Longsheng Hot Spring Resort, one of which is Jiujiang Drifting Club established in 1998, running the 6-kilometer river from Jiangdi Government to Fengtai Bridge and the other is Yanmen Drifting Company Ltd. Established in 1996, running the 4-kilometer river from Fengtai Bridge to Red Army Rock.

Table 2 shows the two companies' operation statistics from 1998 to 2006.

During 1996 and 1997, Yanmen Drifting Company Ltd. was managed by People's Bank of China and not until 1998 was it handed over to Longsheng Tourism Bureau. From 1998 to 2002, the two companies operated separately. During that period, there has been some fluctuations in the number of tourists: there was a $42.9 \%$ increase in 1999 compared with that in 1998 but there was a decline in revenue in 2000 due to the lower ticket fares and there was a sharp decline in the number of tourists to 4000 from 2001 due to the traffic inconvenience caused by the repair work of 321 National Way. Similarly, Jiujiang also achieved an increase in the number of tourists in 1998 and 1999 and had more than 3000 tourists during 1999 and 2000. Also influenced by the repair work of 321 National Way, it had much fewer tourists in 2001 and 2002. Then in 2002, the two companies turned to cooperation and gained great achievements.

After one year's cooperation, they returned to separate operation in 2003. During that year, influenced by SARS, these two companies only had $60 \%$ of the tourists in the previous year.

In 2004, Hot Spring Center Hotel was open. Due to the largely expanded cost, the ticket fares increased from 30 yuan to 98 yuan per person, resulting in a sharp decline in the number of individual tourists, who used to be the major source of drifting tourism. Therefore, they signed a cooperation agreement and divided their customers according to the age of tourists. Jiujiang mainly deals with middle-aged and old people as well as children because of its gently sloping river while Yanmen mainly deals with young people due to its great drop and large amount of water. This special cooperative operation has continued up to now. It is shown in the above table that Yanmen has had better operation results than Jiujiang due to its more appealing tourism product.

\subsection{Analysis on Major Domestic Target Markets}

\subsubsection{Guangxi}

Guangxi Market is one of the most important source markets in whole Longsheng County, especially Guilin, Liuzhou, Hechi and Nanning. Among them, Liuzhou is a key industrial city in Guangxi, or even whole Southwest China, and due to its vicinity to Guilin and its high residents' income, a lot of people travel to Longsheng. Nanning, the capital of Guangxi, with its population of 2,450,000 and high residents' income, has a wide tourism market. The above three cities are the most important source markets in Guangxi and therefore, are markets that should be developed and strengthened with more efforts. In addition to them, Hechi and other developed cities in southeast Guangxi should also be focused on in the near or mid-term future.

\subsubsection{Hunan}

Shaoyang City of Hunan Province, only 2-3 hours' ride away from Longsheng Hot Spring, has long been an important source market for Longsheng tourism especially its hot spring resort. Ever since the mid 1990s, people from Hunan have been accustomed to travelling in Longsheng. With the economic development in Hunan in the recent years, it will play a more important role in Longsheng tourism in the future. Since the change in the ticket price in 2004, there has 
been a decline in the growth rate of Hunan tourists. However, it is picking up in the recent years. In the future market publicity and development, Hunan should be regarded as one of the most important source markets in Ailing River's marketing efforts.

\subsubsection{Guangdong}

Guangdong, one of the most developed provinces in China, ranked fifth among all with its per capita GDP of 28,077 yuan in 2006 and achieved a $12.9 \%$ increase. According to the latest statistics, on the list of the cities with top per capita dispensable income, there are five cities in the Pearl River Delta among the top nine ones, with Dongguan and Shenzhen ranking first and second respectively. Because Guangdong residents have not only high income but enthusiasm for travelling, especially to Guangxi and Hainan, this area is the most important source market for Guangxi as well as Guilin. In the recent years, there have been an increasing number of self-travelling tourists, who will become one of the most important tourist flows at Guilin self-driving tourism market. For a long time to come, Guangdong should be regarded as one of the most important source markets outside Guangxi in the development strategies of Ailing River Scenic Spot.

\subsubsection{The Yangtze River Delta and the Beijing-Tianjin-Tangshan Area}

Some large and medium cities in the Yangtze River Delta and the Beijing-Tianjin-Tangshan Area are the major sources for national tourism in China, especially Beijing, Tianjin, Shanghai, Ningbo and Hangzhou because of their developed economy, high living standards and affordability of long-distance trips. In spite of the long distance between these cities and Guilin (Shanghai-Guilin $1389 \mathrm{~km}$, Beijing-Guilin $1887 \mathrm{~km}$ ), they have convenient transportation, such as several flights between them. According to some relevant statistics in the recent years, the above two areas have become the most rapidly developed markets among all, especially the Yangtze River Delta. To sum up, Ailing River Scenic Spot should put more importance on the above areas in their efforts to develop wider markets.

\section{Major Conclusion and 4P Strategies}

\subsection{Major Conclusion}

Instead of the drifting activity in Ailing River Drifting Scenic Spot itself, which is not attractive enough for the tourists far away from here, the hot spring plays a really critical role. Therefore, this scenic spot should be a secondary part to help to attract more tourists by holding some promotion activities.

Due to the narrower market of drifting tourism compared with others caused by its nature as a kind of adventurous tourism, an intensive marketing strategy should be adopted to design drifting activities with special characteristics to attract more young people to enjoy it instead of non-differential strategy with the hope to attract the whole source market.

\subsection{P Strategies}

\subsubsection{Product Strategy}

More efforts can be made to create a drifting tourism resort with ecological, entertainment and cultural functions based on Longsheng Hot Spring and characterized by light and night drifting.

\subsubsection{Price Strategy}

Night drifting should be priced according to some pricing strategies for new products, which is generally based on skimming pricing and penetration pricing. However, due to the limited expense standards of the tourists to the hot spring as well as the other two competitors, I think customary pricing should be adopted instead. Besides, due to the higher cost caused by lighting and safety management, cost-oriented pricing should also be taken into consideration.

On the whole, customary pricing should be based on with cost-oriented pricing as a supplementary part. In addition, group tourists and individual tourists should be given slightly different ticket fares.

\subsubsection{Promotion Strategy}

A mixed promotion strategy should be adopted in which dragging promotion should be focused on and pushing promotion should be supplementary and investment in advertisements and promotion should be guaranteed. Besides, the staff should conduct their direct promotion activities on tourists to encourage them to buy products. In this aspect, brochures can be relied on to promote tourism products because of their pictorial and literal effects, convenience for long-time preservation and availability of information at any time as well as their low cost. Therefore, this medium has become an important channel to build relations with some potential tourists. In the publicity and promotion of Ailing River Drifting Scenic Spot, this method should be adopted to attract those tourists to Longsheng Hot Spring to come here by giving them some introduction of night drifting by displaying some beautiful pictures and words on this printed medium. 


\subsubsection{Place Strategy}

In this aspect, direct sale should be based on and indirect sale can be a supplementary one. Because Ailing River Drifting Scenic Spot mainly faces those tourists to Longsheng Hot Spring, direct sale should be relied on to attract them since they are quite near to this resort. Besides, indirect sale can be conducted by cooperating with some travel agencies in Longsheng and Guilin in order to attract more tourists from other places.

\section{Summary}

In my opinion, Ailing River Drifting Scenic Spot is a typical small-scale one with only one tourism product, which, restricted by its scale and tourism resources, can not be targeted at the whole source market or promote its product as a widely popular one. Therefore, more efforts should be made to stress its own characteristics, to concentrate its advantages and promote at some specified markets in order to take an active role in the present tourism market.

\section{References}

Cai, Jiacheng. (2004). Development and Management of Drifting Tourism Projects. China Tourism News. 5, 31(4).

Cui, Yuan. Jin, Yanchun. (2007). On the Characteristics of Drifting Tourism and Thoughts about Its Development. Journal of Liaoning Administration College. 2. pp 218-219.

Lin, Nanzhi. (2000). Tourism Marketing. Nankai University Press. Aug.

Liu, Deguang. Chen, Kai. Xu, Hangjun. (2005). Tourism Marketing. Beijing: Qinghua University Press.

Ma, Zongfu. Lin, Fuyu. (2006). Marketing Strategies of Drifting Tourism--- A Case Study of the Drifting Project in Baise Gulong Canyon of Guangxi Province. Market Forum. 11. pp116-117.

Zhang, Jin. (2007). Development Plan for Ailing River Drifting Project in Longsheng Hot Spring Resort.

Zhong, Jiayu. Dai, Meiqi. (2005). On the Development Strategies of Drifting Tourism--- A Case Study of Hunan's Drifting Tourism. Journal of Hunan Economic Management Institute. 4.

Zhou, Pengfei. Li, Huaquan. (2006). A Research on the Theory and Construction of Drifting Project. Contemporary Manager. 8. pp 225-226.

Table 1. The number of tourists and revenue of Longsheng Hot Spring Resort in 2000-2006 (data from the statistics records of Longsheng Tourism Bureau)

\begin{tabular}{|l|l|l|l|l|l|l|l|}
\hline Year & 2000 & 2001 & 2002 & 2003 & 2004 & 2005 & 2006 \\
\hline Number of tourists (in ten thousand) & 11.8 & 12.74 & 14.65 & 15.9 & 13.9 & 15.4 & 16.6 \\
\hline Revenue (in ten thousand yuan) & 1290 & 1810 & 2050 & 2625 & 2720 & 7196 & 8177 \\
\hline
\end{tabular}

Table 2. The operation statistics of Yanmen and Jiujiang companies from 1998 to 2006

\begin{tabular}{|c|c|c|c|c|c|c|c|}
\hline & \multicolumn{3}{|c|}{ Yanmen Drifting Company } & \multicolumn{3}{|c|}{ Jiujiang Drifting Club } & \multirow[b]{2}{*}{ Notes } \\
\hline & $\begin{array}{c}\text { Annual } \\
\text { revenue } \\
\text { (yuan) }\end{array}$ & $\begin{array}{c}\text { Number of } \\
\text { tourists }\end{array}$ & $\begin{array}{c}\text { Ticket } \\
\text { fares/person }\end{array}$ & $\begin{array}{c}\text { Annual } \\
\text { revenue } \\
\text { (yuan) }\end{array}$ & $\begin{array}{c}\text { Number of } \\
\text { tourists }\end{array}$ & $\begin{array}{c}\text { Ticket } \\
\text { fares/person }\end{array}$ & \\
\hline 1998 & 140,000 & 7000 & 20 & 60,000 & 3000 & 20 & Separate \\
\hline 1999 & 300,000 & 10000 & 30 & 61,000 & 3100 & 20 & Separate \\
\hline 2000 & 260,000 & 10000 & 26 & 93,000 & 3100 & 30 & Separate \\
\hline 2001 & 160,000 & 4000 & 30 & 52,000 & 1300 & 40 & Separate \\
\hline 2002 & 300,000 & 5000 & 60 & 80,000 & 2000 & 40 & Cooperative \\
\hline 2003 & 160,000 & 3000 & 53 & 48,000 & 1200 & 40 & Separate \\
\hline 2004 & 280,000 & 6000 & 47 & 96,000 & 2400 & 40 & Cooperative \\
\hline 2005 & 300,000 & 4500 & 67 & 72,000 & 1800 & 40 & Cooperative \\
\hline 2006 & 300,000 & 5000 & 60 & 80,000 & 2000 & 40 & Cooperative \\
\hline
\end{tabular}




\title{
The Crisis Management of Enterprise's Collective Brain Drain
}

\author{
Chunli Yuan \& Chunying Zhang \\ School of Business Administration, Tianjin Polytechnic University \\ Tianjin 300387, China \\ E-mail: yuanchunli666@163.com, zhchy169@163.com
}

\begin{abstract}
This paper take enterprise's collective brain drain as the research object, by using of questionnaire method, historical data, experts consultation method, and other methods of construct the collective brain drain of forewarning indicators, and then use the alternative ranking method to determine and evaluate comprehensively system of indicators to the weight. By constructing the forewarning system to real-time monitor, identify, diagnose and evaluate the trend of enterprise's collective brain drain and on this basis to pre-control, the prior development of corrective measures, the crisis will be resolved in the embryonic stage. Therefore, constructing the forewarning system of enterprise's collective brain drain for the long-term stable development of enterprises has important practical significance.
\end{abstract}

Keywords: Core talent, Collective brain drain, Crisis, Forewarning management, Pre-control

\section{Introduction:}

The brain drain contains individual brain drain and collective brain drain and compared to the individual brain drain, collective brain drain does greater harm to the original enterprises. Collective brain drain is not just only a few people leave the corporation ,but it means the lost of the issue of corporate management skills, core technologies, marketing strategies and ideas, goods supply and marketing channels, customer information and so on. In addition, it will also affect the staff's mood and greatly dampened the morale of the overall enterprise; the more seriously damaged the company's image. Collective brain drain has become the most fatal injuries to enterprise management. In overseas, the research of enterprise's forewarning management is mainly empirical and the contents focus on enterprise-level functions, such as early warning of financial, marketing, but the study of forewarning the loss of staff in the management and building a forewarning principle of unity in the forewarning system is scare.

In china, currently on the brain drain of many causes for the study of countermeasures, such as compensations to keep staff, establish psychological contract, organizational commitment, and so on. Forewarning and pre-control system can effectively make up for the study's defect of the sudden loss of talent and unpredictability. Recently enterprises brain drain has the biggest characteristic of the core talent of "collective resignation", and the trend has intensified. In 1995 when "little overlord" is at the peak, Duan Yongping as manager led almost all middle-level managers of collective resignation, leading to "little overlord" history. Founder, Executive Director Zhou Xianfeng led more than 30 PC technology backbone of joining into Hisense Digital. These incidents have caused great uproar in the industry. Data show that: a staff of 2,300 dollars for the replacement cost in the United States, this is tangible. Intangible capital including: available in the old value of the experience of the staff loss, new employees not familiar with the work environment due to the impact of his skills to play the normal capacity loss, and enterprises in order to guide the new staff and the loss of human and material. From the economics point of view, after control is not better than course control and course control is not better than advance control. Forewarning management belongs to advance control in the control theory, it is through the detection and identification of the factors leading to the incident control the outcome of the case, more effective control over the course control. "Cause analysis - forewarning management - pre-control measures" is as the main line for the loss of enterprise's collective brain drain crisis, with a view to avoiding enterprise from collective brain drain.

\section{Cause Analysis}

Since the establishment of market economic system and improvement the macro environment or career change in policy, update the concept of talent flow, social changes in employment patterns, the emergence of new occupation and the international environmental factors make more jobs and careers of freedom; Impact on the flow of talent have played a role in encouraging and promoting, greatly increases the possibility of brain drain. The main factors of enterprise's collective brain drain including: the external environmental factors, organizational factors, personal factors.

\subsection{External Environmental Factors}

With the advent of the era of knowledge economy, knowledge workers normally have the pursuit of personal 
achievements desire. And the knowledge work's most outstanding characteristics is team model, when a team members to leave their team and his personal values will become very small, single individuals can not be based on the market. Once the core figure left in the team he is bound to take the whole team. Phenomenon of collective loss is the inevitable product of the times. Enterprises to foster a team need to cost a lot of manpower, material and financial resources. Particularly in the high-tech enterprises, the contribution of the individual employees is getting smaller and smaller, and the team's value is getting bigger and bigger. Otherwise, digging a team is more effective than digging individual, which can save a lot of training costs, research and development costs and marketing costs. So, many enterprises use of head hunter dig the mature rival team.

\subsection{Organizational Factors}

To organization aspect, the basic reason of causing excellent teams' loss is that corporate management issues. The main problems are that: high-quality managers, staff incentive mechanism is inadequate and fails to establish an effective evaluation system, the lack of a reasonable salary structure; the team could not build for the long-term development planning and corporate culture. In addition, the company's high-level personnel changes in the overall development strategy and corporate adjustments, making the company's management concept and corporate culture a lot of changes, and this change is unacceptable to the existing team, so team chose to leave.

\subsection{Personal Factors}

The excellent talent wants to achieve through the development of their self-worth, broaden development space and reasonable career planning. When they feel that companies unable to raise the value of their own space and can not learn new skills, lacking of training and growth opportunities they will choose to leave. In addition, a team member agree the way of the core leader with its management conception, work atmosphere, the way very much, the core figure's left could lead to the entire team to follow.

\section{Forewarning Management}

At this stage the construction of forewarning indicator system, including the study of forewarning indicators of system construction, crisis assessment and issue a final warning.

\subsection{Construction of the collective brain drain forewarning indicator system}

Through the questionnaire method, historical data and experts' consultation method in follow SMART principles: Specific, measurable, action-oriented, realistic, and time and resource constrained based on the principles of design indicator system. Although the collective loss is the loss of the individual, but it is not a simple superposition of individual loss. The total index should include: the space of team development, the satisfaction of team compensation and benefits, the harmony degree of team and corporate, the behaviour of team changes, the competitiveness of industry. In accordance with the actual situation and the characteristics of the enterprises of the sector indicators screening and thinning, then the establish second index, third or even fourth index, fifth index, so as to make the minimum index system to reflect the most complete collection of information.

\subsection{Construction of the crisis evaluation system}

Taking into account cost factors and operability, in this process using two-factor evaluation of the crisis assessment and forewarning warning condition. Taking into account cost factors and operability, in this process using two-factor evaluation of the crisis assessment and forewarning warning condition. Risk index is the product of the probability of crisis and the crisis damage degree, according to damage index degree, through historical data and expert's consultation method to determine their collective brain drain damage degree, and send out warnings. First, according to the enterprise's historical data and experts' consultation to determine probability of all the indicators (see table 1). Then, by alternative ranking method identified by the index system of indicators in each damage degree evaluation, that is: choose two indexes which will cause the greatest and lest collective brain drain crisis, and then again in the remaining indicators in which will cause the greatest and lest collective brain drain crisis. In the same way, determine all the indicators of the crisis damage degree in order, and use of experts consultation to determine the weight (see table 2). At last, determine the risk index of collective brain drain crisis.

\subsection{Determine forewarning degree}

Before the collective brain drain happened, there is always some abnormal behaviour.

Sign 1: Team leaders or the core figures that have greater influence on the team present more arrogant and more frequent contacts with the outside world.

Sign 2: Team activities present more frequent and secret characteristic, in the other hand team members are too close contacts with the outside world.

Sign 3: Team complaint increased and ask for to higher requirements for enterprises.

Sign 4: The enthusiasm of team work decreased significantly and the working efficiency became poor. 
Sign 5: Enterprise suddenly appeared a number of gangs, and mainly to a person often entertained some staff members. This situation is likely to be the leave prelude.

Sign 6: While concentrating stage, phenomenon of a group of the quarrel, the commentary justified and phenomenon not have been, but suddenly burst, with centralized and explosive characteristics.

According to the sign of warning changes, in the light of crisis evaluation criteria and combined with actual or future to make suitable amendments to get the severity of the situation by warning degrees. After determining the forewarning indicators and calculated forewarning condition's degree, establish forewarning signal system, which is similar to that adopted a set of traffic control signal red, yellow and green logo, this group of indicators reflected in collective brain drain situation in a different signal. Finally, by analysis the changes in signal, to determine the future of corporate personnel collective brain drain of the trend or the extent of the loss.

\section{Pre-control Measures}

Following the enterprise's collective brain drain forewarning management we can get the extent and the trend of the collective brain drain. Then the task is to take the positive effectual pre-control measures to eliminate or control the spread of problem development.

\subsection{Information Communication}

Human Resources Department in support of high-ranking executives, around the content of enterprise's collective brain drain indicator system, established specialized information channels to meet the specific needs and to ensure smooth flow of information. Then, consisting the Expert Group by the Human Resources Department, heads of other departments and external experts the, to process the collection of information. According to results of forewarning analysis and the past experience design different risky degree, operational emergency project and handling ways to approach of the crisis preparedness strategy base. Such as compensation incentive preparedness base, Cost Constraint preparedness base, legal restraint preparedness base, knowledge management preparedness base.

\subsection{Preparedness Determination and Implementation}

According to warning condition categories, divided into two parts. The first part is storing the conventional case to cope with various crises, it can automatically output a number of countermeasures according to the nature and type of situation. The second part is dealing with non-conventional expert's consultation system, using the Delphi method to complete the consultation exercise to get countermeasures, and record storage strategy for future calls. Finally, preparedness to compare, evaluate, select the best plan. In access to high-level managers' support, from the Human Resources Department to make out an implementation plan, implement pre-control preparedness under plans and steps; really achieve the objective of crisis prevention.

\section{Conclusion}

The establishment of a comprehensive and sensitive collective brain drain crisis system, timely detection endanger the survival and development of enterprise's collective brain drain, forecast its development trends, assess the damage ,promptly issued a warning to the crisis and timely issue warning to the crisis, so that enterprises ahead of crisis intervention, early to take effective measures to prevent the crisis in the implementation of pre-control, will solve the problem in the embryonic stage.

\section{References}

Basak S, Shapiro A. (2001). Value-at-Risk-based Risk Management: optimal policies and asset price. The Review of Financial Studies. 2:371 409.

Hellman, C.M.A. (1997). Job satisfaction and intent to leave. Journal of Social Psychology. 137(6): 677 689.

Liu Ping \& Zhang Chunying. (2006). The Establishment of Core Talent Crisis Forewarning System. Chinese Talents, 6 (In Chinese).

Philips, J.D. (1990). The price tag on turnover. Personnel Journal. 6:58 61. 
Table 1.

\begin{tabular}{lccccccc}
\hline index & $x_{1}$ & $x_{2}$ & $x_{3}$ & $x_{4}$ & $\cdots \cdots$ & $x_{n-1}$ & $x_{n}$ \\
\hline probability & $p_{1}$ & $p_{2}$ & $p_{3}$ & $p_{4}$ & $\cdots \cdots$ & $p_{n-1}$ & $p_{n}$ \\
\hline
\end{tabular}

Table 2.

\begin{tabular}{llllclcl}
\hline index & $x_{1}$ & $x_{2}$ & $x_{3}$ & $x_{4}$ & $\ldots \ldots$ & $x_{n-1}$ & $x_{n}$ \\
\hline damage degree & $q_{1}$ & $q_{1}$ & $q_{3}$ & $q_{4}$ & $\ldots \ldots$ & $q_{n-1}$ & $q_{n}$ \\
\hline
\end{tabular}

Calculation formula:

Probability: $\left\{p_{1}, p_{2}, p_{3}, p_{4}, \ldots \ldots, p_{n-1}, p_{n}\right\}$

Damage degree: $\left\{q_{1}, q_{1}, q_{3}, q_{4}, \ldots . ., q_{n-1}, q_{n}\right\}$

Collective brain drain crisis index: $C=\sum_{i=1}^{n} p_{i} q_{i}$ 


\title{
An Extended Model of Theory of Planned Behaviour in Predicting Exercise Intention
}

\author{
Yap Sheau Fen \\ School of Arts \& Social Sciences, KDU College Sdn Bhd \\ SS22/41, Damansara Jaya, 47400 Petaling Jaya \\ Selangor Darul Ehsan, Malaysia \\ Tel: 60-12-266-4262 E-mail: crystalyap@kdu.edu.my \\ Noor Asyikin Sabaruddin \\ School of Arts \& Social Sciences, KDU College Sdn Bhd \\ SS22/41, Damansara Jaya, 47400 Petaling Jaya \\ Selangor Darul Ehsan, Malaysia \\ Tel: 60-19-202-0162Ｅ-mail: syeekin_s@hotmail.com
}

\begin{abstract}
The main purpose of the present study was to propose and test an extended model with the addition of perceived need in predicting exercise participation, drawing upon the theory of planned behaviour. Cross-sectional data was collected via self-administered surveys from general adults sample $(n=217)$. The instrument was first validated using exploratory and confirmatory factor analysis to test for unidimensionality, convergent and discriminant validity. Model and hypotheses testing were performed using structural equation modelling (SEM). The extended model accounted for a substantial portion of the variance in exercise intention $\left(\mathrm{R}^{2}=0.798\right)$. Specific findings revealed that: (1) all predictors were significantly correlated with exercise intention; (2) attitude components, perceived control, and perceived need predicted exercise intention; (3) instrumental attitude emerged as the strongest predictor of intention. This study has important implications for marketing practitioners, consumer researchers, and public policy makers interested in the determinants of exercise participation.
\end{abstract}

Keywords: Theory of Planned Behaviour, Perceived need, Exercise, Structural Equation Modelling

\section{Introduction}

There are increasing concerns about health and fitness especially among urbanite and higher social class groups. Various health promotion campaigns organised by government and not-for-profit organisations have increased public awareness of the role of healthy lifestyle in disease prevention. This heightened public awareness has resulted in great business opportunities for many marketers. In marketing sense, healthy lifestyle behaviours are related to a set of activities, interests, and opinions orientated toward the consumption of various goods and services. This healthy lifestyle trend drives demand for various healthier products and services and brings great impact on a number of industries. For instance, in the food industry, numerous low-fat, low-cholesterol, low-sugar, and low-preservative foods have come on the market and have been widely promoted.

Healthy lifestyle behaviours are activities undertaken to protect, promote or maintain health (Steptoe, Wardle, Vinck, Tuomisto, Holte and Wichstrøm 1994) which encompass variety of behaviours such as healthy diet, tobacco-free lifestyle, regular exercise, substance use, cautious preventive practices, weight control and managing stress (Omar 2002). Exercise and dietary behaviours have been recognized as the most visible lifestyle shift among consumers (Kraft and Goodell 1993). Generally, people rely on regular exercise as a means to maintain both their physical health and psychological well-being (Plante and Rodin 1990). Given the fact that exercise is recognized as an important aspect of healthy lifestyles and desired health behaviour, the present paper focuses on exercise participation as one of the component of healthy lifestyle behaviour. 
The choices made by individual concerning exercise and fitness activities are a form of consumer behaviour. Little research related to exercise and fitness has been found in the marketing literature. Hence, this paper attempts to develop and test an extended model that explain and predict exercise intentional behaviour from consumer behaviour perspective based on one of the most established social psychology theories, the Theory of Planned Behaviour (TPB, Ajzen 1988, 1991). The TPB has been widely applied to aid the understanding of a variety of health-related behaviours successfully. It provides a systematic and comprehensive framework which allows the assessment of personal, social and psychological effects on individuals' exercise intention.

The contributions of this paper are fourfold. First, it provides understanding of the determinant of exercise intention from consumer behaviour perspective. Second, the original TPB predictors are modelled as multi-components constructs and extended with the addition of perceived need in predicting exercise intention. Third, the relationships between the social cognitive constructs and exercise intention will be addressed, justified, and empirically tested using SEM technique. Lastly, the result provides empirical support for the predictive ability of the extended TPB model. As well as the academic value, this paper has important implications for marketing practitioners, consumer researchers, and public policy makers interested in the determinants of exercise participation.

\section{Theoretical Background}

\subsection{Exercise participation among Malaysians}

Exercise is recognized as an important way to lead a healthy lifestyle. Considerable effort has been put forward to promote exercise among the society as a whole by the Malaysian government agencies and Non-Government Organization (NGOs). Generally, much of the Malaysian population are aware and agree with the benefits of regular physical activity. However, despite all these facts, there are still large percentages of individuals who do not participate in regular exercise. According to the statistic, only $30.9 \%$ of Malaysian engages in light and moderate physical activity on regular basis (Ministry of Health 2006), rendering health promotion campaigns ineffective in improving health-related lifestyle behaviours. A study on exercise participation of 4,807 youth in Malaysia revealed the lack of interest in exercise and sports activities participation among youth (Andres 2006). The condition has detrimental effects as the low score for exercise participation indicates the health of youth would be affected in the long run.

Because of the problems associated with a sedentary lifestyle, many researchers in the West have devoted considerable attention in examining the determinants of healthy lifestyle behaviour. However, a review of literature revealed very few studies examining exercise participation in Malaysia. Most of these studies are commercial-like survey or academic research that covers incomprehensive analysis. Therefore, there is a need to develop more comprehensive framework in understanding the determinants of individual exercise participation.

\subsection{Theory of planned behaviour}

As background to this study, a brief review of the TPB is provided here. The TPB is an extension of the TRA (Fishbein and Ajzen 1975). The TPB extended the TRA by adding the perceived behavioural control (PBC) because the TRA has difficulty in explaining behaviours in which a person does not have volitional control over it. The present study applied TPB instead of TRA to predict exercise behaviour. This is because whether to exercise or not is not entirely under a person's volitional control. There are some control factors that may affect individual's exercise participation such as physical inability, time and money constraint, neighbourhood security, availability of exercise equipments and so on. Hence, it is deemed to be necessary to examine beyond the attitude and subjective norm construct in the TRA but to explore further the control factor that possibly influence individual's exercise participation.

The TPB model posits that intention to perform a given behaviour is the immediate antecedent of that behaviour (Ajzen 2002). Behavioural intention refers to the amount of effort a person exerts to engage in behaviour. It captures the motivation factors necessary to perform a particular behaviour (Courneya, Bobick and Schinke 1999). That is, the more a person intends to carry out the intended behaviour, the more likely he or she would do so (Armitage and Conner 1999). Intention is determined by three conceptually independent variables labelled attitude, subjective norms and PBC. Generally, the more favourable the attitude and subjective norm, and the greater the perceived behaviour al control, the stronger should be the individual's intention to perform a particular behaviour (Ajzen 2002).

According to Ajzen (1991), attitude toward behaviour is the person's favourable or unfavourable feeling of performing that behaviour and is determined by behaviour al beliefs about the outcome of the behaviour and evaluation of the outcome. Subjective norm refers to the individual's perceptions of social pressure in performing or not performing a given behaviour and is determined by normative beliefs which assess the social pressures on the individual about a particular behaviour. Finally, $\boldsymbol{P B C}$ is thought to be a function of control beliefs about the perceived ease or difficulty of carrying out the intended behaviour and may have both direct and indirect effects on behaviour.

\subsection{The addition of perceived need}

It is observed that many health-related behavioural studies have extended the original TPB model by incorporating additional constructs such as moral norms, social support, past behaviour and personality characteristics. Only very few 
researchers have examined perceived need so far. In the health care context, while Van Voorhees, Fogel, Houston, Cooper, Wang and Ford (2006) modelled "low perceived need" for treatment as intention construct based on the TRA model, most of the other studies (e. g. Chisick, Poindexter and York 1998; Rabinowitz, Gross and Feldman 1999; Edlund, Unützer and Curran 2006) focused on examining the demographic and socioeconomic factors that influence individual perceived need. In the food consumption behaviour context, Paisley and Sparks (1998) found expectations of reducing fat intake to be predicted by perceived need independently of the other variables in their extended TPB model.

In agreement with Paisley and Sparks's (1998) argument that perceived need is distinct from other TPB constructs, Povey, Conner, Sparks, James and Shepherd (2000) examined the discriminant validity of perceived need and other TPB predictors as well as investigating the extent to which perceived need could predict dietary behaviours independently of other TPB variables. However, this was only an exploratory study using single-item measurement for perceived need. Povey, et al. (2000) concluded that there is a need to further examine the discriminant validity between perceived need and the attitude components before any arguments concerning inclusion of this component can be fully supported. Hence, the distinction between attitude and perceived need should be addressed before perceived need is included in the present study.

\section{Research Model and Hypotheses}

The TPB model is a flexible model that opens to the inclusion of additional variables (Ajzen 1991) with aim to increase the proportion of the explained variance and to allow generalisation to other research context. This study incorporates perceived need into the extended TPB model in examining exercise intention. The three TPB constructs are originally and traditionally measured as single concepts (Ajzen 1991). Later, Ajzen (2002) suggests that TPB constructs should comprise of two specific components (e.g. affective attitude and instrumental attitude) and acknowledges the conceptual distinction between these components. Several recent empirical studies (i.e. Rhodes and Courneya 2003b; Hagger and Chatzisarantis 2005; Rhodes, Blanchard and Matheson 2006) support the discriminant validity of these components. Since the present paper attempts to identify the specific TPB components that predict exercise intention, a disaggregated structure of correlated multiple components (Rhodes and Blanchard 2006) is deemed more appropriate. Figure 1 illustrates a research model investigating exercise intention, as constructed based on TPB.

\subsection{The effect of attitude components on exercise intention}

An individual's attitude towards performing a particular behaviour is likely to be positive if that person perceives that there are positive outcomes resulting from the behaviour. Using a deductive logic, favourable attitude is likely to increase a person's intention to participate in a given behaviour. A review of literature shown that attitude has been consistently correlated positively with intention and a good predictor of intention. Most studies in the physical activity and / or exercise domain have reported strong relationships between the attitude construct and behavioural intention (e.g. Norman, Conner and Bell 2000; Rhodes, Jones and Courneya 2002; Symons Downs and Hausenblas 2003; Brickell, Chatzisarantis and Pretty 2006; Rhodes, Macdonald and McKay 2006; Everson, Daley and Ussher 2007).

Considering the prediction of behavioural intentions, attitude has been demonstrated to be a significant predictor of various behavioural intentions. For instance, Hagger, Anderson, Kyriakaki, and Darkings (2007) demonstrated that attitude significantly predicted intentions for exercise, dieting and binge drinking behaviour. Many other studies in the exercise domain found attitude to be significant predictor of exercise intention and emerged as the stronger predictor compared to subjective norm and PBC. A positive relationship between affective and instrumental attitude and intentions to exercise is thus expected. Also, the affective attitude and instrumental attitude are both expected to be significant predictors of exercise intention.

H1: Instrumental Attitude will be positively and significantly correlated with and predictive of Exercise Intention

H2: Affective Attitude will be positively and significantly correlated with and predictive of Exercise Intention

\subsection{The effect of subjective norm components on exercise intention}

Most empirical studies revealed a positive relationship between subjective norm components and intended behaviour. A positive relationship between subjective norm components and intentions to exercise is thus expected. However, there are mixed results produced in the literature regarding the predictive ability of subjective norm. While there are many empirical studies support that subjective norm predicted behavioural intention, there were also studies that found subjective norms did not significantly contribute to the prediction of exercise (Rhodes, Blanchard and Matheson 2006). This paper aims to confirm these contradicting findings.

Given the importance of peer influence and family support, exercise participation is also a matter of socialization and social support. The influence significant others have on exercise intention is important and should not be overlooked. The TPB holds that subjective norms predict a person's intention to perform a particular behaviour. Therefore, it is expected that the more one perceives that significant others favour one's participation in exercise activities (i.e. the greater the influence of injunctive norm) and the exercise participation typically performed by significant others (i.e. the greater the influence of descriptive norm), the more likely one will intend to exercise. Hence, it is hypothesised that: 
H3: Injunctive Norm will be positively and significantly correlated with and predictive of Exercise Intention

H4: Descriptive Norm will be positively and significantly correlated with and predictive of Exercise Intention

\subsection{The effect of subjective norm components on exercise intention}

The third social cognitive determinant is PBC, conceptualized in the present paper as an individual's perception of the amount of control (i.e. perceived controllability) one has in terms of the anticipated impediments and obstacles as well as one's perceived capabilities and confidence (i.e. perceived self-efficacy) to participate in exercise activities during leisure time. Ajzen (1991) predicts that PBC influences a person's intention to perform a given behaviour. Using a deductive logic, an individual's behavioural intention tend to increase when there is increase in that person's confidence level and perceptions of the amount of control he or she has over that particular behaviour. There is a good deal of evidence to show that $\mathrm{PBC}$ has an association with behavioural intention and was found to improve the prediction of intention in a variety of contexts. Hence, it was hypothesised that:

H5: Self-efficacy will be positively and significantly correlated with and predictive of Exercise Intention

H6: Perceived Controllability will be positively and significantly correlated with and predictive of Exercise Intention

Despite the importance of perceived need construct, it has been a largely neglected concept in the public policy makers and health-related marketers' strategic considerations. It is evident by the fact that there has been only limited research examining perceived need and this has focused on health care and food consumption. Given the potential significance of perceived need construct in healthcare system management, there is a need to better ascertain the nature of its relationship with exercise intentions. The role of perceived need within the TPB is extended to exercise domain in the present paper. The link between perceived need and exercise intention is expected to hold based on the work of Povey, et al. (2000). It is hypothesized that:

H7: Perceived Need will be positively and significantly correlated with and predictive of Exercise Intention

\section{Research Method}

To examine the effects of perceived need and TPB on an individual's intention to exercise, a cross-sectional survey was employed to test the research model. The research instrument, sampling, and data collection method are designed as below.

\subsection{Instrument development and pre-test}

Regarding instrument construction, all items were adapted from previously published work with necessary wording changes. Specifically, items measuring attitude and PBC components were adapted from Hagger and Chatzisarantis (2005) and Rhodes and Courneya (2003a), whereas items measuring subjective norm components were taken from Rhodes, Blanchard and Matheson (2006). Measurements of exercise intention were derived from Hagger and Chatzisarantis (2005) and Rhodes, Blanchard, Matheson and Coble (2006). Items assessing perceived need were adapted from Payne, Jones and Harris (2004). All items were assessed on 7-point Likert-type scales range from "strongly disagree" to "strongly agree". The background information used to describe the subjects inclusive of gender, age, ethnicity, religion, marital status, level of education, income, and occupation. The questionnaires were pre-tested to ensure clarity and ease of comprehension. Respondents were asked to evaluate the clarity of the wording, ease of comprehension, the level of language in terms of sensitivity, as well as length, format, and instructions for overall survey in order to minimize ambiguities and communication errors. After an explicit discussion with the respondents, several correction and modifications were made in terms of the wording, presentation and structure of the questionnaire.

\subsection{Sample and data collection}

Data were collected from the subjects using personally administered questionnaires. A verbal consent was obtained from the participant prior to distributing the questionnaire. All participants were informed the study was on voluntary basis, and that information provided will be kept confidential. A small souvenir was offered to participants in order to encourage more participation. The exercise of data collection was conducted both during weekdays and weekends. Exercise is an urban phenomenon; it is thus justifiable for the present study to be conducted in the Klang Valley areas since it is the largest urban centre in Malaysia. Participants for the present study were general adult (18 to 65 years of age) recruited through informal contact. To provide an adequate level of confidence in this study, a sample size of 300 respondents was targeted. Of 600 questionnaires sent out, 232 responses were returned for a response rate of $38.7 \%$. Of these returns, only 217 completed questionnaires were usable for the data analyses. The descriptive characteristics of the respondents are shown in Table 1.

\section{Results and Discussions}

The structural equation modelling (SEM) was used for model and hypotheses testing following the two-stage approach suggested by Anderson and Gerbing (1982) using AMOS version 7.0. First, a measurement model was created and subject to a series of validity checks. These measurement model validity assessments included fit indices and 
unidimensionality assessment, convergent validity, discriminant validity, and construct reliability test. Second, upon establishing the model fit, the significance, direction, and size of each structural parameter were estimated.

\subsection{Exploratory measurement results}

\subsubsection{Corrected item-total correlations}

The corrected item-total correlation analyses were conducted for each construct. Table 2 shows the corrected item-total correlation scores, which ranged from 0.497 to 0.869 , with the exception of one of the injunctive norm items (IN2). Based on the traditional cut-off value of 0.50 for evaluating corrected item-total correlation (Lu, Lai and Cheng 2007), IN2 (0.331) was dropped from further analyses.

\subsubsection{Exploratory factor analysis}

The dimensions of the scale were examined by factor analysing the items using the principal components analysis with Varimax rotation method. As shown in Table 3, two items representing affective attitude (i.e. AA5 and AA6) that loaded on Factor 6 were dropped from subsequent analysis. Unexpectedly, all items for perceived control and self-efficacy were loaded in Factor 1. The results indicated that the construct of PBC should be measured as single concept as originally stated by Ajzen (1991). The self-efficacy construct was removed from subsequent analysis as its factor loadings were relatively lower compared to perceived control. The factor analysis results further reinforce the notion that two components existed in attitude and subjective norm constructs, however, this did not apply to PBC. Indeed, this result is consistent with Rhodes and colleagues' recent research finding that self-efficacy items do not measure Ajzen's (1991) PBC construct as well as do controllability items. For model testing and analysis, attitude and subjective norm are modelled as two distinct components whilst perceived control is retained as single construct.

\subsubsection{Coefficient alpha and reliability}

The Cronbach's alpha value for each measure is shown in Table 4. The alpha value for each construct was well above the recommended value of 0.70 , which is considered satisfactory for basic research (Nunnally 1978). However, there are several limitations associated with the use of Cronbach's alpha, including the fact that the alpha value is inflated as the larger number of items included in a scale (Sekaran 2000). Additionally, satisfactory Cronbach's alpha value does not indicate unidimensionality of a particular scale (Gerbing and Anderson 1988). Hence, confirmatory factor analysis is employed for the assessment of unidimensionality.

\subsection{Structural equation modelling}

The model fit was assessed by Chi-square and Normed $\chi^{2} / \mathrm{df}$ value, coupled with other model fit indices like Comparative Fit Index (CFI), Tucker-Lewis Index (TLI), and Root Mean Square Error of Approximation (RMSEA). The recommended cut off value for the goodness of fit indices was based on Hu and Bentler's (1999) recommendation.

\subsubsection{Confirmatory factor analysis (CFA)}

The present study adopts a two-step approach proposed by Anderson and Gerbing (1988). This approach is strongly preferred because structural analyses are often unreliable if the measurement model is of low reliability and validity (Hair, Black, Babin, Anderson and Tatham 2006). Based on data collected from 217 samples, the measurement model was first revised and confirmed using confirmatory factor analysis. Internal consistency, convergent validity, and discriminant validity were performed to ensure data validity and reliability. Then, the structural model that best fitted the data was identified followed by hypotheses testing.

\subsubsection{Assessment of the fit and unidimensionality of the model}

A measurement model should be assessed for goodness-of-fit. The literature suggests that, an acceptable ratio for $\chi^{2} / \mathrm{df}$ value should be less than 3.0 (Hair, et al 2006). Following common practice, acceptable model fit is indicated by value greater than .90 for CFI, TLI and a value of less than 0.08 for RMSEA. However, a cut-off value close to .95 for TLI, CFI; and a cut-off value close to .06 for RMSEA are needed to support that there is a relatively good fit between the hypothesised model and the observed data (Hu and Bentler 1999). Although the initial measurement model $\left(\chi^{2}=965.615\right.$, $\left.\chi^{2} / \mathrm{df}=1.791, \mathrm{TLI}=0.903, \mathrm{CFI}=0.912, \mathrm{RMSEA}=0.061\right)$ yields an acceptable model fit, some modification was made to determine a model that better fit the data. A total of five indicators were eliminated based on modification indices. It is worth noting that the model fit was improved using a conservative strategy, that is, none of the error terms was allowed to covary. Further, the freeing of cross-loadings was also not allowed since the existence of significant cross-loading indicated lack of construct validity (Hair et al. 2006). The revised measurement model fit the data well $\left(\chi^{2}=600.147\right.$, $\left.\chi^{2} / \mathrm{df}=1.563, \mathrm{TLI}=0.937, \mathrm{CFI}=0.945, \mathrm{RMSEA}=0.051\right)$.

\subsubsection{Convergent validity}

To assess convergent validity, the standardised factor loading should be significantly linked to the latent construct and have at least loading estimate of 0.5 and ideally exceed 0.7 (Hair et al. 2006). The CFA results (see Table 5) indicated that each factor loadings of the reflective indicators were statistically significant at 0.001 level. In addition, the factor 
loadings ranged from 0.554 to 0.898 , and no loading was less than the recommended level of 0.50 . Additionally, two other criteria were assessed to ensure convergent validity: (1) construct reliability should be greater than 0.7 (Nunnally 1978), and (2) variance extracted (VE) for a construct should be larger than 0.5 to suggest adequate convergent validity (Fornell and Larcker, 1981). As shown in Table 6, the reliability of each construct exceeded the 0.70 threshold, showing high internal consistency. Table 6 also shows that the VE of each construct exceeded the cut-off of 0.5 . In sum, all constructs of the measurement model demonstrated adequate reliability and convergent validity.

\subsubsection{Discriminant validity}

For examining discriminant validity, chi-square difference between two models: the unconstrained model and the constrained model are compared (Bagozzi and Phillips 1982). In the unconstrained model, the covariance between particular two constructs was freely correlated. However, the covariance of a certain two construct was fixed to 1.0 in the constrained model. Two constructs are claimed as having well discriminant validity if the $\chi^{2}$ difference between the two models is significant. A series of chi-square difference tests were then conducted and the results are shown in Table 7. The results indicated that all $\chi^{2}$ difference test were significant at $p=.001$. The chi-square value for unconstrained measurement model was significantly lower than any constrained models with the possible pair of constructs. In sum, the findings revealed good discriminant validity for all constructs. Clearly, the present result confirms the distinction between attitude components and perceived need. Hence, it further supports the inclusion of perceived need into the current model.

\subsubsection{Structural model results}

The hypothesized structural model was tested using SEM. Each indicator was connected to its theoretical domain in a reflective manner. The structural model included: (a) paths from the TPB components and perceived need to exercise intention; and (b) correlations among the TPB predictors. The structural model was assessed through three main steps. First, the theoretical model should meet the goodness-of-fit to the empirical data satisfactorily based on the same set of fit indexes applied in assessing measurement model. Second, the direction, significance and magnitude of the path corresponding to each hypothesis of the theoretical model were examined. Finally, the squared multiple correlations were examined to determine the proportion of variance that was explained by the exogenous constructs in the theoretical model.

The structural model (see figure 2 ) demonstrated satisfactory model fit $\left(\chi^{2}=630.993, \chi^{2} / \mathrm{df}=1.622, \mathrm{TLI}=0.931, \mathrm{CFI}=\right.$ 0.938 , RMSEA $=0.054$ ) and was used for hypothesis testing. Although the chi-square was significant as expected due to large sample size, the TLI and CFI index were substantially above the preferred .90 threshold. The absolute fit measure of RMSEA was also below the recommended cut-off of 0.06 to be indicative of good model fit (Hu and Bentler 1999). It was reported that $79.8 \%$ of the variance associated with exercise intention was accounted for by its six predictors.

\subsubsection{Results of hypothesis testing}

An examination of the correlation results revealed that all constructs in the present study were positively correlated with each other as hypothesised. The path coefficients and their significance levels for each link are shown in Table 8. All the paths are significant except the links between the subjective norm components and exercise intention. Although injunctive norm $(\mathrm{r}=.523)$ and descriptive norm $(\mathrm{r}=.282)$ had significant bivariate correlation with exercise intention, they had no significant direct effects on exercise intention. Instrumental attitude $(\beta=.461, p<0.001)$ emerged to be the most important predictor of exercise intention follow by affective attitude $(\beta=.377, \mathrm{p}<0.001)$. Perceived control $(\beta$ $=.170, \mathrm{p}<.01)$ and perceived need $(\beta=.163, \mathrm{p}<.001)$ was found to have relatively small effect on exercise intention. Of six hypotheses tested, two hypotheses (H3 and H4) were not supported.

\subsubsection{Effect on intention}

Overall, the multi-components TPB constructs predicted exercise intention quite well with the exception for the subjective norm components. This is consistent with the finding of Godin and Shephard (1985) that subjective norm failed to contribute reliably to the prediction of physical activity intention. Rhodes and Courneya (2003b) also found neither study using two different sampling identified significant effects on exercise intention for both injunctive and descriptive norm. Similarly, several empirical studies have also demonstrated that subjective norm has consistently exhibited either non-significant or of small significant magnitude when it comes to the prediction of exercise intention (Rhodes, Jones and Courneya 2002; Saunders, Motl, Dowda, Dishman and Pate 2004).

Among all TPB constructs, the attitude components were found to have the strongest effect on exercise intention. In many studies using Ajzen's theory of planned behaviour, attitude has consistently produced the strongest effect on behavioural intention (Ajzen 1991). The results make theoretical sense because instrumental attitude refers to perceived benefit associated with performing exercise activities, and affective attitude reflecting one's feelings (e.g. enjoyment, pleasure, and satisfaction) towards exercising. The more favourable one's attitude (be it instrumental or affective) towards exercising, the greater likelihood of that person to engage in exercise behaviour. 
The result indicated that greater perception of control tended to lead to greater likelihood of exercise participation. This finding makes theoretical sense as a person is less likely to exercise if he or she perceives to have less control over the performance of exercise activities (Sheeran, Trafimow and Armitage 2003). Meta-analytic reviews conducted by Godin and Kok (1996) and Armitage and Conner (2001) have supported the positive link between perceived control and behavioural intention. Brickell, Chatzisarantis and Pretty's (2006) study attempted to examine the utility of the TPB in exercise domain also found the control factor made a significant contribution to the prediction of exercise intention. Lastly, consistent with the finding of Povey, et al. (2000), the role of perceived need in predicting exercise intention is supported in the present study.

\section{Conclusion and Implications}

Greater understanding of factors that lead to exercise behaviour is invaluable in the planning and implementation of effective strategies and interventions seeking to increase general public exercise participation. The empirical findings of the present paper offer several implications for consumer researchers. First, the discriminant validity between perceived need and attitude components is supported and hence the assessment of the role of perceived need in predicting other healthy lifestyle behaviour is warranted. Second, the poor performance of subjective components may partly due to lack of clarity in the conceptualisation and measurement of the construct. For instance, specific source of reference, types of social influence and the nature of influence were not stated clearly (Saunders, et al. 2004). Third, the PBC construct is the most controversial TPB predictor; researchers have failed to reach consensus about the definition of control factor. The present finding suggests that PBC should be measured as single control concept as originally stated by Ajzen (1991).

The present paper also offers substantial insights to marketing practitioners and public policy maker interested in persuading general population to adopt healthier lifestyle. The present paper has identified attitude, perception of individual control and perceived need to be important factors when addressing marketing strategies tactics. For instance, fitness centre operators should employ a multifaceted approach that take into account such factors in marketing planning and execution in order to maintain customer loyalty in the long term. In view of the rising advertising and promotion costs, effectively tailored messages that aim at promoting exercise could help in optimising limited budgets and resources. Attitude toward exercise participation was clearly contributed the most to the prediction of intention to exercise in the present study. The practical implication here is that interventions strategies targeting attitude would certainly improve individual exercise intentions and subsequent behaviour. Lastly, perceived opportunities and resources available do play a role in influencing a person's decision to change their behavioural intention. For instance, perceived price (i.e. membership fees) and availability (i.e. convenience) may be potential impediment to join fitness clubs. Further research into the factors underlying the perception of control would certainly be beneficial to marketers and public policy makers.

This study has several limitations. First, the link between intention-actual behaviour as delineated in the TPB model was not addressed. The assessment of actual exercise behaviour could enhance the validity of the study, but such attempt requires longitudinal study which is often difficult and costly to conduct. Second, the investigation of antecedents of attitudes, subjective norm and perceived control as delineated in the TPB model would have provided more precise information that is important to the development of a marketing and health promotion strategy. Third, samples for the present study were drawn from metropolitan areas. However, there might be social and behavioural differences between rural and urban dweller. Fourth, exercise is not a sufficient measure of healthy lifestyle behaviour.

Future research should include the measure of actual exercise behaviour and exploring the antecedents of attitude, subjective norm, and perceived control so that more in-depth insights could be obtained in understanding these TPB measures. Since there might be difference in terms of social and behavioural aspects between rural and urban dweller, future research should also replicate the study to other states in Malaysia. Further, the attempt to investigate other consumer healthy lifestyle behaviours such as healthy eating, tobacco-free lifestyle, substance use, health preventive practices, and weight control is necessary to explore more comprehensive aspect of healthy lifestyle. Lastly, it is recommended that, in addition to replicating the study so as to confirm the findings in other settings, future research should explore the nature and extent of the impact of other possible variables on exercise behaviour such as environmental factor.

\section{References}

Ajzen, I. (1991). The Theory of Planned Behavior. Organizational Behavior and Human Decision Processes, 50 (2), 179-212.

Ajzen, I. (2002). Perceived Behavioral Control, Self-Efficacy, Locus of Control, and the Theory of Planned Behavior. Journal of Applied Social Psychology, 32 (4), 665-683.

Anderson, J. C. \& Gerbing, D. W. (1982). Some Methods for Respecifying Measurement Models to Obtain Unidimensional Construct Measures. Journal of Marketing Research, 19, 453-460. 
Anderson, J. C. \& Gerbing, D. W. (1988). Structural Equation Modeling in Practice: A Review and Recommend Two-step Approach. Psychological Bulletin, 103, 411-423.

Andres, L. (2006). Exercise? Not Us, Say Youth. New Straits Times, October 10, p. 17.

Armitage, C. J. \& Conner, M. (1999). The Theory of Planned Behavior: Assessment of Predictive Validity and Perceived Control. The British Journal of Social Psychology, 38, 35-54.

Armitage, C. J. \& Conner, M. (2001). Efficacy of the Theory of Planned Behavior: A Meta-Analytic Review. The British Journal of Social Psychology, 40, 471-499.

Bagozzi, R. P. \& Phillips, L. W. (1982). Representing and Testing Organizational Theories: A Holistic Construal. Administrative Science Quarterly, 27 (3) (September), 459-489.

Brickell, T. A., Chatzisarantis, N. L. D. \& Pretty, G. M. (2006). Using Past Behavior and Spontaneous Implementation Intentions to Enhance the Utility of the Theory of Planned Behavior in Predicting Exercise. British Journal of Health Psychology, 11, 249-262.

Chisick, M. C., Poindexter, F. R. \& York, A. K. (1998). Factors Influencing Perceived Need for Dental Care by United States Military Recruits. Clinical Oral Invest, 2, 47-51.

Courneya, K. S., Bobick, T. M. \& Schinke, R. J. (1999). Does the Theory of Planned Behavior Mediate the Relation between Personality and Exercise Behavior. Basic and Applied Social Psychology, 21 (4), 317-324.

Edlund, M. J., Unützer, J. \& Curran, G. M. (2006). Perceived Need for Alcohol, Drug, and Mental Health Treatment. Social Psychiatry Psychiatric Epidemiology, 41, 480-487.

Everson, E. S., Daley, A. J. \& Ussher, M. (2007). Brief Report: The Theory of Planned Behaviour Applied to Physical Activity In Young People Who Smoke. Journal of Adolescence. [online] Retrieved January 3, 2007.

Fishbein, M. \& Ajzen, I. (1975). Belief, Attitude, Intentions and Behavior: An Introduction to Theory and Research. Addison-Wesley, Reading, MA.

Fornell, C. \& Larcker, D. F. (1981). Evaluating Structural Equations with Unobservable Variables and Measurement Error. Journal of Marketing Research, 18 (Feb), 39-50.

Gerbing, D. W. \& Anderson, J. C. (1988). An Updated Paradigm for Scale Development Incorporating Unidimensionality and its Assessment. Journal of Marketing Research, 25, 186-192.

Godin, G., \& Kok, G. (1996). The Theory of Planned Behavior: A Review of Its Applications to Health-related Behaviors. American Journal of Health Promotion, 11 (2) (November/December), 87-98.

Godin, G., \& Shephard, R. J. (1985). A Simple Method to Assess Exercise Behavior in the Community. Canadian Journal of Applied Sport Sciences, 10, 141-146.

Hagger, M. S. \& Chatzisarantis, N. L. D. (2005). First-and Higher-order Models of Attitude, Normative Influence, and Perceived Behavioural Control in the Theory of Planned Behaviour. British Journal of Social Psychology, 44, 513-535.

Hagger, M. S. Anderson, M., Kyriakaki, M., \& Darkings, S. (2007). Aspects of Identity and Their Influence on Intentional Behavior: Comparing Effects for Three Health Behaviors. Personality and Individual Differences, 42, 355-367.

Hair, J. F., Black, W. C., Babin, B. J., Anderson, R. E. \& Tatham, R. L. (2006). Multivariate Data Analysis. $6^{\text {th }}$ edition. New Jersey: Prentice Hall.

Hu, L., \& Bentler, P. M. (1999). Cutoff Criteria for Fit Indexes in Covariance Structure Analysis: Conventional Criteria Versus New Alternatives. Structural Equation Modeling, 6, 1-55.

Kraft, F. B., \& Goodell, P. W. (1993). Identifying the Health Conscious Consumer. Journal of Health Care Marketing, $13(3), 18-25$.

Lu, C. S., Lai, K. H., Cheng, T. C. E. (2007). Application of Structural Equation Modeling to Evaluate the Intention of Shippers to Use Internet Services in Liner Shipping. European Journal of Operational Research, 180, 845-867.

Norman, P., Conner, M. \& Bell, R. (2000). The Theory of Planned Behavior and Exercise: Evidence for the Moderating Role of Past Behavior. British Journal of Health Psychology, 5, 249-261.

Nunnally, J. C. (1978), Psychometric Theory, $2^{\text {nd }}$ edition, New York: McGraw-Hill.

Omar, Z. A. (2002). Diet, Physical Exercise and Health: Are We Doing Enough?. NCD Malaysia, 1 (3), 2-3.

Payne, N., Jones, F. \& Harris, P. R. (2004). The Role of Perceived Need within the Theory of Planned Behavior: A Comparison of Exercise and Healthy Eating. British Journal of Health Psychology, 9, 489-504.

Plante, T. G. \& Rodin, J. (1990). Physical Fitness and Enhanced Psychological Health. Current Psychology, 9 (1). 
Povey, R., Conner, M., Sparks, P., James, R. \& Shepherd, R. (2000). Application of the Theory of Planned Behavior to Two Dietary Behaviors: Roles of Perceived Control and Self-efficacy. British Journal of Health Psychology, 5, 121-130.

Rabinowitz, J., Gross, R. \& Feldman, D. (1999). Correlates of A Perceived Need for Mental Health Assistance and Differences Between Those Who Do and Do not Seek Help. Social Psychiatry Psychiatric Epidemiology, 34, 141-146

Rhodes, R. E. \& Courneya, K. S. (2003a). Relationships between Personality, An Extended Theory of Planned Behaviour Model and Exercise Behaviour. British Journal of Health Psychology, 8, 19-36.

Rhodes, R. E. \& Courneya, K. S. (2003b). Investigating Multiple Components of Attitude, Subjective Norm, and Perceived Control: An Examination of the Theory of Planned Behavior in the Exercise Domain. British Journal of Social Psychology, 42, 129-146.

Rhodes, R. E. \& Blanchard, C. M. (2006). Conceptual Categories or Operational Constructs? Evaluating Higher Order Theory of Planned Behavior Structures in the Exercise Domain. Behavioral Medicine, 31 (4) (Winter), 141-150.

Rhodes, R. E., Blanchard, C. M. \& Matheson, D. H. (2006). A Multicomponent Model of the Theory of Planned Behavior. British Journal of Health Psychology, 11, 119-137.

Rhodes, R. E., Blanchard, C. M. Matheson, D. H. \& Coble, J. (2006). Disentangling Motivation, Intention, and Planning in the Physical Activity Domain. Psychology of Sport and Exercise, 7, 15-27.

Rhodes, R. E., Jones, L. W. \& Courneya, K. S. (2002). Extending the Theory of Planned Behavior in the Exercise Domain: A Comparison of Social Support and Subjective Norm. Research Quarterly for Exercise and Sport, 73 (2), 193-199.

Rhodes, R. E., Macdonald, H. M. \& McKay, H. A. (2006). Predicting Physical Activity Intention and Behavior among Children in a Longitudinal Sample. Social Science \& Medicine, 62 (12), 3146-3156.

Saunders, R. P., Motl, R. W., Dowda, M., Dishman, R. K. \& Pate, R. R. (2004). Comparison of Social Variables for Understanding Physical Activity in Adolescent Girls. American Journal of Health Behavior, 28 (5), 426-436.

Sekaran, U. (2000). Research Methods for Business. $3^{\text {rd }}$ edition. John Wiley \& Sons.

Sheeran, P., Trafimow, D. \& Armitage, C. J. (2003). Predicting Behavior from Perceived Behavioral Control: Tests of the Accuracy Assumption of the Theory of Planned Behavior. The British Journal of Social Psychology, 42, 393-410.

Steptoe, A., Wardle, J., Vinck, J., Tuomisto, M., Holte, A. \& Wichstrøm, L. (1994). Personality and Attitudinal Correlates of Healthy and Unhealthy Lifestyles in Young Adults. Psychology and Health, 9, 331-343.

Symons Downs, D. \& Hausenblas, H. A. (2003). Exercising for Two: Examining Pregnant Women's Second Trimester Exercise Intention and Behavior Using the Framework of the Theory of Planned Behavior. Women's Health Issues, 13, 222-228.

Van Voorhees, B. W., Fogel, J., Houston, T. K., Cooper, L. A., Wang, N. Y. \& Ford, D. E. (2006). Attitudes and Illness Factors Associated with Low Perceived Need for Depression Treatment Among Young Adults. Social Psychiatry Psychiatric Epidemiology, 41, 746-754. 
Table 1. Profile of Respondents

\begin{tabular}{|c|c|c|c|}
\hline Demographic Variables & Description & Frequency & Percentage \\
\hline Gender & $\begin{array}{l}\text { Male } \\
\text { Female }\end{array}$ & $\begin{array}{l}113 \\
104\end{array}$ & $\begin{array}{l}52.1 \\
47.9\end{array}$ \\
\hline Age & $\begin{array}{l}\text { Below } 20 \\
20-29 \\
30-39 \\
40-49 \\
\text { Above } 50\end{array}$ & $\begin{array}{l}19 \\
99 \\
54 \\
33 \\
12\end{array}$ & $\begin{array}{l}8.8 \\
45.6 \\
24.9 \\
15.2 \\
5.5\end{array}$ \\
\hline Race & $\begin{array}{l}\text { Malay } \\
\text { Chinese } \\
\text { Indian }\end{array}$ & $\begin{array}{l}99 \\
74 \\
44\end{array}$ & $\begin{array}{l}45.6 \\
34.1 \\
20.3\end{array}$ \\
\hline Religion & $\begin{array}{l}\text { Islam } \\
\text { Buddhism/Taoism } \\
\text { Hinduism } \\
\text { Christianity } \\
\text { Others }\end{array}$ & $\begin{array}{l}101 \\
50 \\
21 \\
41 \\
4\end{array}$ & $\begin{array}{l}46.5 \\
23.0 \\
9.7 \\
18.9 \\
1.8\end{array}$ \\
\hline Marital Status & $\begin{array}{l}\text { Single } \\
\text { Married without children } \\
\text { Married with children } \\
\text { Divorced / Widowed }\end{array}$ & $\begin{array}{l}127 \\
13 \\
72 \\
5\end{array}$ & $\begin{array}{l}58.5 \\
6.0 \\
33.2 \\
2.3\end{array}$ \\
\hline Education Level & $\begin{array}{l}\text { PMR/SRP/LCE or below } \\
\text { SPM/SPVM/MCE/O-Level } \\
\text { STPM/HSC/A-Level } \\
\text { College Diploma } \\
\text { University or Professional Degree }\end{array}$ & $\begin{array}{l}8 \\
49 \\
11 \\
44 \\
105\end{array}$ & $\begin{array}{l}3.7 \\
22.6 \\
5.1 \\
20.3 \\
48.4\end{array}$ \\
\hline Income Level & $\begin{array}{l}\text { Below RM1000 } \\
\text { RM1000 - RM2999 } \\
\text { RM3000 - RM4999 } \\
\text { RM5000 - RM6999 } \\
\text { RM7000 - RM8999 } \\
\text { Above RM9000 } \\
\text { Not Applicable }\end{array}$ & $\begin{array}{l}20 \\
69 \\
47 \\
16 \\
7 \\
4 \\
54\end{array}$ & $\begin{array}{l}9.2 \\
31.8 \\
21.7 \\
7.4 \\
3.2 \\
1.8 \\
24.9\end{array}$ \\
\hline Occupation & $\begin{array}{l}\text { Professional/Managerial Position } \\
\text { Middle Level Manager } \\
\text { Executive/Technician/Production } \\
\text { Own Business } \\
\text { Student } \\
\text { Housewife / Retired or unemployed }\end{array}$ & $\begin{array}{l}26 \\
26 \\
82 \\
13 \\
60 \\
10\end{array}$ & $\begin{array}{l}12.0 \\
12.0 \\
37.8 \\
6.0 \\
27.6 \\
4.6\end{array}$ \\
\hline
\end{tabular}


Table 2. Corrected Item-total Correlations (CITC)

\begin{tabular}{|c|c|c|c|c|c|}
\hline Construct & Item & CITC & Construct & Item & CITC \\
\hline \multirow{6}{*}{$\begin{array}{l}\text { Instrumental } \\
\text { Attitude }\end{array}$} & IA1 & 0.659 & \multirow{6}{*}{$\begin{array}{l}\text { Perceived } \\
\text { Control }\end{array}$} & PC1 & 0.729 \\
\hline & IA2 & 0.556 & & $\mathrm{PC} 2$ & 0.790 \\
\hline & IA3 & 0.709 & & PC3 & 0.713 \\
\hline & IA4 & 0.578 & & PC4 & 0.800 \\
\hline & IA5 & 0.654 & & PC5 & 0.790 \\
\hline & IA6 & 0.683 & & PC6 & 0.729 \\
\hline \multirow{6}{*}{$\begin{array}{l}\text { Affective } \\
\text { Attitude }\end{array}$} & AA1 & 0.715 & \multirow{5}{*}{ Self-efficacy } & SE1 & 0.652 \\
\hline & AA2 & 0.671 & & SE2 & 0.592 \\
\hline & AA3 & 0.718 & & SE3 & 0.799 \\
\hline & AA4 & 0.772 & & SE4 & 0.743 \\
\hline & AA5 & 0.548 & & SE5 & 0.595 \\
\hline & AA6 & 0.515 & \multirow{7}{*}{$\begin{array}{l}\text { Exercise } \\
\text { Intention }\end{array}$} & I1 & 0.739 \\
\hline \multirow{5}{*}{ Injunctive Norm } & IN1 & 0.588 & & $\mathrm{I} 2$ & 0.729 \\
\hline & IN2 & 0.331 & & $\mathrm{I} 3$ & 0.774 \\
\hline & IN3 & 0.663 & & I4 & 0.727 \\
\hline & IN4 & 0.528 & & I5 & 0.719 \\
\hline & IN5 & 0.652 & & I6 & 0.777 \\
\hline \multirow{5}{*}{$\begin{array}{l}\text { Descriptive } \\
\text { Norm }\end{array}$} & DN1 & 0.805 & & $\mathrm{I} 7$ & 0.636 \\
\hline & DN2 & 0.836 & \multirow{3}{*}{$\begin{array}{l}\text { Perceived } \\
\text { Need }\end{array}$} & PN1 & 0.497 \\
\hline & DN3 & 0.869 & & PN2 & 0.735 \\
\hline & DN4 & 0.867 & & PN3 & 0.661 \\
\hline & DN5 & 0.774 & \multicolumn{3}{|c|}{ Total number of items: 43} \\
\hline
\end{tabular}


Table 3. Rotated Factor Matrix for Social Cognitive Statements

\begin{tabular}{|l|l|l|l|l|l|l|}
\hline \multirow{2}{*}{ Items } & Factors & \multicolumn{5}{l|}{} \\
\cline { 2 - 7 } & F1 & F2 & F3 & F4 & F5 & F6 \\
\hline IA1 & .175 & .126 & .355 & .652 & .174 & -.091 \\
\hline IA2 & .182 & .010 & .073 & .666 & .019 & .353 \\
\hline IA3 & .236 & .127 & .391 & .651 & .185 & -.015 \\
\hline IA4 & .142 & -.029 & .011 & .726 & .039 & .366 \\
\hline IA5 & .221 & .173 & .263 & .623 & .261 & .047 \\
\hline IA6 & .308 & -.038 & .338 & .646 & .179 & -.107 \\
\hline AA1 & .163 & .042 & .762 & .257 & .125 & .160 \\
\hline AA2 & .239 & .156 & .750 & .105 & .031 & .158 \\
\hline AA3 & .192 & .010 & .786 & .236 & .127 & .138 \\
\hline AA4 & .216 & .057 & .807 & .225 & .082 & .175 \\
\hline AA5 & .268 & .088 & .262 & .204 & .094 & .730 \\
\hline AA6 & .103 & .025 & .312 & .100 & .072 & .778 \\
\hline IN1 & .072 & .126 & .223 & .156 & .708 & -.017 \\
\hline IN3 & .125 & .143 & .158 & .234 & .744 & .072 \\
\hline IN4 & .136 & .341 & -.034 & -.035 & .683 & .096 \\
\hline IN5 & .179 & .071 & .007 & .132 & .806 & .028 \\
\hline DN1 & .169 & .850 & .067 & .096 & .100 & -.017 \\
\hline DN2 & .139 & .856 & .094 & .089 & .224 & -.009 \\
\hline DN3 & .163 & .905 & .005 & -.016 & .095 & -.018 \\
\hline DN4 & .218 & .878 & .064 & .005 & .158 & .007 \\
\hline DN5 & .238 & .792 & .081 & .093 & .091 & .196 \\
\hline PC1 & .766 & .082 & -.001 & .112 & .018 & .207 \\
\hline PC2 & .807 & .160 & .092 & .099 & .086 & .032 \\
\hline PC3 & .714 & .249 & .254 & .138 & .155 & .031 \\
\hline PC4 & .819 & .192 & .168 & -.016 & .084 & -.013 \\
\hline PC5 & .650 & .126 & .127 & .233 & .032 & -.026 \\
\hline PC6 & .759 & .070 & -.003 & .208 & -.019 & .229 \\
\hline SE1 & .718 & .166 & .125 & .119 & .002 & .226 \\
\hline SE2 & .616 & .144 & .069 & .191 & .120 & .026 \\
\hline SE3 & .718 & .132 & .296 & .160 & .213 & .083 \\
\hline SE4 & .605 & .097 & .259 & .170 & .362 & .097 \\
\hline SE5 & 11.216 & .035 & .243 & .085 & .227 & -.102 \\
\hline Eigen Values & 35.05 & 11.087 & 8.185 & 5.557 & 4.315 & 3.863 \\
\hline Total Variance \\
\hline
\end{tabular}


Table 4. Reliability test

\begin{tabular}{|l|l|l|}
\hline Construct & No. of item & Cronbach's Alpha \\
\hline Instrumental Attitude & 6 & 0.853 \\
\hline Affective Attitude & 4 & 0.887 \\
\hline Injunctive Norm & 4 & 0.792 \\
\hline Descriptive Norm & 5 & 0.936 \\
\hline Perceived Control & 6 & 0.901 \\
\hline Exercise Intention & 7 & 0.910 \\
\hline Perceived Need & 3 & 0.783 \\
\hline
\end{tabular}

Table 5. Parameter estimates, critical ratios, and item reliability for the revised measurement model

\begin{tabular}{|c|c|c|c|c|c|c|}
\hline $\begin{array}{l}\text { Latent } \\
\text { Constructs }\end{array}$ & Items & $\begin{array}{l}\text { Unstandardised } \\
\text { Loading }\end{array}$ & $\begin{array}{l}\text { Standardised } \\
\text { Loading }\end{array}$ & $\begin{array}{l}\text { Standard } \\
\text { Error }\end{array}$ & $\begin{array}{l}\text { Critical } \\
\text { Ratio }^{\mathrm{a}}\end{array}$ & $\begin{array}{l}\text { Item } \\
\text { Reliability }\end{array}$ \\
\hline \multirow{5}{*}{$\begin{array}{l}\text { Instrumental } \\
\text { Attitude }\end{array}$} & IA6 & 1.000 & .754 & - & $-{ }^{b}$ & .569 \\
\hline & IA5 & 1.022 & .734 & .096 & 10.653 & .539 \\
\hline & IA4 & .636 & .554 & .081 & 7.882 & .306 \\
\hline & IA3 & 1.049 & .794 & .091 & 11.579 & .630 \\
\hline & IA1 & 1.097 & .749 & .101 & 10.885 & .561 \\
\hline \multirow{4}{*}{$\begin{array}{l}\text { Affective } \\
\text { Attitude }\end{array}$} & AA4 & 1.000 & .863 & - & - & .744 \\
\hline & AA3 & .985 & .824 & .066 & 14.821 & .678 \\
\hline & AA2 & .943 & .752 & .073 & 12.917 & .566 \\
\hline & AA1 & 1.016 & .822 & .069 & 14.776 & .676 \\
\hline \multirow{3}{*}{$\begin{array}{l}\text { Injunctive } \\
\text { Norm }\end{array}$} & IN5 & 1.000 & .719 & - & - & .517 \\
\hline & IN3 & 1.198 & .854 & .122 & 9.843 & .730 \\
\hline & IN1 & 1.115 & .661 & .129 & 8.624 & .436 \\
\hline \multirow{4}{*}{$\begin{array}{l}\text { Descriptive } \\
\text { Norm }\end{array}$} & DN5 & 1.000 & .807 & - & - & .651 \\
\hline & DN4 & 1.240 & .898 & .080 & 15.492 & .806 \\
\hline & DN2 & 1.143 & .884 & .075 & 15.189 & .781 \\
\hline & DN1 & 1.162 & .825 & .084 & 13.816 & .680 \\
\hline \multirow{4}{*}{$\begin{array}{l}\text { Perceived } \\
\text { Control }\end{array}$} & PC5 & .840 & .624 & .097 & 8.666 & .390 \\
\hline & PC4 & 1.149 & .886 & .096 & 12.015 & .784 \\
\hline & $\mathrm{PC} 2$ & 1.210 & .894 & .100 & 12.085 & .800 \\
\hline & PC1 & 1.000 & .707 & - & - & .500 \\
\hline \multirow{7}{*}{$\begin{array}{l}\text { Exercise } \\
\text { Intention }\end{array}$} & INT7 & 1.000 & .672 & - & - & .451 \\
\hline & INT6 & 1.421 & .826 & .131 & 10.866 & .683 \\
\hline & INT5 & 1.355 & .776 & .132 & 10.297 & .602 \\
\hline & INT4 & 1.351 & .762 & .133 & 10.131 & .580 \\
\hline & INT3 & 1.341 & .805 & .126 & 10.624 & .647 \\
\hline & INT2 & 1.283 & .756 & .128 & 10.064 & .572 \\
\hline & INT1 & 1.350 & .786 & .130 & 10.408 & .617 \\
\hline \multirow{3}{*}{$\begin{array}{l}\text { Perceived } \\
\text { Need }\end{array}$} & PN3 & 1.000 & .784 & - & - & .614 \\
\hline & PN2 & 1.159 & .896 & .112 & 10.310 & .804 \\
\hline & PN1 & .575 & .563 & .072 & 7.977 & .317 \\
\hline
\end{tabular}

Fit indices: $\chi^{2}=600.147, \chi^{2} / \mathrm{df}=1.563, \mathrm{TLI}=0.937, \mathrm{CFI}=0.945, \mathrm{RMSEA}=0.051$

Note: ${ }^{a}$ C.R. is the critical ratio obtained by dividing the estimate of the covariance by its standard error. A value exceeding 1.96 represents significance level of $0.05 ;{ }^{b}$ some critical ratios were not calculated because loading was set to 1 to fix construct variance; All item loadings in CFA model were significant at 0.001 level. 
Table 6. Confirmatory Factor Analysis for Convergent Validity

\begin{tabular}{|l|l|l|l|l|}
\hline Construct & No. of Items & Item Loading & Reliability & Variance Extracted \\
\hline Instrumental Attitude & 5 & $0.554-0.794$ & 0.843 & 0.521 \\
\hline Affective Attitude & 4 & $0.752-0.863$ & 0.887 & 0.666 \\
\hline Injunctive Norm & 3 & $0.661-0.854$ & 0.774 & 0.561 \\
\hline Descriptive Norm & 4 & $0.807-0.898$ & 0.914 & 0.729 \\
\hline Perceived Control & 4 & $0.624-0.894$ & 0.858 & 0.618 \\
\hline Exercise Intention & 7 & $0.672-0.826$ & 0.910 & 0.593 \\
\hline Perceived Need & 3 & $0.563-0.896$ & 0.783 & 0.578 \\
\hline
\end{tabular}

Table 7. Measurement Model Fit: Discriminant Validity

\begin{tabular}{|c|c|c|c|c|c|c|}
\hline \multirow{2}{*}{ Links } & \multicolumn{2}{|c|}{ Fixed correlation } & \multicolumn{3}{|c|}{ Freely estimated correlation } & \multirow{2}{*}{$\begin{array}{l}\text { Chi square } \\
\text { difference }\end{array}$} \\
\hline & d.f. & Chi square & Correlation & d.f. & Chi square & \\
\hline $\mathrm{IA}-\mathrm{AA}$ & 27 & 91.622 & .71 & 26 & 39.163 & 52.46 \\
\hline $\mathrm{IA}-\mathrm{IN}$ & 20 & 106.23 & .55 & 19 & 43.31 & 62.92 \\
\hline $\mathrm{IA}-\mathrm{DN}$ & 44 & 200.89 & .26 & 43 & 120.18 & 80.71 \\
\hline $\mathrm{IA}-\mathrm{PC}$ & 27 & 96.95 & .47 & 26 & 37.19 & 59.76 \\
\hline $\mathrm{IA}-\mathrm{INT}$ & 54 & 193.146 & .83 & 53 & 126.43 & 66.72 \\
\hline $\mathrm{IA}-\mathrm{PN}$ & 27 & 158.748 & .33 & 26 & 73.702 & 85.05 \\
\hline $\mathrm{AA}-\mathrm{IN}$ & 14 & 76.037 & .41 & 13 & 17.21 & 58.827 \\
\hline $\mathrm{AA}-\mathrm{DN}$ & 20 & 86.81 & .25 & 19 & 26.37 & 60.44 \\
\hline $\mathrm{AA}-\mathrm{PC}$ & 20 & 71.72 & .42 & 19 & 24.37 & 47.35 \\
\hline $\mathrm{AA}-\mathrm{INT}$ & 44 & 143.33 & .80 & 43 & 94.07 & 49.26 \\
\hline $\mathrm{AA}-\mathrm{PN}$ & 14 & 83.73 & .35 & 13 & 22.91 & 60.82 \\
\hline $\mathrm{IN}-\mathrm{DN}$ & 14 & 60.216 & .39 & 13 & 18.199 & 42.02 \\
\hline $\mathrm{IN}-\mathrm{PC}$ & 14 & 81.69 & .22 & 13 & 30.027 & 51.66 \\
\hline $\mathrm{IN}-\mathrm{INT}$ & 35 & 145.02 & .24 & 34 & 76.13 & 68.89 \\
\hline $\mathrm{IN}-\mathrm{PN}$ & 9 & 78.36 & .20 & 8 & 19.15 & 59.21 \\
\hline $\mathrm{DN}-\mathrm{PC}$ & 20 & 68.94 & .36 & 19 & 36.84 & 32.10 \\
\hline $\mathrm{DN}-\mathrm{INT}$ & 44 & 163.04 & .16 & 43 & 83.64 & 79.4 \\
\hline $\mathrm{DN}-\mathrm{PN}$ & 14 & 76.85 & .12 & 13 & 11.874 & 64.976 \\
\hline $\mathrm{PC}-\mathrm{INT}$ & 44 & 142.29 & .27 & 43 & 84.815 & 57.475 \\
\hline $\mathrm{PC}-\mathrm{PN}$ & 14 & 80.86 & .13 & 13 & 13.534 & 67.326 \\
\hline INT - PN & 35 & 150.17 & .22 & 34 & 77.117 & 73.05 \\
\hline
\end{tabular}

Table 8. The Results of Hypotheses Testing

\begin{tabular}{|l|l|l|l|l|l|l|}
\hline Paths & Hypothesised & $\beta$ & SE & Critical ratio & P & Supported \\
\hline H1: IA - INT & + & .461 & .085 & 4.916 & $* * *$ & Yes \\
\hline H2: AA - INT & + & .377 & .054 & 4.881 & $* * *$ & Yes \\
\hline H3: IN - INT & + & .054 & .045 & .890 & .373 & No \\
\hline H4: DN - INT & + & -.063 & .030 & -1.236 & .216 & No \\
\hline H6: PC - INT & + & .170 & .037 & 2.996 & .003 & Yes \\
\hline H7: PN - INT & + & .163 & .033 & 3.542 & $* * *$ & Yes \\
\hline
\end{tabular}

Note: $\beta=$ standardised regression weight; $\mathrm{SE}=$ standard error; Hypothesis 5 was not tested as self-efficacy was dropped from further analysis based on exploratory factor analyses

$* * * \mathrm{p}<0.001$ 


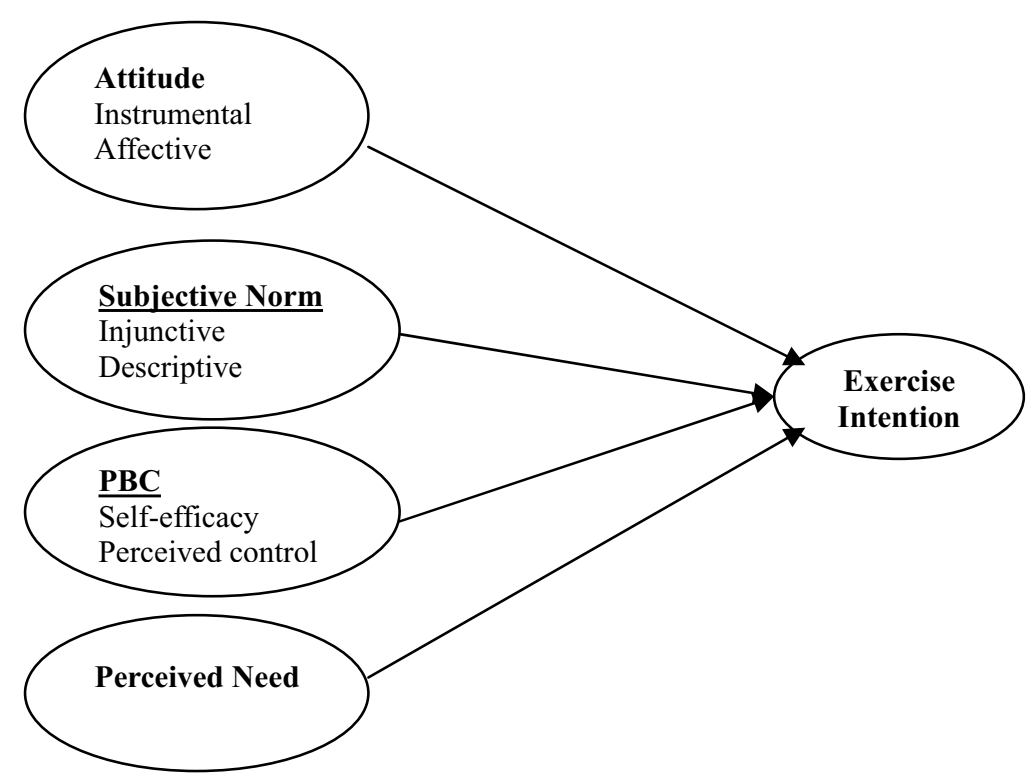

Figure 1. The research model

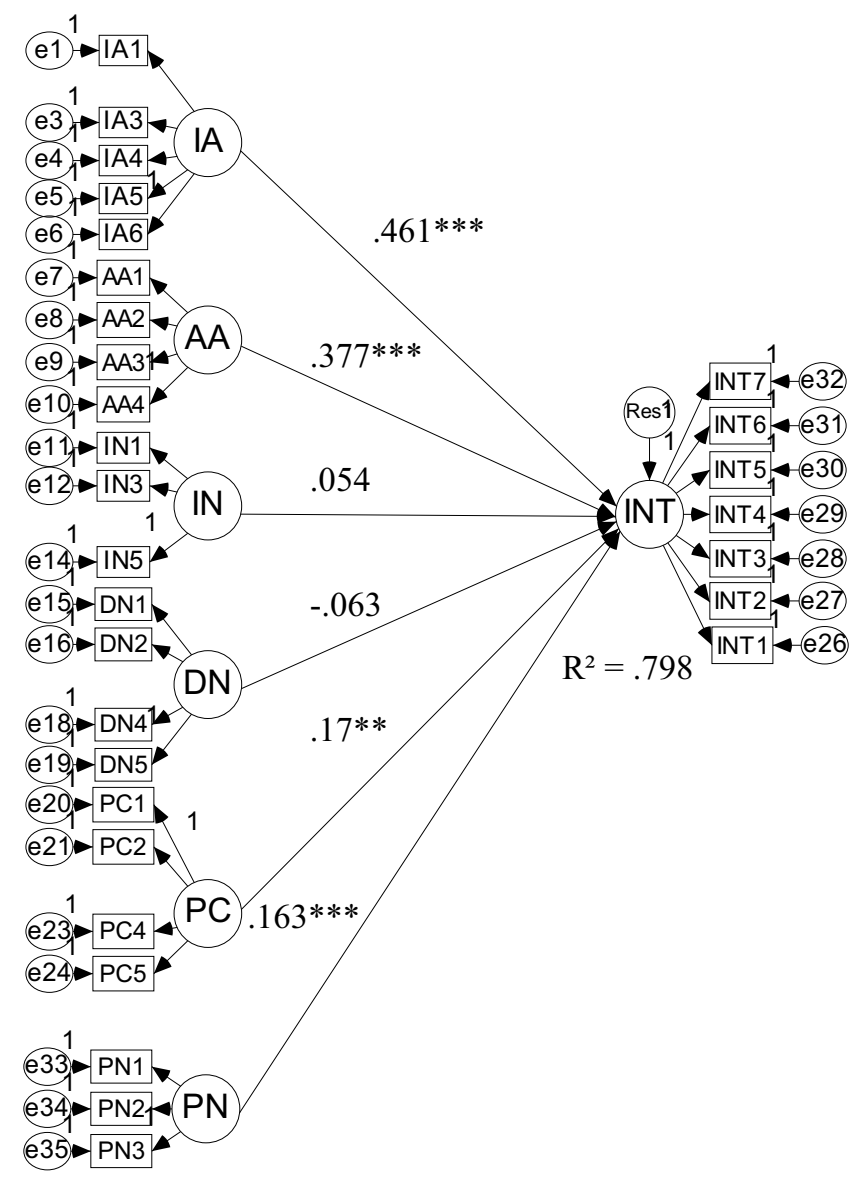

Figure 2. Results of the research model.

Note: $\left(\chi^{2}=630.993, \chi^{2} / \mathrm{df}=1.622, \mathrm{TLI}=0.931, \mathrm{CFI}=0.938, \mathrm{RMSEA}=0.054\right)$ 


\title{
Studies on Spillover of Scientific and Technological Knowledge in High-tech Industry Clusters
}

\section{---Taking Jinan High-tech Development Zone for Example}

\author{
Zhenpeng Kong \\ School of International Trade, Shandong University of Economics \\ Jinan 250014, China \\ Tel: 86-531-8790-0826_E-mail: kongkairui@yahoo.com.cn \\ Qigang Yuan \\ School of International Trade, Shandong University of Economics \\ Jinan 250014, China \\ E-mail: sh199619@beelink.com
}

\begin{abstract}
To achieve the "second pioneering" in high-tech development zone, it should vigorously develop high-tech industrial clusters to make a breakthrough. Only on the basis of industry clusters, by the establishment of an effective platform for science and technology innovation, through the vigorous support of technology with general character in industrial clusters, can improve the technological innovation capability of industrial clusters. Taking the industrial clusters in high-tech development zone in Jinan for example, the thesis has analyzed the inevitability of the spillover of scientific and technological knowledge. The results of analysis have supported the point of view that the strategy of scientific and technological innovation in the high-tech development zones should be based on the industrial clusters.
\end{abstract}

Keywords: Spillover of Scientific and Technological knowledge, High-tech Cluster, Studies

In the process of implementing the independent innovation and promoting high-tech industrialization, China's high-tech development zones have become the "habitats" of high-tech enterprises. But overall, China's high-tech zones lack of the ability of independent innovation. Although the industry has developed in a quick speed (Note 1) the value-added ratio is low for which the root is the few contributions of the independent intellectual property rights to the industries. It is reference significance for policy-making in the correct and objective understanding of the feasibility of inevitability of the spillover of scientific and technological knowledge. This thesis is composed of four parts. Part I is the preface. Part II analyzes the inevitability of the spillover of scientific and technological knowledge in the cluster brought forth even without the technological transfer. Taking the high-tech development zones in Jinan for example, Part III analyzes the gradualness of the spillover of scientific and technological knowledge. Part IV is the conclusion.

\section{Introduction}

\subsection{Studies on Literature of Technological Innovation}

In the early 20th century, Joseph Schumpeter-the economist of Austrian descendant in America, had proposed in the works "Theory of Economic Development" which made him famous that the so-called "technological innovation" was that the first commercial application of the new technologies and new inventions was to establish a new production function or supply function and to introduce a new combination of production factors and production conditions in the production system. Unfortunately, Schumpeter's argument for a long time did not attract people's attention. It is until the 1970s in 20th century, in the sum-up of the cyclical development and the law of the recession in the economic development that the theory of technological innovation of Schumpeter has aroused the concern of the mainstream economists and has been developed to a forefront of scientific study - study of economic and technical innovation, being called "the new Schumpeter principle."

Compared with the classic Schumpeterian theory, the new Schumpeter principle has paid more attention to technological innovation, and emphasized that "technological innovation" mainly included activities of three aspects: firstly, product innovation, referring to the commercialization of the technical changeable products. It can be entirely 
new products, and can also be improvements to the existing products. Secondly, process innovation, also known as technology innovation, referring to the major changes of the production technology of products, including new techniques, new equipments, new managements and new organizational methods. Thirdly, technology transfer.

\subsection{Studies on Literature of Technology Spillover}

The study methods of technology spillover in the clusters has been first advocated by Marshal in 1920, and been further studied by David and Rosenbloom (1990), Krugman (1991), Kelly and Hageman (1999), and others. It has been proposed that there has been three advantages in the clusters, that is, cluster exterior nature. First, the strength of the reservoir of the labor forces having been formed intensively in the location by the intra-industry enterprises because of the same industry or closely related industries. Second, relevant raw materials and other input elements which can be obtained in low cost. Third, the spillover of scientific and technological knowledge engendered among the neighboring enterprises and institutions as a result of the strengthening of the exchange of knowledge. Dobkins (1996), Paci, Usai (1999) and Hansen (2002) have also studied on the exterior nature and innovation space of the cluster. Their studies have discovered that the first two advantages in the above three have the indirect impact on the innovation capacity in the culture. At the same time, the third advantage has a direct impact not only on the labor force and enterprises in the cloture, but also on the process of innovation.

The above studies have provided us with the idea being used as reference. Through the establishment of models, the thesis has further verified the feasibility and inevitability of technology transfer and spillover of scientific and technological knowledge in the cluster.

\section{Model Analysis of the Spillover of Scientific and Technological Knowledge within the Industry Cluster}

\subsection{Model Assumptions}

Among the numerous industry clusters within the country, the vast majority of them take the big enterprises as their centers, the numerous small and medium-sized enterprises being the periphery to form the cluster of "vertebral shape". Under the assumptions of premises of clusters of "vertebral shape", through the establishment of the production function model including the variable of technological spillover, the following analyzes to explain how the cluster innovation and learning mechanism plays a role and how to enhance the competitiveness of the entire cluster through the large enterprises driving the progress of small enterprises.

The industry cluster function: $\mathrm{Q}=\mathrm{F}(\mathrm{R}, \mathrm{T}, \mu, \mathrm{N}, \mathrm{M})$.

$\mathrm{Q}$ is the output of the industry cluster; $\mathrm{R}$ is the resource essentials; $\mathrm{T}$ is the technology; $\mu$ is the ratio of technology spillover; $\mathrm{N}$ and $\mathrm{M}$ represents the number of overseas-funded enterprises and that of domestic-funded ones respectively.

\subsection{The Technology Spillover Engendered by the Technological Innovations in Large Enterprises}

We assume that the large enterprises have made the independent innovations whereas the small ones have not. The production function of enterprises in the industry cluster is determined by the essentials represented by $\mathrm{R}$ and the productivity of essentials represented by E. The essentials can be divided into two parts, one part being the essentials $R_{p}$ used in the production, the other part being the essential inputs $R_{R}$ used in the research and development. The production function of each enterprise of the large and small enterprises is

$$
Q=E * R_{p}
$$

Here, we assume that there is no technological innovation in the large and small enterprise. The amount of technological knowledge in the cluster is $T_{c}=T_{0}$.

There is a close relationship between the essential productivity and the amount of technological knowledge in the whole cluster. Therefore,

$$
E=a \cdot T_{C}^{\gamma}
$$

At this time, there is an enterprise which begins to make the first independent technological innovation. On the one hand, the technologies $\mathrm{T}$ obtained in the innovation are related to the amount of technological knowledge $T_{c}$ in the cluster; on the other hand, they are related to its own essential inputs of research and development $R_{R}$.

$$
T=T_{C}^{\delta} \cdot R_{R}=T_{0}^{\delta} \cdot R_{R}
$$

Whereas the technologies $\mathrm{T}$ obtained by the large enterprises through the technology innovations can be divided into two parts, one part being their own technological knowledge of the large enterprises $T_{1}$, the other part being the public technological knowledge $T_{2}$ in the industry cluster having been spillover.

$$
T=T_{1}+T_{2}
$$


We mark the spillover ratio of scientific and technological knowledge as

$$
\mu=T_{2} / T
$$

The spillover ratio of scientific and technological knowledge $\mu$ is the variable representing the innovations and characteristics of learning mechanism in the cluster.

If the number of large enterprises which have made one time of technological innovation is $\mathrm{N}$, then the knowledge amount of the whole enterprise cluster will become:

$$
T_{C}=T_{0}+\int_{0}^{N} T_{2} d x=T_{0}+N \cdot T_{2}
$$

\subsection{The Function Analysis of the Acceptation of Technology Spillover by Small Enterprises}

Because we put the research emphasis on the industry clusters of numerous small and medium-sized enterprises and make the studies on the outputs of the small enterprises, we turn our view to the small enterprises now.

The production function of the small enterprises is also:

$Q=E * R_{p}, E=a \cdot T_{C}^{\gamma}$

Because at this time $T_{C}=T_{0}+\int_{0}^{N} T_{2} d x=T_{0}+N \cdot T_{2}, \quad E=\alpha\left(T_{0}+N \cdot T_{2}\right)^{y}$.

According to (5), $T_{2}=\mu \mathrm{T}$ and (3) $T=T_{C}^{\delta} \cdot R_{R}=T_{0}^{\delta} \cdot R_{R}$, now we can obtain the concrete form of the

production function of small enterprises,

$Q=\alpha\left(T_{0}+N \cdot T_{2}\right)^{\gamma} R_{p}$

It can obtain through the use of $T_{2}$ and $T$ into the above equation:

$Q=\alpha\left(T_{0}+N \cdot \mu \cdot T_{0}^{\delta} R_{R}\right)^{\gamma} R_{p}$

Because $R_{R}+R_{p}=R$, finally, we can educe the production function in the largest outputs of the small enterprises:

$Q=\frac{\alpha\left[\left(T_{0}{ }^{\delta} \cdot \mu \cdot N \cdot R\right)^{2}-T_{0}{ }^{2}\right]}{4 T_{0}{ }^{\delta} \cdot \mu \cdot N}$

The production function in the largest outputs of the small enterprises the number of which being $\mathrm{M}$

$Q=M \cdot \frac{\alpha\left\lfloor\left(T_{0}^{\delta} \cdot \mu \cdot N \cdot R\right)^{2}-T_{0}^{2}\right\rfloor}{4 T_{0}^{\delta} \cdot \mu \cdot N}$

The essential inputs $R$ are constant variables. We can write the above equation in short:

$Q=M \cdot \varphi(\mu) \cdot \omega(\mu) \mathrm{Q}$

Therefore, we can draw the conclusion that in the industry clusters of "vertebral shape", the outputs Q in the largest outputs of the small enterprises is the function of the spillover ration of scientific and technological knowledge $\mu$ and the scale of the cluster $\mathrm{M}+\mathrm{N}$.

\section{Case Analysis of Jinan High-tech Development Zone}

Being established in 1991, Jinan high-tech development zone is one of the first national-level high-tech zones approved by the State Council. In the development of industry clusters, Jinan high-tech zone has focused on building eight national professional industrial zones. There are more than 3,000 enterprises of all types, and more than 200 high-tech enterprises within the zone. By strengthening the construction of industrial clusters, the scale of the enterprises in the zone continues to expand. There are 15 world's top 500 enterprises having settled such as Korea's LG, Japan's Matsushita, Suzuki, NEC, Texas Instruments, Pepsi, American Standard, Volvo, and Sanyo. Through the enhanced international cooperation, the spillover effect of scientific and technological knowledge has been strengthened. The high-tech zone has built Chinese-Ukrainian High-tech Cooperation Park, being one of the national government cooperation projects. Qilu Software Park has established the relationship of friendly sister park with Bangalore Software Park in India. It has also cooperated with the oversea well-known software companies in the construction of "Microsoft Solution Lab", IBM solution Laboratory, Nortel Networks Laboratory and DSP Joint Laboratory. Through the cooperation with IBM Company in America, Qilu Software Institute has established the international computer training centre. Environmental Science and Technology Park has cooperated with Nordic SEM Company to establish the industrial base of environmental science and technology.

About the high-tech talent scale, there are 60,000 people who are directly engaged in the high-tech industry in Jinan high-tech zone, including more than 1,500 masters and doctors. In 2006, the product sale income realized annually by the above-scale enterprises is 56.7 billion yuan, with 15 billion yuan as the industry added value, 22.1 billion yuan as 
output value of high-tech industry, 814.11 million dollars as export income. About the commitment to high-tech projects, more than 100 projects of the national torch plan have been undertaken, with more than 300 projects of provincial and departmental torch plan being undertaken.

The spillover effects of scientific and technological knowledge in Jinan Hi-tech development zone have been embodied in: First, it has promoted the human capital to flow among the enterprises. Second, it has promoted cooperation interaction among enterprises. Third, the flow of the human capital and knowledge has accelerated the birth of new enterprises through the derivation of localization of enterprises. The enterprises having obtained the spillover effect can reduced the innovation costs and improve the capability of technological development, thus accelerating the spread of knowledge.

\section{Conclusion}

In order to achieve the "second pioneering" in China's high-tech development zones, we should vigorously develop hi-tech industry clusters to make a breakthrough. Only on the basis of industry clusters, by the establishment of an effective platform for science and technology innovation, through the vigorous support of technology with general character in industrial clusters, can improve the technological innovation capability of industrial clusters.

\section{References}

Caves R.E. (1971). International Corporations: the Industrial Economics of Foreign Investment. Economics, 38:1-27.

David, P. \& Rosenbloom, J. (1990). Marshallian Factormarket Externalities and the Dynamics of Industrial Localization. Journal of Urban Economics, 28, 349-370.

Dobkins, L. H. (1996). Location, Innovation and Trade: The Role of Localization and Nation-based Externalities. Regional Science and Urban Economics, 26, 6, 591-613.

E.D.Domar. (1997). The Effect of Foreign Investment on the Balance of Payments, The American Economic Review, NewYork.

Hansen, N. (2002). Dynamic Externalities and Spatial Innovation Diffusion: Implications for Peripheral Regions. International Journal of Technology Policy and Management, 2, 3; 260.

Kelly, M. \& Hageman, A. ( 1999). Marshallian Externalities in Innovation. Journal of Economic Growth, 4, 1, p. 39.

Wang J Y \& M Blomstrom. (1992). Foreign Investment and Technology Transfer, a Simple Model, European Economic Review, 36(1):137-155.

\section{Notes}

Note 1. In 2007, the total income and total production value in 54 high-tech development zones in our country has reached 4300 billion yuan and 3600 billion yuan respectively. The industry added value was 852 billion yuan, accounting for about $9.4 \%$ in the industry added value of the country. 


\title{
Study on the Cultivation of Special Industry with New Competitive Predominance for Xinjiang Economy
}

\author{
Xuefeng Wang \\ Economy \& Trade College, Shihezi University of Xinjiang \\ Shihezi 832003, China
}

Tel: 86-993-205-7130 E-mail: wxf_tea@shzu.edu.cn

\begin{abstract}
This article starts from the meanings of the special industry, analyzes the selection principle and cultivation of the special industry, discusses the cultivation of special industry for Xinjiang Province, and gives the policy advices for the development of the special industry in Xinjiang Province.
\end{abstract}

Keywords: Special industry, Competitive predominance, Cultivation

With the quick development of China economy, the differences of economic development among regions are gradually extending. Because of the special national situation of China, in the relative undeveloped region of Xinjiang, the basic status of traditional agriculture and animal husbandry is more important. Comparing with the past, the production ability of agriculture and animal husbandry has been largely enhanced, but relative to the development speed of the secondary industry and the third industry, the development speed of the agriculture and animal husbandry is relatively slow, which also restrain the development of Xinjiang Province.

Because of the vast territory, the resource gifts that various regions develop the agriculture in China are different and various regions possess different regional features and historical cultures. The development mode of regional economy in China has not a fixed standard, so different regions should select different agricultural development modes according to the regional difference features. Furthermore, the problem what we need solve is how to combine the industrial development of region with the historical cultural feature of region and look for new regional industrial development management mode, and find a new development road outside of the traditional industry. With the continually deepening of China socialism market economy reform, in the society taking the market as the basic resource deployment mode and mechanism, as viewed from the principle of maximum benefit, the growth of regional economy finally depends on the regional special industry, and the regional resource deployment with abundant efficiency should be a sort of expansion and compensation of regional special industry. As the growth point of regional economy, the special industry is mainly represented as the support driving the structure adjustment and development of county economy, the best approach to shake off the poverty and attain prosperity for the undeveloped counties, the load bringing farmers into the market, and the important channel to arrange country surplus labor force. Therefore, for the development of the Xinjiang, the most important aspect is to develop the special industry and promote the harmonious development between economy with society and the complete advancement of the society.

\section{The concept of the special industry and the principles to develop the special industry}

As viewed from the economics, the product includes manufactures, excavated products and farm produces. And in the same way, the "special product" means the products which are accreted with certain product, possess irreplaceable creation using value or appearance of same kind of product, and can fulfill popular special demands. The special industry takes the special product and special resource (including natural resource and social resource) as the base, takes the modern industrial and agricultural technologies as the supports, takes the market economy operation mode as means, surrounds the special products and special resources to implement comprehensive development, and forms the industrial system which is different with other traditional industries, possesses bright regional character, irreplaceable character, sustainable development character, competitive character, higher economical benefit and wide development foreground, and can develop the special product which can fulfill the public demands. As viewed from the geographical economics, the special industry means the industry with regional characters that can full utilize various regional advantages in the economical region based on the national economical geographical division. In a word, the special industry means the industry which can give prominence to local resource predominance and market competition and possess different characters comparing with other industries.

According to the definition of the special industry, the development of the special industry should refer to following principles. 
(1) Persisting in the orientation of the market. The industry selection of the special industry must be oriented by the market, i.e. taking the market demand, especially the competitive market demand, not the natural resource and traditional industry (product) as the essential orientation. The resource and traditional industry (product) are only bases and conditional to develop special industry. The special industry is divided into three types including the special industry based on the difference of natural resources, the special industry based on the difference of social resources, and the special industry based on the difference of comprehensive competition. The market demand is the premise to develop the industry. When the industry is conformed, we should consider not only the demands of local market, but also the needs of domestic market, and should not only research and analyze the demands of actual market, but also forecast the trend of future market demand. Otherwise, the market capacity should be fully considered.

(2) Exerting the comparison advantage. We should adjust measures to local conditions, select the industry and products with maximum local advantage to develop, form comparison advantage when the resource advantage is transformed into the industry advantage and the economic advantage as quick as possible.

(3) Paying attention to the proper centralization. To cultivate and develop the leading industry with regional character, the county region is the key part. However, the character of the county region decides that when we develop the special leading industry, we must make choice and only hold one or two industries, even several counties unite to develop one industry and really form the scale. Thus, the scale benefit can be formed and the reasonable deployment of production factors can be realized.

(4) Paying attention to the sustainable development and ecological environment optimization. The special industry must strengthen the management in the development. The management must promote the development and it is the center to develop the special industry. The management must possess the character of science, the character of modernity, and the character of operation. The management should be the behavior that every employee will to accept, and it reflects all employees' willing to pursue high efficient production values, and accords with the requirement of modern production. We must start from the human resource training to strengthen the management. So to establish the learning enterprise should be the aim for every special industry enterprise.

(5) The principle of the market orientation for the special industry. "Some things should be done, and other things should not be done". "Seeking few and seeking special".

(6) Going on the road promoting the special industry with science and technology. To enhancing the contribution ratio of high technology to the increase of special industry and to cultivate a group of special talents should be the emphasis and the difficulty to develop the special industry.

(7) The localization, export orientation and modernization are main develop trends for the regional special industry.

\section{The selection and cultivation of the special industry in Xinjiang Province}

According to above characters, the concept of industry and the principles such as high jumping-off point, proper scale, deep layer development and industrialization management to cultivate and develop the special industry, to develop the special industry in Xinjiang, we should select special industries in the national economic system and various industries, and position, cultivate and develop these special industries. Of course, with the development and utilization of the resource and the updating of the industry, some industries which are not outstanding now will be developed to the special industries, and this article will not discuss these industries.

\subsection{Developing the special industry with high added values}

The special industries take the purpose of product, making method, exchange locale and industrial management with notable features as basic characters. At the same time, the special industries must possess profitable advantage. To develop the special industry with high added values can extend the profit space for the product. For example the "four red (including tomato, safflower, medlar and capsicum)" industry has been quickly developed in recent years and formed scale industry, and it has become another new economic increase point after cotton for the development of Xinjiang economy. The extension of the industry chain makes the "four red" industry become the special industry with high added values.

\subsection{Developing the special industry in rigid cold region}

The rigid cold industry is the special resource for Xinjiang, and it can fulfill the special demands of the society. So we must try to develop various industries, such as developing green plants and precious medicinal materials in Xinjiang region, protecting and developing rare medicinal animals, developing the tour industry with beautiful natural view, delightful climate condition and harmonious human and natural environment, especially developing various kinds of special tour including mountaineering investigation tour, rare animal and plant investigation, special living tour in minority region, and establishing special tour region such as forest tour region. 


\subsection{Developing the handicraft industry of minority}

It is the traditional industry advantage in Xinjiang. We must take the demand as the aim, give priority to the handicraft, and pay attention to the products and making methods. Mostly, we should drive the green products, especially beautiful, harmonious and healthy citizen beautification and family courtyard as emphases. Therefore, we must develop the market system. The Xinjiang market is included in the national market, but the character of Xinjiang market should be kept. Based on the natural condition of Xinjiang and the industrial character, we can sale special consumables, tour remembrances and traditional handicrafts, and we can select good region to establish special market, attract consumers and drive the development of the economy. As one of basic industries in most provinces of west, the tour industry must specially emphasize the production and sale of tour remembrances.

\subsection{Developing the cultivation of livestock product industry}

Actively extend the improved beef cattle variety such as Limousin, actively organize forces to improve the variety of Tan Sheep in Xinjiang Province, enhance the meat output and the reproduction ratio, and enhance the single milk-output level and seasonal balance milk-output. As a whole, most enterprises with beef and mutton and milk manufacture have relatively small production scale, undeveloped technology, weak brand consciousness, and loose association with the market and farmers.

\subsection{Developing the cultivation of medical product industry}

First, based on the special predominant resources of Xinjiang, we must establish the modern Chinese medicine production base according with national standards, develop the modern Chinese medicine and nutrition healthy food with local features and national features, perfect the development system of Chinese medicine, promote the industrial structure adjustment through the modernization of Chinese medicine, and make the Chinese medicine industry become the special industry to drive the national economy of Xinjiang. Second, we should establish "Xinjiang Chinese medicine modern science and technology industry base", and accept it into the 10th Five Year Plan. Third, many main medicinal plants such as snow lotus with high quality and medicinal value are famous in China, and professional personnel in Xinjiang should actively exert modern medicine research technology to enhance the science and technology content of Xinjiang medicinal resource, and make the medicinal resource of Xinjiang really transform from resource advantage into economic advantage, and make the medicinal industry become the leading industry for the industrial economy in Xinjiang Province.

\subsection{Developing the cultivation of tour industry}

First, we should establish the overall arrangement of the tour industry. A tour development network arrangement with layers and emphasis should be established. To develop the special tour industry, we should strengthen the construction of the hardware, such as the tour base construction, the traffic and communication construction and the hotel construction. Second, we should strengthen the construction of tour software environment. We should increase the drumbeating force, push the series tour products with feature and influence, strengthen the tour management and enhance the content of science and technology, strengthen the training to tour managers and bring up tour managers with high quality and high standards.

\section{The necessary policy supports to develop the special industry in Xinjiang Province}

For Xinjiang, the development of the special industry is a quit long historical process. The reason is that though Xinjiang possesses good conditions and numerous special products to develop the special industry, but up to now, the special industry system with proper scale, high efficiency, radiation band and strong active function has not been formed. So the various party committees and governments should first create a loose, equal and advantageous policy environment for the development of the special industry, and the local governments should also establish some concrete policy measures to match many policy measures about the Development of the West Regions issued by the State Department.

(1) Aiming at actual situations, the municipality party committee and the government should organize relative departments and social economics experts, scholars to implement comprehensive investigation and evaluation to the special products and resources of Xinjiang, and further confirm the special industries which have been formed, filtrate special products and special resources to be developed to the special industries, list detailed list and supervise these products and resources. Based on that, the government should issue the development list of special industry to develop special industries for various regions. Various regions should select the special products and special resources which adapt the local development to cultivate and develop properly.

(2) The municipality government should establish a special management institution to develop the special industry in some relative office and bureau, and the management institution can fell in the whole development list of special industries in the whole municipality, and confirm the objective which should be firstly developed and establish the benefit policies to develop the special industry. All enterprises (including state owed enterprise, stage holding enterprise, 
collective enterprise, individual enterprise) which products belong to the range of the special industry should enjoy the benefit policy and support from the government. With the formation of special industry, the government should strengthen the consciousness of famous protection, establish the protection measures, strictly forbid imposture products and ensure the development of the special industry. For example, to support the development of the tour industry, first, we should establish the laws and regulations as quick as possible, to ensure the healthy development of special tour industry from many aspects such as organization, service and participation. Second, the government should invest certain development capital properly to improve the hardware environment of the tour industry, and quicken the development of the special tour industry.

(3) The government should establish the development and support fund of special industry for the municipality. Whether collectivity or individual which contribute for the development of Xinjiang special industry, the municipality should support them. The government should centralize strengths from various aspects, increase the science and technology degrees of special industry, attract exterior excellent results, continually quicken the self innovation steps of science and technology, try to form many science and technology results which can actually drive the special industry and possess independent intellectual property rights, and enhance the whole science and technology content of special industry in Xinjiang.

(4) The municipality government should also offer proper benefits for the enterprises or departments developing the special industry from finance, financing, revenue and land utilization. For example, the municipality, city and county should take some capitals to construct the base establishments and matching establishments for the special industry to perfect the development condition of the special industry when the finance allows, the finance department should properly broaden the load condition for the departments of the special industry, especially we should encourage that the rural credit cooperative cooperation, rural cooperative fund and other rural finance departments or civilian credit institutions provide certain short term loans with low interests to farmers in the regions which have conditions to develop the special industry, the revenue department can derate $15 \%$ of enterprise income tax for the enterprises according with the development program of special industry in the municipality, return more than $15 \%$ of special industry tax to the enterprises which have been imposed to support the development of the special industry, and for the enterprises and individuals to develop the special industry, under the strict land utilization, expropriation and approval procedures, the land management department should properly broaden the land utilization and approval conditions, and firstly consider the demands to develop the special industry under same conditions.

(5) The government should encourage large companies and enterprises with strength to participate in the development of special product and special resource in Xinjiang, which can help to quickly form the special industry of Xinjiang. The government also should adopt the measures to invite investments, propagandize the special industry list and benefit policies confirmed by Xinjiang to the whole China in order to attract exterior capitals and forces to participate in the development of Xinjiang special industry.

\section{References}

Hejian. (2005). The Policy Selection to Develop the Special Industry: the Thinking Based on "Four Reds" Industry in Xinjiang Province. Group Economics Research. No.17.

Li, Zhuqing \& Yu, Yanchun. (2001). Adjusting the western Regional Structure of Production, Developing the Advantage Industry and Regional Economy with the Different Features. Heilongjiang National Series. No.4.

Shen, Daoquan. (2001). Developing Feature Industry, Promoting the Exploitation of the Western China. Nationalities Research in Qinghai (Social Science). No.2.

$\mathrm{Xu}$, Binyou. (2005). On Financial Support and Development of Characteristic Industry in Western China. Journal of Guangdong College of Finance and Economics. No.2. 


\title{
Student Satisfaction and Service Quality: Any Differences in Demographic Factors?
}

\author{
Azleen Ilias \\ School of International Business and Finance Labuan \\ Universiti Malaysia Sabah, Labuan International Campus, 87000, F.T Labuan, Malaysia \\ Tel: 60-8-746-0517 E-mail: neelza80@yahoo.co.uk \\ Hishamuddin Fitri Abu Hasan \\ Research and Planning Department, Public Service Department of Malaysia \\ Federal Government Administrative Centre, 62510, F.T Putrajaya, Malaysia \\ Tel: 60-12-500-3429Ｅ-mail: hishamfitri@jpa.gov.my \\ Rahida Abd Rahman \& Mohd Rushdan bin Yasoa' \\ School of International Business and Finance Labuan \\ Universiti Malaysia Sabah, Labuan International Campus, 87000, F.T Labuan, Malaysia \\ Tel: 60-8-746-0517Ｅ-mail: neelza80@yahoo.co.uk
}

\begin{abstract}
Previously, very less research done to test demographic factors that contribute towards satisfaction and service quality. This study attempts to examine the differences of selected demographic factors (gender, races and semester of studies) on the students' satisfaction and service quality. Furthermore, this study is also to examine any relationship between age and students' satisfaction and service quality. This study was conducted using a set of questionnaire to 200 Bachelor Degree students from two private higher education institutions. The study will provide results from empirical test of these differences and relationships. The empirical results of this study can provide any differences, which related to students' satisfaction on service quality.
\end{abstract}

Keywords: Service Quality, Private higher education institutions

\section{Introduction}

\subsection{Introduction}

In today's competitive academic environment where students have many options available to them, factors that enable educational institutions to attract and retain students should be seriously studied. Higher education institutions, which want to gain competitive edge in the future, may need to begin searching for effective and creative ways to attract, retain and foster stronger relationships with students. As a private organization, it has to depend on the interaction and mechanism of the market. As a result, competition to woo as many students as possible or so-called "potential customer" may become more and more intense. To make the matter harder, as a private institution, it does not have the "privilege" to receive any subsidies or financial assistances from the government (Teo, 2001).

An expectation that cannot be fulfilled on the institutions is the key factors for students' withdrawal (Alridge and Rowley, 2001). According to the study by Kanji, Abdul Malek and Wallace (1999) do give some insights on the real situation of the Higher Education Institutions in Malaysia. Most institutions do give a great deal of importance to meeting customers' expectations which is similar to business organization, but they still lack customer awareness among the staff, and it has become a common drawback for many institutions.

This bring us to an understanding that students will have more opportunity to support their continued enrollment into higher educational institutions and on how well the educational programs and services met students' expectations for services. In this competitive market, satisfaction with services may make the difference (Parasuraman, Zeithaml and Berry 1996). This study attempts to explore the aspects of service quality and the level of satisfaction among the students of private higher education institutions. 


\subsection{Problem Statement}

Particularly in Malaysia, National Accreditation Body (LAN) once had to reject accreditation applications of 40 programs by private higher learning institutions due to the weaknesses in core course structures. Among factors that contributed toward the problems were the lecturers' lack of skills to handle the task and failure to attain the required curriculum standard set up by LAN (Mohd Feroz Abu Bakar, 2004).

The government for example has for long not compromising on the quality of education offered and hope to see that the private higher education will provide a quality education toward the students ("We won't compromise", 2001). This of course is in-synchronization with the current trend in education industry. Former Education Minister Tan Sri Musa Mohamad, has once made a statement regarding the weakness in the private HEI. According to him, he is aware there is a change of attitude among the present students nowadays as they are getting bolder in exercising their rights to demand for quality. One of his remarks on this issue is, "Don't be surprised if a student takes one of you to court for not teaching properly.” (Rajah and Nadarajah, 2000).

In fact this is true as an issue on professionalism of an administration and the academic staffs of the private higher institution has been raised in one of the newspaper by the frustrated student due to his/her college misguided concern on issues like college reputation by "forcing" the students to involve in charitable activities that in the end overlook the bigger issue which is their academic performance ("Unprofessional College", 2004). This of course shows that students nowadays are indeed do not wait and see for the changes to be made but will put an effort to find an effective channels to voice their grievances if the management do not demonstrate that they care towards the complaints.

The intention here is obvious and well made but the problem is, comparing to the public higher education learning, it seems the perceptions of the people toward the private higher education tend to be biased in term of quality. It seems that the majority of students and parents especially Bumiputera place their hopes on public higher education institutions. If the students fail to be offered a place there, the perception is that he or she will have a bleak future. This is something that should not happen, as even the Prime Minister himself does not want these institutions to be the "last resort options" or a poorer alternative to public universities (Ling, 2003).

\subsection{Research Question}

RQ1: What are the differences of selected demographic factors on the students' satisfaction?

RQ2: What are the differences of selected demographic factors on the service quality?

RQ3: What is the relationship between age and students' satisfaction?

RQ4: What is the relationship between age and service quality?

\subsection{Research Objectives}

Generally, the purpose of this study is to determine the difference in service quality and student satisfaction in two private higher institutions. Several factors in service quality that will be discussed and analyzed are Tangibility, Assurance, Reliability, Responsiveness and Empathy.

The purpose of this research:

- To examine the differences of selected demographic factors (gender, races and semester of studies) on the students' satisfaction

- To examine the differences of selected demographic factors (gender, races and semester of studies) on the service quality.

- To examine any relationship between age and students' satisfaction

- To examine any relationship between age and service quality

\subsection{Significance of the Study}

Enhancing service quality has been demonstrated across numerous industries. The quality of service that can be applied to universities, especially to private universities, differentiates them from their public counterparts. Private HEI while attempting to compete at academic levels with other HEIs should offer an added advantage to champion quality services to their students. Notably, it can even be assumed to be an important road to the competitive excellence for the service oriented organization as by neglecting these aspects of quality services will put such organization at a competitive disadvantage compared to its counterparts because most of its revenues are enrollment related thus affecting its financial health (Zammuto et al., 1996). This study is important because it is going to measure the level of service quality and the level of satisfaction among the students as have been stressed by Iacobucci, Ostrom and Grayson (1995), "Presumably, if quality programs were initiated based on marketing research- that is, the changes were market driven and customer oriented- the quality improvements should lead to customer satisfaction" (p. 296). The result from the study can be used to give valuable information on the elements and the dimensions, which have been given a priority by students in assessing the quality of services and satisfaction. In addition to that, this study is going to provide the conclusions and 
some recommendations, which are hoped that it's going to provide useful information to the private higher education institutions.

\section{Literature}

\subsection{Service Quality in Higher Education}

It is interesting to identify here about the applicability of SERVQUAL to education sector, meaning that there is a suitability of applying it in higher education. Numerous studies have adapted this measurement in HEI, such as SQ in business schools (Rigotti and Pitt, 1992) and higher educational institutions (Cuthbert, 1996; Soutar and McNeil, 1996; Saaditul, Samsinar and Wong, 2000).

In the study by Cuthbert (1996) it has been found that among the dimension in SQ, the score for tangibility (3.34) is the highest, followed by assurance (3.21), reliable (3.11), responsive (3.04) and empathy (2.58). However he added that this does not represent tangibility as a major contributor towards satisfaction of the students as he believes it is the service encounter which is the determinant factor. O'Neill and Palmer (2004) also hold the exact same idea that, although tangibility is ranked as the best in term of overall performance score, but it has been ranked as the least importance by the students compared to process and empathy. Study by Perisau and McDaniel (1997) is best described as, assurance and reliability has been identified as the most important suggesting that students are most concern with the knowledge, courtesy and ability to inspire trust and confidence which is part of the assurance dimension.

Nevertheless, there are studies that have a different opinion on the importance of tangibility dimension in service quality. Smith and Ennew (2001) outlined an interesting aspect in his research toward the SQ in higher education. He highlighted that there is difficult aspect in the choice of satisfaction perception of customer between the affective indignation and the technical functionality. For example, the particular facility consumed by the students could be judged according to how reliable they are (technical functionality) or according to their ages, appearances, courtesy and empathy (affective). The perfect reliable facility, which is not up to date, but are capable of carrying out the task, may still be negatively rated if the users expect the university to provide up to date facility. He also showed that there were specific supportive items known as peripheral aspect and the university facilities, which students consume such as cafeterias and residential accommodation that will directly and indirectly have a significant impact on the evaluation of the university. Based on the study by Umbach and Porter (2002), it also appears that the size or a number of faculties within a department in HEI is important in explaining student satisfaction.

LeBlanc and Nguyen (1997) for example stressed on the reputation as a factor, which is tied closely to management's capacity to foster an organizational climate directed at serving the needs of its customers and to the image of the HEI. It is also process-related in that, it involves an ability to inspire trust and confidence and provide personal attention to students in a professional and caring manner. In term of importance, the study has shown that perceived value is derived mainly from price/quality, a factor that is closely tied to the business school's capacity to offer sufficient services to students and convince them that they are receiving quality services in exchange for what they give by means of their tuition fees.

While Ford, Joseph and Joseph (1999) go a little bit more specific on the services in their study about service quality by comparing the importance score of service quality in higher education for the New Zealand student sample and the United States sample. They found that for the New Zealand sample, academic reputation has been ranked as the first followed by career opportunities, programme issues, cost/time, physical aspects, location and others while for the USA sample, it was found that the first rank is academic reputation, cost/time, programme issues, others, physical aspects and choice influences.

Earlier researches on service quality in higher education also often emphasized academic more than administration, concentrating on effective course delivery mechanisms and the quality of courses and teaching (Atheeyaman, 1997; Cheng and Tam, 1997; Soutar and McNeil, 1996; Griemel-Fuhrmann and Geyer, 2003). However there are also an attempt to look upon the administrative side of higher institution like the study by Kamal and Ramzi (2002), which attempt to measure student perception of registration and academic advising across different faculties and other administrative services to assure positive quality service that compliments the academic.

\subsection{Service Quality and Students'Satisfaction}

Service Quality is commonly noted as a critical prerequisite for establishing and sustaining satisfying relationship with valued customers. In this way, the association between service quality and customer satisfaction has emerged as a topic of significant and strategic concern (Cronin and Taylor, 1992). In general, perceived service quality is an antecedent to satisfaction (Spreng and Mckoy, 1996). Thus, a proper understanding of the antecedents and determinants of customer satisfaction can be seen as to have an extraordinarily high monetary value for service organization in a competitive environment (Lassar, Manolis and Winsor, 2000).

Bigne, Moliner and Sanchez (2003) found that the overall service quality have a significant relationship with 
satisfaction at $\mathrm{R}=0.66$. Ham and Hayduk (2003) have confirmed that, even in the higher educational settings, there is a positive correlation between perception of service quality and student satisfaction, and analyzing upon the relationship based on each of the dimension of service quality, reliability $(\mathrm{R}=0.547$; sig. $=0.000)$ has the strongest relationship followed by responsiveness and empathy $(\mathrm{R}=0.5431$; sig. $=0.000)$, assurance $(\mathrm{R}=0.492$; sig. $=0.000)$ and tangibility $(\mathrm{R}=0.423$; sig. $=0.000)$.

Elliot and Shin (2002) found that the highly significant variables in the model that appear to directly impact overall customer satisfaction with university performance are: (1) excellence of instruction in major $(0.0522 ; p<0.0002)$, (2) able to get desired classes $(0.0935 ; \mathrm{p}<0.0000)$, (3) knowledgeable advisor $(0.0517 ; \mathrm{p}<0.0000)$, (4) knowledgeable faculty $(0.0406 ; \mathrm{p}<0.0094)$, (5) overall quality of instruction $(0.0510 ; \mathrm{p}<0.0000)$, (6) tuition paid is a worthwhile investment $(0.0749 ; \mathrm{p}<0.0000)$, (7) approachable advisor $(9.0631 ; \mathrm{p}<0.0000)$, (8) safe and secure campus $(0.0646$; $\mathrm{p}<0.0000)$, (9) clear and reasonable requirements for major $(0.0539 ; \mathrm{p}<0.0000),(10)$ availability of advisor $(0.0537$; $\mathrm{p}<0.0000)$, (11) adequate computer labs $(0.0631 ; \mathrm{p}<0.0000)$, (12) fair and unbiased faculty $(0.0443 ; \mathrm{p}<0.0004)$, and (13) access to information $(-0.367 ; \quad \mathrm{p}<0.0021)$.

\subsection{Demographic Factors}

\subsubsection{Gender}

a) Gender in Satisfaction

Most of the study found that there is no significant difference between gender and satisfaction (Corts, Lounsbury, Saudargas and Tatum, 2000; Rosenthal, Folse, Alleman, Bourdreaux, Soper and Bergen, 2000; Carey et al. 2002).

Yet there are some studies that suggest otherwise finding that women have a lower satisfaction compare to men (Renzi, Allen, Sarmento and McMillin, 1993; Umbach and Porter, 2002). Perry, Sekelsy and Skarsten, (2003) also share the same finding except that the women seems to be more satisfied than male.

\section{b) Gender in Service Quality}

The study by Soutar and McNeil (1996) found that there is a significant relationship between gender and satisfaction with service quality as it would seem that males are more satisfied than females. This however is different based on the study by Joseph and Joseph (1998) that showed there is no significant difference between male and females.

In addition to that, Ham and Hayduk (2003) also supported this finding when from their research; it is found that gender has no significant relationship with perceived service quality even though the findings do show that males are more satisfied compared to females.

\subsubsection{Race/Ethnicity}

\section{a) Race/Ethnicity in Satisfaction}

Terenzini, Rendon, Upcraft, Millar, Allison, Gregg, and Jalomo (1996) explains that those who are minorities tend to focus on the academic aspects rather than social compared to non minority which are more concern on social aspects like meeting friends, developing friendship. As a result, the minority students tend to be more critical to the satisfaction on academic scopes compared to non-minority.

This is similar to the finding of Mather (2000) when measuring an overall satisfaction in the context of academic experience and social experience showed that non minority students score a higher level of satisfaction on the academic experience compared to the minority students.

Eimers (2001) may well support both of the findings above when he found that there is a significant difference between ethnicity and satisfaction on campus climate (minority $(\mathrm{m})=3.38$, non minority $(\mathrm{nm})=3.57$ ) and overall assessment $(\mathrm{m}=3.32 ; \mathrm{nm}=3.50)$ of higher institution with non-minority scores higher mean but Elrod and Remirez (2002) and Perry et al (2003) disagree with it when their finding shows that there is no significant difference between ethnicity and satisfaction.

\section{b) Race/Ethnicity in Service Quality}

Carey et al. (2002) in a study based on 3 different ethnicity to measure its differences with satisfaction level based on three scales which is responsibility to the diverse population, concern to the individual rights and student centeredness, reported that there is a significant difference when taking into account on the responsibility of the university towards the diverse population which surprisingly that the Caucasian students scored a lower satisfaction level compared to the other minority students.

\subsubsection{Semester of Studies}

\section{a) Semester of Studies in Satisfaction}

Corts et al. (2000) in his study on this demographic factor show that there is no significant differences between a junior and a senior students thus implying that their experience in the higher institution do not change their perception on 
satisfaction.

b) Semester of studies in Service Quality

Hill (1995) found that there is stability on the students' expectations over time suggesting that there were probably formed prior to arrival at university compared to students perceive quality as there is a reduction in quality experienced indicating that it is less stable.

To prove it further, the mean score for the students based on the semester of studies in the study by Oldfield and Baron (2000) showed that the score for the final year students were lower than those of the first year thus suggesting that as the students become more experienced in the higher educational settings, students tend to be more critical in their perception on the service quality.

Study by O'Neill (2003) has a better way of explaining through the use of longitudinal study to determine time factor on the perception of the service quality. This study that used the original instrument of SERVQUAL on the sample of 657 indicates that student's rate their perceptions of a phenomenon differently at the time of consumption compare to their rating subsequently.

Conversely, Hill (1995) showed that the time factor have an influence over the expectation by raising it which in the end affect the perceptions of the previous service. However, the study by Ham and Hayduk (2003) may tell a different story as it only has a significant relationship with the reliability dimension while others do not have a significant relationship.

\subsubsection{Age}

\section{a) Age in Satisfaction}

Age factor is also found to have no significant difference to the level of satisfaction (Carey, et al., 2002) thus suggesting that age factor cannot be related with the perception of satisfaction.

b) Age in Service Quality

Based on the study by Ham and Hayduk (2003) it is found that age have no significant relationship with service quality in higher educational settings for the students from Southern Wesleyan University (SWU) and Western Michigan University (WMU).

\subsection{Hypotheses of the Study}

Ho1: There is no significant difference between male and female in their satisfaction.

Ho2: There is no significant difference between male and female in the service quality

Ho3: The satisfaction of the students is same irrespective to the races.

Ho4: The satisfaction of the students is the same irrespective to the semester of studies.

Ho5: Service quality in higher education is the same irrespective to the races.

Ho6: Service quality in higher education is the same irrespective to the semester of studies

Ho7: There is no significant relationship between age and overall student satisfaction.

Ho8: There is no significant relationship between age and service quality in higher education

\section{Methodology}

\subsection{Research Framework}

This study was adopted from Parasuraman's SERVQUAL dimensions. The dependent variable in this study is overall student satisfaction that is measured by the overall satisfaction with the HEIs. The independent variable in this study is service quality in higher education that measures the level of satisfaction with service performance. The dimensions included in this variable are tangibility, assurance, responsiveness, reliability, and empathy. In addition to that, this study also tries to put together the demographic factors that will be used to measure the significance level with service quality and student satisfaction. Those factors include gender, age, races or ethnicity and semester of study.(see Figure 1)

\subsection{Sample}

The samples in this study were bachelor degree students studying at a Private HEIs. For that purpose, directory from http://www.studymalaysia.com/jps/directori/ senarai_ipts.shtml is use to identify the related private higher institutions that may serve as potential respondents. Respondent consists of Bachelor Degree students from Kuala Lumpur Infrastructure University College (KLiUC) and Kolej Universiti Teknologi dan Pengurusan Malaysia (KUTPM). We have distributed 230 questionnaires for every institution. Finally, 200 respondents completed and returned the questionnaires, which represents about $87 \%$ response rate.

\subsection{Instrumentation}

This study used questionnaire as a medium to obtain the data needed. There are three sections in the questionnaire, 
consisting of Section A: Demographic factor, Section B: Measurement of Service Quality in Higher Education and Section C: Measurement of Student Satisfaction. In this section A, four question covering from the subjects of gender, age, race or ethnicity, and their semester of study. Followed by section B: service quality in higher education and section C: student satisfaction. Instrument used in this research is adapted from Parasuraman et al. (1990) with some of the items used extracted from LeBlanc and Nguyen (1997) using the five dimensions in service quality (tangibility, assurance, reliability, responsiveness and empathy) using the Likert scale from 1 for not satisfied at all to 6 for very satisfied. In measuring student satisfaction, instrument for this variable was adapted from Atheeyaman (1997). In this variable, it has six items with Likert scale ranges from 1 for much worse than expected to 6 for much better than expected.

\subsection{Data Analysis Procedures}

The data analysis for this study conducted through 'Statistical Package for Social Science' software or SPSS version 12. The study also tested reliability of the instrument so that it enables to produce a robust and valid result.

\section{Findings}

\subsection{Profiles of the respondents}

The demographic information includes the following characteristic of participants: gender, age, semester of studies and ethnicity. The demographics information is represented in Table 1.1 based on frequency distributions and percentages.

From the 200 respondents in this study, 95 (47.5\%) are male and $105(52.5 \%)$ are females. The calculated mean age of the respondents is 23 years old with the majority of the students being 22 years old (33\%). Most of the respondents are in the fourth semester of their study (28\%), followed by fifth semester and above (27\%), second semester (20\%), third semester $(14.5 \%)$ and first semester (10.5\%). Majority of the respondents are Malay (72\%) followed by Chinese and Indian $(25 \%)$ and other ethnicity contributing about $3 \%$.

\subsection{T-Test Results}

The results of the T-test are shown in the Table 1.2 below. The differences in the satisfaction between male and female are 4.2561 and 4.0873 respectively with standard deviations of 0.99906 and 0.87556 (sig. $=0.204$ ). Thus, the result failed to reject Hol because there was no significant difference between male and female in their satisfaction.

The results of the T-test on the differences between male and female on service quality are also shown in the Table above with mean for male and female is 4.1491 and 4.0041 respectively and standard deviations at 0.72790 with significant level 0.138 . Thus, the result failed to reject Ho2 because there was no significant difference between men and women in service quality.

\subsection{ANOVA Results}

\section{ANOVA test for satisfaction}

The results of the ANOVA test shown in the Table 1.3 below do not indicate any significant differences in the level of satisfaction among the 4 groups of races $(\mathrm{F}=1.453$; sig. $=0.229)$. Therefore, the result failed to reject Ho3 because satisfaction was the same irrespective to the races.

It is the same for another ANOVA test on semester of study, which also indicates that there are no significant differences in the level of satisfaction $(\mathrm{F}=0.332$; sig. $=0.856)$. Therefore, the result failed to reject Ho4 because satisfaction was the same irrespective to the semester of studies.

ANOVA test for service quality

The result on the ANOVA test shown in Table 1.3 does not indicate any significant differences in the level of service quality among the four groups of races $(\mathrm{F}=0.972$; sig. $=0.407)$. Therefore, the result failed to reject $\mathrm{Ho} 5$ because service quality in higher education is the same irrespective to the races.

Another result on ANOVA test in Table 1.3 also does not indicate any significant differences in the level of service quality among the five groups $(\mathrm{F}=0.722 ; \mathrm{p}=0.578)$. Therefore, it failed to reject Ho6 because service quality in higher education is the same irrespective to the semester of studies.

\subsection{Correlation Results}

The outputs in Table 1.4 indicate the relationship result between age and satisfaction and service quality determinants. However, age as the result shows that there is no significant relationship for both satisfaction and service quality. Therefore, it has answered three hypotheses related to this analysis. The first fail to reject Ho7 as there is no significant relationship between age and satisfaction. The second also fail to reject $\mathrm{Ho} 8$ as there is no significant relationship between age and service quality. 


\section{Discussion and Conclusion}

In this final section of the study, discussions on the important findings of the study will be reviewed in terms of its significance and support by other researches. This study attempts to examine the differences of selected demographic factors (gender, races and semester of studies) on the students' satisfaction and service quality and secondly to examine any relationship between age and students' satisfaction and service quality.

\subsection{Discussion}

\subsubsection{Student satisfaction}

The results on demographic factors (gender, races and semester of studies) do not show any significance differences with satisfaction. Therefore, this study failed to reject Ho1, Ho3 and Ho4.

Ho1: there is no significant difference between male and female in their satisfaction.

This result is consistent with the finding from Corts et al. (2000), Rosenthal et al. (2000) and Carey et al. (2002), which found no significant difference, based on gender toward satisfaction. Therefore it rejects finding by Renzi et al. (1993) and Umbach and Porter (2002), which stated that male have higher satisfactions than female. Even though it did find male have a higher satisfaction compared to female still the result was not significant. In addition, this result contradicts with the finding by Perry, Sekelsy and Skarsten, (2003) that not only found there was a significant differences in satisfaction between male and female, but suggesting that women have a higher level of satisfaction compared to male.

Ho3: The satisfaction of the students is the same irrespective to the races.

Terenzini et al. (1996), Matter (2000) and Eimers (2001) try to give an indication that there is a difference on satisfaction if it is viewed on the basis of minority and non-minority students, suggesting that minorities tend to be more critical in their satisfaction evaluation but Elrod and Remirez (2002) and Perry et al (2003) tend to disagree with it because for them the results have suggest that there is no significant differences based on races. Thus, this study agreed with Elrod and Remirez (2002) and Perry et al (2003) as the result shows that satisfaction of the students would be the same irrespective to the races.

Ho4: The satisfaction of the students is the same irrespective to the semester of studies.

The finding has suggested that satisfaction is the same irrespective to the semester of studies. Although the students that gain more experience in the higher institution tend to be more critical in their evaluation, but the result does not find any significant differences in the level of satisfaction. This is consistent with the finding by Corts et al. (2000) that show the same finding when it was conducted on the junior and senior students in higher education.

Ho7: There is no significant relationship between age and student satisfaction.

Consistent with the finding by Carey, et al. (2002) this finding too does not find any significant relationship between age and satisfaction. This mean that age is not the determinant toward satisfaction irrespective of whether the students are mature, old or young.

\subsubsection{Service Quality}

The study on the demographic factors show the same finding like satisfaction as it demonstrates that demographic factors (gender, semester of studies, ethnicity) do not have any significant difference with service quality.

Ho2: there is no significant difference between male and female in their perceived service quality

The finding is consistent with the result by Joseph and Joseph (1998) Ham and Hayduk (2003), which also found the same thing. However this result contradict with the result depicted by Soutar and McNeil (1996) which show a significant different between gender and service quality

Ho5: Service quality in higher education is the same irrespective to the races.

The finding shows that service quality in higher education would be the same irrespective of races. Therefore whether the students are Chinese, Indians or Malays, the perceptions on service quality are still the same. Based on the finding by Carey et al. (2000), even though there is a differences on the responsibility of the university towards the diverse population, but the other two scales showed no significant difference. So, this mean that if service quality to be measured on overall aspects, the finding may show otherwise.

Ho6: Service quality in higher education is the same irrespective to the semester of studies.

Although in a way, this study tend to agree that students tend to be more critical to their evaluation on service quality as they becoming more experience as suggested by Oldfield and Baron (2000) and how the research by O'Neill (2003) who look upon time factor which influence the rating on service quality by suggesting that the expectation tend to rise which in the end affecting the perceptions of the previous service. Based on the result of this research, it fails to show a significant difference on service quality based on races. 
Ho8: There is no significant relationship between age and service quality in higher education.

The result gave an indication that age does not have any significant relationship with service quality. This is consistent with the finding Ham and Hayduk (2003) that found no relationship between age and service quality.

\subsection{Conclusion}

From the results, it is clear that there are no differences in students' satisfaction towards service quality determinants and overall service quality. The important factors (gender, races and semester of studies and age) that been tested do not have any important role in determining students' satisfaction. Thus, it confirms what other literature try to suggest here, which is by improving service quality, it may potentially improve the students' satisfaction as well and that is the priority of the private higher institutions due to the fact that they have to compete to earn interest from the students to study there.

\subsection{Limitation and Recommendation}

Service quality has been widely accepted as an antecedent of satisfaction and neglecting it may jeopardize the competitiveness of an organization as satisfaction and competitiveness of a service related organizations are inter-related. For that, denying or neglecting the importance of service quality is the same like risking the continuation and the competitiveness of the institutions because by taking it into consideration service quality can actually explain almost $48 \%$ variance in satisfaction. More than that, by focusing on critical factor in service quality especially empathy and assurance mean that the institution is paving a way toward a better evaluation in satisfaction.

(1) One of the limitation in this study is to the context of respondents is very limited to only two private higher institutions that offered bachelor degree courses. As this private higher institutions do offer courses for the diploma and certificate courses, than it should be reasonable that they too are included in the future research.

(2) Further study is suggested to make a comparative study to investigate whether there are any differences in service quality and student satisfaction between public higher institutions and private higher institutions.

(3) Further study should also take serious consideration in terms of accessibility to the data collection because most of the institutions have been very reluctant in giving good cooperation. A serious preparation towards the unexpected situation is needed thus that it is in the ability researcher to face and in control of the situation.

\section{References}

Alridge, S. \& Rowley, J. (2001). Conducting a withdrawal survey. Quality in Higher Education, 7(1), 55-63.

Atheeyaman, A. (1997) Linking student satisfaction and service quality perceptions: the case of university education. European Journal of Marketing, 31(7), 528-540.

Bigne, E., Moliner, M. A. \& Sanchez, J. (2003). Perceived quality and satisfaction in multi service organizations: The case of Spanish public services. The Journal of Services Marketing, 17 (4), 420-442.

Carey, K., Cambiano, R. L. \& De Vore, J. B. (2002). Student to faculty satisfaction

United States. HERDSA, 93-97. Retrieved August

at a Midwestern university in the http://www.ecu.edu.au/conferences/herdsa/main/papers/ref/pdf/ Carey.pdf.

Cheng, Y. T. \& Tam, W. M. (1997). Multi-models of quality in education. Quality Assurance in Education, 5(1), 22-31.

Clewes, D. (2003). A Student-centred Conceptual Model of Service Quality in Higher Education. Quality in Higher Education, 9(1), 69-85.

Corts, D. P., Lounsbury, J. W., Saudargas, R. A. \& Tatum, H. E. (2000). Assessing undergraduate satisfaction with an academic department: a method and case study. College Student Journal. Online: dari World Wide Web: http://www.findarticles.com /cf_0/m0FCR/mag.jhtml on $7^{\text {th }}$ January 2004.

Cronin, J. J. Jr. \& Taylor, S. A. (1992). Measuring service quality: a re-examination and extension. Journal of Marketing, $56,55-68$.

Cuthbert, P. F. (1996). Managing service quality in HE: is SERVQUAL the answer? Part 2. Managing Service Quality, 6(3), 31-35.

Danielson, C. (1998). Is satisfying college students the same as decreasing their dissatisfaction? AIR 1998 Annual Forum Paper. Paper presented at the Annual Forum of the Association for Institutional Research (38th, Minneapolis, MN, May 17-20, 1998), US Michigan.

Elliot, K. M. \& Shin, D. (2002). Student satisfaction: an alternative approach to assessing this important concept. Journal of Higher Education Policy and Management, 24(2), 197-209.

Eimers, M. T. (2001). The Impact of Student Experiences on Progress in College: An Examination of Minority and non minority differences. NASPA Journal, 38(3), 386-409. 
Elrod, R. \& Remirez, R. (July 12, 2002). A Comparison of Institutional Factors \& Student Satisfaction: Retention Implications in a Hispanic Serving Community College. Paper presented at National Community College Hispanic Council 7th Annual Summer Leadership Conference.

Ford, J. B., Joseph, M. \& Joseph, B. (1999). Importance-performance analysis as a strategic tool for service marketers: the case of service quality perceptions of business students in New Zealand and the USA. The Journal of Services Marketing, 13(2), 171-186.

Griemel-Fuhrmann, B. \& Geyer, A. (2003). Students' evaluation of teachers and instructional quality-analysis of relevant factors based on empirical evaluation research. Assessment \& Evaluation in Higher Education, 28 (3), $229-238$. Gronroos, C. (1984). A service quality model and its marketing implications. European Journal of Marketing, 18(4), 36-44.

Ham, L. \& Hayduk, S. (2003). Gaining competitive advantages in higher education: analyzing the gap between expectations and perceptions of service quality. International Journal of Value-Based Management, 16 (3), $223-242$.

Hill, F. M. (1995). Managing service quality in higher education: the role of the student as primary consumer. Quality Assurance in Education, 3(3), 10-21.

Hom, W. (2002). Applying Customer Satisfaction Theory to Community College Planning of of Student Services. IJournal. Retrieved January $7^{\text {th }} 2004$, from http://www.ijournal.us/ issue_02/ij_issue02WillardHom_01.htm.

Iacobucci, D., Ostrom, A. \& Grayson, K. (1995).Distinguishing service quality and customer satisfaction: the voice of the consumer. Journal of Consumer Psychology, 4(3), 277-303.

Joseph, M. \& Joseph, B. (1998). Identifying needs of potential students in tertiary education for strategy development. Quality Assurance in Education, 6(2), 90-96.

Kamal Abouchedid \& Ramzi Nasser (2002). Assuring quality service in higher education: registration and advising attitudes in a private university in Lebanon. Quality Assurance in Education, 10(4), 198-206.

Kanji, G. K., Abdul Malek bin A.Tambi \& Wallace, W. (1999). A comparative study of quality practices in higher education institutions in the US and Malaysia. Total Quality Management, 10(3), 357-371.

Kotler, P. \& Clarke, R. N. (1987). Marketing for health care organizations. Englewood Cliffs, NJ: Prentice-Hall.

Lassar, W. M., Manolis, C. \& Winsor, R. D. (2000). Service quality perspectives and satisfaction in private banking, Journal of Service Marketing, 14 (3), 244-271.

LeBlanc, G. \& Nguyen, N. (1997). Searching for excellence in business education: an exploratory study of customer impressions of service quality. International Journal of Educational Management, 11(2), 72-79.

Ling, C. S. (April 09, 2003). Equal quality education' at private centers. New Strait Time - Management Times.

Mahiah, S., Suhaimi, S. \& Ibrahim., A.(2006). Measuring the level of customer satisfaction among employees of human Resource Division. Advances in Global Business Research 2006. Vol. 3. No.1. ISSN: 1549-9332.

Maushart, J. (December 4, 2003). Study says students are satisfied with college experience. The Daily Aztec, San Diego State U.

Mather, P. (2000). Research, Assessment, and Testing Diversity at ECU: Student Perspectives. Retrieved December $28^{\text {th }}$ 2003 from http://www.ecu.edu.html.

Mohd Feroz Abu Bakar (19 ${ }^{\text {th }}$ October 2004). LAN tolak 40 program IPTS. Berita Harian, 3.

Oldfield, B. M. \& Baron, S. (2000). Students perception of service quality in a UK university business and management faculty. Quality Assurance in Education, 8 (2), 85-95.

O’Neill, M. (2003). The influence of time on student perceptions of service quality: The need for longitudinal measures, Journal of Educational Administration, 41(3), 310-324.

O'Neill, M. A. \& Palmer, A. (2004). Importance-performance analysis: a useful tool for directing continuous quality improvement in higher education. Quality Assurance in Education, 12(1), 39-52.

Palacio, A. B., Meneses, G. D. \& Perez, P. J. P. (2002). The configuration of the university image and its relationship with the satisfaction of students. Journal of Educational Administration, 40(5), 486-505.

Parasuraman, A., Zeithaml, V. A. \& Berry, L. L. (1985). A conceptual model of service quality and its implications for future research. Journal of Marketing, 49, 41-50.

Parasuraman, A., Zeithaml, V. \& Berry, L. (1988). SERVQUAL: a multiple item scale for measuring consumer perceptions of service quality. Journal of Retailing, 6(1), 12-36.

Parasuraman, A., Zeithaml, V. A. \& Berry, L. L. (1990). Five imperatives for improving service quality. Sloan 
Management Review, 29-38.

Parasuraman, A., Zeithaml, V. A. \& Berry, L. L (1996). The behavioral consequences of service quality. Journal of Marketing, 60(2), 31-46.

Perisau S. E. \& McDaniel, J. R. (1996). Assessing service quality in schools of business. International Journal of Quality and Reliability Management, 14(3), 204-218.

Perry, M. J., Sekelsy, M. J. \& Skarsten, F. (March, 2003). University of Michigan-Flint Student Satisfaction Surveys Results. Retrieved January $7^{\text {th }}$, 2004, from http://www.vca.umflint.edu/.

Rajah, D. \& Nadarajah, V. (August 8th, 2000). Go for quality: Musa suggests methods for varsities to improve, New Strait Time, 1.

Renzi, B. M., Allen, M. J., Sarmiento, Y. Q. \& McMillin, J. D. (1993). Alumni perception of the impact of gender on their university experience. Journal of College Student Development, 34, 154-157.

Rowley, J. E. (1996).Customer compatibility management: an alternative perspective on student-to-student support in higher education. International Journal of Educational Management, 10(4), 15-20.

Saaditul Ibrahim, Shamsinar Md SIdin \& Wong Chee Meng (2000). Customer satisfaction towards service quality of higher education in Malaysia. Seminar FEP 2000 Pulau Pinang, 20 - 23 October 2000. Retrieved November $9^{\text {th }}$, 2004, from http://www.econ.upm.edu.my/ repport/mgm11b.html.

Sekaran, U. (1992). Research method for business: A skill building approach. New York: John Wiley \& Sons Inc.

Smith, R. \& Ennew, C. (2001, January). Service quality and its impact on word of mouth communication in higher education. Online: http://www.unim. nottingham.ac.uk/dbm/papers/ 2001-01.pdf. on 15 ${ }^{\text {th }}$ September 2004.

Solomon, M. R. (1996). Consumer behavior. Englewood Cliffs, NJ: Prentice-Hall.

Soutar, G. \& McNeil, M. (1996). measuring service quality in a tertiary institution. Journal of Educational Administration, 34(1), 72-82.

Spencer, R. (1991). After the registration revolution. College and University, 66(4), 209-12.

Spreng, R. A. \& Mackoy, R. D. (1996). An empirical examination of a model of perceived service quality and satisfaction, Journal of Retailing, 72(2), 52-64.

Sweet, J.A. \& Nelson, A. (1997). 1996 UW-Madison undergraduate student satisfaction survey: summary of results. University of Wisconscin Survey Center, University of Wisconsin. Retrieved on August 28 ${ }^{\text {th }}$, 2004, from http://www.ssc.wisc.edu/ sweet/stud96-pt1.html.

Teo, C. L. (October $21^{\text {st }}$ 2001). Realities of private institution. New Strait Time, 4.

Terenzini, P., Rendon, L., Upcraft, L., Millar, S., Allison, K., Gregg, P. \& Jalomo, R. (1996). The transition to college: Diverse students, diverse stories. Research in Higher Research in Higher Education, 35, 57-73.

Umbach, P. D. \& Porter, S. R. (2002). How do academic departments impact student satisfaction? Understanding the contextual effects of departments. Research in Higher Education, 43(2), 209 - 234.

Unprofessional College. (2004, November $\left.1^{\text {st }}\right)$. Harian Metro, 11.

We won't compromise on quality of private higher education, says Hon. (April 02 $\left.{ }^{\text {nd }}, 2001\right)$. New Strait Time, 4.

William, J. (2002). The student satisfaction approach: student feedback and its potential role in quality assessment and enhancement. 24 $4^{\text {th }}$ EAIR Forum, Prague, 8-11 September.

Zammuto, R. F., Keaveney, S. M. \& O'connor, E. J. (1996). Rethinking student services: assessing and improving service quality. Journal of Marketing in Higher Education, 7(1), 45-69.

Zeithaml, V. (1987). Defining and relating price, perceived quality and perceived value. Cambridge, MA: Marketing Science Institute. 
Table 1. Profile of Respondents

\begin{tabular}{|c|c|c|}
\hline Variables & Frequency (n) & Percentage $(\%)$ \\
\hline \multicolumn{3}{|l|}{ Gender } \\
\hline Male & 95 & $47.5 \%$ \\
\hline Female & 105 & $52.5 \%$ \\
\hline \multicolumn{3}{|l|}{ Age } \\
\hline 21 & 40 & $20.0 \%$ \\
\hline 22 & 66 & $33.0 \%$ \\
\hline 23 & 63 & $31.5 \%$ \\
\hline 24 & 20 & $10.0 \%$ \\
\hline 25 & 6 & $3.0 \%$ \\
\hline 26 & 2 & $1.0 \%$ \\
\hline 28 & 2 & $1.0 \%$ \\
\hline 29 & 1 & $0.5 \%$ \\
\hline \multicolumn{3}{|l|}{ Mean age $=22.54$} \\
\hline \multicolumn{3}{|l|}{ Ethnicity } \\
\hline Malay & 144 & $72.0 \%$ \\
\hline Chinese & 25 & $12.5 \%$ \\
\hline Indian & 25 & $12.5 \%$ \\
\hline Others & 6 & $3.0 \%$ \\
\hline \multicolumn{3}{|l|}{ Semester } \\
\hline First Semester & 21 & $10.5 \%$ \\
\hline Second Semester & 40 & $20.0 \%$ \\
\hline Third Semester & 29 & $14.5 \%$ \\
\hline Fourth Semester & 56 & $28.0 \%$ \\
\hline Fifth and Above & 54 & $27.0 \%$ \\
\hline
\end{tabular}

Table 2. T-Test Result

\begin{tabular}{|l|l|l|l|l|l|l|l|}
\hline Gender & N & Mean & $\begin{array}{l}\text { Std. } \\
\text { Deviation }\end{array}$ & $\begin{array}{l}\text { Std. Error } \\
\text { Mean }\end{array}$ & $\mathrm{t}$ & Df & Sig. (2 tailed) \\
\hline Satisfaction & & & & & & & \\
\hline Male & 95 & 4.2561 & 0.99906 & 0.10250 & 1.274 & 198 & 0.204 \\
\hline Female & 105 & 4.0873 & 0.87556 & 0.08545 & 1.265 & 187.986 & 0.207 \\
\hline Total & 200 & & & & & & \\
\hline Service Quality & & & & & & & 1.489 \\
\hline Male & 95 & 4.1491 & 0.72790 & 0.07468 & 198 & 0.138 \\
\hline Female & 105 & 4.0041 & 0.64836 & 0.06327 & 1.481 & 189.249 & 0.140 \\
\hline Total & 200 & & & & & & \\
\hline
\end{tabular}


Table 3. ANOVA Results

\begin{tabular}{|c|c|c|c|c|}
\hline Variables & Mean & Std. Deviation & $\mathbf{F}$ & Sig. F \\
\hline \multicolumn{5}{|l|}{ Student Satisfaction } \\
\hline \multicolumn{5}{|l|}{ Races } \\
\hline Malay & 4.1412 & 0.81800 & 1.453 & 0.229 \\
\hline Chinese & 4.1000 & 1.33420 & & \\
\hline Indian & 4.4867 & 1.07467 & & \\
\hline Others & 3.7500 & 1.00416 & & \\
\hline \multicolumn{5}{|l|}{ Semester } \\
\hline First Semester & 4.2698 & 1.20240 & 0.332 & 0.856 \\
\hline Second Semester & 4.2583 & 1.06079 & & \\
\hline Third Semester & 4.2184 & 1.06263 & & \\
\hline Fourth Semester & 4.1280 & 0.83242 & & \\
\hline Fifth Semester and above & 4.0741 & 0.76798 & & \\
\hline \multicolumn{5}{|l|}{ Service Quality } \\
\hline \multicolumn{5}{|l|}{ Races } \\
\hline Malay & 4.0346 & 0.62168 & 0.972 & 0.407 \\
\hline Chinese & 4.1213 & 0.87313 & & \\
\hline Indian & 4.2754 & 0.84909 & & \\
\hline Others & 3.9493 & 0.68105 & & \\
\hline \multicolumn{5}{|l|}{ Semester } \\
\hline First Semester & 4.0590 & 0.70225 & 0.722 & 0.578 \\
\hline Second Semester & 4.1784 & 0.72205 & & \\
\hline Third Semester & 4.1938 & 0.68278 & & \\
\hline Fourth Semester & 4.0137 & 0.78322 & & \\
\hline Fifth Semester and above & 3.9969 & 0.55291 & & \\
\hline
\end{tabular}

Table 4. Correlation Results

\begin{tabular}{|l|l|l|l|l|l|l|l|}
\hline Variable Type & $\mathrm{Y}$ & $\mathrm{X} 1$ & $\mathrm{X} 2$ & $\mathrm{X} 3$ & $\mathrm{X} 4$ & $\mathrm{X} 5$ & $\mathrm{X} 6$ \\
\hline $\begin{array}{l}\text { Dependent } \\
\mathrm{Y}=\text { Satisfaction }\end{array}$ & 1.00 & & & & & \\
\hline $\begin{array}{l}\text { Independent } \\
\mathrm{X} 1=\text { Age }\end{array}$ & 0.09 & 1.00 & & & & & \\
\hline $\mathrm{X} 2=$ Tangibility & $0.568^{* *}$ & -0.27 & 1.00 & & & & \\
\hline $\mathrm{X} 3=$ Assurance & $0.582^{* *}$ & -0.018 & $0.699^{* *}$ & 1.00 & & & \\
\hline $\mathrm{X} 4=$ Reliability & $0.555^{* *}$ & -0.031 & $0.728^{* *}$ & $0.789^{* *}$ & 1.00 & & \\
\hline $\mathrm{X} 5=$ Responsiveness & $0.556^{* *}$ & -0.026 & $0.669 * *$ & $0.776^{* *}$ & $0.847^{* *}$ & 1.00 & \\
\hline $\mathrm{X} 6=$ Empathy & $0.640^{* *}$ & -0.037 & $0.688^{* *}$ & $0.623^{* *}$ & $0.763^{* *}$ & $0.747^{* *}$ & 1.00 \\
\hline $\mathrm{X} 7=$ Service Quality & $0.653^{* *}$ & -0.031 & $0.899^{* *}$ & $0.867^{* *}$ & $0.914^{* *}$ & $0.885^{* *}$ & $0.849^{* *}$ \\
\hline$*$ Correlation is significant at the 0.05 level (2-tailed) & & & \\
\hline$*$ Correlation is significant at the 0.01 level (2-tailed) & & & \\
\hline
\end{tabular}




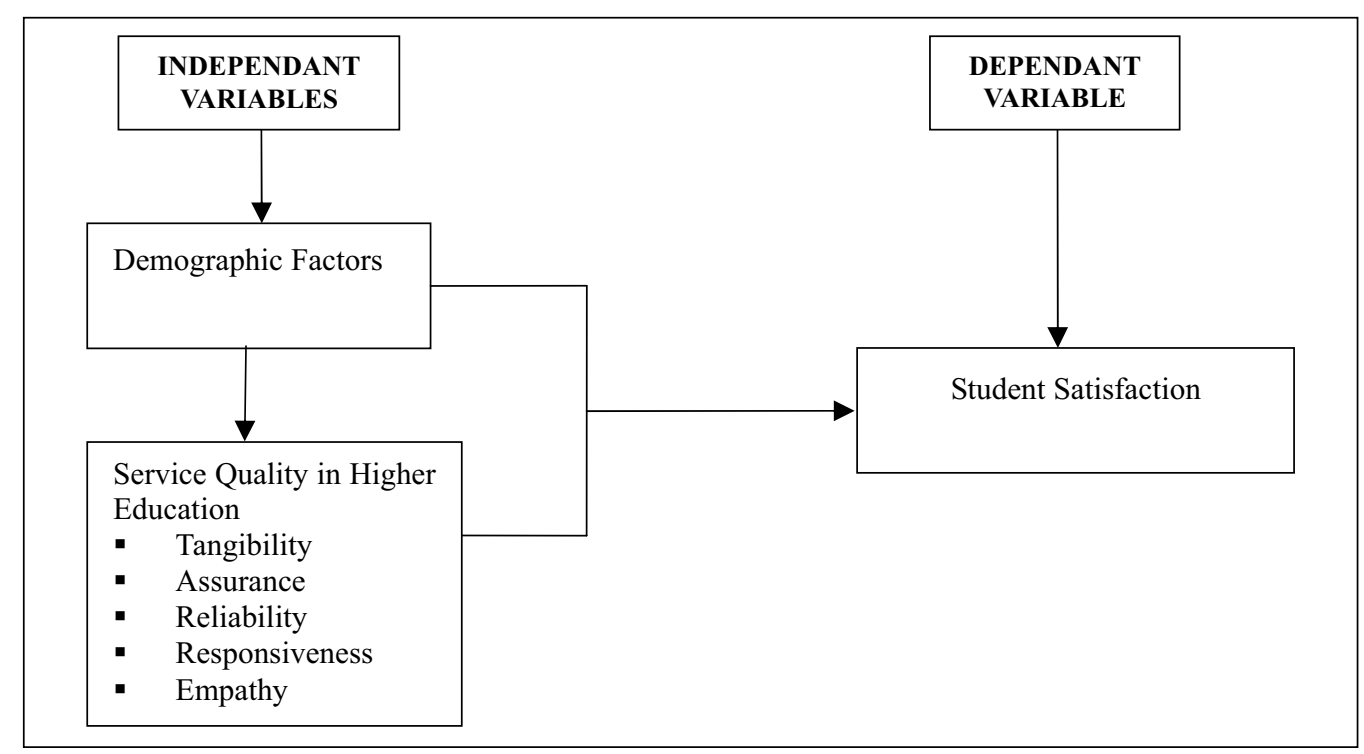

Figure 1. Research Framework 


\title{
Do Institutional Differences Affect Leverage Choice?
}

\author{
Xiaoyan Niu \\ School of Accounting, Shandong Economic University \\ Er Huan Dong Lu 7366, Jinan, Shandong, China \\ Tel: 86-531-8852-5940Ｅ-mail: qiuxiao25@hotmail.com
}

\begin{abstract}
This study conducts a cross-country comparison of capital structure and its determinants between UK and Germany to test alternative theories of capital structure within different institution traditions. The purpose of this study is to bring into focus the possible effect of institution differences on capital structure choice and its firm-level determinants.
\end{abstract}

Keywords: Capital structure, Firm-level determinants, OLS regression model, Institutional differences

\section{Introduction}

The capital structure of a firm describes the way in which a firm raised capital needed to establish and expand its business activities. It is a mixture of various types of equity and debt capital a firm maintained resulting from the firm's financing decisions.

Previous studies concluded that firms' leverage ratio closely related to firm-level characteristics. For an instance, Harris and Raviv (1991) summarize that "leverage increases with fixed assets, non-debt tax shields, investment opportunities and firm size and decreases with volatility, advertising expenditure, the probability of bankruptcy, profitability and uniqueness of the product." Most of previous empirical evidences were based on US firms with few notable exceptions. However, the experience of a single country may cover the effects of different financial system and economic tradition on capital structure choice. Cross-country comparisons are essential for the understanding of the difference in leverage choices across countries. And also cross-country comparison can be used to suggest linkages between institutional differences and empirical results about capital structure.

In order to investigate whether the capital structure and the relation between firms' financing choice and firms' characteristics differs under different institutional characteristics, this thesis compares the capital structure choice and its determinants of two European countries: UK and Germany, which similar in their levels of economic development but follow different institutional traditions. UK is known to follow a market-based tradition (also called Anglo-Saxon market-based model) with large numbers of listed companies of relative small size and the takeover market is highly active. Due to the arm's length relationship with the lenders, the firms in UK may face more information asymmetry problems. Firms in Germany operate under a bank-based tradition (also called continental Europe bank-based model), where banks play a central role in the economy and stock markets are fairly underdeveloped. There are fewer listed companies in Germany but their sizes are comparably larger than the firms in UK. In Germany, Banks' ownership in the firm creates a supervision incentive that helps to reduce the information asymmetry.

In this thesis, I will explain capital structure using three ratios: total book-debt ratio, long-term book-debt ratio and long-term market-debt ratio. These three ratios help to get a better understanding of the difference between U.K and Germany in financing patterns, including leverage ratios, maturity structure and financing choice between internal and external financing. The basic regression we estimate is based on the model used by Rajan and Zingales (1995), in which tangibility, profitability, size and market-to-book ratio being the independent variables, whereas regressors in this study are extended by including tax rates and liquidity. The data set is chosen to be recent to shed light on some prospects of the current debate about the capital structure and its determinants in bank- and market-based countries.

The results reveal that firm-specific characteristics ${ }^{1}$ (There is wildly accepted wisdom that macroeconomic conditions, such as the level of development of bank and stock market, real GDP growth, inflation rates also influence firms' capital structure choice. But test of macroeconomic impacts cannot be carried out in this thesis, for a sample of only two countries. However, the difference of macroeconomic conditions between the two countries will be presented in the next section.) affect capital structure both in UK and Germany: tangibility and liquidity have the expected sign and consistent in the two countries. While the results also show the considerable differences in relations of capital structure and firm-specific characteristics: tax rate, size, profitability and market-to-book ratio, show different effects in UK and Germany. The variation in the results suggests that the institutional differences contribute to the capital structure choice of the firms. 
The rest of the thesis is organized as follows: Section 2 makes a comparison of some major institutional differences between UK and Germany. Section 3 discusses the data collecting process and regression model used in this thesis. Empirical results and interpretation is also presented in this part 4. Section 5 concludes the paper.

\section{Institutional differences between UK and Germany}

UK and Germany are classified as market-based and bank-based financial system based on the size or power of banking sector. However, this is just one important aspect of the institutional differences between the two countries. They also differ in legal system, patterns of corporate governance etc. Here I'll review some major institutional differences between UK and Germany and their potential influences on capital structure choice.

\subsection{Bankruptcy law}

UK and Germany follow different legal system: UK is common law while Germany follows a civil law tradition. There is a typical claim that common law provides better protection to investors than civil law does (See for example, Watson (1974)). In this subsection, a comparison of legal system will be presented, mainly focusing on the differences in bankruptcy law.

As Harris and Raviv (1992) suggest, bankruptcy law should be regarded as an integral aspect of a debt contract. There are a number of important effects of bankruptcy law: first, its strict enforcement of creditor rights enhances ex ante contractibility; second, it gives creditors the rights to punish managers in financial distress, thus inducing strong incentives for managers to stay clear of it; finally, strict enforcement reduces the costly and long drawn out that haggling between claimholders that ensues when there is a possibility that the original contract my be violated. (Rajan and Zingales (1995))

Insert Table 1 here

The bankruptcy law of the two countries differs considerably. Table 1 presents a brief summary of the principal bankruptcy procedure in the UK and Germany. The LLSV (La Porta, Lopez-de-Silance, Shleifer and Vishny) creditor-rights score is 3 for Germany and 4 for the UK, which indicates that British bankruptcy law provides better protection to creditors than German bankruptcy law does.

By contrast, UK bankruptcy law is more efficient in creditor rights protection than its Germany counterpart. The difference in legal system efficiency may be reflected in firms' capital structure choice, especially debt maturity structure. When the legal system is inefficient, short-term debt is more likely to be employed than long-term debt. Diamond (1991) argues that, short-term financing may reduce the expropriation of creditors by borrowers. As the short-term debt allows the creditors to review the firm's decision frequently and vary the terms of financing before sufficient losses have accumulated to make default by the borrowers. Hence, we would expect an inverse relationship between the inefficiency of a country's legal system and the use of long-term debt.

\subsection{Market-based vs. Bank-based system}

Is there systematic difference between the level of leverage in bank-based countries and market-based countries? It seems that no clear conclusion has been reached yet. Rajan and Zingales (1995) compare the aggregate leverage ratios across G-7 countries and found that contrary to the previous thought that firms in bank-based countries will have more debt than firms in market-based countries, firm leverage is fairly similar across the G-7 countries. Hence, they argue that the classification of bank-based and market-based economy is reflected more in the banks power and stock markets development than in the amount of debt. In this subsection, we will compare the power of bank and stock-market development between UK and Germany, and their possible influences on capital structure choice.

In a bank-based financial system, banks play a leading role in allocating financial resources, oversee the investment decisions of corporate managers and provide risk management vehicles. The stock markets are highly underdeveloped and used by a few firms and individuals. As the banking sector is controlled under a few large banks, there will be low competition.

While in a market-based financial system, securities markets share centre stage with banks in terms of getting society's savings to firms, exerting corporate control, and easing risk management. Banks play the role of lenders' last resort in a market-based system.

Insert Table 2 here

The ratio of domestic credit provided by the banking sector to the gross domestic product (GDP) is a measure of the development of banking sector. Table 2 shows that, the ratio of domestic credit over GDP is nearly the same for UK and Germany (both are around 145\%). Daimond (1984) argues that intermediaries, such as banks, have economics of scale in obtaining information. They may also have greater incentives to use collected information to discipline borrowers than small investors subject to free-rider problem. Hence, a developed banking sector will facilitate access to external financing. In Germany, large bank and inter-corporate shareholdings are widespread. Companies raise most of their 
external finance from banks that have close relationships with them. While it is not the case for UK, the evolution in the UK of a banking sector that lacks integration with industrial strategy at either the macro or micro level, leads to a high level of dependence of UK firms on equity markets to finance expansion. (Hutton(1996); Charkham (1994)). So we expect that German firms will issue more debt than British firms on average.

Market capitalization ratio is used to measure the size of stock markets. The activity or liquidity of stock markets is approximated by the ratio of stock value traded over GDP. Compared with Germany, the stock market in UK is apparently larger in size and more active. The stock market capitalization and liquidity ratio of UK are $119 \%$ and $174 \%$, while in Germany, the ratios are only $35 \%$ and $62 \%$.

\subsection{Ownership and Control}

Another important institution difference between UK a Germany is the level of ownership concentration and the working of the market for corporate control. Due to the lack of adequate data, here we briefly describe the differences in terms of ownership and control and discuss their potential implications afterwards.

In Germany, corporate ownership is highly concentrated in the hands of a relatively small number of blockholders. These usually consist of banks, family owners and other companies that are bound in networks of cross-shareholdings. Together they account for over two thirds of German share ownership (Lanno(1999)). In Germany, firms usually operate a two-tier board system, made up of a management board and a supervisory board. The blokholders exercise close control over the firms they invest, usually through board representation and the exercise of majority voting rights. Banks play an important role in industrial finance and this important role is often matched by the influence they exercise through board representation and voting rights derived from their ownership of shares and also by acting as proxies for small shareholders. As a consequence of concentrated ownership and underdeveloped stock market, hostile acquisitions are rarely heard.

In the UK, share ownership is widely dispersed among a large number of investors, especially institutional investors, and firms operate under a one-tier supervisory board (board of directors). Lanno(1999) investigates that institutional investors account for over two thirds of corporate ownership. Although on aggregate level, institutions hold a large fraction of total share of UK firms. Single investor shareholdings in a company usually amount to no more than a few percent, often much less. Holdings of more than 10 per cent are rare and are generally accounted for by small family-controlled firms or those with a significant state interest (Vitols et al (1997)). The large dispersed ownership structure may result in the divergent interest between principle and agent. As La Porta et al(2000) point out, minority investors who, due to collective action problems and easy exit opportunities, are unable or unwilling to exercise direct control, will not invest unless their interests are adequately protected from rent seeking managers. Consequently, UK financial market regulation and legal system have developed to reconcile the contradict interests between principle and agent that arise with dispersed ownership. Apart from these regulation devices, the existence of an active takeover market provides an external mechanism of corporate control. Manne(1965) argues that, a well functioning market for corporate control may deter managers from running the firm below its performance potential since that would make the firm vulnerable to takeover. Compared with Germany, UK is characterized by a more active market for corporate control, i.e., there exist a much higher numbers of mergers and hostile takeovers. Hence we expect that a more active market for corporate control to provide stronger incentives for high firm performance.

\section{Data collecting and empirical model}

\subsection{Proxies of firm-level capital structure determinants and theoretical predicted signs.}

Previous studies have shown that a number of factors affect firm's capital structure choice, such as tangibility, tax, size, profitability, growth opportunities and volatility etc. In their distinguished works, Harris and Raviv (1991) summarize that "leverage increases with fixed assets, non-debt tax shields, investment opportunities and firm size and decreases with volatility of earnings, advertising expenditure, the probability of bankruptcy, profitability and uniqueness of the product." However, the relationship between the factors and capital structure is not consistent. The empirical results vary, and sometimes contradict in many studies. Moreover, comparisons of capital structure across countries reveal that institutional differences may affect the cross-sectional relation between leverage and factors. In the next sub-section, we will present the proxies used in this thesis to test the determinants of corporate leverage choice in U.K and Germany, the two countries that are homogeneous in their level of economic development but follow different institutional traditions.I summarize the firm-level determinants of capital structure, definitions and theoretical predicted signs in Table 3.

Insert Table 3 here

\subsection{Data description and sample selection}

The data set were derived from Compustat Global. It contains historic data up to 12 years for more than 65 countries around the world, including income statement, balance sheets and market data. By standardizing the reporting methods, meaningful financial comparisons can be made among publicly traded companies. For the purpose of this thesis, we 
utilize this database to obtain variables for all non-financial firms in U.K and Germany from 2003 to 2005. Financial firms such as banks and insurance companies were eliminated from the sample because the non-comparable of balance sheet with non-financial companies. The study period was chosen to be recent to gain an insight of current aspects of capital structure of the two countries. The firms' data extracted from Compustat to compute necessary proxies include total debt, long-term debt, total assets, current assets, current liabilities, market value of equity, book value of equity, property plant and equipment total net (PPENT), total sales, tax rates, and return on assets. The original samples for U.K and Germany are 844 and 619 firms respectively. Because all the regressors are averaged through three years, so the firms lacking data on the required variables in the consecutive period 2003-2005 are eliminated from the database by Eviews. The firms with either the total debt ratio or long-term debt ratio exceed $100 \%$ or containing a negative market to book ratio are removed from the data set. Since these data are obviously resulted from typographical errors. This filtration criterion helps to reduce the potential bias. The final data set contains 525 and 218 firms for UK and Germany respectively.

\subsection{Dependent and Independent Variables}

\subsubsection{Dependent Variables}

This thesis employs three measures of leverage: total book-debt ratio (TD), long-term book-debt ratio (LD) and long-term market-debt ratio (MLD) ${ }^{4}$ (Because of the data limitation, here book value of debt is used instead of market value of debt. As Bowman (1980) demonstrated that the cross-sectional correlation between the book value and market value of debt is very large, so the misspecification due to using book value measures is probably fairly small.) The precise definitions are presented in Appendix A. Here I use total book-debt ratio (TD) as the main measure of leverage and the other two measures are employed for robustness checks. The preference for total debt ratio above long-term debt ratio is derived by the nature that total debt ratio represents the debt capacity of a firm. When a firm wants to obtain more debt, the creditors will not only focus on how much the firm's long-term debt is, but also take into account the portion of short-term debt. The choice for a book value measure of leverage above a market value measure mainly has two reasons. First, a market value measure may induce spurious correlation. This is especially relevant for the market-to-book ratio. Even without a causal relationship between the market-to-book ratio and the market-debt ratio, a negative relationship will be measured ${ }^{5}$. (Titman and Wessels (1988) argue that, assume all firms have the same debt ratio in book values. The cross-section variation in market value debt ratio will be fully determined by the difference between the book and market value of the firms.)A second reason of using book-debt ratio may stem from the fact that market values are too volatile too be used as a measure. Many studies such as Toy et al. (1974) show that financial executives consider capital structure choice in book value rather than market value terms.

\subsubsection{Independent Variables}

I use seven independent variables as proxies of firm-level capital structure determinants. The seven independent variables are: tangibility, size, tax rate, profitability (ROA), growth opportunity (MTB), volatility and liquidity. To capture the size effect on the leverage of firms, two alternative measures are used, i.e. natural logarithm of total sales and natural logarithm of total assets of a firm. Table 4 presents the correlation matrix of independent variables.

Insert Table 4 here

While checking for correlation matrix, two potential collinearity problems may arise. First, $\log ($ sales) variable reveals higher correlation with other independent variables than $\log ($ assets $)$ measure. For example, the correlation of $\log ($ sales)(SIZE1) with liquidity(LIQ) are -0.447 in British firms, for $\log$ (assets)(SIZE2), the correlation reduces to -0.209 . For German firms in the sample, the correlation between $\log ($ sales)(SIZE1) and profitability(ROA) is 0.468 , the correlation between $\log$ (sales)(SIZE1) and liquidity(LIQ) -0.439. While for $\log$ (assets)(SIZE2) measure, the correlations are 0.357 with ROA and -0.249 with LIQ. So $\log$ (assets) is adopted as the only proxy for size after checking the correlation matrix. Second problem stems from the high correlation of profitability (ROA) and volatility, the correlation coefficient is -0.813 in UK and -0.853 in Germany. To avoid the potential collinearity problem, volatility is eliminated from the independent variables. Finally, six independent variables are adopted in this thesis, which are tangibility, size, tax rate, profitability, growth opportunity and liquidity. The precise definitions are presented in Appendix B.

In an attempt to isolate the analysis from the potential reverse causality, which exists between the independent, and dependent variable, most empirical studies of capital structure lag their independent variables, which are typically a smoothed series (See e.g., Titman and Wessels (1988) and Rajan and Zingales (1995)). Following Timan and Wessels, I average the independent variables for three years to reduce the noise, then regress the 2003 debt measures against the average tangibility, size, tax rate, profitability, growth opportunity and liquidity for the period 2003-2005.

\subsection{Regression model}

I estimates the relationship between tangibility, size, tax rate, profitability, growth opportunity and liquidity against three debt measures using ordinary least squares (OLS) cross-sectional regressions ${ }^{6}$ ( I also estimated cross-sectional 
regressions using censored Tobit analysis adopted by Rajan and Zingales (1995). However, as they do, the OLS and Tobit results are found to be very similar. Therefore, I report the results based on OLS regression for simplicity.)The estimated regression model is specified in Equation (1):

Leverage $[$ Firm i $]=\beta_{0}+\beta_{1}$ TANG $_{i}+\beta_{2}$ TAX $_{i}+\beta 3$ SIZE $_{i}+\beta_{4}$ ROA $_{i}+\beta_{5}$ MTB $_{i}+\beta_{6}$ LIQ $_{i}+\varepsilon_{i}$

where:

Dependent variables are the three measures of debt in 2003. Independent variables are three years averages (2003-2005) of the corresponding variables.

Leverage [Firm i] is the average level of leverage of firm $i$ in the country in 2005. Three measures are used: total book-debt ratio, long-term book-debt ratio, and long-term market-debt ratio. Total book-debt ratio is defined as total debt over book value of total assets; long-term book debt ratio is long-debt over book value of total assets; long-term market debt ratio is long-term debt over market value of assets (calculated as book value of assets less book value of equity plus market value of equity).

TANGi is shorthand term for tangibility defined by the book value of property, plants and equipment total net (PPENT) scaled by total assets of firm i, and averaged through 2003-2005.

TAXi is the average effective tax rate for firm $i$ in the period 2003-2005.

SIZEi represents size of firm i, proxies by natural logarithm of total assets and averaged through 2003-2005.

ROAi is the shorthand term for return on assets, calculated by earnings before interest and tax divided by total assets. We use it as a proxy of profitability and average through the study period.

MTBi is growth opportunities of the firm i in study period, proxies by market value of equity over book value of equity and average from 2003 to 2005 .

LIQi represents liquidity. It is calculated as the current assets divided by current liabilities of firm $i$ and averaged through 2003-2005.This ratio serves as an indicator of firm's ability to pay short-term obligations.

\section{Empirical results and interpretations}

\subsection{Summary Statistics}

As we have mentioned above, in Germany, large banks and inter-corporate shareholdings are widespread. Companies raise most of their external finance from banks that have close relationships with them. While in UK, the evolution of a banking sector that lacks integration with industrial strategy at either the macro or micro level, leads to a high level of dependence of UK firms on equity markets to finance expansion. (Hutton (1996); Charka (1994)). So we expect that German firms will issue more debt than British firms on average. This expectation is confirmed from the leverage ratios in the sample firms.

\section{Insert Table 5 here}

Descriptive statistics (Table 5) shows that, in the sample firms, on average German firms have higher debt (total-book, long-term book and long-term market debt) ratios $(23.84 \%, 13.03 \%$ and $11.61 \%)$ than British firms $(16.78 \%, 10.51 \%$ and $8.74 \%$ ). The relatively higher debt ratios in German confirm the view that German firms tend to borrow more than British firms because of the easier access to debt finance. The lower debt ratios in the UK emphasize the relative importance of equity finance where share ownership is widely dispersed.

Insert Table 6 here

As table 6 shown, three measures of leverage are highly correlated with each other. In UK, the correlation is 0.802 between book total and long-term debt ratios (TD and LD), 0.921 between book and market long-term debt ratios (LD and MLD). In Germany, the correlation is 0.762 between book total and long-term debt ratios (TD and LD), 0.944 between book and market long-term debt ratios (LD and MLD). As these debt measures are highly correlated, for simplicity, the interpretation of regression results will mainly base on total debt ratio.

Among the explanatory variables, the correlations are at reasonable levels (under 0.40 ), which indicate that there will not be serious multicollinearity problems.

\subsection{Cross-sectional Regressions}

Insert Table 7 here

As table 7 shown, among the independent variables, tangibility and liquidity are the only two variables that have the expected and consistent signs both in UK and Germany. Other variables, such as tax, size, market-to-book ratios and profitability show different effects across the two countries, which indicates that institutional differences may play an important role in capital structure determinants. In the paragraphs below we discuss the role of firm-level capital structure determinants in detail. 


\subsubsection{Tangibility}

The coefficients of tangibility variable are both positive and significant at in UK and Germany. This positive relation is consistent with the theoretical predictions. As Jensen and Meckling (1976) point out that, the agency cost of debt exits as the firm may shift to riskier investment after the issuance of debt, and transfer wealth from creditors to shareholders to exploit the option nature of equity. If a firm's tangible assets are high, then these assets can be used as collateral, mitigating the lender's risk of suffering such agency costs of debt. Hence, a high fraction of tangible assets is expected to be associated with high leverage, and also the value of tangible assets should be higher than intangible ones in case of bankruptcy. Besides, Williamson (1988) and Harris and Raviv (1990) suggest leverage should increase with liquidation value and both papers also predict that leverage is positively correlated with tangibility, which is now once more confirmed by this study.

\subsubsection{Effective tax rate}

In the previous section we argue that, under the premise of sufficient taxable income, effective tax rate is expected to be positively associated with the level of debt. Thus firms with higher taxable income ought to have more debt to benefit from tax-shield gain. On the other hands, higher effective tax rate also reduce internal funds and increase the cost of capital. Hence a negative relationship between effective tax rate and level of debt is expected. Some studies also find no significant relation between effective tax rate and leverage ratio. Since the theoretical predictions are mixed, the sign of correlation might vary, depending on which of the (sometimes contradicting) effects seems to be dominant.

In our sample, the estimated coefficient of effective tax rate is significantly negative in UK and positive while insignificant in Germany. These distinctive effects of tax rate may stem from the differences in the debt financing related cost (e.g., agency and bankruptcy costs) between the two countries. Since British firms have arm length relationship with the lenders, information asymmetry problems are likely to be more severe than German firms. If the debt financing related costs prevailed over the tax benefits of debt financing, a negative effect of tax rate may be found.

\subsubsection{Size}

In our regression, this variable also creates inconsistent results across the two countries. In UK, the coefficient of SIZE is 1.83 and significant at $1 \%$ level, implying that the borrowing capacity of firm is positively correlated to the size of the firm. This result is consistent with the theoretical expectations. Since larger firms are not only more diversified and have more stable cash flow, but size can also be interpreted as a reversed proxy for bankruptcy cost. Rajan and Zingales (1995) suggest that larger firms are less likely to bankrupt; therefore, size would be positively correlated with debt.

While for German firms, the coefficient between size and leverage is negative and highly insignificant with a p-value of 0.96 , which means that the null hypothesis that the coefficient equals to zero cannot be rejected with the probability $96 \%$. Although the coefficient is insignificant, it requires some explanation since it contradicts the theories about size and capital structure. Rajan and Zingales (1995) also find that the coefficient on size has a different effect in Germany than in the other G-7 countries.

A tentative explanation may base on the concentrated ownership structure in German firms and the inter-corporate share holdings with banks. As debt serves to discipline managers' behavior (Jensen and Meckling (1976)), larger firms ought to issue more debt to mitigate the conflicts between managers and shareholders. Since size proxies the relative dilution of control, smaller firms are more subject to shareholder intervention in the case of mismanagement because a reasonably small group of shareholders can gain a controlling interest in the firms. However, this argument may not hold for German firms. Roe (1993) examines corporate governance in Germany, Japan and the United States and argue than large German firms are much like small U.S. firms. Since German banks control large shares of firms, even the largest German companies. For instance, the three largest German banks control 60.64 percent shares of the largest German firm, Siemens; the second largest, Daimler-Benz, is 41.80 percent controlled by Deutsche Bank (Roe (1993)). Hence, in Germany, the concentrated ownership and close relationship with banks force management to act in the shareholders' interests. Thus, the discipline role of debt is of less importance in Germany. The above argument suggests that the centralized firm control in Germany is responsible for the insignificant effect of size on leverage.

\subsubsection{Growth Opportunities}

Contrary to the theoretical predictions and majority of empirical evidence, market-to-book ratio is found to have a significantly positive correlation with leverage ratios in Germany. The estimated coefficient in British firms is negative while insignificant at conventional level. (Although the coefficient for long-term market leverage is significant at $10 \%$ level, it may due to the spurious correlation induced by market value).

In Myer's (1977) model, existing debt provokes a conflict interest between debtholders and equityholders. This conflict causes the firm to pass through positive NPV projects. However, this explanation seems not apply to German firms in our sample where high growth firms tend to use more debt. Rajan and Zingales (1995) argue that firms with high market-to-book ratios suffer higher costs of financial distress, so leverage ratio should be negatively correlated with 
growth opportunities. While we put forward a tentative argument that high growth firms in Germany may experience lower costs of financial distress. Because the lenders of German firms, especially the banks, are frequently present in the supervisory board, and this close relationship with management help the lenders to be better aware of the quality of the firm and investment opportunities as well. Hence this close relationship with lenders gives firms easier access to external borrowing and reduces the risk premium demanded by the lenders. Furthermore, in a bank-based system a special bank-firm relationship may exist even if the bank does not hold shares. This is the case in the German "Hausbank" context where a bank has a very close relationship with an enterprise leading to special lending behavior over the business cycle and in financial distress situations (Kremp et al(1999)). Thus, high growth firms in Germany are less subject to financing constraints from the banking sector, and the conflict between debt holders and equity holders in Myers's (1977) model doesn't apply. Instead, the positive and highly significant coefficient of the market-to-book ratio indicates that, German firms with growth opportunities generally hold more debt.

\subsubsection{Profitability}

Results in Table 7 reveal a significant negative relationship between profitability and leverage in Germany. This is consistent with pecking order theory, which argues that firms prefer internal funds to finance their investments before raising external debt capital. This argument is based on the view that higher profitability increases internal funds and hence reduces the need for external finance. By implication our results are inconsistent with agency-based theoretical models where debt is used as a discipline device to ensure that managers pay out profits rather than build their empires (Myer's (1977)), and then for firms with free cash flow, or high profitability, high debt can restrain management discretion (Jensen (1986)).

The relationship between profitability and leverage is also negative UK, but it is not significant at $10 \%$ level. A possible explanation may lies in the effects of widely dispersed ownership structure. Because of the much wider distribution of share ownership, information asymmetry problem is expected to be more severe in UK than Germany. British firms may be required to distribute more dividends, which, in turn, reduces the importance of profitability when considering corporate financing decisions.

\subsubsection{Liquidity}

This is one variable creating strong consistency across the two countries in our sample. Liquidity is significantly negatively related to leverage ratios for both German firms and British firms in our sample. This inverse relationship between liquidity and leverage confirms our expectation that firms with high liquidity tend to avoid raising external loan capital. Thus reduces the leverage ratio of firms.

\section{Conclusion}

In this study I conduct a cross-country comparison of capital structure and its determinants between UK and Germany to test alternative theories of capital structure within different institution traditions. The purpose of this study is to bring into focus the possible effect of institution differences on capital structure choice and its firm-level determinants.

Empirical evidence shows that on average German firms have more debt than British firms; among the explanatory variables, some variables, such as tangibility and liquidity, have the expected sign and are consistent across the two country. While other variables, such as tax rate, size, profitability and market-to-book ratio, show different effects in UK and Germany. This result indicates that institutional differences may be significant determinants of capital structure. These findings also indicate that institutional differences contribute to the variation in capital structure choice and the effects of determinants. While the explanations of causes of cross-country differences are tentative, further research and evidence is required to verify which institution effect produce the observed correlations.

\section{References}

Alan A. Bevan \& Jo Danbolt. (2000). "Capital structure and its determinants in the United Kingdom: a decompositional analysis", Working Paper University of Glasgow.

Bancel, F. \& Mittoo, U. (2002). "The determinants of capital structure choice: A survey of European firms", Working paper series, SSRN.

De Jong, A. \& Van Dijk, R. (2002). "Determinants of leverage and agency problems”, Research Paper, Tilburg University.

Harris, M., \& Raviv, A. (1991). "The theory of capital structure", Journal of Finance 46, 297-355.

Hovakimian, A., Opler, T. \& Titman, S. (2001). "The debt-equity choice", Journal of Financial and Quantitative Analysis 36, 1-24.

Kim, Y., \& Sorensen, E. (1986). "Evidence on the impact of the agency costs of debt in corporate debt policy", Journal of Financial and Quantitative Analysis 21, 131-144.

MacKie-Mason, J. (1990). “Do taxes effect corporate financing decision?” Journal of Finance 45, pp. 1471-1495. 
Myers, S. (1984). "The capital structure puzzle”, Journal of Finance 39, 575-592.

Rajan, R.G. \& L. Zingales. (1995). "What do we know about capital structure? Some evidence from international data", Journal of Finance 50, 1421-1460.

Roe, M. J. (1993). "Some differences in corporate structure in Germany, Japan and the United States", Law Journal 102, 1927-2003.

Titman, S. \& R. Wessels. (1988). “The determinants of capital structure choice”, Journal of Finance 43, 1-19.

\section{APPENDIX A: Dependent Variable Definitions}

TD Total book-debt ratio, calculated as total debt (DT) divided by book value of total assets (AT) TL = DT / AT (Equation A1)

LD Long-term book-debt ratio, the ratio of total long-term debt (DLTT) to book value of total

$$
\text { assets (AT) } \quad \mathrm{LD}=\mathrm{DLTT} / \mathrm{AT} \quad \text { (Equation A2) }
$$

MLD Long-term market-debt ratio, the ratio of total long-term debt (DLTT) to market value of total assets (book value of assets (AT) less book value of equity (SEQ) plus market value of equity (MKVAL)) MLD $=$ DLTT $/(\mathrm{AT}-\mathrm{SEQ}+\mathrm{MKVAL}) \quad$ (Equation A3)

\section{APPENDIX B: Independent Variable Definition}

Tangibility

(TANG)

Effective tax rate

(TAX)

Size (SIZE)

Market-to-book

ratio(MTB)

Profitability

(ROA)

Liquidity

(LIQ)

$\mathrm{LIQ}=\mathrm{AC} / \mathrm{LC}$
The ratio of book value of property, plants and equipment total net (PPENT) to book value of total assets (AT). (Equation B1)

$$
\text { TANG }=\text { PPENT } / \text { AT }
$$

The ratio of income taxes - total (TXT) to taxable income (pretax income (PI) less appropriations to untaxed reserves (AUTXR)). (Equation B2) TAX $=$ TXT $/$ (PI - AUTXR)

The natural logarithm of total assets (AT). (Equation B3)

SIZE $=\log ($ AT $)$

The ratio of market value of equity (MKVAL) to book value of equity (SEQ). (Equation B4)

MTB $=$ MKVAL / SEQ

The ratio of earnings before interests and taxes (EBIT) to total assets (AT). (Equation B5)

$$
\mathrm{ROA}=\mathrm{EBIT} / \mathrm{AT}
$$

The ratio of current assets (AC) to current liabilities (LC).

(Equation B6) 
Table 1. Bankruptcy procedures in UK and Germany

\begin{tabular}{|c|c|c|}
\hline Main procedure & $\begin{array}{c}\text { UK } \\
\text { Administrative receivership }\end{array}$ & $\begin{array}{c}\text { Germany } \\
\text { Insolvenzordnung (the } 1999 \text { code) }\end{array}$ \\
\hline Bankruptcy trigger & Default (covenant breach) & $\begin{array}{l}\text { Cessation of payments or } \\
\text { over-borrowing }\end{array}$ \\
\hline Control rights & Secured creditor & $\begin{array}{l}\text { Creditors under court } \\
\text { supervision (secured creditors } \\
\text { have more power) }\end{array}$ \\
\hline Automatic stay & None & 3 months \\
\hline $\begin{array}{l}\text { Super-priority } \\
\text { financing }\end{array}$ & None & Creditors' approval required \\
\hline Dilution of secured claim & None & Limited \\
\hline $\begin{array}{l}\text { LLSV creditors score } \\
(\max =4)\end{array}$ & 4 & 3 \\
\hline
\end{tabular}

This table lists principal bankruptcy procedures in UK and Germany and compares the main characteristics. Creditor protection scores estimated by La Porta, Lopez-de-Silanes, Sheifer and Vishny (1998) are reported in the bottom row.

Table 2. Banking sector and stock market indicators of UK and Germany (2003)

\begin{tabular}{|c|c|c|c|c|c|c|}
\hline Countries & $\begin{array}{l}\text { GDP } \\
\text { (current \$) }\end{array}$ & $\begin{array}{l}\text { Bank } \\
\text { Credit }\end{array}$ & Listed companies & $\begin{array}{l}\text { Market } \\
\text { Capitalization }\end{array}$ & $\begin{array}{l}\text { Market } \\
\text { Liquidity }\end{array}$ & $\begin{array}{l}\text { Turnover } \\
\text { Ratio }\end{array}$ \\
\hline $\begin{array}{l}\text { U.K } \\
\text { Germany }\end{array}$ & $\begin{array}{l}\text { \$-billion } \\
1566 \\
1984\end{array}$ & $\begin{array}{l}\% \text { of GDP } \\
145 \\
145\end{array}$ & $\begin{array}{l}1701 \\
715\end{array}$ & $\begin{array}{l}\% \text { of GDP } \\
119 \\
35\end{array}$ & $\begin{array}{l}\% \text { of GDP } \\
174 \\
62\end{array}$ & $\begin{array}{l}135 \\
141\end{array}$ \\
\hline
\end{tabular}

Bank credit is domestic credit provided by the banking sector includes all credit to various sectors on a gross basis, with the exception of credit to the central government. It is used to measure the growth of banking system because it reflects the extent to which savings are financial. Market capitalization (also known as market value): measure the development of stock market, calculated as share price times the number of shares outstanding. Market liquidity is the total value traded divided by GDP. Turnover ratio is the total value of shares traded during the period divided by the average market capitalization for the period. It is another measure of liquidity, and high turnover indicates low transaction costs. Average market capitalization is calculated as the average of the end-of-period values for the current period and the previous period. Listed companies are the domestically incorporated companies listed on the country's stock exchanges at the end of the year. This indicator does not include investment companies, mutual funds, or other collective investment vehicles.

Source: World Development Indicators 2004, World Bank. 
Table 3. Summaries of determinants of capital structure, definitions and theoretical predicted signs

\begin{tabular}{|c|c|c|}
\hline $\begin{array}{l}\text { Proxy } \\
\text { (Abbreviation) }\end{array}$ & Definitions & Predicted \\
\hline Tangibility(TANG) & Book value of plants and equipment -total net (PPENT) & \\
\hline $\operatorname{Tax}(\mathrm{TAX})$ & scaled by total assets. & \\
\hline Size (SIZE) & Effective tax rate & $+/-$ \\
\hline Profitability (ROA) & Natural logarithm of total sales & + \\
\hline Growth & Earnings before interest and tax divided by total assets & $+/-$ \\
\hline opportunities(MTB) & Market value of assets over book value of assets & \\
\hline Volatility (VOL) & Standard deviation of ROA & \\
\hline Liquidity (LIQ) & Current assets divided by current liabilities & - \\
\hline \multicolumn{3}{|c|}{ Note: "+" means that leverage increases with the factor. } \\
\hline \multicolumn{3}{|c|}{ “_” means that leverage decreases with the factor. } \\
\hline \multicolumn{3}{|c|}{ “+/-"means that both positive and negative relations between leverage and the factor are possible. } \\
\hline
\end{tabular}

Table 4. Correlation matrix of dependent and independent variables(include volatility variable and both measures of size)

\begin{tabular}{|c|c|c|c|c|c|c|c|c|c|c|c|}
\hline UK & TD & LD & MLD & TANG & SIZE1 & SIZE2 & TAX & MTB & $\mathrm{ROA}$ & LIQ & VOL \\
\hline TD & 1.000 & & & & & & & & & & \\
\hline LD & 0.800 & 1.000 & & & & & & & & & \\
\hline MLD & 0.732 & 0.920 & 1.000 & & & & & & & & \\
\hline TANG & 0.251 & 0.300 & 0.374 & 1.000 & & & & & & & \\
\hline SIZE1 & 0.147 & 0.182 & 0.171 & 0.063 & 1.000 & & & & & & \\
\hline SIZE2 & 0.184 & 0.310 & 0.297 & 0.201 & 0.791 & 1.000 & & & & & \\
\hline TAX & -0.066 & 0.017 & -0.006 & -0.052 & 0.315 & 0.230 & 1.000 & & & & \\
\hline MTB & -0.074 & -0.029 & -0.148 & -0.222 & -0.081 & -0.085 & -0.006 & 1.000 & & & \\
\hline $\mathrm{ROA}$ & 0.014 & 0.076 & 0.071 & 0.183 & 0.358 & 0.176 & 0.375 & 0.015 & 1.000 & & \\
\hline LIQ & -0.263 & -0.197 & -0.195 & -0.254 & -0.447 & -0.209 & -0.162 & 0.018 & -0.197 & 1.000 & \\
\hline VOL & -0.020 & -0.081 & -0.116 & -0.181 & -0.199 & -0.140 & -0.245 & 0.003 & -0.813 & 0.065 & 1.000 \\
\hline Germany & TD & LD & MLD & TANG & SIZE1 & SIZE2 & TAX & MTB & ROA & $\begin{array}{l}\text { LIQ } \\
\end{array}$ & VOL \\
\hline TD & 1.000 & & & & & & & & & & \\
\hline LD & 0.762 & 1.000 & & & & & & & & & \\
\hline MLD & 0.720 & 0.942 & 1.000 & & & & & & & & \\
\hline TANG & 0.430 & 0.523 & 0.589 & 1.000 & & & & & & & \\
\hline SIZE1 & 0.204 & 0.112 & 0.129 & 0.251 & 1.000 & & & & & & \\
\hline SIZE2 & 0.157 & 0.141 & 0.169 & 0.242 & 0.862 & 1.000 & & & & & \\
\hline TAX & 0.099 & 0.032 & -0.014 & 0.059 & 0.185 & 0.102 & 1.000 & & & & \\
\hline MTB & 0.147 & 0.133 & 0.006 & -0.019 & 0.019 & -0.055 & 0.116 & 1.000 & & & \\
\hline ROA & 0.059 & 0.022 & 0.061 & 0.339 & 0.468 & 0.357 & 0.334 & 0.089 & 1.000 & & \\
\hline LIQ & -0.454 & -0.327 & -0.314 & -0.302 & -0.439 & -0.249 & -0.041 & -0.065 & -0.061 & 1.000 & \\
\hline VOL & -0.102 & -0.078 & -0.109 & -0.339 & -0.370 & -0.328 & -0.284 & -0.014 & -0.853 & 0.007 & 1.000 \\
\hline
\end{tabular}

Total book-debt ratio (TD) is defined as the total debt divided by total assets. Long-term book-debt ratio (LD) is defined as the total long-term debt divided by total assets. Long-term market-debt ratio (MLD) is the ratio of long-term debt to 
market value of total assets(calculated as book value of assets less book value of equity plus market value of equity). Tangibility (TANG) is calculated as property plant and equipment total net divided by total assets. Here we employ two measures of size. SIZE1 is the nature logarithm of total sales and SIZE2 is the nature logarithm of total assets. Effective tax rate (TAX) is the ratio of total tax charge to total taxable income. Market-to-book ratio (MTB) is market value of equity over book value of equity. Return on assets (ROA) is defined as earnings before interests and tax divided by total assets. Liquidity (LIQ) is the ratio of current assets to current liabilities. Volatility (VOL) is the standard deviation of ROA.

Table 5. Descriptive statistics of dependent and independent variables for UK and Germany

\begin{tabular}{|l|l|l|l|l|l|l|l|l|l|}
\hline UK & TD & LD & MLD & TANG & SIZE & TAX & MTB & ROA & LIQ \\
\hline Mean & 16.78 & 10.51 & 8.74 & 31.51 & 4.28 & 21.00 & 2.25 & -2.69 & 2.13 \\
\hline Median & 13.60 & 4.83 & 3.72 & 26.56 & 4.31 & 24.57 & 1.44 & 2.59 & 1.44 \\
\hline Std.Dev & 15.75 & 12.79 & 11.31 & 24.42 & 1.25 & 20.41 & 2.53 & 17.08 & 2.53 \\
\hline Minimum & 0.00 & 0.00 & 0.00 & 1.03 & 0.66 & -71.91 & 0.19 & -112.8 & 0.25 \\
\hline Maximum & 95.63 & 62.40 & 76.20 & 98.56 & 6.80 & 90.79 & 22.25 & 24.40 & 21.93 \\
\hline
\end{tabular}

\begin{tabular}{|l|l|l|l|l|l|l|l|l|l|}
\hline Germany & TD & LD & MLD & TANG & SIZE & TAX & MTB & ROA & LIQ \\
\hline Mean & 23.87 & 13.03 & 11.61 & 24.41 & 4.68 & 24.41 & 2.18 & -4.71 & 2.87 \\
\hline Median & 23.04 & 9.82 & 7.91 & 21.30 & 4.65 & 29.55 & 1.54 & 0.90 & 1.95 \\
\hline Std.Dev & 17.73 & 12.82 & 11.98 & 18.71 & 1.03 & 27.35 & 2.96 & 14.65 & 2.93 \\
\hline Minimum & 0.00 & 0.00 & 0.00 & 0.41 & 2.36 & -84.75 & 0.13 & -71.26 & 0.19 \\
\hline Maximum & 83.70 & 54.65 & 57.99 & 91.13 & 6.81 & 91.46 & 33.23 & 21.93 & 24.04 \\
\hline
\end{tabular}

Total book-debt ratio (TD) is defined as the total debt divided by total assets. Long-term book-debt ratio (LD) is defined as the total long-term debt divided by total assets. Long-term market-debt ratio (MLD) is the ratio of long-term debt to market value of total assets (calculated as book value of assets less book value of equity plus market value of equity). Tangibility (TANG) is calculated as property plant and equipment total net divided by total assets. We define size(SIZE) as the nature logarithm of total assets. Effective tax rate (TAX) is the ratio of total tax charge to total taxable income. Market-to-book ratio (MTB) is market value of equity over book value of equity. Return on assets (ROA) is defined as earnings before interests and tax divided by total assets. Liquidity (LIQ) is the ratio of current assets to current liabilities. The number of observations (firms) is 525 for UK and 218 for Germany. 
Table 6. Correlation matrix of dependent and independent variables

\begin{tabular}{|l|c|c|c|c|c|c|c|c|c|}
\hline UK & TD & LD & MLD & TANG & SIZE & TAX & MTB & ROA & LIQ \\
\hline TD & 1.000 & & & & & & & & \\
\hline LD & 0.802 & 1.000 & & & & & & & \\
\hline MLD & 0.734 & 0.921 & 1.000 & & & & & & \\
\hline TANG & 0.249 & 0.294 & 0.372 & 1.000 & & & & & \\
\hline SIZE & 0.198 & 0.321 & 0.310 & 0.182 & 1.000 & & & & \\
\hline TAX & -0.075 & -0.003 & -0.021 & -0.038 & 0.211 & 1.000 & & & \\
\hline MTB & -0.080 & -0.039 & -0.157 & -0.222 & -0.097 & -0.006 & 1.000 & & \\
\hline ROA & 0.022 & 0.079 & 0.077 & 0.191 & 0.193 & 0.378 & 0.004 & 1.000 & \\
\hline LIQ & -0.267 & -0.201 & -0.200 & -0.258 & -0.233 & -0.167 & 0.026 & -0.213 & 1.000 \\
\hline
\end{tabular}

\begin{tabular}{|l|r|l|l|l|l|l|l|l|l|}
\hline Germany & TD & LD & MLD & TANG & SIZE & TAX & MTB & ROA & LIQ \\
\hline TD & 1.000 & & & & & & & & \\
\hline LD & 0.762 & 1.000 & & & & & & & \\
\hline MLD & 0.721 & 0.944 & 1.000 & & & & & & \\
\hline TANG & 0.428 & 0.530 & 0.593 & 1.000 & & & & & \\
\hline SIZE & 0.133 & 0.119 & 0.147 & 0.230 & 1.000 & & & & \\
\hline TAX & 0.093 & 0.043 & -0.002 & 0.076 & 0.136 & 1.000 & & & \\
\hline MTB & 0.149 & 0.135 & 0.011 & -0.015 & -0.074 & 0.111 & 1.000 & & \\
\hline ROA & 0.063 & 0.030 & 0.069 & 0.342 & 0.368 & 0.338 & 0.070 & 1.000 & \\
\hline LIQ & -0.452 & -0.332 & -0.320 & -0.311 & -0.242 & -0.061 & -0.057 & -0.125 & 1.000 \\
\hline
\end{tabular}

Total book-debt ratio (TD) is defined as the total debt divided by total assets. Long-term book-debt ratio (LD) is defined as the total long-term debt divided by total assets. Long-term market-debt ratio (MLD) is the ratio of long-term debt to market value of total assets (calculated as book value of assets less book value of equity plus market value of equity). Tangibility (TANG) is calculated as property plant and equipment total net divided by total assets. We define size(SIZE) as the nature logarithm of total assets. Effective tax rate (TAX) is the ratio of total tax charge to total taxable income. Market-to-book ratio (MTB) is market value of equity over book value of equity. Return on assets (ROA) is defined as earnings before interests and tax divided by total assets. Liquidity (LIQ) is the ratio of current assets to current liabilities.

Table 7. OLS analysis results on total book-debt ratio

\begin{tabular}{|l|c|c|}
\hline & UK & Germany \\
\hline Intercept & $\mathbf{1 0 . 7 6}(0.00)$ & $\mathbf{1 7 . 6 8}(0.00)$ \\
\hline TANG & $\mathbf{0 . 1 1}(0.00)$ & $\mathbf{0 . 3 4}(0.00)$ \\
\hline SIZE & $\mathbf{1 . 8 3}(0.00)$ & $-0.05 \quad(0.96)$ \\
\hline TAX & $\mathbf{- 0 . 1 0}(0.01)$ & $0.06 \quad(0.16)$ \\
\hline MTB & $-0.15 \quad(0.56)$ & $\mathbf{0 . 7 7}(0.03)$ \\
\hline ROA & $-0.03(0.41)$ & $\mathbf{- 0 . 1 8}(0.03)$ \\
\hline LIQ & $\mathbf{- 1 . 3 7}(0.00)$ & $\mathbf{- 2 . 0 7}(0.00)$ \\
\hline Number of observations & 525 & 218 \\
\hline Adjusted R2 & 0.13 & 0.30 \\
\hline
\end{tabular}

The dependent variable is total book-debt ratio (TD) which is total debt divided by book value of total assets in 2006. Tangibility (TANG) is calculated as property plant and equipment total net divided by total assets. We define size (SIZE) as the nature logarithm of total assets. Effective tax rate (TAX) is the ratio of total tax charge to total taxable income. 
Market-to-book ratio (MTB) is market value of equity over book value of equity. Return on assets (ROA) is defined as earnings before interests and tax divided by total assets. Liquidity (LIQ) is the ratio of current assets to current liabilities. All the independent variables are three-year averages (2003-2005). p-values are in parentheses. The regression is estimated using ordinary least squares (OLS) model. The estimated equation is: Leverage [Firm i] $=\beta 0+\beta 1$ TANGi $+\beta 2$ SIZEi $+\beta 3$ TAX i $+\beta 4 \mathrm{MTBi}+\beta 5 \mathrm{ROAi}+\beta 6 \mathrm{LIQi}+\varepsilon i$.

Note: Coefficients in bold are significant at conventional levels.

Table 8. OLS analysis results on Long-term book-debt ratio

\begin{tabular}{|c|c|c|}
\hline & UK & Germany \\
\hline Intercept & $-4.02(0.08)$ & $4.29 \quad(0.31)$ \\
\hline TANG & $\begin{array}{ll}0.12 & (0.00)\end{array}$ & $\begin{array}{ll}\mathbf{0 . 3 6} & (0.00)\end{array}$ \\
\hline SIZE & $\begin{array}{ll}2.81 & (0.00)\end{array}$ & $\begin{array}{ll}-0.09 \quad(0.91)\end{array}$ \\
\hline TAX & $\begin{array}{ll}-0.04 \quad(0.15) \\
\end{array}$ & $\begin{array}{ll}0.03 & (0.31)\end{array}$ \\
\hline MTB & $0.21 \quad(0.32)$ & $\mathbf{0 . 5 1}(0.03)$ \\
\hline ROA & $\begin{array}{ll}-0.01 \quad(0.75) \\
\end{array}$ & $\begin{array}{ll}\mathbf{- 0 . 1 7} & (0.00)\end{array}$ \\
\hline$\overline{L I Q}$ & $\begin{array}{ll}\mathbf{- 0 . 4 7} & (0.03)\end{array}$ & $\begin{array}{ll}\mathbf{- 0 . 8 3} & (0.00)\end{array}$ \\
\hline Number of observations & 525 & 218 \\
\hline Adjusted R2 & 0.16 & 0.31 \\
\hline
\end{tabular}

The dependent variable is long-term book-debt ratio (TD) which is total long-term debt divided by book value of total assets in 2006. Tangibility (TANG) is calculated as property plant and equipment total net divided by total assets. We define size (SIZE) as the nature logarithm of total assets. Effective tax rate (TAX) is the ratio of total tax charge to total taxable income. Market-to-book ratio (MTB) is market value of equity over book value of equity. Return on assets (ROA) is defined as earnings before interests and tax divided by total assets. Liquidity (LIQ) is the ratio of current assets to current liabilities. All the independent variables are three year averages (2003-2005). p-values are in parentheses. The regression is estimated using ordinary least squares (OLS) model. The estimated equation is: Leverage $[$ Firm i $]=\beta 0+\beta 1$ TANGi $+\beta 2$ SIZEi $+\beta 3$ TAX i $+\beta 4 \mathrm{MTBi}+\beta 5 \mathrm{ROAi}+\beta 6 \mathrm{LIQi}+\varepsilon i$.

Note: Coefficients in bold are significant at conventional levels.

Table 9. OLS analysis results on Long-term market-debt ratio

\begin{tabular}{|c|c|c|}
\hline & UK & Germany \\
\hline Intercept & $\begin{array}{ll}-2.99 & (0.13)\end{array}$ & $\begin{array}{ll}3.78 & (0.34)\end{array}$ \\
\hline TANG & $\begin{array}{ll}\mathbf{0 . 1 4} & (0.00)\end{array}$ & $\begin{array}{ll}\mathbf{0 . 3 8} & (0.00)\end{array}$ \\
\hline SIZE & $\begin{array}{ll}2.26 & (0.00)\end{array}$ & $\begin{array}{ll}-0.05 & (0.95)\end{array}$ \\
\hline TAX & $-0.04 \quad(0.10)$ & $0.01 \quad(0.83)$ \\
\hline MTB & $-0.29 \quad(0.10)$ & $\begin{array}{ll}0.03 & (0.89)\end{array}$ \\
\hline ROA & $-0.01 \quad(0.70)$ & $\begin{array}{ll}\mathbf{- 0 . 1 4} & (0.01)\end{array}$ \\
\hline LIQ & $\begin{array}{ll}-0.36 & (0.06)\end{array}$ & $\begin{array}{ll}\mathbf{- 0 . 7 0} & (0.00)\end{array}$ \\
\hline Number of observations & 525 & 218 \\
\hline Adjusted R2 & 0.20 & 0.35 \\
\hline
\end{tabular}

The dependent variable is long-term market-debt ratio (TD) which is total long-term debt divided by market value of total assets in 2006. Tangibility (TANG) is calculated as property plant and equipment total net divided by total assets. We define size (SIZE) as the nature logarithm of total assets. Effective tax rate (TAX) is the ratio of total tax charge to total taxable income. Market-to-book ratio (MTB) is market value of equity over book value of equity. Return on assets (ROA) is defined as earnings before interests and tax divided by total assets. Liquidity (LIQ) is the ratio of current assets to current liabilities. All the independent variables are three-year averages (2003-2005). p-values are in parentheses. The regression is estimated using ordinary least squares (OLS) model. The estimated equation is: Leverage $[$ Firm i] $=\beta 0+\beta 1$ TANGi $+\beta 2$ SIZEi $+\beta 3$ TAX i $+\beta 4 \mathrm{MTBi}+\beta 5 \mathrm{ROAi}+\beta 6$ LIQi $+\varepsilon i$.

Note: Coefficients in bold are significant at conventional levels. 


\title{
Design and Evaluation to Internal Control of Shaanxi Textile Enterprises
}

\author{
Junxun Li \\ School of Management, Xi'an Polytechnic University \\ Xi'an 710048 , China \\ Tel: 86-29-8233-0197Ｅ-mail: dmezy@163.com \\ Xiaoyan Wei \\ Shaanxi Branch, Zhongrui Yuehua Certified Public Accountants Co., Ltd \\ Xi'an 710068, China
}

Tel: 86-29-8100-5139Ｅ-mail: yan5252020@sina.com

\begin{abstract}
Internal control means that enterprises in order to improve their self quality of business information, promote operation efficiency, fully obtaining and using the each kind of resources, under the related laws and regulations, so as to reach the fixed management goal, take the various kinds of restrictions and regulative organization, planning, methods and procedure in the enterprises internal. Design and evaluation internal control standards of textile enterprises, it is not only the urgent demand of enterprises development strategy; but also is an important measures to enterprises implementing scientific development view. This paper analyses present state of the internal control of Shaanxi textile enterprises, mainly expounds the design idea and evaluation process, methods of internal control from five factors.
\end{abstract}

Keywords: Shaanxi textile enterprises, Internal control, Design, Evaluation

In June 28th, 2008, the basic norm of the enterprises internal control was first issued by Ministry of Finance and other five ministries, the objective is to reasonable guarantee legal norms in business management, capital safety, truthfulness and integrality of financial report and relevant information, raise business efficiency and result and promoting enterprises realize the development strategy. It is well known that internal control as the internal mechanism of as self-accommodation and self-restriction mechanism of enterprises manufacturing and prosecution was plays an important role in enterprises management system. The establishment and implementation of internal control is not only the most basic part of enterprises, but also the safeguard of the survival and development. Otherwise, internal control is also an important part of risk management, the establishment of risk management target provides a prerequisite for the design and implementation of internal control, internal control is based on a risk assessment, and the implementation of the results should be evaluated. Shaanxi textile enterprises need sustained and healthy development, we must establish and implement effective internal control system, improve the governance structure, enhance the risk management, regulate the function of influence, strengthening supervision and restraint, encourage enterprises to achieve strategic objectives, and regulate development. With the implementation of strategic target of "construct the outstanding western province", as a pillar industry of Shaanxi province in the textile industry, it is high time to establish and implement effective internal control target.

\section{The present situation of Internal Control of Shaanxi Textile Enterprises}

The most Shaanxi textile enterprises was founded in the 50's -60's of last century, for a long time, owing to the influence of "three multi and one heaviness" (employment textile workers multi, difficulties enterprises multi, questions left over multi, high society burden), together with the factors that the weakness of enterprises internal control and financial regurgitation feeding are less, these enterprises has confronted difficulties. Into the 90 's of 20 Century, this industry occurred situation of continuity operation loss, through "the reduction of products and depletion of numbers, merger and reorganization" and other measures, in 2000, provincial textile industry albeit achieves turning losses into profits, but the economic gap has been widened between Shaanxi textile enterprises and coastal provinces. To reject the equipment and fund factors, one of a very important reason is internal control system are not perfect enough, because of the textile industry belongs to meager profit operation, once the managers had insufficient understanding to the internal control, it will inevitably become formalization, the enterprises internal friction will be large, and the pressure of cost also increased. According to investigation, current many enterprises still adopt the primitive and backward production processes and extensive management methods, so as to cause poor quality of yarns and grey fabric, materials consumption is high, enterprises low profitability, income generally lower of employee, the lack of attraction and cohesion, its lead to many brain drain, sustainable development is subjected severe obstruction due to internal control absence. Taking the Tanghua groups Shaanxi company for example, the enterprise has a long history state-owned with 
more than 36820 staffs, its 5 enterprises of subsidiary has policed bankruptcy row-column by state council in this year, and decided allocate to the local government management. Meanwhile, some state-owned textile enterprises and nongovernmental enterprises distribute in the zone of central shaanxi plain, they are lack strict internal control system, its internal control system mainly exist locomotors activity of each manager,so it has high casualness, meanwhile, it's usually incoherence in implementation process. Most textile enterprises are invalidation of internal control; it has become the "necklace" of the sustainable development of the Shaanxi textile enterprises. In 2008, due to all kinds of costs continuous rising, it is restricted to improving product price, the profit margins are continually compressed of textiles, some enterprises has fall into predicament of no order can be making, many enterprises also has fall into predicament of the order sufficient but no profit, or the order increasing but its profits decrease.

\section{The design of Internal Control of Shaanxi Textile Enterprises}

In view of the present situation of Shaanxi textile enterprises, when we are designed the internal control system, we are should from five aspects fully considered such as internal environment, risk assessment, control activity, information and communication, internal supervision.

\subsection{Design of the internal environment}

Internal environment is the basis for the implementation of internal control, it's generally includes following 5 factors: the governance structure, the organization establishment, the distribution of powers and responsibilities, the internal audit, the human resource policy and the enterprises culture etc.

(1) The design of the governance structure, the organization establishment and the distribution of powers \& responsibilities: According to the "company law" and "articles of association" regulations, Shaanxi textile enterprises should to set up sound corporate administrative structure. In order to ensuring the company's internal control system to be implemented, so the company management according to the organizational structure step by step authorization. The workers congress or the general meeting of shareholders is the top authorities to implement management and supervision of the company's internal control. The board of directors as a decision-making of permanent establishment, responsible for the workers congress or the general meeting, to the company's operating activities important decision problems in the decision-making deliberation and make a decision, or submitted deliberation to the workers congress or the general meeting. The board of supervisors is a supervision institution of company; it's responsible for monitor to the company director, the manager tier and corporate finance.

(2) The design of the internal audit system: The internal audit except auditing account books of enterprises, it is also including customs officer, evaluated internal controlling system is perfect or not and inner organizations execution efficiency, then put forward some suggestions and report of the enterprise highest management department. Design should be considered from three aspects: First, independent organizations. It can be independent exercise the audit supervision and have a certain authority, also it have a certain power of appointment to the problems or situation of the audit process. Second, staff is refinement and efficient, but also meet the requirements of internal audit work. Third, it should be coordinated to the other functions of institutions, coordinate with each other, restriction and promote.

(3) The design of the human resource policy: The human resource policy is an important scarce resource; it is one kind of tools of the enterprises to gain competition advantage. Its design should including the human resource management organization security of functions, the human resource planning, and the personnel selection and added the human resource education and training, the staff's assessment and evaluation, the salary and incentive mechanism, also including the mechanism to leave talents etc.

(4) The design of the enterprises culture: The enterprises culture is designed in order to realize its mission, unification thought of the textile workers, concepts, attitude, behaviors and values. So it is urgent to achieve the following points: (1)scouring and introduced into the elements of enterprises culture, constructing the cultural system of textile enterprises, formation a spirit of enterprise strength, developing cultural competitiveness;(2) The establishment of enterprise culture working groups, design the organization of the enterprises culture; (3)Penetration the cultural idea of those that can have a lasting invigorative function. The enterprises culture should outstanding culture of innovation, Develop staff handbook and around its spirit level, substance level and system level construction.

\subsection{Design of the risk assessment}

For a long time, the risk management more emphasis the risk process control and ex-post control of the textile enterprises, due to the lack of risk-warning mechanism, so lead to the risk monitoring index is inadequate, the basic construction comparatively weakness of the monitoring system. When we design the internal control, must base on the "basic norms of corporate internal controls" as a criterion, considering the internal control and efficiency from the point of the strategic risk.

The internal control turning the strategic risk to implement control, it's not a concept, but it is need a transformation from the guiding thought and conduct standard of the corporate governance and management layer, also needed the 
guarantee of corporate governance mechanism, needed tangible strategic target and can combination human, money and material resources of all support to realization strategic targets, although these condition and foundation showed different in different enterprises, it's impossible to set a unified model, but also its attention point of risk almost same. In the design to be followed rules of comprehensiveness, of early warning, of maneuverability and dynamic character, through investigation to the existing textile enterprises internal control implement situation, making a relevant test, then evaluated to its soundness, rationality and effectiveness, in order to determine whether dependence the properties, scope, emphasis and methods of the internal control and substantive tests. The specific contents included: the risk assessment process, target system, internal risk and external risks, the risk identification, the risk determined importance and coping strategy etc.

\subsection{Design of the control activity}

The control activity means enterprises based on risk assessment results, by using the corresponding control measures, making the risk at can be endure scope. The specific contents included: separation of interlinked duties, major risk authorization control, audit and approval control, budget control, safety of assets, reporting system, financial report authenticity, and analysis control of the economic activities, performance appraisal control and information system control etc.

\subsection{Design of the information and communication}

The so called information and communication mean the enterprises timely and accurate collecting, transfer with internal controls-related information, ensure the information effective communication between enterprise internal and enterprise external. In the design to be should cover the information management system of textile enterprises, enterprises internal information control, enterprises external information control and enterprises communication mechanism etc.

\subsection{Design of the internal supervision}

The internal supervision means that enterprises supervise and inspect to the internal control establishing and the situation of implementation, evaluate effectiveness of internal controls, find deficiencies of internal control, and enterprise should promptly be improved. Including:

(1) Design of monitoring institution: Because of the Shaanxi state-owned textile still dominate, in order to ensure the security and integrity of the state-owned assets, the enterprises should set up ministry of audit, equipped with full-time internal audit staff, exercise of independent audit function, make some internal audit and supervision on financial income and expenditure of enterprises and economic activities.

(2) Supervision system design: In order to improve the corporate governance structure, standardize the company economic behavior, and safeguarding legitimate rights and interests of the shareholders, Shaanxi textile enterprises should establish a system of internal audit, to review and evaluate the economic activities of enterprises authenticity, legitimacy and the effectiveness of internal controls. All major issues should be established into a sound and reasonable system of internal control system.

(3) Internal control deficiencies reporting and improved: we recommend establish internal audit departments; regularly check the deficiencies of company's internal control system, to assess their effectiveness and efficiency of the implementation and timely suggestions for improvement. Internal audit staff should check the internal control deficiencies and unusual items, and write recommendations for improvements into the internal audit report truthfully.

(4) Internal control self-assessment: Use of specific methods by regular to test the implementation of internal control and write assessment reports, as the main decision for the Enterprise management.

In a word, the design of Internal control should be operate around the control environment, it is not only the basic of the other four related factors, but also the framework of enterprise discipline and internal control, it directly impact on cognitive about the internal control of the business staff, If there is no effective control environment, perhaps there will not have the four other outstanding elements which is have outstanding results.

\section{The evaluation of Internal Control of Shaanxi Textile Enterprises}

The traditional internal control evaluation methods mainly rely on the subjective judgment of professionals from the qualitative aspects of the evaluation, so in this way will lack some scientific nature. Based on the requirement of Basic regulation of enterprise internal control, combine with the Shaanxi textile enterprise's own characteristics, the evaluation of internal controls should focus on two aspects: firstly, construct the textile enterprises in Shaanxi internal control evaluation index system. Including research and analysis of the enterprise internal control system design a system of indicators for evaluation consist of the title of every indicators, content, standards, weight, etc. Secondly, make use of the complete design evaluation index system, through the collection of qualitative and quantitative evaluation information, compare the evaluation scores and evaluation index and standard, and then reflect the merits of internal control in Shaanxi textile enterprises, draw integration evaluation conclusions. This paper will pay more attention on discussing evaluating the internal control textile enterprises in Shaanxi by the Matrix Method. 


\section{1 major evaluation steps}

(1)The enterprise internal control will be divided into a number of elements (control environment, risk assessment, information systems and communication, internal supervise), they were given different weights (Table 1), each element contains a number of key indicators or key factors, there are six key indicators, the control environment should include elements of integrity and moral values (weight 0.25 ), competence ability (weight 0.15 ), the level of participation of governance (weight 0.15 ), management concept and style (weight 0.15 ), organizational structure and responsibility division (weight 0.15 ), human resources policies and practices (weight 0.15 ), which confirm the scoring of each factor under different elements.

(2) Confirm the importance of all key indicators or factors to the various elements, and figure out the integrated scoring of every element.

(3) Establish the important coefficient of various elements to the internal control, and figure out the integrated scoring coefficient of internal control.

(4) Establish the scoring standards of internal controls under different conditions, and figure out overall score of internal control (Table 2).

\subsection{Internal control evaluation of the overall score calculation}

(1) Calculate the elements of control environment indicators score

(1)Firstly, let the evaluated textile enterprises in Shaanxi to be the target, calculate the score of key factor which is the subordinate of the integrity and moral values under different conditions (Include the regulation of conduct, corporate culture, management of the exemplary role, etc.);

Secondly, calculate the integrated score coefficient by the matrix method of the integrity and moral values;

Matrix composite coefficient $=$ Evaluation factors coefficient matrix $\times$ Scoring matrix

(2) Use of the similarly methods calculated the Matrix composite coefficient competence ability, the level of participation of governance, management concept and style, organizational structure and responsibility division, human resources policies and practices;

(3) Calculate the control environment scoring matrix;

Control environment scoring matrix $=$ Evaluation factors coefficient matrix $\times$ the subordinate key indicators of the various elements of comprehensive scoring matrix

(4) Normalize the general indicators coefficient matrix;

(5)Determine the control environment under the four condition "excellent, good, medium and poor" scoring matrix;

(6) Calculate the general score of the control environmental factors indicators; the general score of the control environmental factors indicators $=$ the general indicators of coefficient matrix $\times$ the scoring matrix of the elements in different conditions.

(2)The index scores of other elements of internal control (risk assessment, information systems and communication, internal supervise) is similar to the former principle.

(3)According to the weight of internal control elements in the internal control factors (Table 1), figure out the integrated assessment score of internal control.

\section{Conclusion}

In the 2008China Cotton Industry Development Summit Forum and the International Cotton Trade Fair, the experts made it clear that the textile industry in eastern developed regions should be promote to transform to resources, land, and labor advantage in the western region gradually, and seek more cost competitive advantage. In October 2007, Xi'an government formulated the "textile city in Xi'an of the revitalization development planning framework". This purpose is to correctly guide textile enterprises in Shaanxi by the government to promote the healthy development. July 16th, 2008, the largest corporate bankruptcy so far in Shaanxi province-Tanghua designated enterprises under the central policy of the insolvency of the group officially launched. This bankruptcy is not an end, but to promote the textile enterprises in Shaanxi have a greater development in the future. These days, our country enhances some textiles, clothing and other goods of export tax rebate rate from 11 percent to 13 percent. All these indicate that favorable external environment will help the textile industry in Shaanxi to construct the system of internal control. In the near future, through a series of internal control construction, the textile in Shaanxi will reproduce the past glory.

\section{References}

Ministry of Finance People's Republic of China, etc. (2008). About print and published the "basic regulation of internal control". Beijing: Accounting .No.7. 
Zhao, Boping. (2008). Tanghua Groups policy initiated bankruptcy. Xi'an: Huashang Newspaper. July 17 , p: A7.

Luo, Qing. (2007). Internal control design, test and evaluation. Beijing: Economic Science Press. p357-369.

Yan, Jiamin. (2007). Shaanxi Textile Industry Development and Reform senior seminar held in Xi'an. Beijing: China Textile Newspaper. May 29, p: 1.

Table 1. Internal control factor weight

\begin{tabular}{|c|c|c|c|c|c|}
\hline Element & $\begin{array}{c}\text { Control } \\
\text { environment }\end{array}$ & $\begin{array}{c}\text { Risk } \\
\text { assessment }\end{array}$ & $\begin{array}{c}\text { Information } \\
\text { and } \\
\text { communication }\end{array}$ & $\begin{array}{c}\text { Control } \\
\text { activities }\end{array}$ & $\begin{array}{c}\text { Internal } \\
\text { supervise }\end{array}$ \\
\hline Weight & 0.25 & 0.15 & 0.2 & 0.25 & 0.15 \\
\hline
\end{tabular}

Table 2. Internal control evaluation index score standards

\begin{tabular}{|c|c|c|c|c|}
\hline \multirow{2}{*}{ Item } & \multicolumn{3}{|c|}{ Meet the key factors } & \multirow{2}{*}{$\begin{array}{c}\text { Do not meet the key } \\
\text { factors }\end{array}$} \\
\cline { 2 - 4 } & excellent & good & medium & 0 \\
\hline Score & 1 & 0.8 & 0.6 & 0 \\
\hline
\end{tabular}




\title{
The Department Store in Hong Kong: Local Institutional Changes and the Concession Business Model
}

\author{
Matthew M. Chew \\ Department of Sociology, Hong Kong Baptist University \\ Kowloon Tong, Kowloon, HKSAR, China \\ Tel: 852-3411-7132 E-mail: mmtchew@hkbu.edu.hk
}

\begin{abstract}
As a declining retail format, how is the department store managing to survive in Hong Kong? How has it transformed itself in response to contemporary retail environments? Are these institutional transformations different from those observed in the US and Europe? In what ways are they different and how have they shaped local department stores? This essay explores these questions through examining recent institutional changes of department stores in Hong Kong. Data for this study were collected through qualitative observation, documentary analysis, and in-depth interviews of department store managers and consultants. I find that Hong Kong's department stores have pursued a major and successful institutional transformation between 1998 and the present: they strategically abandon the conventional department store format and develop a concession-oriented one. I illustrate the special characteristics, structural benefits, and potentials problems of the concession-oriented department store format through analyses of the power relationship between concessionaire and department stores, the changing work processes in department stores, and the cost and risk implications of concessions in the contemporary retail context of Hong Kong.
\end{abstract}

Keywords: Hong Kong retailing, Department stores, Concession, Retail change, Retail management, Shopping malls

\section{Introduction}

The department store retail format emerged in the mid- $18^{\text {th }}$ century in the US and France, and steadily grew since the late- $18^{\text {th }}$ century in the UK, the US, and Continental Europe. It has been well documented that it underwent a period of decline in the past few decades in the US, Europe, and East Asia (Chong, 1996; Eurostat, 1993; May and McNair, 1977; Sternlieb and Hughes, 1987; Sun, Kay, and Chew, 2008; Willans, 1996). However, few have explored the details of how the retail format is doing outside of the US and Europe. A large number of department stores are still present around the world and there are important questions regarding them that should interest scholars of retailing. How have these department stores managed to survive? How are they transforming themselves in response to contemporary retail changes? Are these institutional transformations different from those in contemporary US and Europe? In what ways are they different and how have they shaped local department stores? This essay explores these questions through examining the case of department stores in Hong Kong. I will especially focus on how Hong Kong's department stores have pursued institutional changes and survival strategies that are quite different from those in the US and the UK.

In the context of their declining importance within the retail institutional mix, department stores are attempting to adapt themselves to contemporary retail circumstances. The somewhat similar timing of decline of the department store format around the world reflects that there are certain globally common factors undermining the format. Large overhead and inflexible cost structure are two salient examples. In addition, competition from new and improved specialty stores formats, such as efficient multiples or high-profile specialty stores, has negatively impacted on department stores everywhere. Changes in shoppers' consumption pattern towards specialized lifestyle niches constitute another factor that undermines the department store format. At the same time, given the very different social and economic circumstances across nations around the globe, there are likely to be additional locally specific factors that undermine (or benefit) the department store format in different national contexts. In response to these locally specific factors, department stores in different countries are pursuing somewhat different institutional changes to ensure survival and profitability. As a side effect of these different institutional changes, contemporary department stores around the world are developing institutional characteristics in divergent directions. The case of department stores in Hong Kong illustrates this interesting development.

\section{Locally specific factors that undermine department stores in Hong Kong}

\subsection{The development of shopping malls in Hong Kong}

The contemporary urban formation of Hong Kong indirectly and subtly give rise to certain retail geographic changes 
that are different from familiar North American and European cases. It is often said that Hong Kong urban development emphasizes a vertical direction of urban expansion (tall buildings) rather than a horizontal one (urban sprawling). Because of the relatively limited extent of urban sprawling, Hong Kong does not feature densely populated downtown districts surrounded by huge suburban or industrial areas with low population density. Because there are few suburban or industrial areas, Hong Kong does not have any greenfield or brownfield shopping malls.

There are relatively far-from-downtown urban districts in Hong Kong and these areas are almost as 'malled' as suburbs in North America and Europe during the past few decades. But the out-of-town malls in Hong Kong possess certain special characteristics that impacted on their reception of the department store format. Instead of being oriented around particular suburban areas, almost all large out-of-downtown malls in Hong Kong are based on the stations of the city's two major mass transit systems. The East Kowloon Railway and the Mass Transit Railway were both completed in the 1980s, and they link downtown areas of Hong Kong to non-downtown residential areas and relatively remote satellite towns. Since Hong Kong is one of the most densely populated cities in the world in terms of residents per land area, within the walking distance of each stations of the two railways live tens of thousands of residents. Due to the enormous traffic of people around the railway stations, large shopping malls were developed immediately next to the stations. There are a few large out-of-downtown malls (eg. those in Tuen Mun or Whampoa) in Hong Kong that are not built around railway stations. These malls are based on satellite towns or housing estates which accommodate numerous of residents. Similar to malls based on railway stations, these malls are guaranteed enormous consumer traffic simply by virtue of their location.

The abundant and guaranteed consumer traffic to these out-of-downtown malls in Hong Kong distinguishes them from typical greenfield or brownfield shopping malls in North America and Europe in an important way. Because greenfield or brownfield malls do not usually have a large number of residents living within their walking distance, the attraction of shopper traffic is a central problematic in the management of malls. A common way to improve shopper traffic is to have a department store serve as an anchor (Dawson, 1983). Department stores work well as an anchor because the wide range of goods they carry appeal to a broad base of shoppers. Having a good anchor, the smaller and more specialized retail stores in a greenfield or brownfield mall will be more likely to receive a minimal amount of shopper traffic, which in turn contributes to the overall success of the mall (Hines and Clurman, 1988). This is the reason that department stores are usually given very favorable rental terms (relative to the smaller shops in the same mall) by the mall management. While an increasingly large number of older department stores in American downtown areas were closed down since the 1960s, new department stores were being established in suburban malls. Even though these new department stores have smaller floor spaces and less prestigious store images compared to conventional downtown department stores, they nonetheless provide a viable means of survival for the department store format. The regional department store chain in the US, for example, currently operates on the basis of a large number of smaller department stores in suburban malls and a small number of huge department stores in the downtown areas of major cities.

Because the out-of-downtown malls in Hong Kong do not require an anchor to attract consumer flow, they are not obliged to give any rental discount to department store tenants. According to one of my informants (an architect experienced in designing shopping malls), the managers of malls in Hong Kong generally appreciate the value of having a department store tenant, but they tend to see the department store tenant more as a prestige booster that directly attract prestigious specialty store chain tenants (eg. expensive global brandnames) than as an anchor for the mall. The majority of out-of-downtown malls in Hong Kong in fact do not feature any department store tenants. Hence, the survival of Hong Kong department stores cannot rely on their functioning as anchors in large shopping malls, and the institutional changes found in contemporary Hong Kong department stores are also not particularly oriented towards adaptation to the circumstances of Hong Kong's suburban shopping malls, as I will show.

\subsection{Downtown location and high rental rates}

Urban decay in American cities in the second half of the $20^{\text {th }}$ century forcefully undermined the downtown department store, though urban center regeneration is reversing the trend in the past decade. A host of inter-related negative impacts came with the decaying of downtowns, including the decrease of shopper traffic, change to a less affluent shopper base, and the tarnishing of store image. The downtown areas of Hong Kong have not gone through a similar process of urban decay. The oldest central business district, the Central, had always retained the most prestigious office buildings and shopping areas. Three other old business and shopping districts - Causeway Bay, Tsimshatsui, and Mongkok - have never ceased to be the busiest shopping districts in Hong Kong. No other geographic districts in Hong Kong surpass these four downtown areas in offering shopping facilities and prestige to stores, although a few new shopping districts (eg. the several interconnected malls in Shatin) may offer a similarly large amount of shopper traffic.

Instead of undergoing decay, the aforementioned four districts in Hong Kong underwent important renewals that strengthen their position as central shopping areas in the past three decades. Large and luxurious new shopping malls were built, older ones were linked together by various kinds of structures, and most malls are conveniently linked to mass transit railway stations in air-conditioned or automated walkways. In contrast to American downtowns, the 
downtown areas of Hong Kong never lacked affluent consumers, locational prestige, or upscale built environment in their surroundings.

The tendency for out-of-town malls in Hong Kong to not feature department stores in them, together with the fact that the old downtown districts remain to be the central shopping districts in Hong Kong, strongly pressures Hong Kong's department stores to remain located in downtown areas. Approximately half of all department stores in Hong Kong are located in the four major central shopping districts. Moreover, the department stores that are located in out-of town malls tend to be small and unprestigious. Examples include Seiyu in Shatin and Jusco in Tuen Mun. And the CitiStore chain of department stores, which specialize in out-of town mall locations, carry such a limited range of merchandize that they can hardly be recognized as department stores by a strict industrial definition.

The most significant consequence for Hong Kong department stores of remaining in downtown areas is their being forced to pay extremely high rents. In 1990, Hong Kong climbed to the second place in the world ranking of retail rental rates, closely following those of Tokyo (Phillips, Sternquist, and Mui, 1992). Hong Kong's real estate and retail rents continued to soar in the 1990s before the Asian Crisis, arriving at a peak of US \$693 per square foot in 1994 and still maintaining at \$642 in 1997 for the Causeway Bay district (Fellman, 1996; Jones Lang LaSalle, 1994-1997). Rental rates stayed at a low level for the first few years after 1997, but soared again in the past few years (Jones Lang LaSalle, 1998-2004). Although local department store chains owned some of the buildings where their stores are located, these stores still pay a high opportunity cost. The majority of foreign invested department stores had to bear the high rental rates. Japanese department stores, for example, were heavily affected by rent rates - some were forced to retreat from Hong Kong and others went through business restructuring or change of ownership. Some of the inherently inflexible cost features of the department store format became highly destructive with high rental rates. For example, department stores' need to carry a range of lower profitability (per retail area) merchandize seriously undermined the overall profitability of the store.

The impact of high rental rates was exacerbated by the unsympathetic attitude of real estate developers towards department stores. Department stores in Hong Kong get relatively short rental contracts. Hong Kong's real estate developers commonly arrange for two-year or three-year rental contracts for businesses tenants in order to gain more frequent opportunities to raise the rental rates; real estate prices in Hong Kong continue to soar year after year before 1997. At the same time, real estate developers have been reluctant to adjust the rental rates below the leasing contract when real estate prices plunged after the Asian Crisis. One of the reasons is that because real estate developers in general tend not to have a systematic long-term plan for marketing malls (Kirkup and Rafiq, 1999). But it is also because Hong Kong's particular urban formation does not at all pressure real estate developers to rely on or work with department stores, as I previously discussed.

\section{Concession as the major institutional adaptation of Hong Kong's department stores}

Not particularly needed by out-of-downtown malls and having to pay extremely high rents, department stores in Hong Kong have been undergoing pressure since the early 1990s to initiate institutional changes to ensure their profitability. Initially, few institutional changes were actually implemented because the local economic bubble provided strong consumer expenditures that kept profitability afloat. The rapid escalation of rental rates in the mid-1990s and the enormous negative impact of the Asian Crisis effectively forced the majority of surviving department stores in the late-1990s to implement significant institutional transformations. The most salient changes in the period between 1998 and the present may be summarized as a strategic transformation from the conventional department store format towards a concession-oriented department store structure.

'Concession' refers to the leasing of partitioned retail counters within a department store to concessionaires. Concessionaires include manufacturers, suppliers, or licensed importers that manage individual brands of products. Concession retail counters are often described as 'shops within shops,' a notion that vividly conveys the spatial, operational, and formal institutional fragmentation that they bring to department store. Concession is certainly not new or unique to Hong Kong. It has been adopted in the UK and the US by a range of large store formats in the past decades (McGoldrick, 1987; Worthington, 1985; 1988). It is also increasingly utilized at present by department store managers in the contemporary West to improve store competitiveness (Aldridge, 2004a; 2004b). Department stores also have the convention of make concession arrangements for a small and selected range of merchandize, the most notable of which is cosmetics.

Nonetheless, the extent to which concession is adopted by Hong Kong's department stores is extraordinary and warrants examination. According to my retail consultant and department store manager informants, all department stores apart from three chains in Hong Kong are devoting most of their prime floor areas and over $70 \%$ of their total retail floor space to concession counters. The Japanese department stores that rented their retail space instead of purchased it were hit hardest by the late-1990s' economic downturn, and they were the first to adopt concession for survival. For example, Sogo changed ownership in 1998 and the new management immediately turned the store into a collection of concession counters. The effort was very successful and by the present, Sogo devotes over $90 \%$ of space to concessions, many of 
which are the world's most prestigious brands. Locally owned chains were the slowest to adopt concession because of the conservative nature of their family-based management and in some cases ownership of their own retail premise. For example, the Sincere Chain did not begin to broadly adopt concession until around 2002, though they presently devote about $70 \%$ of their space to concession.

The three chains that did not dedicate more than half of their space to concession counters, including Lane Crawford, Uny, and Mark and Spencer, constitute informative counter-examples. Lane Crawford is an exceptional chain that successfully hybridizes the prestige apparel chain operations and the conventional department store format. Its stores carry a wider range of merchandise than the prestige apparel store and a narrower range of merchandise than the conventional department store. At the same time, all of them are premium price-range fashion products and most of the stores' floor space is assigned to apparel. The upscale nature of these stores makes it necessary for them to occupy prestigious downtown locations. They are more capable of paying the high rents because the high value of their merchandise render their retail space more productive than department store that carry merchandise with wider price ranges.

The Uny Chain was able to avoid the development toward a concession-oriented model mainly because it specializes in out-of-downtown locations. In contrast to the majority of Japanese department store chains, Uny placed its department stores exclusively in malls placed within large housing estates with tens of thousands of middle-class inhabitants. Rental rates in these locations are less exorbitant than downtown locations yet shopper traffic is equally abundant. The reason that the Mark and Spencer Chain avoids concession is clearly associated with its focus on selling own brand merchandise. Since Mark and Spencer stores tend to fill their retail space with own brand apparel, they do not have the option of pursuing concession as a major solution.

\section{Relationship between concessionaires and the department store}

To comprehend how concession-oriented department stores diverge from the conventional department store format, the most indispensable factor to investigate is the power play between the department store and its concessionaires. Concession arrangements involve complex cooperation, conflict of interests, and political negotiation between a department store and its concessionaires. From the point of view of the department store management, concessionaires not only need to help bear the overhead and operational costs of the store, they should also contribute to maximizing sales turnover and shopper traffic of the store. Department stores therefore usually welcome prestigious or popular brands to become their concessionaires. In addition, it also prefers concessionaires to offer as steep a discount as possible in store-wide sales and discount their merchandise as frequently as possible.

Manufacturers and retailers in Hong Kong set up concession arrangements with department stores because of risk and cost considerations. High retail rental rates threaten them, especially specialty chains and multiples that expand mainly through opening an increasingly large number of stores. Concession arrangements lower the risk of such expansion by means of lowering rental costs, and rental costs in Hong Kong constitute a large portion of a retailer's overhead and operational expenses. Concession terms typically allow the concessionaire to pay lower-than-market-value rents and make up for the low rent by sharing a certain percentage of their monthly profits with the department store. They may or may not end up making more profit by setting up a concession counter instead of a shop in a mall or on busy streets. But their risks of operational expansion are effectively lowered. Shopper traffic of the department store is also an inherent attraction of concession arrangement for manufacturers and retailers. However, it functions an important attraction primarily for new market entrants or non-established brands. Concessionaires typically ask the department store management to assign to them a good floor section within the department store as well as to attract shoppers through paying for the store's centralized marketing and advertisement services.

In setting up a concession contract, the department store and the concessionaire negotiate on rental rates, profit sharing terms, advertising costs sharing terms, and other secondary details. For example, an informant (manager of a leading local casual wear brand) reveals that her company pays a rental rate of HKD 250 per square feet at a major Causeway Bay department store, which is slightly less than half of the average market rental value. The counter pays between $20 \%$ and $25 \%$ of its profit to the department store. Contract terms can vary a great deal, depending on the relatively power of the department store and the concessionaire.

Consignment, an arrangement that is in some aspects similar to concession, is not widely adopted by Hong Kong's department stores. In a consignment arrangement, a manufacturer or retailer places their brand merchandise in a department store for sale and shares the profit from sales of the merchandise with the store. To Hong Kong's manufacturers and retailers, consignment may be seen as a limited version of concession with the similar functions of risk control, guaranteed shopper traffic, and lowered rents. However, consignment is much less attractive than concession to the department store management, even though consignment involves a smaller degree of deviation from the conventional department store format. It is because in contrast to concession, consignment contributes very little to the lowering of overhead and operational costs of department stores. Consignment mainly lowers merchandise and inventory costs, but Hong Kong's department stores primarily focus on controlling their rent and staff costs. 


\section{Institutional changes brought about by concession arrangements}

The turning of over $70 \%$ of the retail floor space of a department store into concession counters - as most of Hong Kong's departments stores do - leads the store far away from the conventional department store format. Significant operation and structural changes are entailed. The most notable change involves that of merchandizing and buying operations. If estimated indirectly via retail floor space, only $10 \%$ to $30 \%$ of the merchandise of Hong Kong's department stores are directly selected, acquired, and managed by the store staff. The rest is under the management of the individual brands that constitute the concessionaires of the department stores.

The shift of a large percentage of the department stores' buying and merchandizing workload to the concessionaires necessitates changes to the department stores' buying and merchandizing departments. In some cases, buying and merchandizing departments are downsized, and new departments are built to deal with the concession related work. In other cases, buying and merchandizing staffs are kept and the departments are re-tuned to deal with the new workload. For instance, menswear merchandisers may pick up the work of selection and management of menswear concessionaires.

With the incoming of numerous concessionaires, new types of routine work are created. Examples include the selection and contracting of new concessionaires, or the management of existing concessionaires. Not anymore focusing singly on store merchandise, these kinds of work are very different from the conventional buying, merchandizing, or sales work processes of a department store. They focus instead on management of the concessionaire tenant mix, negotiation with individual brands, and mobilization and coordination of the department store's concessionaires for collective goals. These work processes may be described as a cross-over between those of a shopping mall manager and those of a conventional department store manager.

Another notable institutional change in Hong Kong's department stores resulting from concession involves frontline sales assistants. Most concessionaires hire and train their own sale personnel to work at concession counters in department stores. Hong Kong's department stores therefore tend to lay off the majority of their sales assistants and relegate frontline sales work to concessionaires. Sales managers are usually kept, however. Even though their workload of training and managing sales assistants are minimized, the sales assistants and sales work of concessionaires still need to be monitored, indirectly managed, and coordinated.

In addition to buying, merchandizing, and frontline sales, the work of visual merchandizing is also partly shifted to concessionaires. Both prestigious fashion brands and middle price range large apparel chains want to centrally manage visual merchandizing of all their store counters in Hong Kong in order to manage brand image. They have specialized personnel to take care of the visual merchandizing of their concession counters. Concessionaires are sometimes allowed to take over the visual merchandizing in the department store's display window if their counters occupy the prime window spots of the store. But Hong Kong's department stores still tend to keep a number of visual merchandizing staff for the work of window display and signage. The coordination of brands in the same floor section is also a vital visual merchandizing work for concession-oriented department stores. The symbolism (including a range of items such as posters and music) and interior design of a cluster of concession counters in a floor section are bound to be very different. Without proper coordination, the floor section as a whole may turn into an unattractive shopping environment. It is the responsibility of the department store's visual merchandizing staff to deal with these potential problems.

Cashier work can in principle be easily shifted to concessionaires, but the majority of Hong Kong department stores prefer to keep it to the store. Central administration of cashiering helps the department store to keep track of the turnover figures of all concessionaires. Even if the data may not be required for retail information systems (since the concessionaires will do such analyses for themselves), they are needed as a database for the sharing of profits between the department store and individual concessionaires.

Subtle changes are introduced into marketing, advertising, and sales campaigning of Hong Kong's department stores by a concession-oriented business model. The management and building of a department store brand can become very different when the store is not the one who merchandizes. The merchandise sold in Hong Kong's department store is selected by the buyers and merchandisers of concessionaires. The department store still gets to choose its own particular mix of brand suppliers, thereby indirectly affecting the range of merchandise sold in store. Yet brands that are available to set up concession counters in Hong Kong's department stores are not unlimited in supply. They are largely limited to local brands, East Asian ones, and established global ones from Europe and North America. Moreover, concessionaires tend to offer very similar merchandise in their concession counters in different department stores.

In general, the work of department store brand-building is complicated as well as undermined. For example, local department store chains used to market their merchandise through making and distributing their own catalogs in the 1990s. At present, they have stopped making department store catalogs altogether. The Lane Crawford chain, which still merchandize a comparatively large share of its merchandise, is perhaps the only department store can still make use of catalogs in Hong Kong. It is not clear how department store catalogs should differentiate from their competitors' when 
more than $70 \%$ of the store's merchandise is entirely decided by concessionaires.

The efforts and strategies of concession-oriented department stores to advertise also diverge from that of conventional department stores. Their advertisement contents tend to avoid foregrounding the reality of the store as a highly decentralized institution with numerous concession counters. Otherwise it may devolve into advertisement for a disparate collection of individual brands. But presenting the department store as an integral whole is not always plausible and truthful under the new circumstances. For instance, department store sale ads in Hong Kong used to attract shoppers through detailing how much exactly specific products are discounted. Such a type of ads is currently uncommon because concessionaires might consider it as a threat to their brands' prestige and it is also difficult for department stores to balance the interest of various concessionaires when specific products are named in ads.

Sales campaigns, a powerful and frequently used marketing method in the Chinese context, become one of the focal points of power political contentions between department stores and their concessionaires. Increased shopper traffic and turnover during sale campaigns benefit department store as well as concessionaires. However, sale campaigns usually cost concessionaires more than department stores. In a concession-oriented department store, merchandise that is discounted is not paid for by the department store. In other words, the price reduction necessitated by the sale burdens concessionaires much more than department stores. No wonder an informant (a middle level manager of a local department store chain) observes that sales campaigns are almost two times more frequent than before after her department store had adopted a concession-oriented model. Concessionaires are also reluctant to accept the steep discount rate that department stores tend to fix collectively for store-wide campaigns. The department store does not in principle need to consider how sale campaigns negatively affect individual concessionaires. If a concessionaire's brand image and profitability are hurt because of frequent sales, the department store does not directly bear the consequences anyways. Negotiations with concessionaires on discount rates have become one of the onerous routine of the department store management in Hong Kong.

\section{Discussion and Conclusion}

I have elaborated how the concession-oriented department store deviates in various ways from the conventional department store format. Buying, merchandizing, and front-line sales functions are greatly reduced. Negotiation with concessionaires and management of them in order to ensure rent revenue become a central operational focus. The management of a concession-oriented department store to some extent resembles that of a shopping mall, and the operation of a concession-oriented department store to a certain degree resembles that of a real estate business.

The adoption of the concession-oriented model in Hong Kong represents a viable way through which department stores can cope with the conventional department store format's inherent weaknesses in comparison with specialty stores. Instead of competing head-to-head against specialty stores, Hong Kong's department stores choose to join forces with specialty brand manufacturers and retailers. The concession-oriented department store is practically outsourcing its major retailing functions to specialty stores.

From the point of view of retail change theory, the rise of the concession-oriented model may be interpreted as a dialectic synthesis of the shopping mall format and the conventional department store triggered by the retail environment of high rental rates, downtown locations, and anchorless malls in Hong Kong. The dialectic theory highlights how two different competitive retail formats institutionally shift towards each other to generate a new hybrid format that contains the advantages of both (Maronick and Walker, 1974). On the one hand, specialty stores could gain additional advantages from setting up concession counters in department stores because they can benefit from the department store's shopper traffic, lowered rental rates, department store brand, and experienced retail management. On the other hand, department stores are challenged by high rents, a serious threat that has rendered the concession-oriented business model acceptable to Hong Kong's department store management. So far, the concession model has been quite successful. It has helped many Hong Kong's department stores to stay profitable and has attracted numerous prestigious brands to the concession counter option.

The concession-oriented model is not without potential problems, however. The difficulty it produces for department store brand building, the coordination problem involved with incoherent visual merchandizing in a floor section, or the great efforts needed to mobilize concessionaries for any collective efforts are some examples. The future experiences of Hong Kong's department stores will certainly inform us more about these and other emergent problems of the concession-oriented department store format.

The considerable institutional changes of Hong Kong's department store should also alert retail scholars to the great extent to which department stores across the globe can vary in responding to the decline of the conventional department store format. A fruitful research direction for future studies will be to explore this global variation in other parts of Asia as well as other non-Western countries. A comparison of the divergent institutional adaptations of the department store in different parts of the world not only informs us on how the retail business is doing in different localities, but also promises to offer theoretical insights on retail change and competitive retail formats. 


\section{References}

Aldridge, A. (2004a). Department stores offer a touch of retail magic. Marketing, Nov 24, pp.15.

Aldridge, A. (2004b). Retailers find there's cash in concessions. Marketing, Sept 15, pp.15.

Chong, L. (1996). Department stores in troubled waters: a Singapore encounter. International Journal of Retail and Distribution Management, 24 (1), 34-39.

Dawson, J.A. (1983) Shopping Centre Development, London: Longman.

Fellman, J. (1996). Causeway Bay on top of the world for shop rents. Hong Kong Standard, Dec 24.

Haines, G. H., Simon, J.R. \& Alexis, M. (1971). The dynamics of commercial structure in central city areas. Journal of Marketing, 35(April), 10-18.

Hines, M. A. \& Clurman, E. D. (1988). Shopping Centre Development and Investment (2nd ed.). New York: John Wiley \& Sons, Inc.

Jones Lang LaSalle. (1994-2004). Asia Pacific Property Digest. Hong Kong: Jones Lang LaSalle.

Kirkup, M. H. \& Rafiq, M. (1999). Marketing shopping centres: challenges in the UK context. Journal of Marketing Practice: Applied Marketing Science, 5 (5), 119-133.

Maronick, T. J. \& Walker, B. J. (1974). The Dialectic Evolution of Retailing. Proceedings: Southern Marketing Association, Atlanta: Georgia State University.

May, E. G. \& McNair, M. P. (1977). Department stores face stiff challenge in next decade. Journal of Retailing, 53(Fall), 47-58.

McGoldrick, P. J. (1987). Shops within shops: the consumer viewpoint. Retail and Distribution Management, 15(4), 9-12.

Phillips, L. A., Sternquist, B.. J. \& Mui, S. (1992). Hong Kong department stores: retailing in the 1990s. International Journal of Retail and Distribution Management, 20(1), 16-24.

Simmons, J. \& Chan, K. W. (1992). The retail structure of Hong Kong. Centre of Urban Planning and Environment Management Working Paper number 53, The University of Hong Kong.

Sternlieb, G. \& Hughes, J. W. (1987). The demise of the department store. American Demographics, 9 (8), $30-32$ and 59.

Sun, N.L.V., Kay, R. \& Chew, M. M. (2008 forthcoming). Development of a retail life cycle: the case of the department store industry in Hong Kong. Asia Pacific Business Review.

Willans, J. (1996). Department store: an enduring retail format. Journal of Fashion Marketing and Management, 1(2), 146-150.

Worthington, S. (1988). Concessionaires — a strategic option for retailers", European Journal of Marketing, 22 (3), 14-20.

Worthington, S. (1985). Shops within shops: the concessionaire's point of view. Retail and Distribution Management, Vol. 13, No. 5; p. 32-5. 
A journal archived in Library and Archives Canada

A journal indexed in CANADIANA (The National Bibliography)

A journal indexed in AMICUS

A leading journal in business and management

\section{International Business Research}

\section{Quarterly}

Publisher Canadian Center of Science and Education

Address 4915 Bathurst St. Unit\#209-309,Toronto, ON. M2R 1 X9

Telephone 1-416-208-4027

Fax 1-416-208-4028

E-mailibr@ccsenet.org

Website www.ccsenet.org

Printer William Printing Inc.

Price CAD. $\$ 20.00$

IS SN $1913-9004$

|||||||||||||||||||||||| 